\title{
Factors Controlling Tungsten Mobility in W-Cu Skarn Tailings from the Cantung Mine, Northwest Territories, Canada
}

by

Brent Gerard Kazamel

A thesis submitted to the Department of Geological Sciences and Geological Engineering In conformity with the requirements for the degree of Master of Science

Queen's University

Kingston, Ontario, Canada

September, 2020

Copyright $@$ B Brent Gerard Kazamel, 2020 


\begin{abstract}
Few studies have addressed the mobility of tungsten in mine waste, which could act as a point source for metal leaching. This study addresses the behaviour of tungsten in tailings at the Cantung Mine in the Northwest Territories, Canada. In addition to this study, this thesis includes a literature review regarding the environmental geochemistry of tungsten.
\end{abstract}

In the Cantung tailings, tungsten is present as scheelite $\left(\mathrm{CaWO}_{4} ; 0.1-0.7 \mathrm{wt} . \%\right)$, copper is hosted in chalcopyrite $\left(\mathrm{CuFeS}_{2} ; 0.1-1.5 \mathrm{wt} . \%\right)$, and gangue mineralogy consists of abundant pyrrhotite $\left(\mathrm{Fe}_{1-\mathrm{x}} \mathrm{S} ; 0.2-49\right.$ wt.\%), calc-silicate minerals (26-62 wt.\%), and carbonate minerals $(0-30$ wt.\%). In July 2018, nine surface water samples, five tailings pore-water samples, and thirteen tailings samples were collected from the Cantung Mine's tailings. Water samples have been analyzed by high resolution inductively coupled mass spectrometry (HR-ICP-MS), yielding tungsten concentrations ranging from 5.3 to $26.3 \mu \mathrm{g} / \mathrm{L}$, exclusively in samples with $\mathrm{pH}$ values between $7.05-8.05$. Tungsten and iron concentrations are both on average $1.6 \mathrm{x}$ higher in unfiltered aliquots compared to filtered aliquots, suggesting that tungsten is transported as dissolved species but is also adsorbed to suspended Feoxyhydroxide minerals. Tailings were analyzed by scanning electron microscopy (SEM) paired with automated mineralogy software (MLA), synchrotron-based $\mu \mathrm{XRD}-\mathrm{XRF}$, and partial leach extractions. The scheelite content of Tailings Pond 3 (TP3) and the FRT are similar (0.15 wt.\% and 0.21 wt.\%, respectively), and scheelite shows no evidence of alteration. Synchrotron-based $\mu \mathrm{XRD}$ of Feoxyhydroxide minerals in the FRT identify goethite $(\mathrm{FeOOH})$ and lepidocrocite $(\gamma$-FeOOH$)$, whereas $\mu$ XRD spectra of pyrrhotite rims from TP3 do not match Fe-minerals, with the exception of rare rims that match hematite $\left(\mathrm{Fe}_{2} \mathrm{O}_{3}\right)$ and maghemite $\left(\gamma-\mathrm{Fe}_{2} \mathrm{O}_{3}\right)$. The $\mu$ XRF maps of the hematite-maghemite rims have prominent tungsten peaks, which represents included scheelite grains and possibly structurally incorporated tungsten, likely formed during ore processing. The hydroxylamine leaches yield higher tungsten concentrations in tailings samples from the impoundments than samples from the FRT, suggesting the tailings impoundments have more tungsten that is associated with poorly crystalline and 
amorphous Fe-oxyhydroxide phases than the FRT. Over time, labile-hosted tungsten in the FRT may have been washed down the Flat River during Fe-oxyhydroxide recrystallization and high energy flooding events. 


\section{Acknowledgements}

The first of many thank-you's goes to my supervisors, Heather Jamieson and Matt Leybourne, for their mentorship, guidance, and patience over the past few years. I am extremely privileged, honored, and proud to be part of the Jamieson Clan and the QFIR family, and couldn't have asked for a more wonderful group of people to develop my career as a geochemist with. The Winter Wonderlands, defense parties, and Grad Club beer discussions were some of the highlights of my time at Queen's. Heather, I fell in love with the north during our trip to Cantung, and our long, beautiful drives to and from the mine will be forever in my mind. Thank you so much for giving me this opportunity, and for the opportunities that have stemmed as a result from completing this thesis. Matt, your contributions to this thesis are innumerable. Having access to world class analytical facilities at QFIR, and same-day access to a worldclass geochemist for answers to my (often redundant) questions has been invaluable. Both of you held infinite patience during periods when I was low, and I honestly don't think my thesis would have been completed without your understanding. It has been a pleasure working with both of you.

This thesis is dedicated to Kurt Kyser, who took me under his wing that one fateful summer in Kingston. After expressing my interest in geochemistry, Kurt offered me a summer student position at QFIR and exposed me to my first taste of analytical and field work, which lead to me completing an undergraduate thesis under his supervision. Kurt's enthusiasm for science, his lust for life, and his dedication to QFIR inspired me to pursue a career in geochemistry, and even more so to pursue a life of passion. I wish you could have reviewed this thesis, that we could've share the excitement of the results, or even just to have seen you shake your head and say, "nah".

This thesis wouldn't be possible without Hendrik Falck, the Cantung connoisseur. Thank you for assisting with field work, and for sharing your big-brain knowledge of the Cantung deposit, of the history of the mine, and of the physiography of the Flat River valley. A brewpub visit in is order during my next visit to Yellowknife! A very special thank-you is in order for Dan Layton-Matthews, who first sparked 
my interest in geochemistry via ternary diagrams in second year petrology, and another to Noel James for our discussions about big-picture global issues, science and creativity, and for just being a rad dude. Guy Narbonne, thank you for taking care of me when I got sick in Namibia, and for expressing not even the slightest discontent about missing part of the Etosha safari. Rob Harrap, I don't know how to express my thanks to you. We've had so many discussions throughout my undergraduate and master's degrees about anything and everything, but the ones where I came in distressed and left with some clarity are undoubtedly the most important.

To all of the QFIR family, thank you for all of the analytical assistance, the laughs, and the wine over the years. April, your bubbling enthusiasm made walking into the lab always a joy, thank you for teaching me so, so much about stable isotope analysis. Alex and Chips, thank you for your assistance, for putting up with my incompetence, and for teaching me the ways of the ICP. Steve, thank you for bringing me into the field for the first time, for your co-supervision of my undergraduate thesis, and for always being open for a chat. Agatha, it was always a pleasure having nerd conversations over the SEM and in the breakroom. Your assistance with my SEM-MLA analyses are a big part of this thesis. Summers spent in the basement of Bruce Wing were the best.

To the Queen's Geo department grad student family, thank you for all the amazing Gronchs, the Fur Cups, the Halloween parties, the softball games... There are too many good times to list. The Jamieson Clan (Chris, Clare, Amy, Kat, Sean, Diana, Allie), your comments on my presentations have been extremely valuable - I think I'll be incorporating your tips for a long time! Clare and Amy, thank you for running my samples at the synchrotron, for the collaborative effort interpreting the data, and for the obsessive conversations about Fe-oxyhydroxide minerals. Kat, thanks for supporting my presentation in Yellowknife, for the hot pot, and for being a fun travel companion. A major thank you for all of the fun climbs, and even the not-so-fun one which resulted in a trip to the hospital. You stayed at the hospital with me all day, and I'm glad you did. Popeyes fam (Hannah, Emma, Jackson), thank you for all the good 
times, for being great housemates (not you, Hannah), and for throttling my enthusiasm for Feoxyhydroxides and geophysics in the Yukon.

Last, but absolutely, definitely, not even close to the least, thank you to my family. Mom and Dad, you have been uncompromisingly supportive of every endeavor of my life, and my gratitude cannot be constrained to the acknowledgements section of a thesis. You have put up with endless griping about this thesis, and pushed me to complete it in the most loving way. Even as I write this, you are motivating me to put the final touches on this document by enticing me with the satisfaction of a well-deserved golf game tomorrow. You always know what's best, even when I say you don't. Thank you. Jessica, you inspire me in every way. You've always had my back, no matter what time of day I called. Although our professions could not be any different, you were instrumental for the completion of this thesis. 


\section{Table of Contents}

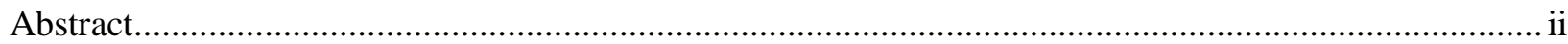

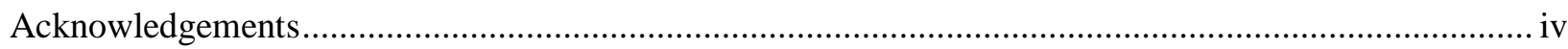

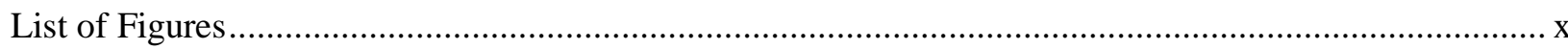

List of Tables

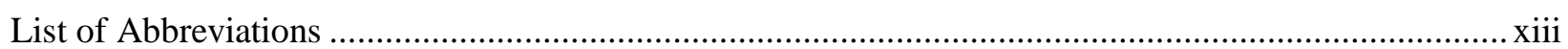

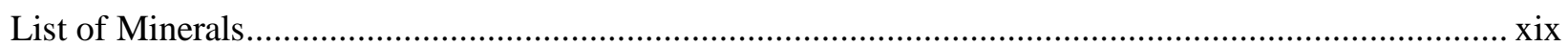

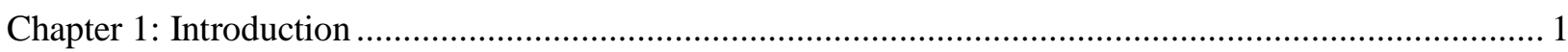

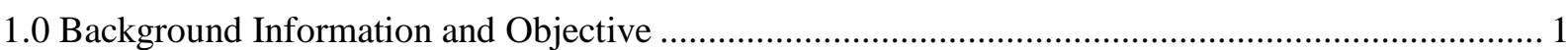

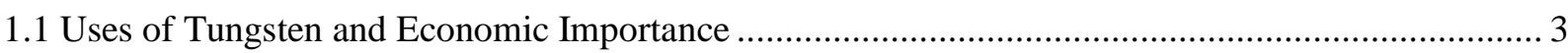

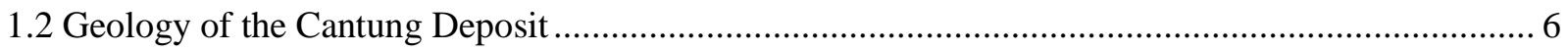

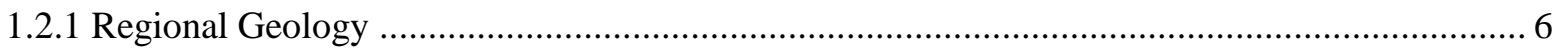

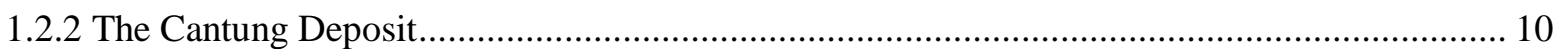

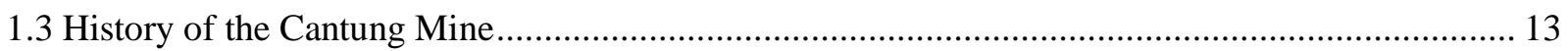

1.4 Physiography and Hydrology of the Cantung Mine ................................................................. 15

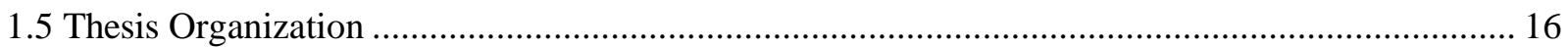

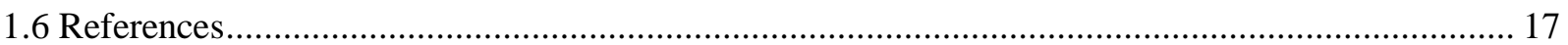

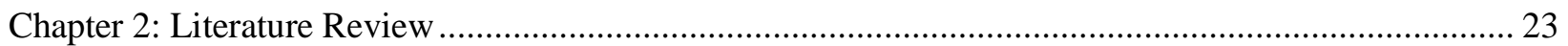

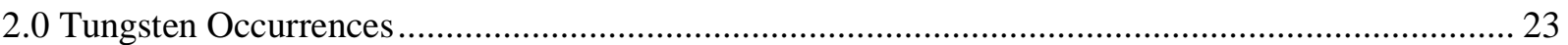

2.0.1 Crustal Abundance and Primary Mineralogy ........................................................................ 23

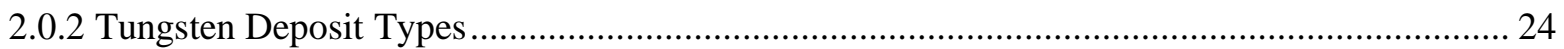

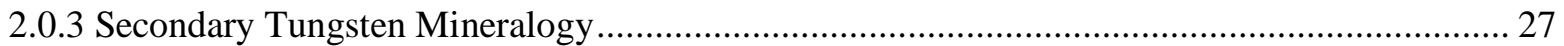

2.1 Anthropogenic Sources of Tungsten to the Environment ............................................................ 29

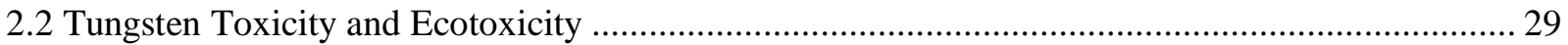

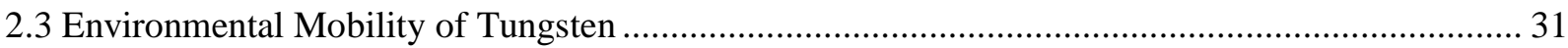

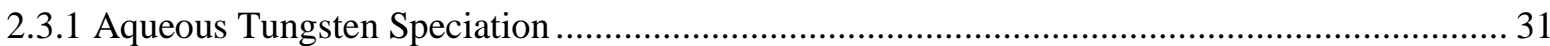

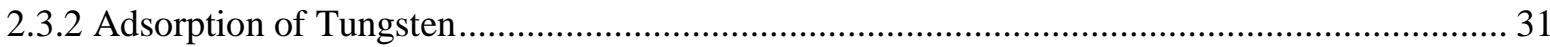

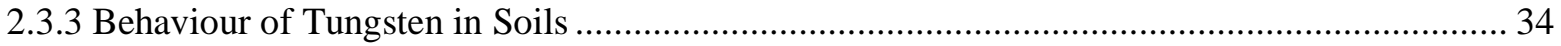

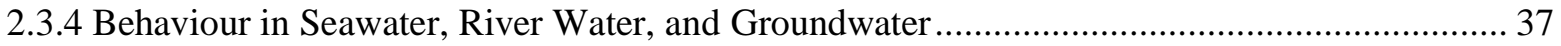

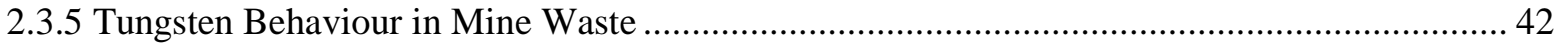

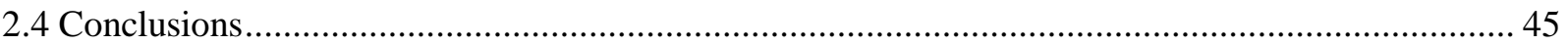

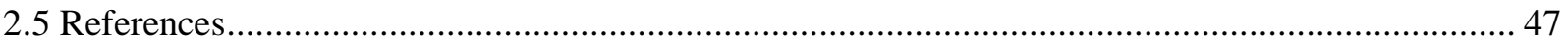

Chapter 3: Factors Controlling Tungsten Mobility in W-Cu Skarn Tailings from the Cantung Mine,

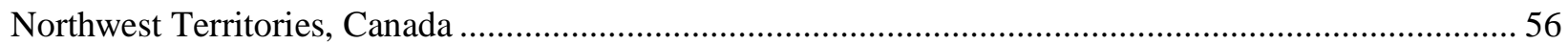

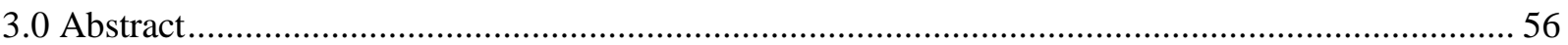




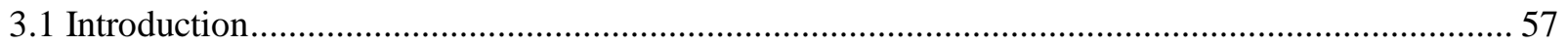

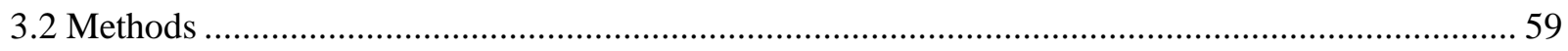

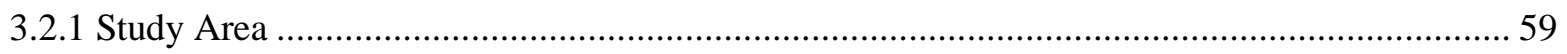

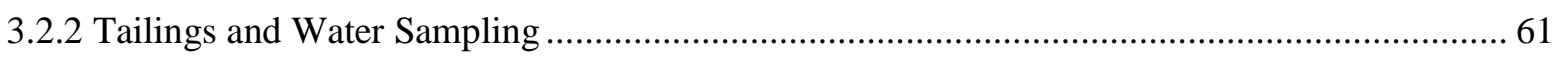

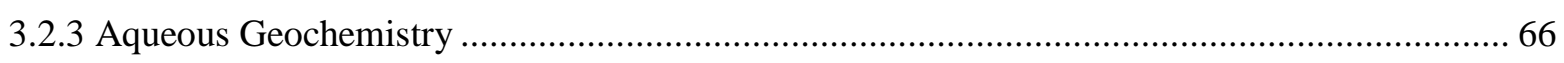

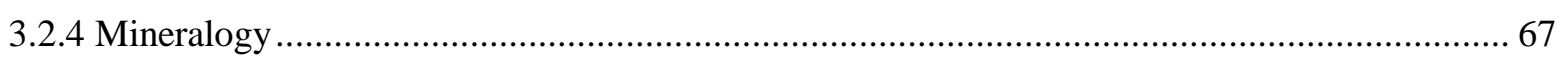

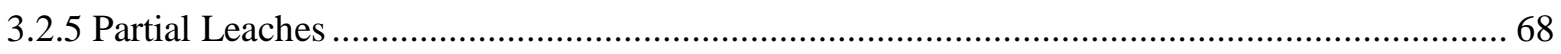

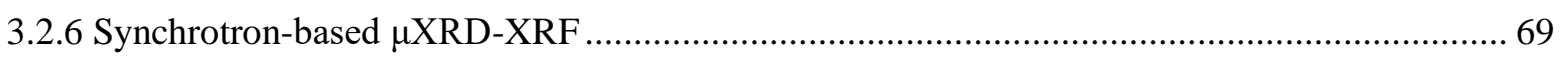

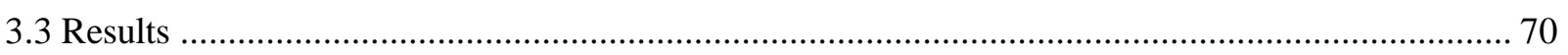

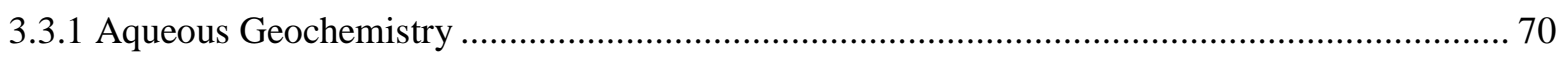

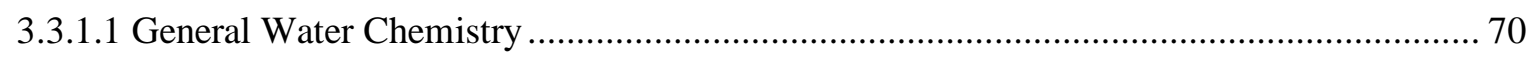

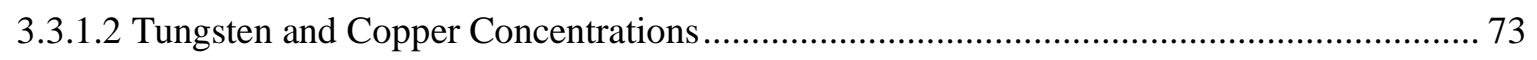

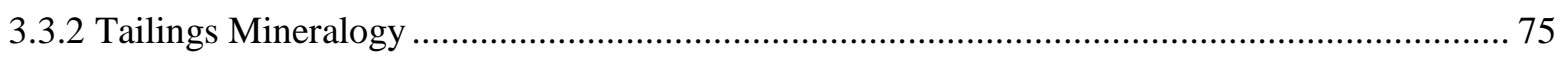

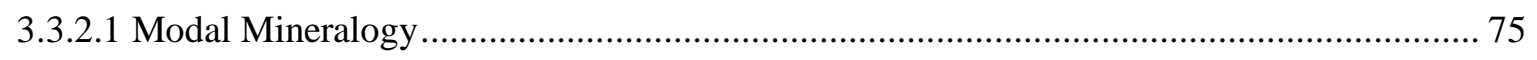

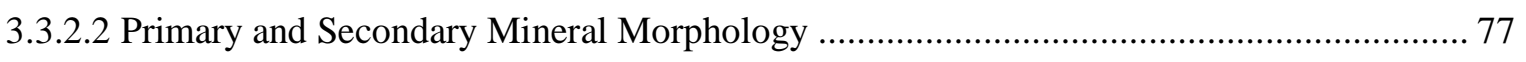

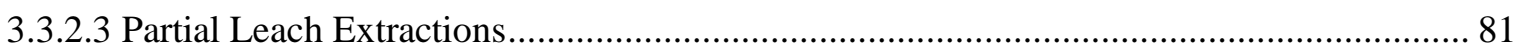

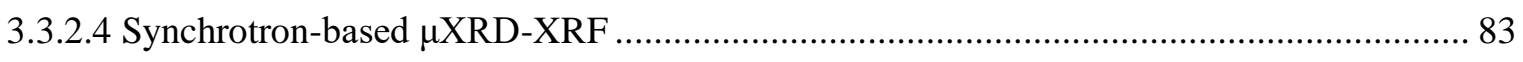

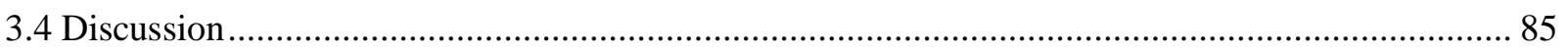

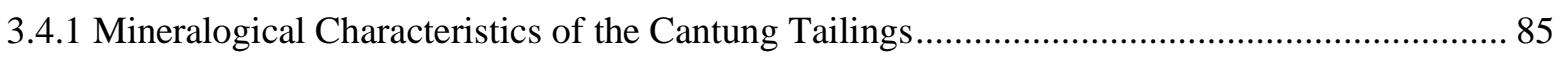

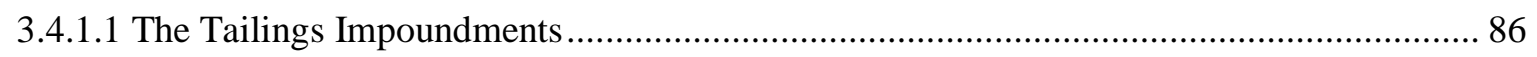

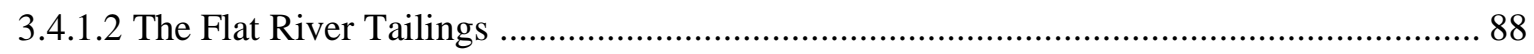

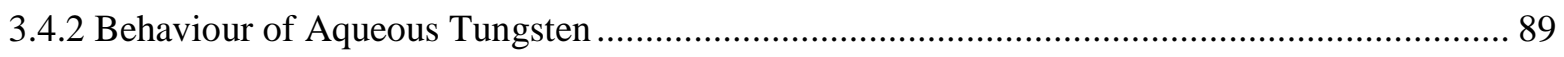

3.4.3 Tungsten Mobility in the Flat River Tailings ................................................................. 92

3.4.4 Considerations for Tungsten Behaviour in Mine Waste ..................................................... 96

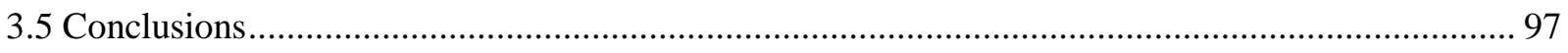

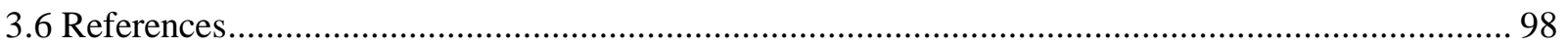

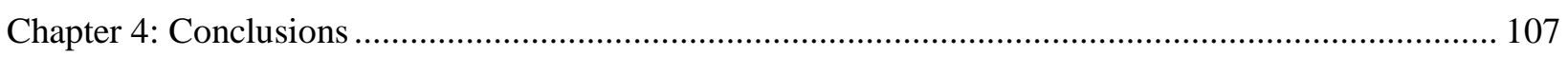

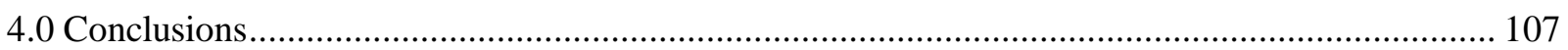

4.1 Recommendations for Future Work …................................................................................. 110

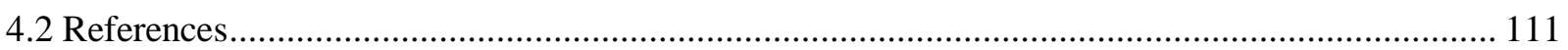

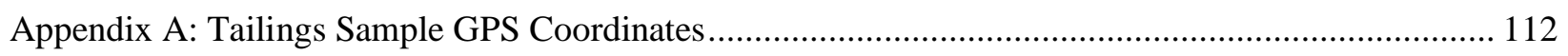

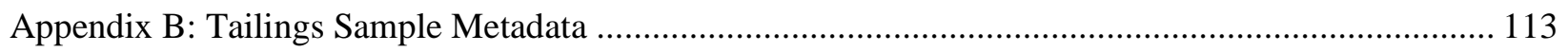

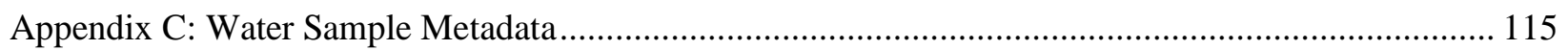

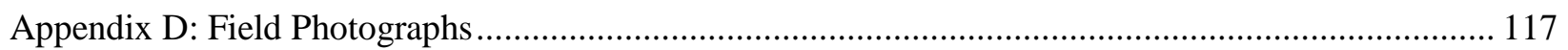

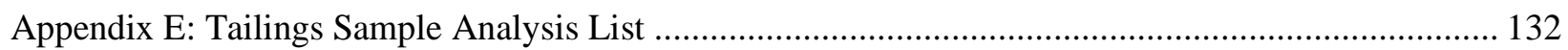




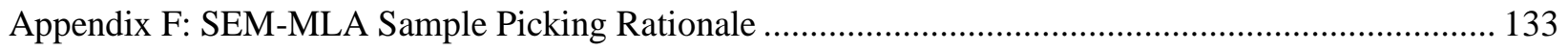

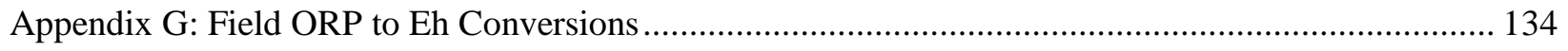

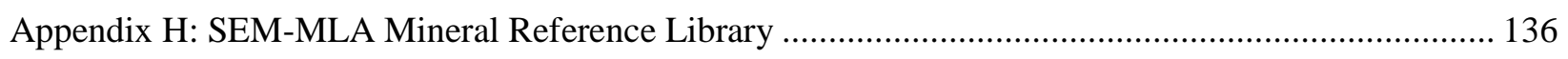

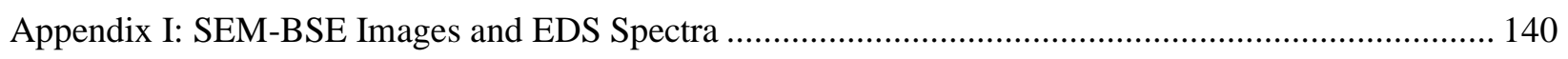

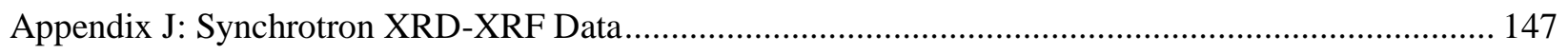

Appendix K: Hydroxylamine Leach Residue Photographs ............................................................... 154

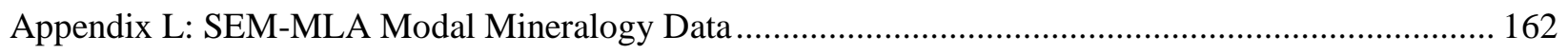

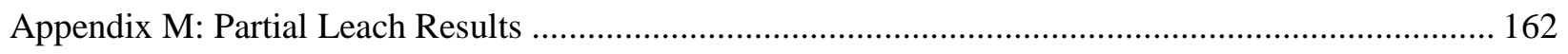

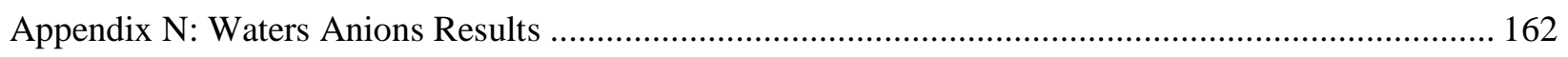

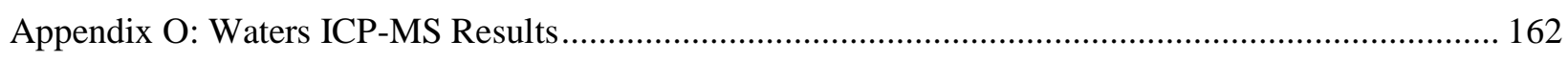




\section{List of Figures}

Figure 1.2 End-product uses of tungsten in 2012, modified from Brown and Pitfield (2014). "Hard metals" refers mainly to tungsten carbide and "mill products" refers to the electronic applications of metallic tungsten. The "others" category includes tungsten compounds used for pigmentation and chemical applications of tungsten.

Figure 1.3 Primary tungsten production by country for the years 1970, 1980, 1990, 2000, 2010, and 2018. Data sourced from the British Geological Survey (2020). Note that Russia includes the former Soviet Union. Modified after Brown and Pitfield (2014).

Figure 1.4 Location of the Cantung Mine in the Northwest Territories, Canada, modified from Ootes et al. (2013). ARR = Arctic Red River; GR = Gayna River; KR = Keele River; LR = Liard River; MP = Mackenzie Platform; MR = Mackenzie River; MtR = Mountain River; NNR = North Nahanni River; RR = Redstone River; NWT = Northwest Territories; RTR = Ravensthroat River; SB = Selwyn Basin; SNR = South Nahanni River; YT = Yukon Territory.

Figure 1.5 Geological map and cross section of the Cantung Deposit, modified from Rasmussen et al. (2011). Location of the Cantung Mine infrastructure indicated. CS = Circular Stock; MS = Mine Stock. 11 Figure 2.1 The locations of major tungsten deposits worldwide, modified from Brown and Pitfield (2014). Location of the Cantung Mine indicated.

Figure 3.1 Location of the Cantung Mine in the Northwest Territories, Canada, modified from Ootes et al. (2013). ARR = Arctic Red River; GR = Gayna River; KR = Keele River; LR = Liard River; MP = Mackenzie Platform; MR = Mackenzie River; MtR = Mountain River; NNR = North Nahanni River; RR = Redstone River; NWT = Northwest Territories; RTR = Ravensthroat River; SB = Selwyn Basin; SNR = South Nahanni River; YT = Yukon Territory.

Figure 3.2 Airphoto of the Cantung Mine site with sampling locations. Note that the airphoto was taken in 2014 during active tailings deposition in TP5, which currently has supernatant only on the north side of the pond. The pond at the base of TP2 where FRT-SW-01 was taken was full during sampling, with tailings exposure restricted to small beaches.

Figure 3.3 Tungsten concentrations in water samples with tungsten above detection limit, and only samples that have been filtered are shown. Error bars are 2 standard deviations of the ICP-MS measurement.

Figure 3.4 Tungsten and copper concentrations vs. $\mathrm{pH}$ for all surface waters and porewaters collected in this study. Error bars are two standard deviations of the mean of each ICP-MS measurement. All samples are filtered to 0.45 micron unless stated otherwise.

Figure 3.5 Modal mineralogy (wt.\%) of samples representing endmembers of tailing alteration at Cantung.

Figure 3.6 SEM-BSE images of alteration textures observed in the FRT and TP3. A: Pyrrhotite grain from TP3-TS-01 showing early stages of oxidation with etching along the grain boundary and a rim of Fe-oxyhydroxide. B: More aggressively altered pyrrhotite grain from TP3-TS-01 with parallel bands of Fe-oxyhydroxide replacing pyrrhotite along cleavage planes, encased by a rim of Fe-oxyhydroxide. Note the unaltered pyrrhotite grain in the top left of the image. C: Lithic fragment from FRT-TS-05 consisting of scheelite, pyrrhotite, plagioclase, and biotite, enveloped by acicular goethite. D: Pseudomorph of pyrrhotite from FRT-TS-01 with parallel bands of goethite. Note the porous texture. E: Relict core of chalcopyrite cemented by gypsum from FRT-TS-01. Weathering rind identified as jarosite by the prominent K peak in its EDS spectrum. F: Pseudomorph of pyrrhotite from FRT-TS-01 with equant, pseudocubic crystals of jarosite sheathed by a rind of goethite. The bottom of the grain shows parallel bands of goethite (bright grey) being replaced by jarosite (darker grey). 
Figure 3.7 Bar charts showing the partial leach recoveries of iron and tungsten. Samples are ordered by their relative degree of alteration as determine by SEM-MLA, with the least-altered samples at the top and most altered at the bottom. Note that only the cold and hot hydroxylamine hydrochloride leaches were sequential so the width of their bars represents the amount extracted. The recoveries by aqua regia, Li-metaborate fusion, and 4-acid digestion are plotted as residual values as if they were sequential, however their bar maxima represent the amount extracted (i.e. their true bar width starts from 0 ).

Figure 3.8 Synchrotron-based $\mu \mathrm{XRF}$ maps and $\mu \mathrm{XRD}$ patterns of a partially oxidized pyrrhotite grain from TP3 (panels A-D) and a pyrrhotite pseudomorph from the FRT (panels E-H). Micro-XRD measurements in panels $C, D, G$, and $\mathrm{H}$ were done with a spot size of $2 \mu \mathrm{m}$ and a dwell time of 10,000 ms. The center of the bullseyes in panels A, B, E, and F mark the exact location of the $\mu$ XRD measurements. A: Pyrrhotite enveloped by a hematite-maghemite rim with fragments of scheelite. B: Micro-XRF map of the grain in panel A, note that the color intensity does not reflect exact tungsten and iron concentrations. C: Two-dimensional $\mu$ XRD image showing Debye-Scherrer bands of hematite (Hem), maghemite (Mgh), and graphite (Gr). Samples were carbon coated to create a conductive surface during SEM analyses but was not removed before the synchrotron-based analyses, so graphite is present in all $\mu$ XRD patterns. D: Integrated $\mu$ XRD pattern showing relative peak intensities. E: Pyrrhotite completely replaced by goethite and lepidocrocite. F: Micro-XRF map of grain in panel E. G: Twodimensional $\mu \mathrm{XRD}$ image showing Debye-Scherrer bands of goethite (Gt), lepidocrocite (Lpc), and graphite (Gr). Artefacts were masked by the red circles on the image before 1D pattern integration. H: Integrated $\mu \mathrm{XRD}$ pattern showing relative peak intensities, note that the large peak at $11.7^{\circ} 2 \Theta$ is due to overlap between goethite and graphite.

Figure 3.9 Tungsten and copper vs. iron concentrations for all surface waters collected in this study. Note that iron and copper concentrations are plotted on a log scale. Samples below the detection limit were assigned a value one half of the detection limit. Error bars are two standard deviations of the mean value of each ICP-MS measurement. 


\section{List of Tables}

Table 3.1 Metadata and field notes for all tailings samples collected. FRT = Flat River Tailings, TP3 = Tailings Pond 3, TP4 = Tailings Pond 4, TP5 = Tailings Pond 5, TS $=$ Tailings Sample.

Table 3.2 Water parameters and concentrations of major elements for all water samples. Filtered concentrations reported are from the FA aliquot, with the exception of the porewater samples and FR01 which are from the FA + HF aliquot. TP3 = Tailings Pond 3, TP5 = Tailings Pond 5, FRT = Flat River Tailings, FR = Flat River Surface Water, $\mathrm{PWL}=$ Porewater, $\mathrm{SW}=$ Surface Water. *Values are elemental $\mathrm{S}$ reported by ICP-MS, converted to $\mathrm{SO}_{4}$. A value of "_." indicates the parameter was not measured or the sample was not collected. 


\section{List of Abbreviations}

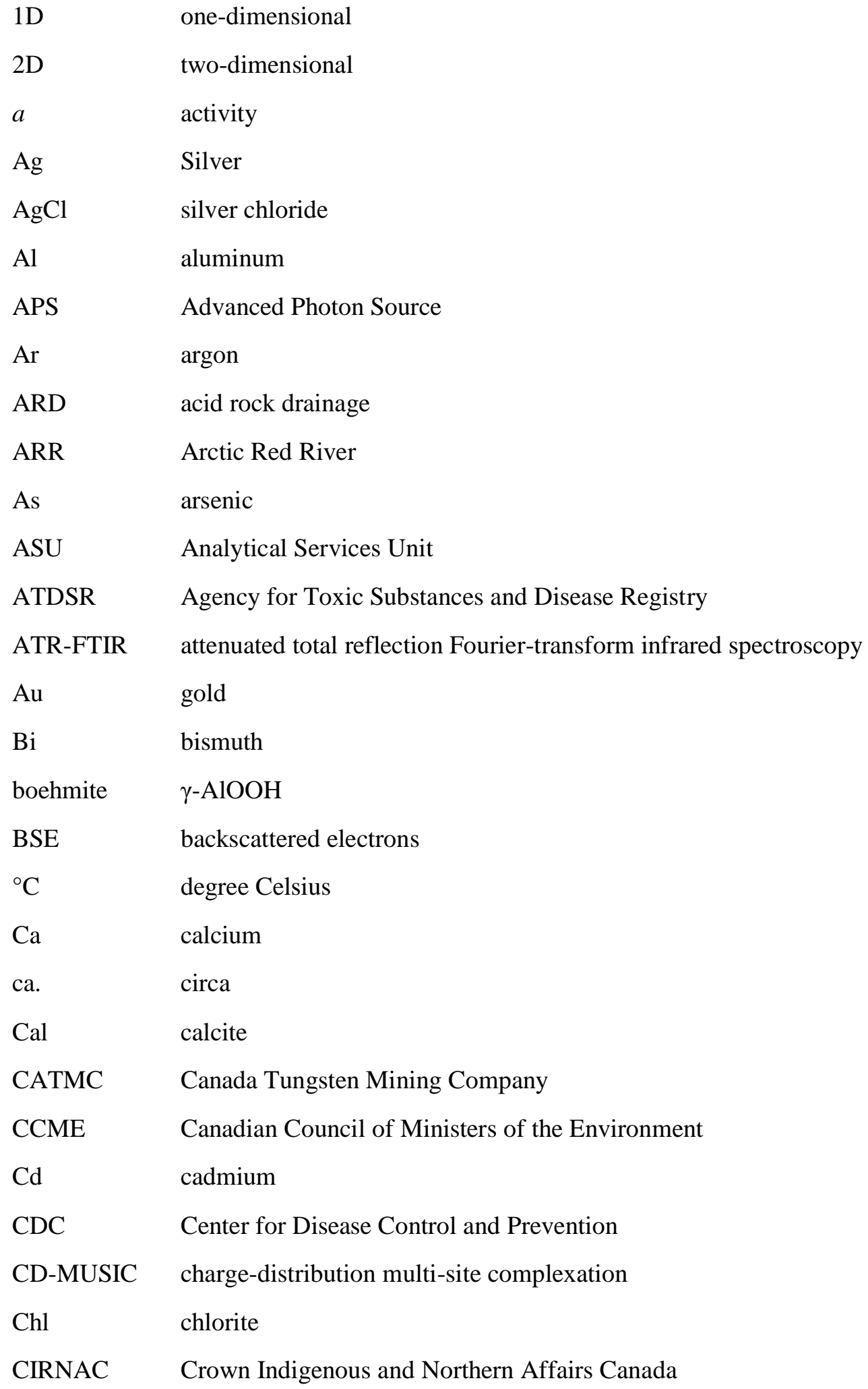




\begin{tabular}{|c|c|}
\hline $\mathrm{Cl}$ & chlorine \\
\hline $\mathrm{Cl}^{-}$ & chloride \\
\hline $\mathrm{cm}$ & centimeter \\
\hline Co & cobalt \\
\hline $\mathrm{CO}_{2}$ & carbon dioxide \\
\hline $\mathrm{CO}_{3}^{2-}$ & carbonate \\
\hline CS & Circular Stock \\
\hline $\mathrm{Cu}$ & copper \\
\hline DI & de-ionized \\
\hline DLM & Diffuse Layer Model \\
\hline DO & dissolved oxygen \\
\hline DL & detection limit \\
\hline $\mathrm{EC}$ & European Comission \\
\hline $\mathrm{EC}$ & electrical conductivity \\
\hline EDS & energy-dispersive $x$-ray spectroscopy \\
\hline Eh & redox potential \\
\hline EPA & Environmental Protection Agency \\
\hline $\mathrm{E}(\mathrm{SEM})$ & environmental scanning electron microscopy \\
\hline EXAFS & extended $\mathrm{x}$-ray adsorption fine structure \\
\hline $\mathrm{F}$ & fluorine \\
\hline $\mathrm{F}^{-}$ & fluoride \\
\hline FA & filtered and acidified with nitric acid \\
\hline $\mathrm{FA}+\mathrm{HF}$ & filtered and acidified with nitric and hydrofluoric acid \\
\hline $\mathrm{Fe}$ & iron \\
\hline FEG & field emission gun \\
\hline $\mathrm{FeOOH}_{(\mathrm{am})}$ & amorphous Fe-oxyhydroxide \\
\hline FR & Flat River \\
\hline FRT & Flat River Tailings \\
\hline g & gram \\
\hline$\mu \mathrm{g}$ & microgram \\
\hline Gr & graphite \\
\hline
\end{tabular}




\begin{tabular}{|c|c|}
\hline GR & Gayna River \\
\hline GSC & Geological Survey of Canada \\
\hline $\mathrm{Gt}$ & goethite \\
\hline $\mathrm{H}$ & hydrogen \\
\hline $\mathrm{HCl}$ & hydrochloric acid \\
\hline $\mathrm{HClO}_{4}$ & perchloric acid \\
\hline $\mathrm{HCO}_{3}^{-}$ & bicarbonate \\
\hline Hem & hematite \\
\hline $\mathrm{HF}$ & hydrofluoric acid \\
\hline HFSE & high field strength element \\
\hline $\mathrm{Hg}$ & mercury \\
\hline HNO & nitric acid \\
\hline $\mathrm{H}_{3} \mathrm{O}^{+}$ & hydronium \\
\hline HR-ICP-MS & high resolution inductively coupled plasma mass spectroscopy \\
\hline $\mathrm{H}_{2} \mathrm{WO}_{4}$ & tungstic acid \\
\hline ICP-AES & inductively coupled plasma atomic emission spectroscopy \\
\hline ICP-MS & inductively coupled plasma mass spectroscopy \\
\hline $\mathrm{K}$ & potassium \\
\hline $\mathrm{KCl}$ & potassium chloride \\
\hline $\mathrm{kD}$ & kilodalton \\
\hline $\mathrm{kg}$ & kilogram \\
\hline $\mathrm{km}$ & kilometer \\
\hline $\mathrm{KR}$ & Keele River \\
\hline Ksp & solubility product \\
\hline $\mathrm{kV}$ & kilovolt \\
\hline $\mathrm{L}$ & liter \\
\hline Lpc & lepidocrocite \\
\hline LR & Liard River \\
\hline $\mathrm{m}$ & meter \\
\hline M & molar concentration \\
\hline$\mu \mathrm{m}$ & micrometer \\
\hline
\end{tabular}




\begin{tabular}{|c|c|}
\hline $\mathrm{M} \Omega$ & megaohm \\
\hline Мa & mega-annum \\
\hline $\mathrm{mg}$ & milligram \\
\hline $\mathrm{Mg}$ & magnesium \\
\hline $\mathrm{Mg \#}$ & magnesium number \\
\hline Mgh & maghemite \\
\hline $\mathrm{mL}$ & milliliter \\
\hline MLA & Mineral Liberation Analysis \\
\hline $\mathrm{mm}$ & millimeter \\
\hline $\mathrm{mM}$ & millimolar \\
\hline $\mathrm{Mn}$ & manganese \\
\hline$\delta-\mathrm{MnO}_{2}$ & manganese oxide \\
\hline Mo & molybdenum \\
\hline $\mathrm{MoO}_{4}{ }^{2-}$ & molybdate \\
\hline MP & Mackenzie Platform \\
\hline $\mathrm{MPa}$ & megapascal \\
\hline MR & Mackenzie River \\
\hline $\mathrm{ms}$ & milliseconds \\
\hline MS & Mine Stock \\
\hline MtR & Mountain River \\
\hline $\mathrm{N}_{2(\mathrm{~g})}$ & nitrogen gas \\
\hline $\mathrm{Na}$ & sodium \\
\hline NATCL & North American Tungsten Corporation Limited \\
\hline NFA & not filtered, but acidified with nitric acid \\
\hline $\mathrm{NH}_{2} \mathrm{OH} \cdot \mathrm{HCl}$ & hydroxylamine hydrochloride \\
\hline $\mathrm{Ni}$ & nickel \\
\hline $\mathrm{Nd}$ & neodymium \\
\hline ng & nanogram \\
\hline NNR & North Nahanni River \\
\hline $\mathrm{NO}_{3}^{-}$ & nitrate \\
\hline NWT & Northwest Territories \\
\hline
\end{tabular}




\begin{tabular}{|c|c|}
\hline $\mathrm{O}$ & Oxygen \\
\hline ORP & oxidation-reduction potential \\
\hline $\mathrm{Pb}$ & lead \\
\hline $\mathrm{pH}$ & A numerical measure of the acidity or alkalinity of a solution \\
\hline $\mathrm{pH}_{\mathrm{pzc}}$ & $\mathrm{pH}$ of the point of zero charge \\
\hline PHREEQC & pH Redox Equilibrium (in C language) software \\
\hline $\mathrm{pKa}$ & dissociation constant \\
\hline $\mathrm{PO}_{4}{ }^{2-}$ & phosphate \\
\hline POM & polyoxometalate \\
\hline $\mathrm{ppb}$ & parts per billion \\
\hline ppm & parts per million \\
\hline PWL & porewater sample \\
\hline QFIR & Queen's Facility for Isotope Research \\
\hline $\mathrm{Rh}$ & rhodium \\
\hline$r_{\text {ion }}$ & ionic radius \\
\hline $\mathrm{RR}$ & Redstone River \\
\hline RSD & relative standard deviation \\
\hline RTR & Ravensthroat River \\
\hline $\mathrm{s}$ & seconds \\
\hline S & sulfur \\
\hline$S^{2-}$ & sulfide \\
\hline SAED & Select-area electron diffraction \\
\hline SB & Selwyn Basin \\
\hline SEDEX & Sedimentary Exhalative \\
\hline SEM & scanning electron microscopy \\
\hline $\mathrm{Sn}$ & tin \\
\hline SNR & South Nahanni River \\
\hline $\mathrm{SO}_{4}{ }^{2-}$ & sulfate \\
\hline SPL-Lt & sparse phase liberation \\
\hline $\mathrm{Sr}$ & strontium \\
\hline STEM & scanning transmission electron microscopy \\
\hline
\end{tabular}




\begin{tabular}{|c|c|}
\hline stpd & short tons per day \\
\hline SW & surface water \\
\hline TDS & total dissolved solids \\
\hline $\mathrm{Te}$ & tellurium \\
\hline TP1 & Tailings Pond 1 \\
\hline TP2 & Tailings Pond 2 \\
\hline TP3 & Tailings Pond 3 \\
\hline TP4 & Tailings Pond 4 \\
\hline TP5 & Tailings Pond 5 \\
\hline TS & tailings sample \\
\hline $\mathrm{U}$ & Uranium \\
\hline$\mu \mathrm{g}$ & microgram \\
\hline US & United States \\
\hline USA & United States of America \\
\hline USD & United States Dollar \\
\hline USGS & United States Geological Survey \\
\hline $\mathrm{W}$ & tungsten \\
\hline $\mathrm{WO}_{3}$ & solid tungstate \\
\hline $\mathrm{WO}_{4}{ }^{2-}$ & tungstate \\
\hline $\mathrm{WS}_{4}^{2-}$ & tetrathiotungstate \\
\hline wt. $\%$ & weight percent \\
\hline XBSE & extended backscatter electron \\
\hline$\mu \mathrm{XANES}$ & micro X-ray absorption near edge structure \\
\hline$\mu \mathrm{XRD}$ & micro X-ray Diffraction \\
\hline$\mu \mathrm{XRF}$ & micro X-ray Fluorescence \\
\hline YT & Yukon Territory \\
\hline $\mathrm{Zn}$ & zinc \\
\hline
\end{tabular}




\section{List of Minerals}

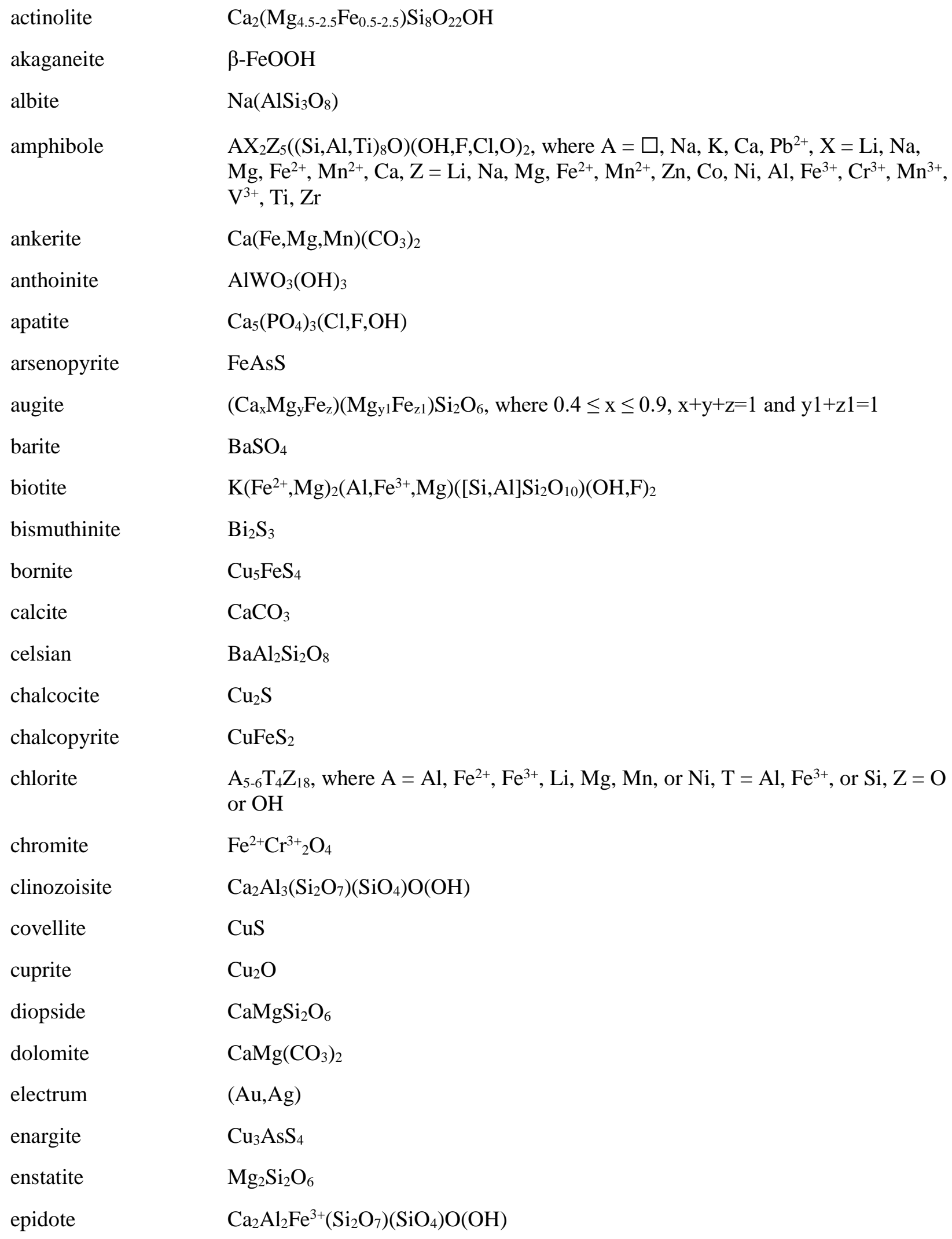




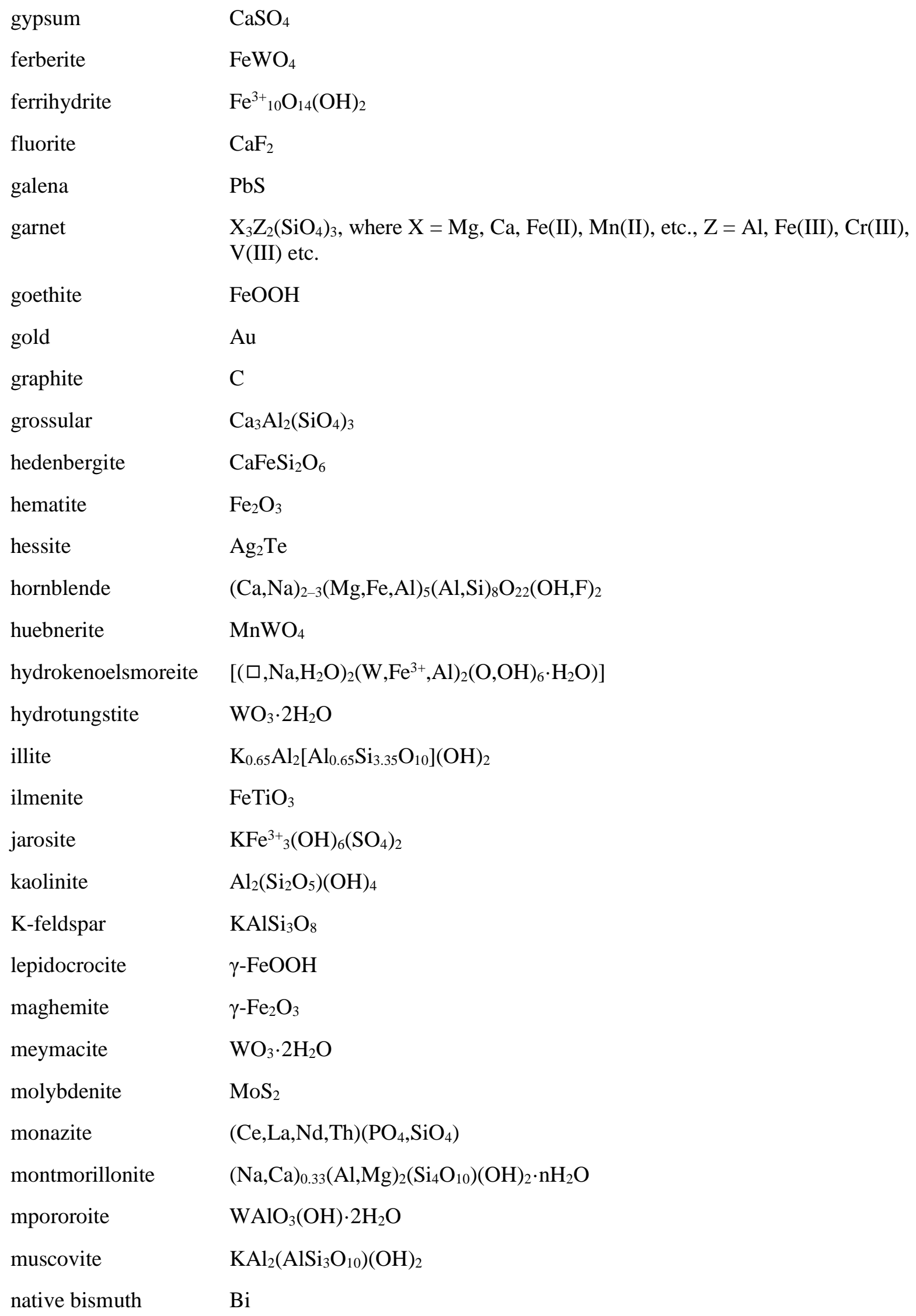




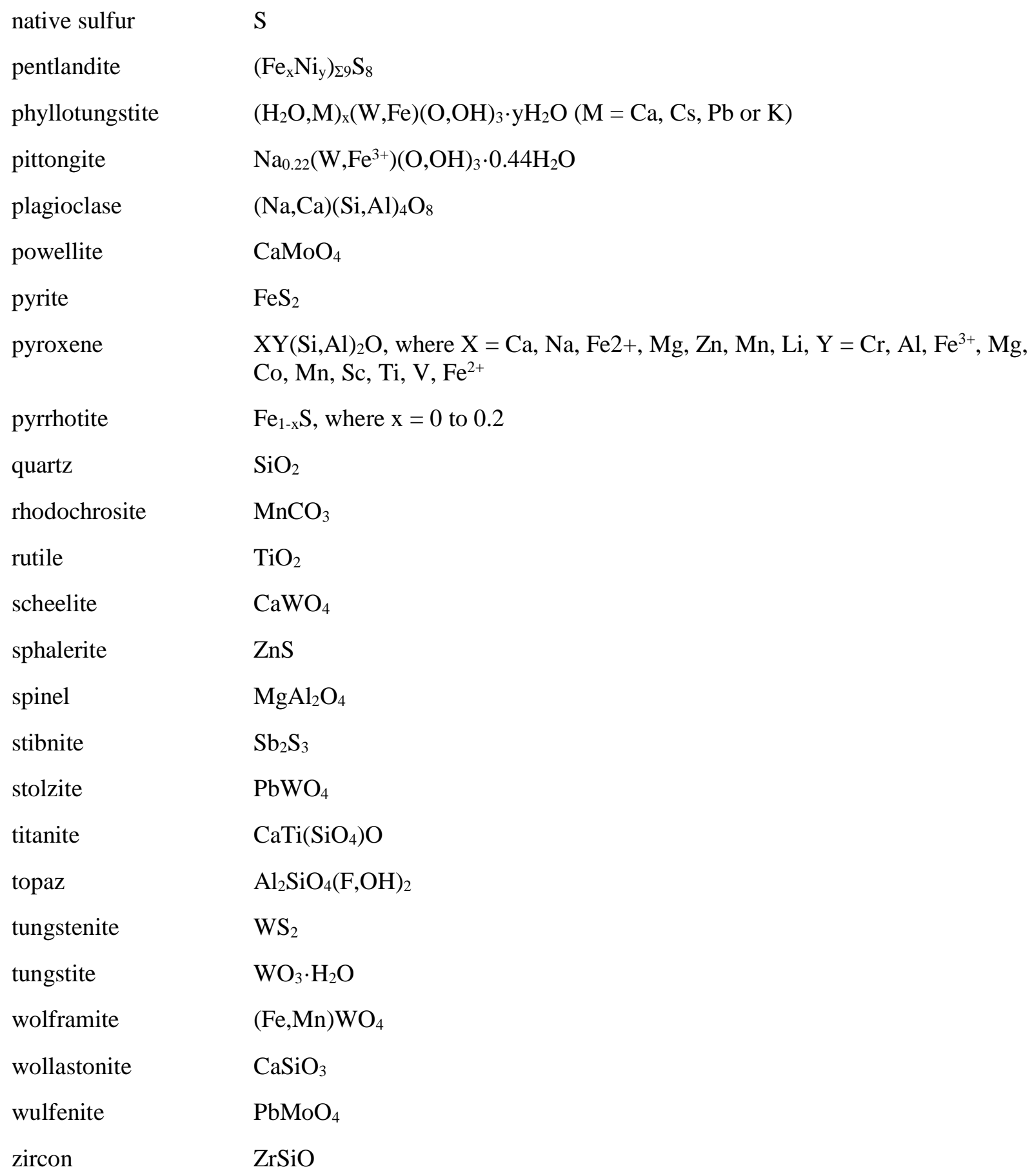




\section{Chapter 1: Introduction}

\subsection{Background Information and Objective}

This thesis aims to determine the controls on tungsten mobility in historic floodplain tailings and more recent dam-tailings at the Cantung Mine in the Northwest Territories, Canada. In addition, this thesis contains a literature review of the environmental mobility of tungsten and it's ecotoxicity. Most studies regarding tungsten mobility have focused on groundwater, surface water, and soil systems (e.g. Johannesson et al., 2000; Seiler et al., 2005; Bednar et al., 2009; Johannesson et al., 2013; Mohajerin et al., 2016; Datta et al., 2017; Bostick et al., 2018; Steenstra et al., 2020), but little attention has been given to its mobility in mine waste which may be a point source of metal leaching (Petrunic and Al, 2005; Hällström et al., 2019). As tungsten has few substitutes for many of its industrial uses, the number of tungsten mining operations is expected to increase in the future (Brown and Pitfield, 2014; Leal-Ayala et al., 2015), increasing the potential for tungsten leaching to the environment from anticipated tailings systems. Legacy mines containing high concentrations of tungsten in tailings, waste rock, and slag also pose potential environmental risk, particularly as the long-term stability of tungsten minerals is poorly understood. In light of the potential toxicological effects of tungsten to humans and other organisms, it is imperative to gain a better understanding of the behaviour of tungsten for more effective management, closure, and remediation of both contemporary and legacy W-bearing mine waste.

The environmental mobility of tungsten has received increased attention in recent years due to its potential toxicity to humans (Koutsospyros et al., 2006; Datta et al., 2017). In 2003, the United States Center for Disease Control and Prevention (CDC) launched an investigation to determine the cause of a childhood leukemia cluster in Fallon, Nevada, USA (Koutsospyros et al., 2006). Urine samples collected from individuals in Fallon had tungsten concentrations as high as 15 times the national average (Koutsospyros et al., 2006), and Fallon drinking water had elevated tungsten concentrations ranging from 
$0.25-0.337 \mu \mathrm{g} / \mathrm{L}$ (ATDSR, 2005), in addition to elevated concentrations of seven other metals, arsenic, and pesticides (Koutsospyros et al., 2006). Tungsten was predicted to be the cause of the outbreak as none of the other contaminants are known to cause leukemia, although the toxicology of tungsten was largely unknown at the time. Since the events in Fallon, the toxicology and low-temperature geochemical behaviour of tungsten has been more intensely studied, and in 2008 tungsten was classified as an emerging contaminant by the United States Environmental Protection Agency (EPA) (US EPA, 2008). To date, it has not been concluded whether tungsten was responsible for the Fallon outbreak and research is still ongoing (Witten et al., 2012; Datta et al., 2017). However, the ingestion of tungsten has been linked to other deleterious clinical manifestations in humans and other organisms (e.g. Strigul et al., 2010; Kennedy et al., 2012; Witten et al., 2012; Kelly et al., 2013; VanderSchee et al., 2018). Dissolved tungsten is not currently a regulated contaminant in Canada, the United States, or the European Union (Canadian Council of Ministers of the Environment, 2008; Strigul et al., 2009; Datta et al., 2017). To date, the only jurisdiction to have regulated tungsten is the former Soviet Union, who set limits of $50 \mu \mathrm{g} / \mathrm{L}$ $\mathrm{W}$ for drinking and practical-use water reservoirs, $0.8 \mu \mathrm{g} / \mathrm{L} \mathrm{W}$ for fishing reservoirs, and $0.15 \mathrm{mg} / \mathrm{m}^{3} \mathrm{~W}$ for air in populated areas (Strigul et al., 2009). The United States EPA recommended tungsten screening levels for contaminated sites ["Superfund" sites as defined by the Comprehensive Environmental Response, Compensation, and Liability Act (CERCLA)] are $63 \mathrm{mg} / \mathrm{kg} \mathrm{W}$ for residential soils, $930 \mathrm{mg} / \mathrm{kg}$ W for industrial soils, $16 \mu \mathrm{g} / \mathrm{L} \mathrm{W}$ for tap water, and $2.4 \mathrm{mg} / \mathrm{kg} \mathrm{W}$ for soils at risk for leaching to groundwater (US EPA, 2020).

This thesis aims to determine the controls on tungsten mobility in historic floodplain tailings and more recent dam-tailings at the Cantung Mine in the Northwest Territories, Canada. To do so, tailings samples, tailings porewaters, and surface waters were collected from the Cantung mine and a variety of techniques were employed to determine the tungsten concentrations in the tailings (both solid and aqueous) and to identify the solid-phase hosts of tungsten. Specific goals of this thesis are to: 
1. Evaluate the stability of scheelite in both the historic floodplain tailings impoundment tailings and identify secondary mineral hosts of tungsten;

2. Determine the aqueous concentrations of tungsten in the Cantung tailings and relate the concentrations to the mineralogy of the tailings and the geochemical parameters of the waters; and

3. Identify scenarios in which tungsten may be transported via water from the tailings to the surrounding environment.

\subsection{Uses of Tungsten and Economic Importance}

Historically, the main use of tungsten was for incandescent lightbulb filaments, owing to the stability of tungsten at high temperatures (Lassner and Schubert, 2000; Brown and Pitfield, 2014). The use of incandescent lightbulbs has largely been phased out with the widespread use of more efficient light

sources; however, the contemporary demand for tungsten is rising due to its usefulness for other industrial applications (Fig. 1.1; Brown and Pitfield, 2014; Leal-Ayala et al., 2015). Today, the main end-products of tungsten are tungsten carbide and steels alloyed with tungsten, which accounted for $83 \%$ of its endproduct use in 2012 (Fig. 1.2; Brown and Pitfield, 2014). Tungsten carbide is dense, has a high melting point $\left(2870{ }^{\circ} \mathrm{C}\right)$, is extremely hard $(8.5-9$ on Mohs scale), and is used for cutting, drilling, and other applications that require maintained strength and resistance to wear at high temperatures (Brown and Pitfield, 2014). Steel (and other metals including $\mathrm{Cu}$, Mo, and $\mathrm{Ni}$ ) are alloyed with tungsten to increase their density, hardness, and heat resistance, and have a wide range of uses similar to those of tungsten carbide. Tungsten has also received increased demand as a replacement for lead in some products due to concerns about lead toxicity, notably as a high-density replacement in fishing weights and ammunition (Brown and Pitfield, 2014). The unique properties of tungsten, particularly its high resistance to heat, make it non-substitutable for many of its industrial applications without increased cost or decreased effectiveness (Brown and Pitfield, 2014). 


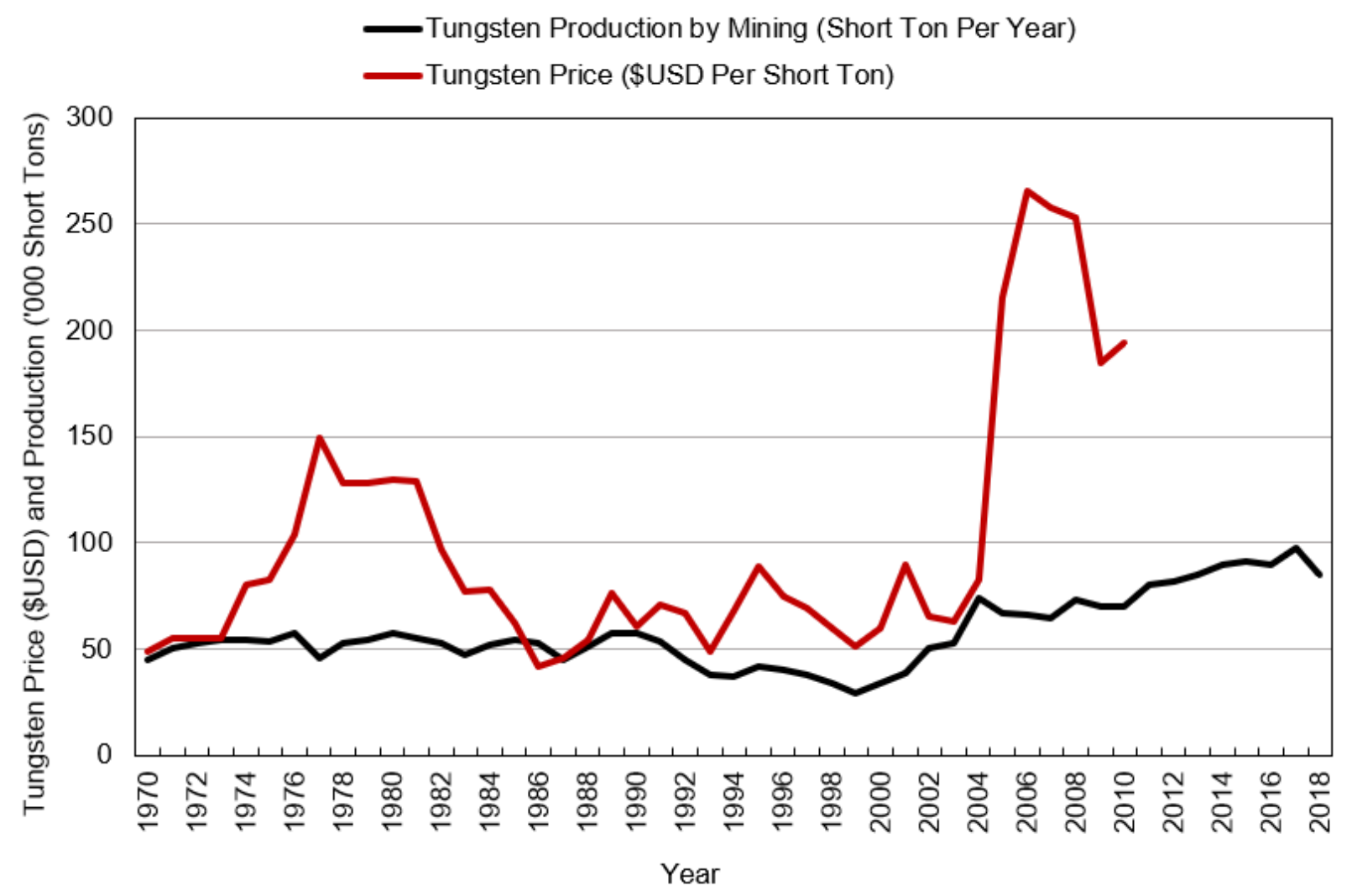

Figure 1.1 World tungsten production by mining and value per short ton from. Tungsten price data is sourced from the USGS (2013), note that data is only available until 2010. Primary tungsten production from mining data is sourced from the British Geological Survey (2020). Modified after Leal-Ayala et al. (2015). 


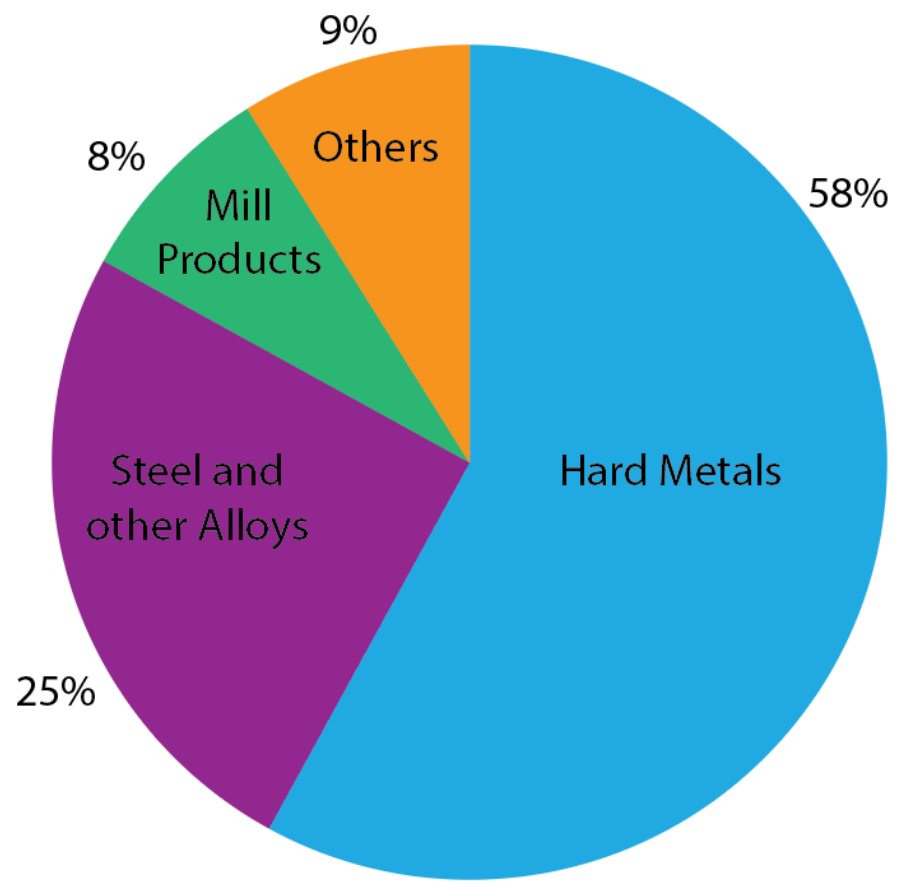

Figure 1.2 End-product uses of tungsten in 2012, modified from Brown and Pitfield (2014). "Hard metals" refers mainly to tungsten carbide and "mill products" refers to the electronic applications of metallic tungsten. The "others" category includes tungsten compounds used for pigmentation and chemical applications of tungsten.

The lack of effective industrial substitutions for tungsten coupled with the high potential for supply shortages has placed tungsten on the list of critical metals by the European Commission (EC) and the United States Geological Survey (USGS) (EC, 2010; Fortier et al., 2018). A critical metal (or material) is defined as a material in which a supply shortage would result in a large negative economic impact (Graedel et al., 2014). Although tungsten deposits are widespread across the world with relatively large reserves in Russia ( $8 \%$ of global reserves), Canada (4\% of global reserves), and the USA ( $4 \%$ of global reserves), China has by far the highest tungsten endowment (62\% of global reserves; Brown and Pitfield, 2014). Prior to the 1980 's, primary tungsten production from mining was not dominated by any country in particular, although China, the former Soviet Union, Canada, and the USA were major producers (Fig. 1.3; Brown and Pitfield, 2014). With low production costs, China ramped up primary tungsten production and manufacturing of tungsten products in the 1980's, flooding the market and outcompeting other countries (Brown and Pitfield, 2014). Subsequently, China has imposed production 
quotas for mines operating within China, increased taxes on the export of Chinese tungsten ores, and decreased the export quota for manufactured tungsten products. As a result, China has monopolized both primary tungsten production and the manufacturing of tungsten products, which poses concerns of potential supply shortages and has led the classification of tungsten as a critical metal (Brown and Pitfield, 2014).

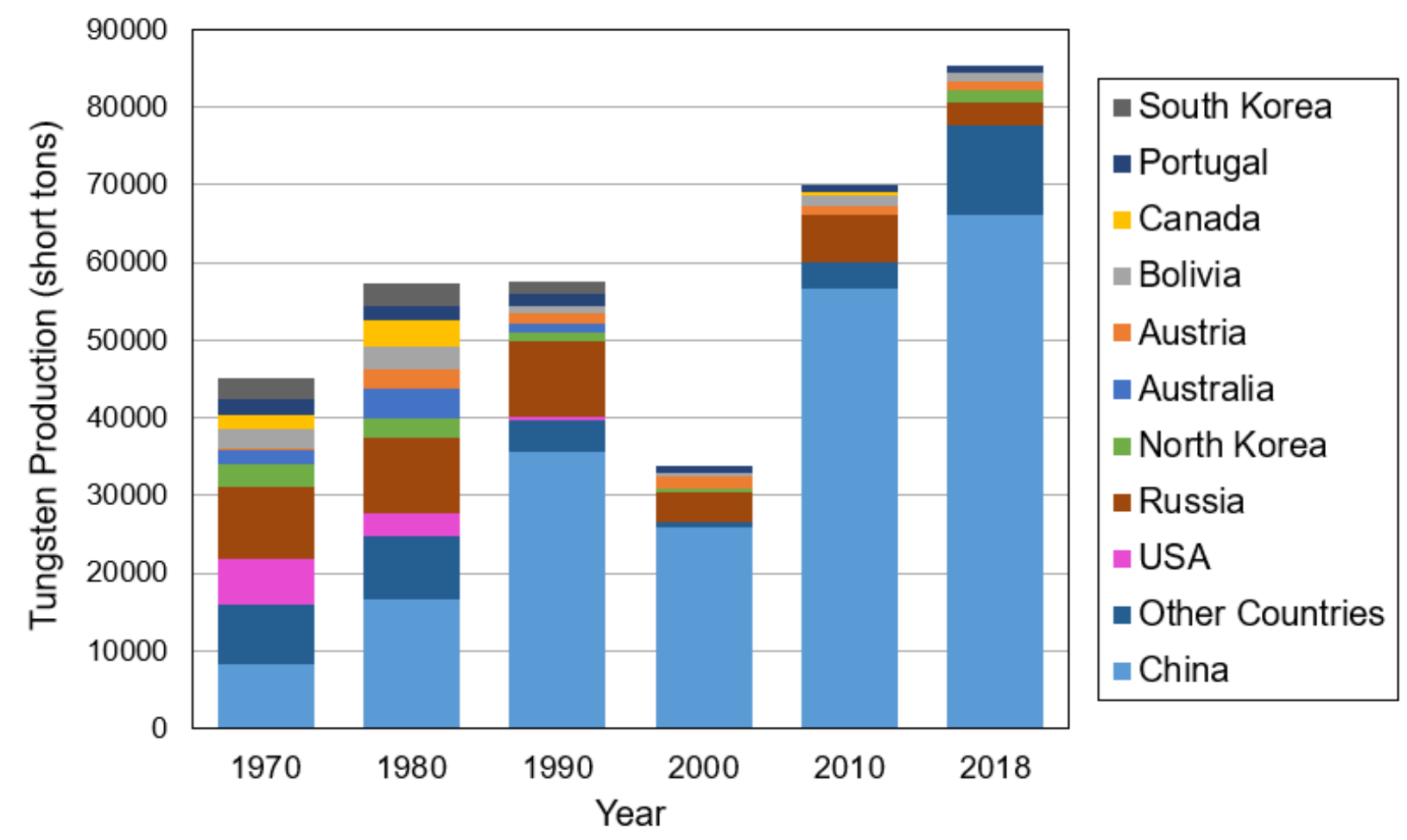

Figure 1.3 Primary tungsten production by country for the years 1970, 1980, 1990, 2000, 2010, and 2018. Data sourced from the British Geological Survey (2020). Note that Russia includes the former Soviet Union. Modified after Brown and Pitfield (2014).

\subsection{Geology of the Cantung Deposit}

\subsubsection{Regional Geology}

The Cantung deposit is located within the Selwyn Basin of the Canadian Cordilleran Miogeocline, which composes the bulk of the Mackenzie Mountains (Fig. 1.4; Ootes et al., 2013). To the east of the Cantung deposit, the Mackenzie Mountains are dominantly composed of older miogeoclinal rocks of the Mackenzie Platform. To the west, the Selwyn Basin continues, followed by a complex 
amalgamation of accreted terranes within the Yukon that have both exotic and composite provenance (Nelson and Colpron, 2007). The geodynamic events leading to the formation of the Cantung Deposit (and other tungsten-skarn deposits in the region) involve rifting, passive margin sedimentation, thrust-fold deformation and metamorphism, extension-related plutonism, and skarnification (Nelson and Colpron, 2007; Mair et al., 2006; Mair et al., 2011).

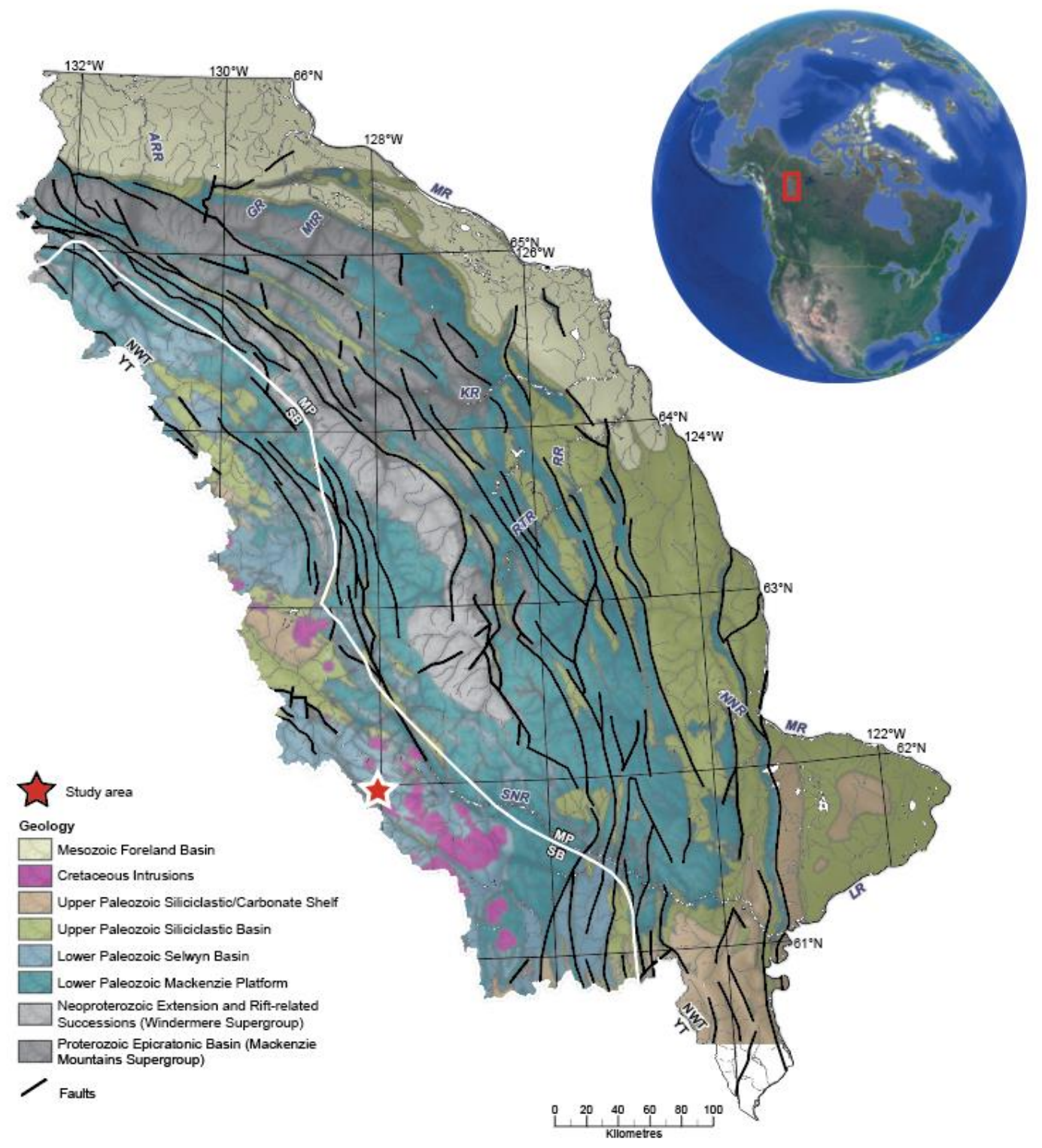

Figure 1.4 Location of the Cantung Mine in the Northwest Territories, Canada, modified from Ootes et al. (2013). $\mathrm{ARR}=$ Arctic Red River; GR = Gayna River; KR = Keele River; $\mathrm{LR}=$ Liard River; MP = Mackenzie Platform; MR = Mackenzie River; MtR = Mountain River; NNR = North Nahanni River; RR = Redstone River; NWT = Northwest Territories; RTR = Ravensthroat River; SB = Selwyn Basin; SNR = South Nahanni River; YT = Yukon Territory. 
Rifting of the supercontinent Rodinia during the Neoproterozoic (ca. 780-720 Ma; Narbonne and Aitken, 1995) led to opening of the Paleo-Panthallasic Ocean, and formed the western passive margin of the continent Laurentia (Nelson and Colpron, 2007). Within the region of the Mackenzie Mountains, passive margin sedimentation began coeval with rifting, resulting in the deposition of continental shelf to slope facies carbonates and siliciclastic rocks of the Windermere Supergroup (Narbonne and Aitken, 1995). Rifting continued across the Proterozoic-Phanerozoic boundary, prograding the passive margin to accommodate slope to basin facies sedimentation of the Hyland Group turbidites. The Hyland Group represents the basal unit of the Selwyn Basin, and is constrained to Early Cambrian (Mair et al., 2006). Stratigraphically above the Hyland Group lies an 800 m thick package of Lower Cambrian to Middle Devonian basinal shales, limestones, siltstones, chert, and dolomitic mudstones (Mair et al., 2006). It is these calcareous strata that host the mineralization of the Cantung Deposit, although tungsten mineralization did not occur until the Cretaceous (Archibald et al., 1978; Ootes et al., 2013).

Sedimentation continued elsewhere in the Selwyn Basin throughout the Paleozoic, accompanied by intermittent rifting and at least three episodes of mafic alkalic volcanism (Goodfellow et al., 1995; Mair et al., 2006). High heat flow and normal faulting during this time yielded favourable conditions for formation of syngenetic Pb-Zn deposits within the Selwyn Basin (e.g. the Anvil, MacMillan Pass, and Howard's Pass SEDEX districts) (Goodfellow, 2007; Gadd et al., 2017). In the Jurassic, tectonism changed to a compressional regime with the accretion of the Yukon-Tanana Terrane (Mair et al., 2006). The Yukon-Tanana Terrane is considered to be a composite terrane composed of rifted fragments of ancestral North America and a large variety of plutonic, volcanic, and sedimentary rock packages with continental-arc affinity. Accretion of the Yukon-Tanana Terrane caused thin-skin deformation of the Selwyn Basin and Mackenzie Platform, creating the fold-thrust sheets that give relief to the present-day Mackenzie Mountains (Mair et al., 2006). During accretion, rocks of the Selwyn Basin were metamorphosed to lower greenschist facies with ${ }^{40} \mathrm{Ar} /{ }^{39} \mathrm{Ar}$ mica cooling ages of $103 \mathrm{Ma}$ (Mair et al., 2006). The orogenic event caused development of northwest trending structural fabrics in the region of 
the Cantung deposit and major structural features that follow the same trend (Mair et al., 2006). However, structures hosting the deposit have an east-west orientation that may be related to emplacement of the mineralizing pluton (Salmabadi et al., 2019).

Orogenic thickening of the Yukon-Tanana Terrane likely caused delamination of the lower lithospheric crust during the early to mid-Cretaceous. Delamination was followed by asthenospheric upwelling, uplift, and extension-related plutonism (115 - $110 \mathrm{Ma}$; Hudson, 1994) within the YukonTanana Terrane (Mair et al., 2006). Although the epicenter of sub-lithospheric heat flow was directly beneath the Yukon-Tanana Terrane, post-collisional magmatism also occurred shortly after (96 - $90 \mathrm{Ma}$; Hart et al., 2004) on the flanks of the rift within the Selwyn Basin (Mair et al., 2011). Three plutonic suites are recognized to have been emplaced during this time period: The Tombstone, Mayo, and Tungsten plutonic suites, which collectively comprise the Tombstone-Tungsten Magmatic Belt (Hart et al., 2004). The suites are essentially coeval (96 - 90 Ma; Hart et al., 2004), yet are petrologically and geochemically distinct as a result of their geodynamic position relative to the rift (Hart et al., 2004; Mair et al., 2011). The Tombstone and Mayo suites are interpreted to have been generated from a metasomatized sub-continental lithospheric mantle source, based on primitive $\mathrm{Nd}$ and $\mathrm{Sr}$ isotopic signatures, the presence of calc-alkaline lamprophyres, and high Mg\#s of xenocrystic pyroxene (Mair et al., 2011). Due to their genesis in the sub-continental lithospheric mantle, the suites have high $\mathrm{Au}$ endowment, typified by reduced intrusion related Au mineralization such as at the Fort Knox, Scheelite Dome, and Dublin Gulch deposits (Hart et al., 2004).

The Tungsten Suite is the most petrologically distinct, and is interpreted to be generated from melting of crustal rock more distal on the flank of the rift (Mair et al., 2011; Hart et al., 2004). The suite is characterized by being felsic-intermediate and peraluminous (S-type), crystallizing garnet and more rarely two-mica granites (Hart et al., 2004). The initial Nd and Sr isotopic signature of the Tungsten suite intrusions indicate a continental crustal source, which are the reduced pelitic and carbonaceous rocks of the Laurentian passive margin (Mair et al., 2011; Hart et al., 2004). Although the Tungsten suite is not fertile for gold mineralization, its crustal source causes it to be highly fractionated and fertile for 
significant tungsten mineralization (Hart et al., 2004). Petrogenetic tungsten endowment, coupled with abundant carbonaceous rocks in the Selwyn Basin, which the Tungsten Plutonic Suite intruded, has resulted in the formation of world class W-skarn deposits, including the Cantung Deposit and its sister deposit, Mactung (Ootes et al., 2013).

\subsubsection{The Cantung Deposit}

The Cantung Deposit is one of the highest-grade W-Cu skarn deposits in the world (Brown and Pitfield, 2014). The local stratigraphy (listed in order of decreasing age) consists of the Lower Argillite Member of the Proterozoic Vampire Formation, the Swiss Cheese Limestone, Ore Limestone, Upper Argillite, and Dolomite Members of the Cambrian Sekwi Formation, overlain by the Cambrian Rabbitkettle Formation (Fig. 1.5; Rasmussen et al., 2011). The sedimentary units are intruded by the MidCretaceous (101.15 \pm 0.44 to $98.2 \pm 0.4$ Ma; Rasmussen et al., 2011) Mine Stock monzogranite pluton of the Tungsten Plutonic Suite. The deposit has two ore zones, the Open-Pit orebody and the E-zone orebody, separated on either limb of a tight recumbent antiform, which pre-dates skarn formation (Fig. 1.5; Falck et al., 2019). In the Open Pit orebody, mineralization is hosted within the Swiss Cheese Limestone and Ore Limestone Members and is exposed at the surface. Mineralization is characterized by disseminated scheelite and chalcopyrite mainly in banded to massive high-temperature grossularhedenbergite skarn facies with lesser amounts of hydrous actinolite-pyrrhotite skarn facies (Rasmussen et al., 2011). Pyrrhotite within the Open Pit orebody is hexagonal (Mesh Environmental, 2008). The E-Zone orebody is located on the lower limb of the recumbent fold with mineralization hosted within the Ore Limestone Member. Proximal to the Mine Stock, skarn facies in the E-zone are hydrous and grade from biotite, to biotite-pyrrhotite, to actinolite-pyrrhotite, to actinolite facies with distance from the Mine Stock. Distal from the Mine Stock and on the outer-fringes of the E-zone, mineralization is associated with anhydrous grossular-hedenbergite skarn facies (Rasmussen et al., 2011). Pyrrhotite within the Ezone is predominantly monoclinic (Mesh Environmental, 2008). All facies are exoskarns, and are thought 
to have formed from the same magmatic fluid (Mathieson and Clark, 1984; Rasmussen et al., 2011), although recent studies suggest more a more complex fluid history (Lentz et al., 2019; Elongo et al., 2020). The coarsest scheelite and highest W-grades are associated with the biotite-pyrrhotite facies in the E-zone orebody. Accessory minerals in minor abundance in the Cantung deposit include apatite,

sphalerite, pyrite, gold, fluorite, barite, and bismuth and tellurium minerals. Gold mineralization in the Open pit and E-zone orebodies is present as electrum with up to $30 \mathrm{wt} . \%$ silver, and is strongly associated with native bismuth, bismuth-tellurides, bismuthinite $\left(\mathrm{Bi}_{2} \mathrm{~S}_{3}\right)$, and hessite $\left(\mathrm{Ag}_{2} \mathrm{Te}\right)$ (Falck et al., 2019;

Lentz et al., 2019).
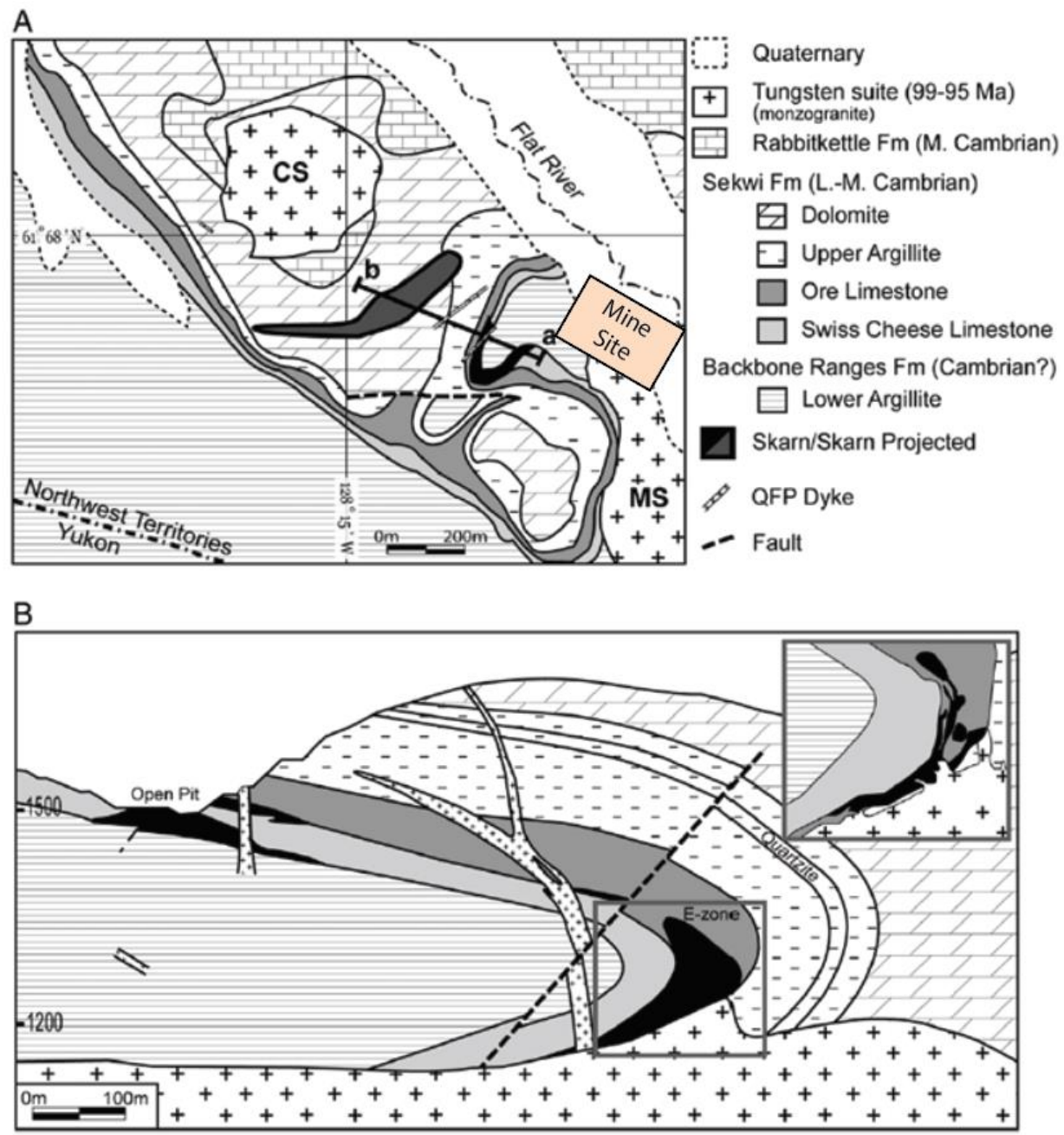

Figure 1.5 Geological map and cross section of the Cantung Deposit, modified from Rasmussen et al. (2011). Location of the Cantung Mine infrastructure indicated. CS = Circular Stock; MS = Mine Stock. 
The first studies on the genesis of the Cantung deposit recognized an assemblage of early-stage, anhydrous, high-temperature $\left(450-500{ }^{\circ} \mathrm{C}\right)$ retrograde skarn facies (garnet-pyroxene, pyroxenepyrrhotite, amphibole-pyrrhotite, biotite-pyrrhotite facies) followed by the formation of hydrous, lowtemperature $\left(<300^{\circ} \mathrm{C}\right)$ prograde facies (amphibole and biotite-rich facies) (Zaw, 1976; Archibald et al., 1978; Mathieson and Clark, 1984). Tungsten is thought to have been transported by magmatic fluids sourced from the Mine Stock pluton, or from a younger alkali-feldspar pluton nearby (Mathieson and Clark, 1984). All skarn facies are mineralized with scheelite, although the biotite-pyrrhotite and amphibole-pyrrhotite facies have the highest tungsten grades and the garnet-pyroxene facies have the lowest. Noting very high spatial correlations with pyrrhotite, it has been suggested that scheelite mineralization was near coeval with pyrrhotite, and that scheelite precipitation was triggered by a rise in $\mathrm{pH}$ and $a \mathrm{Ca}^{2+}$ from the dissolution of carbonate minerals as a result of increasing acidity by pyrhotite precipitation (Mathieson and Clark, 1984).

More recent studies generally accept the genetic model of skarn formation at Cantung proposed by Mathieson and Clark (1984), but offer different theories for the paragenesis of ore minerals (Rasmussen et al., 2011; Lentz et al., 2019; Elongo et al., 2020). Rasmussen et al. (2011) suggested that tungsten was sourced from a highly evolved residual magma chamber well beneath the crystallized carapace of the Mine Stock pluton, and was transported to the overlying country rock via sub-vertical aplitic dykes formed in overpressure-induced fractures during the latest stages of magma crystallization. Elongo et al. (2020) recently developed a paragenetic sequence for scheelite and sulfide mineralization at Cantung by detailed petrography of mineral textures and cross-cutting relationships, and determined that scheelite mineralization occurred in all stages of skarn formation (both prograde and retrograde facies). However, contrary to previous models, pyrrhotite was found only to be coeval with the prograde garnetpyroxene facies and with the latest-stage alteration that overprints even the retrograde skarn facies. Elongo et al. (2020) suggested that the spatial correlation between scheelite and pyrrhotite at Cantung does not indicate co-precipitation, as suggested by Mathieson and Clark (1984), but rather is a function of the same fluid pathways exploited by magmatic and metasomatic fluids during all stages of alteration. 
Lentz et al. (2019) suggested that the skarn facies and vein systems at Cantung are products of multiple complex hydrothermal events rather than the relatively simple single-event model proposed by earlier authors. In sheeted quartz veins and the hydrous (actinolite-biotite-pyrrhotite) skarn facies, the textures of electrum and bismuth minerals suggest they reached saturation during crystallization of silicate minerals, and continued crystallizing long after silicate crystallization ceased (Lentz et al., 2019). Dates produced by $\mathrm{U}-\mathrm{Pb}$ geochronology on sheeted quartz veins with $\mathrm{W}-\mathrm{Au}$ mineralization are older than all skarn facies, whereas the gold-rich hydrous skarn facies represents the youngest alteration at Cantung (Lentz et al., 2019).

\subsection{History of the Cantung Mine}

Reconnaissance mapping in 1953 by the Geological Survey of Canada (GSC) led to the first reported showings of base metal mineralization in the Flat River area. In 1958, the Cantung property was staked by the Mackenzie Syndicate after scheelite was discovered in the Flat River, which led to a major drilling program and the discovery of the Open Pit orebody at Cantung in 1959 (Silke, 2009). From this discovery, the Canada Tungsten Mining Corporation (CATMC) was formed in 1960, who conducted feasibility studies in 1960 and 1961. In 1962, the mine's infrastructure was built, and the Nahanni Range Road connecting the mine and Watson Lake, Yukon was constructed (Cummings and Bruce, 1977).

Production from the Open Pit orebody began in 1962. Mining was done only during the snowfree season, which lasted from mid-June to late-September. Ore was transported to a primary jaw crusher, and was either sent directly to the mill or stockpiled (Cummings and Bruce, 1977). Scheelite recovery in the first three years of production was low, due to a trial and error approach to ore processing. The first floatation circuit was built in March 1963 and yielded low recovery, resulting in the first mine closure in August 1963. The mine resumed operations in 1964 with the addition of gravity shaker tables, which produced a concentrate separate from flotation (Silke, 2009). All tailings generated from ore processing during this period were deposited directly into the Flat River floodplain until 1965, when Tailings Pond 1 
(TP1) was constructed. Between 1965 and 1973, all tailings were stored in Tailings Ponds 1 and 2

(Samuels and Shaw, 2014). In 1965, recovery rates increased and the mine produced a gravity concentrate and flotation concentrate separately (Silke, 2009). The mill was destroyed by a fire in 1966 and operations ceased until a new mill was constructed in 1967. The new mill was used throughout the rest of the mine's life (Delaney and Bakker, 2014), but periodically had its capacity increased.

A step-out drilling program was initiated in 1970 to increase reserves of the open pit ore body, resulting in the interception of the E-zone orebody at depth (Cummings and Bruce, 1977). Construction of the underground mine began in 1972. In 1973, Tailings Ponds 1 and 2 were covered with $\sim 1.5$ to 3 m of till, and tailings deposition began in the newly constructed Tailings Pond 3 (TP3) (pHase Geochemistry, 2014). In mid-1974, the concentrator switched from processing Open Pit ore to E-zone ore (Cummings and Bruce, 1977). Shifting production underground resulted in great expansion of site infrastructure, including increasing the mill capacity from 500 stpd (short tons per day) in 1975 to 1000 stpd in 1979 (Delaney and Bakker, 2014), and development of year-round accommodations for permanent employees (Cummings and Bruce, 1977). The mine closed in 1986 due to low tungsten prices (Delaney and Bakker, 2014).

After tungsten prices improved in 2000, the mine reopened in 2001, under operation by North American Tungsten Corporation Limited (NATCL) with production of ore from the underground orebody (Delaney and Bakker, 2014). The mine closed again in 2003 after being placed under control of the Companies Creditors Arrangement Act, but resumed operations in 2005 after an arrangement was made to deal with creditors (Delaney and Bakker, 2014). From 2005 onward, there has been intermittent mining of an underground extension of The Open Pit orebody known as the "PUG" zone (pHase Geochemistry, 2014). In 2007, tailings deposition switched from Tailings Pond 3 to Tailings Pond 4 (TP4), and Tailings Pond 5 (TP5) was used as an exfiltration pond (pHase Geochemistry, 2014). Mining operations were suspended again in 2009 due to low tungsten prices, but resumed in 2010 (Delaney and Bakker, 2014). In 2013, tailings deposition switched to TP5, and in 2014, a newly constructed waste water treatment facility 
was constructed to allow direct discharge of treated tailings water to the environment (Delaney and Bakker, 2014). NATCL declared bankruptcy in 2015, and the mine is currently owned by Crown Indigenous Relations and Northern Affairs Canada (CIRNAC), who manage care and maintenance of the site.

\subsection{Physiography and Hydrology of the Cantung Mine}

The Cantung Mine is located at $\sim 1130$ m elevation in a U-shaped valley known as the Flat River valley (Delaney and Bakker, 2014). The region has a subarctic climate (Dfc Köppen climate classification), receiving $~ 650 \mathrm{~mm}$ of annual precipitation split evenly between snow and rain (Environment Canada, 2019). Winters are characterized by short, cold days (mean temperature of -19.5 ${ }^{\circ} \mathrm{C}$ ), with severe winter conditions extending from October to May (Delaney and Bakker, 2014). Summer days are long and cool with a mean temperature of $9.5^{\circ} \mathrm{C}$. Snow accumulation in the valley averages at 1270 mm annually (Delaney and Bakker, 2014), likely a result of wind deposition from the high mountains. Permafrost is extensive but discontinuous (Delaney and Bakker, 2014). The valley hosts subalpine woodland vegetation, consisting of stands of white spruce and lodgepole pine, dwarf willow, dwarf birch, ericaceous shrubs, and lichen crusts (Environment Canada, 2020).

Outcrop exposure is restricted to higher elevation on either sides of the valley, and consists of carbonate and siliceous strata of the Selwyn Basin. Mountains are flanked with talus slopes and till cover, thickening towards the center of the valley. Till provenance is from local Selwyn Basin strata and cretaceous granitic intrusive rocks, derived from local alpine glaciation (Duk-Rodkin et al., 2007).

In the center of the valley lies the Flat River and its floodplain, which has headwaters just northwest of the mine. The river is high energy and has a meandering morphology, with numerous oxbow lakes and abandoned channels in its floodplain. Stream sediment consists of sand to boulder sized clasts. The Flat River recharges by small mountain streams and groundwater. A geochemical load balance by 
O'Kane Consultants Inc. and pHase Geochemistry modelled recharge in the vicinity of the Cantung property to be dominated by surface run off of these small streams. Groundwater flow is perpendicular to the valley's center line with some side weep in the direction of Flat River flow (O'Kane Consultants Inc. and pHase Geochemistry, 2017). Downstream, the Flat River discharges into the South Nahanni River and eventually the Nahanni River, ultimately joining the Mackenzie River draining to the Arctic Ocean (Parks Canada, 2019).

In 1973, Environment Canada installed a hydrograph in the Flat River near its entrance to the Cantung property, which recorded discharge rates on a daily basis between 1973 - 1988 (Environment Canada, 2019). The river is ice-covered in the winter, with flow rates averaging $0.38 \mathrm{~m}^{3} / \mathrm{s}$ under ice in January. The onset of spring thaw typically occurs in mid to late May, and is characterized by a dramatic increase in flow rate (averaging $6.2 \mathrm{~m}^{3} / \mathrm{s}$ by June 1 ). Flow rates gradually increase as summer progresses, with peak flows averaging $7.8 \mathrm{~m}^{3} / \mathrm{s}$ in July. Variability in the hydrograph data may record extreme hydrologic events in the Flat River. For example, two weeks of anomalously high discharge rates between 12.1 to $22.6 \mathrm{~m}^{3} / \mathrm{s}$ were recorded in July 1978 , which may be indicative of a flooding event.

\subsection{Thesis Organization}

This thesis is organized into four chapters. Chapter one outlines the importance and scope of the project and the geology and physiography of the Cantung Deposit. Chapter two is a literature review of low-temperature tungsten geochemistry and ecotoxicity. Chapter three is a manuscript to be submitted for journal publication (Applied Geochemistry), co-authored by Heather Jamieson, Matthew Leybourne, and Hendrik Falck. The manuscript contains the method, results, and discussion for this thesis and addresses the objectives outlined in section 1.1. Chapter four contains the conclusions of this thesis and a list of recommendations for future work that could be done to address tungsten mobility within the Cantung tailings and other $\mathrm{W}$-rich tailings, and recommendations for managing tungsten in mine waste. 


\subsection{References}

Agency for Toxic Substances and Disease Registry (ATSDR). 2005. Toxicological profile for Tungsten. Atlanta, GA: U.S. Department of Health and Human Services, Public Health Service. Retrieved from https://www.atsdr.cdc.gov/ToxProfiles/tp.asp?id=806\&tid=157

Archibald, D.A., A.H. Clark, E. Farrar, and U.K. Zaw. 1978. Potassium-argon ages of intrusion and scheelite mineralization, Cantung, Tungsten, Northwest Territories. Canadian Journal of Earth Sciences. vol. 15, no. 7, pp. 1205-1207.

Bednar, A.J., R.E. Boyd, W.T. Jones, C.J. McGrath, D.R. Johnson, M.A. Chappell, and D.B. Ringelberg. 2009. Investigations of Tungsten Mobility in Soil Using Column Tests. Chemosphere. vol. 75, no. 8, pp. 1049-56. https://doi.org/10.1016/j.chemosphere.2009.01.039

Bostick, B. C., J. Sun, J. D. Landis, and J.L. Clausen. 2018. Tungsten Speciation and Solubility in Munitions-Impacted Soils. Environmental Science \& Technology. vol. 52, no. 3, pp. 1045-1053. https://doi.org/10.1021/acs.est.7b05406

British Geological Survey. 2020. World Mineral Statistics Dataset. Keyworth, UK: British Geological Survey. Retrieved from https://www.bgs.ac.uk/mineralsUK/statistics/worldStatistics.html

Brown, T., and P. Pitfield. 2014. Tungsten. In Critical Metals Handbook. John Wiley \& Sons. pp. 385413. https://doi.org/0.1002/9781118755341.ch16

Canadian Council of Ministers of the Environment. 2008. Canadian Water Quality Guidelines. Retrieved from https://www.ccme.ca/files/Resources/supporting_scientific_documents/cwqg_pn_1040.pdf

Cummings, W.W., and D.E. Bruce. 1977. Canada Tungsten - Change to Underground Mining \& Description of Mine-Mill Procedures. CIM Bulletin. vol. 70, no. 784, pp. 94-101.

Datta, S., Vero, S.E., G.M. Hettiarachchi, and K. Johannesson. 2017. Tungsten Contamination of Soils and Sediments: Current State of Science. Current Pollution Reports. vol. 3, no. 1, pp. 55-64. https://doi.org/10.1007/s40726-016-0046-0

Delaney, B., and F.J. Bakker. 2014. Technical Report on the Cantung Mine, Northwest Territories, Canada. Report for NI 43-101. Retrieved from http://www.natungsten.com/i/pdf/Tech-Report-CanTungMine-Northwest.pdf

Duk-Rodkin, A., D. Huntley, and R. Smith. 2007. Quaternary geology and glacial limits of the Nahnni National Park Reserve and adjacent areas, Northwest Territories, Canada. Mineral and Energy Resource Assessment of the Greater Nahanni Ecosystem under consideration for the expansion of the Nahanni National Park Reserve, Northwest Territories. Geological Survey of Canada. Open File 5344, pp. 125129. https://doi.org/10.4095/224546

Elongo, V., P. Lecumberri-Sanchez, H. Legros, H. Falck, E. Adlakha, and A. Roy-Garand. 2020. Paragenetic Constraints on the Cantung, Mactung and Lened Tungsten Skarn Deposits, Canada: 
Implications for Grade Distribution. Ore Geology Reviews. In press.

https://doi.org/10.1016/j.oregeorev.2020.103677

Environment Canada. 2019. Canadian Climate Normals 1961-1990, Tungsten Station, Northwest Territories. Retrieved from

https://climate.weather.gc.ca/climate_normals/results_1961_1990_e.html?searchType=stnName\&txtStati onName=tungsten $\&$ searchMethod $=$ contains $\&$ txtCentralLatMin $=0 \&$ txtCentralLatSec $=0 \&$ tx tCentralLong $\underline{\text { Min }=0 \& \text { txtCentralLong } S e c=0 \& \operatorname{stn} I D=786 \& \text { dispBack }=1}$

Environment Canada. 2020. Monthly Discharge for Flat River at Cantung Camp (10EA002) [NT]. Retrieved from

https://wateroffice.ec.gc.ca/report/historical e.html?stn=10EA002\&dataType=Monthly\&parameterType= Level\&year $=2010 \&$ mode $=$ Graph

European Commission (EC). 2010. Critical raw materials for the EU. Report of the Ad-hoc Working Group on defining critical raw materials. European Commission Enterprise and Industry. Retrieved from http://ec.europe.eu/enterprise/policies/raw-materials/critical/index en.htm

Falck, H., H.E. Jamieson, B.G. Kazamel, E. Salmabadi, K. Hickey, J. Hanley, E. Adlakha, A. RoyGarand, C. Lentz, V. Elongo, E. Legros, P. Lecumberri-Sanchez, K.L. Shelton. 2019. The Cantung Tungsten Mine, Northwest Territories, Canada: an overview of the geology and summary of ongoing research projects. Sn-W-Critical Metals \& Associated Magmatic Systems Conference Extended Abstract. Retrieved from https://researchonline.jcu.edu.au/58850/1/Camuti\%20et\%20al.\%20SnW\%20Conference\%20Abstract\%20Volume\%20June\%202019.pdf

Fortier, S.M., N.T. Nassar, G.W. Lederer, J. Brainard, J. Gambogi, and E.A. McCullough. 2018. Draft critical mineral list-Summary of methodology and background information-U.S. Geological Survey technical input document in response to Secretarial Order No. 3359: U.S. Geological Survey Open-File Report 2018-1021. https://doi.org/10.3133/ofr20181021

Gadd, M.G., D. Layton-Matthews, J.M. Peter, S. Paradis, and I.R. Jonasson. 2017. The world-class Howard's Pass SEDEX Zn-Pb district, Selwyn Basin, Yukon. Part II: the roles of thermochemical and bacterial sulfate reduction in metal fixation. Mineralium Deposita. vol. 52, no. 3, pp. 405-419.

https://doi.org/10.1007/s00126-016-0672-x

Goodfellow, W.D., M.P. Cecile, and M.I. Leybourne. 1995. Geochemistry, petrogenesis, and tectonic setting of lower Paleozoic alkalic and potassic volcanic rocks, northern Canadian Cordilleran miogeocline. Canadian Journal of Earth Sciences vol. 32, no. 8, pp. 1236-1254.

https://doi.org/10.1139/e95-169

Goodfellow, W.D. 2007. Base metal metallogeny of the Selwyn Basin, Canada. Mineral deposits of Canada: a synthesis of major deposit-types, district metallogeny, the evolution of geological provinces, and exploration methods: Geological Association of Canada. Mineral Deposits Division. Special Publication no. 5, pp. 553-579.

Graedel, T.E., G. Gunn, and L.T. Espinoza. 2014. Metal resources, use and criticality. Critical metals handbook. John Wiley \& Sons. pp. 1-19. 
Hällström, L., L. Alakangas, and O. Martinsson. 2019. Scheelite Weathering and Tungsten (W) Mobility in Historical Oxidic-Sulfidic Skarn Tailings at Yxsjöberg, Sweden. Environmental Science and Pollution Research. vol. 27, pp. 6180-6192. https://doi.org/10.1007/s11356-019-07305-1

Hart, C.J., J.L. Mair, R.J. Goldfarb, and D.I. Groves. 2004. Source and redox controls on metallogenic variations in intrusion-related ore systems, Tombstone-Tungsten Belt, Yukon Territory, Canada. Earth and Environmental Science Transactions of The Royal Society of Edinburgh. vol. 95, no. 1-2, pp. 339356. Retrieved from https://www.researchgate.net/profile/Craig_Hart3/publication/231894665 Source and redox controls o n_metallogenic_variations_in_intrusion-related_ore_systems_Tombstone-

Tungsten_Belt_Yukon_Territory_Canada/links/55620c9d08ae9963a11b480d/Source-and-redox-controlson-metallogenic-variations-in-intrusion-related-ore-systems-Tombstone-Tungsten-Belt-Yukon-TerritoryCanada.pdf

Hudson, T.L., G. Plafker, and H.C. Berg. 1994. Crustal melting events in Alaska. The geology of Alaska: Boulder, Colorado, Geological Society of America, Geology of North America. vol. 1, pp. 657-670. Retrieved from http://dggs.alaska.gov/pubs/id/22261

Johannesson, K.H., W.B. Lyons, E.Y. Graham, and K.A. Welch. 2000. Oxyanion Concentrations in Eastern Sierra Nevada Rivers-3. Boron, Molybdenum, Vanadium, and Tungsten. Aquatic Geochemistry. vol. 6, no. 1, pp. 19-46. https://doi.org/10.1023/A:1009622219482

Johannesson, K.H., H.B. Dave, T.J Mohajerin, and S. Datta. 2013. Controls on Tungsten Concentrations in Groundwater Flow Systems: The Role of Adsorption, Aquifer Sediment Fe(III) Oxide/Oxyhydroxide Content, and Thiotungstate Formation. Chemical Geology. vol. 351, 76-94.

https://doi.org/10.1016/j.chemgeo.2013.05.002

Kelly, A.D., M. Lemaire, Y.K. Young, J.H. Eustache, C. Guilbert, M.F. Molina, and K.K. Mann. 2013. In vivo tungsten exposure alters B-cell development and increases DNA damage in murine bone marrow. toxicological sciences. vol. 131, no. 2, pp. 434-446. https://doi.org/10.1093/toxsci/kfs324

Koutsospyros, A., W. Braida, C. Christodoulatos, D. Dermatas, and N. Strigul. 2006. A Review of Tungsten: From Environmental Obscurity to Scrutiny. Journal of Hazardous Materials. vol. 136, no. 1, pp. 1-19. https://doi.org/10.1016/j.jhazmat.2005.11.007

Kennedy, A.J., D.R. Johnson, J.M. Seiter, J.H. Lindsay, R.E. Boyd, A.J. Bednar, and P.G. Allison. 2012. Tungsten Toxicity, Bioaccumulation, and Compartmentalization into Organisms Representing Two Trophic Levels. Environmental Science \& Technology. vol. 46, no. 17, pp. 9646-52. https://doi.org/10.1021/es300606x

Lassner, E., W.D. Schubert, E. Lüderitz, and H.U. Wolf. 2000. Tungsten, tungsten alloys, and tungsten compounds. Ullmann's Encyclopedia of Industrial Chemistry. https://doiorg.proxy.queensu.ca/10.1002/14356007.a27_229

Leal-Ayala, D. R., J.M. Allwood, E. Petavratzi, T.J. Brown, G. Gunn. 2015. Mapping the Global Flow of Tungsten to Identify Key Material Efficiency and Supply Security Opportunities. Resources, Conservation and Recycling. vol. 103, pp. 19-28. https://doi.org/10.1016/j.resconrec.2015.07.003 
Lentz, C.P.E., C.R.M. McFarlane, and H. Falck. 2019. Gold mineralization at the Cantung W-Cu skarn: Our present level of understanding. Yellowknife Geoscience Forum Oral Presentation Abstract. Retrieved from https://www.nwtgeoscience.ca/gsforum/sites/gsforum/files/2019_abstract_volume.pdf

Mair, J.L., C.J. Hart, and J.R. Stephens. 2006. Deformation history of the northwestern Selwyn Basin, Yukon, Canada: Implications for orogen evolution and mid-Cretaceous magmatism. Geological Society of America Bulletin. vol. 118, no. 3-4, pp. 304-323. https://doi.org/10.1130/B25763.1

Mair, J.L., G.L. Farmer, D.I. Groves, C.J. Hart, and R.J. Goldfarb. 2011. Petrogenesis of postcollisional magmatism at Scheelite Dome, Yukon, Canada: evidence for a lithospheric mantle source for magmas associated with intrusion-related gold systems. Economic Geology. vol. 106, no. 3, pp. 451-480. https://doi-org.proxy.queensu.ca/10.2113/econgeo.106.3.451

Mathieson, G.A., and A.H. Clark. 1984. The Cantung E Zone Scheelite Skarn Orebody, Tungsten, Northwest Territories; a Revised Genetic Model. Economic Geology. vol. 79, no. 5, pp. 883-901. https://doi.org/10.2113/gsecongeo.79.5.883

Mohajerin, T., G.R. Helz, and K.H. Johannesson. 2016. Tungsten-Molybdenum Fractionation in Estuarine Environments. Geochimica et Cosmochimica Acta. vol. 177, pp. 105-19. https://doi.org/10.1016/j.gca.2015.12.030

Narbonne, G.M., and J.D. Aitken. 1995. Neoproterozoic of the Mackenzie Mountains, Northwestern Canada. Precambrian Research. vol. 73, no. 1-4, pp. 101-121. https://doi.org/10.1016/0301$\underline{9268(94) 00073-Z}$

Nelson, J., and M. Colpron. 2007. Tectonics and metallogeny of the British Columbia, Yukon and Alaskan Cordillera, 1.8 Ga to the present. Mineral deposits of Canada: a synthesis of major deposit-types, district metallogeny, the evolution of geological provinces, and exploration methods: Geological Association of Canada, Mineral Deposits Division. Special Publication no. 5, pp. 755-791. Retrieved from http://cmscontent.nrs.gov.bc.ca/geoscience/publicationcatalogue/External/EXT060.pdf

O'Kane Consultants Inc. and pHase Geochemistry, 2017. Updated Geochemical Load Balance and Risk Assessment, Cantung Mine, NWT. Prepared for: North American Tungsten Corp. Ltd http://registry.mvlwb.ca/Documents/MV2015L2-0003/MV2015L2-0003\%20-\%20NATCL\%20\%20Integrated \%20Geochemical\%20Load\%20Balance\%20and\%20Risk\%20Assessment\%20Report\%20\%20Jan27-17.pdf

Ootes, L., S.A. Gleeson, E. Turner, K. Rasmussen, S. Gordey, H. Falck, E. Martel, and K. Pierce. 2013. Metallogenic Evolution of the Mackenzie and Eastern Selwyn Mountains of Canada's Northern Cordillera, Northwest Territories: A Compilation and Review. Geoscience Canada. vol.40, no. 1, pp. 4069. https://doi.org/10.12789/geocanj.2013.40.005

Parks Canada. 2019. Nahanni National Park Reserve: Hydrology. Retrieved from https://www.pc.gc.ca/en/pn-np/nt/nahanni/decouvrir-discover/natculld

Petrunic, B.M., and T.A. Al. 2005. Mineral/Water Interactions in Tailings from a Tungsten Mine, Mount Pleasant, New Brunswick. Geochimica et Cosmochimica Acta. vol. 69, no. 10, pp. 2469-2483. https://doi.org/10.1016/j.gca.2004.10.031 
Mesh Environmental. 2008. Geochemical Characterization of the Cantung Mine Tailings, NWT. Prepared for: North American Tungsten Corp. Ltd. Retrieved from http://registry.mvlwb.ca/Documents/MV2002L2-0019/MV2002L2-0019\%20-\%20NATCL\%20\%20Renewal\%20-\%20Application\%20-\%20Final\%20Tailings\%20Characterization\%20Jan.03-08.pdf

pHase Geochemistry. 2014. Geochemical Risk Assessment, Cantung Mine, NWT. Prepared for: North American Tungsten Corp. Ltd. http://registry.mvlwb.ca/Documents/MV2015L2-0003/MV2015L20003\%20-\%20NATCL\%20-\%20Geochemical\%20Risk\%20Assessment\%20Report\%20-\%20May3014.pdf

Rasmussen, K.L., D.R. Lentz, H. Falck, and D.R. Pattison. 2011. Felsic magmatic phases and the role of late-stage aplitic dykes in the formation of the world-class Cantung Tungsten skarn deposit, Northwest Territories, Canada. Ore Geology Reviews. vol. 41, no. 1, pp. 75-111. https://doi.org/10.1016/j.oregeorev.2011.06.011

Salmabadi, E., K.A. Hickey, H. Falck. 2019. The relative timing of regional shortening and pluton emplacement in the southeastern Selwyn Basin, Cantung, NT. Yellowknife Geoscience Forum Oral Presentation Abstract. Retrieved from https://www.nwtgeoscience.ca/gsforum/sites/gsforum/files/2019_abstract_volume.pdf

Seiler, R.L., K.G. Stollenwerk, and J.R. Garbarino. 2005. Factors Controlling Tungsten Concentrations in Ground Water, Carson Desert, Nevada. Applied Geochemistry. vol. 20, no. 2, pp. 423-41. https://doi.org/10.1016/j.apgeochem.2004.09.002

Silke, R. 2009. The Operational History of Mines in the Northwest Territories, Canada. NWT Geoscience Office. Retrieved from www.miningnorth.com/_rsc/sitecontent/library/NWT_Mines_History_RSilke2009.pdf

Steenstra, P., N. Strigul, and J. Harrison. 2020. Tungsten in Washington State surface waters. Chemosphere. vol. 242, 125151. https://doi.org/10.1016/j.chemosphere.2019.125151

Strigul, N., A. Koutsospyros, and C. Christodoulatos. 2009. Tungsten in the Former Soviet Union:

Review of Environmental Regulations and Related Research. Land Contamination and Reclamation. vol. 17, no. 1, 189-215. https://doi.org/10.2462/09670513.923

Strigul, N., A. Koutsospyros, and C. Christodoulatos. 2010. Tungsten Speciation and Toxicity: Acute Toxicity of Mono- and Poly-Tungstates to Fish. Ecotoxicology and Environmental Safety. vol. 73, no. 2, pp. 164-171. https://doi.org/10.1016/j.ecoenv.2009.08.016

U.S. Geological Survey. 2013. Metal prices in the United States through 2010: U.S. Geological Survey Scientific Investigations Report 2012-5188. Retrieved from http://pubs.usgs.gov/sir/2012/5188

United States Environmental Protection Agency. 2008. Emerging Contaminant - Tungsten. National Service Center for Environmental Publications. Retrieved from https://nepis.epa.gov/Exe/ZyNET.exe/P1000L3K.TXT?ZyActionD=ZyDocument\&Client=EPA\&Index= $2006+$ Thru $+2010 \&$ Docs $=\&$ Query $=\&$ Time $=\&$ EndTime $=\&$ SearchMethod $=1 \&$ TocRestrict $=$ n $\&$ Toc $=\&$ Toc Entry $=\& Q$ Field $=\& Q$ Field Year $=\& Q$ FieldMonth $=\& Q$ FieldDay $=\&$ IntQFieldOp $=0 \&$ ExtQFieldOp $=0 \& X m \mathrm{ml}$ Query $=\&$ File $=$ D\%3A\%5Czyfiles\%5CIndex\%20Data\%5C06thru10\%5CTxt\%5C00000002\%5CP1000L3 $\underline{\text { K.txt } \& U s e r=A N O N Y M O U S \& P a s s w o r d=a n o n y m o u s \& S o r t M e t h o d}=\mathrm{h} \% 7 \mathrm{C}-$ 
\&MaximumDocuments=1\&FuzzyDegree=0\&ImageQuality=r75g8/r75g8/x150y150g16/i425\&Display=h pfr \&DefSeekPage $=x \&$ SearchBack=ZyActionL\&Back=ZyActionS\&BackDesc $=$ Results\%20page $\&$ Maxim $\underline{\text { umPages }=1 \& \text { ZyEntry }=1 \& \text { SeekPage }=x \& \text { ZyPURL }}$

United States Environmental Protection Agency. 2020. Regional Screening Levels (RSLs) - Generic Tables as of May 2020. Risk Assessment. Retrieved from https://www.epa.gov/risk/regional-screeninglevels-rsls-generic-tables

VanderSchee, C.R., D. Kuter, A.M. Bolt, F.C. Lo, R. Feng, J. Thieme, ... and D.S. Bohle. 2018. Accumulation of persistent tungsten in bone as in situ generated polytungstate. Communications Chemistry. vol. 1, no. 1, pp. 1-6. https://doi.org/10.1038/s42004-017-0007-6

Witten, M.L., P.R. Sheppard, and B.L. Witten. 2012. Tungsten toxicity. Chemico-biological interactions. vol. 196, no. 3, pp. 87-88. https://doi.org/10.1016/j.cbi.2011.12.002

Zaw, K. 1976. The Cantung E-zone orebody Tungsten, Northwest Territories: a major scheelite skarn deposit. MSc Thesis Dissertation, Queen's University. 


\section{Chapter 2: Literature Review}

\subsection{Tungsten Occurrences}

\subsubsection{Crustal Abundance and Primary Mineralogy}

Tungsten is a greyish-white transition metal with atomic number 74, in Group VIB of the periodic table along with chromium, molybdenum, and seaborgium. Its stable isotopes (with natural abundances in brackets) are ${ }^{180} \mathrm{~W}(0.13 \%),{ }^{182} \mathrm{~W}(26.3 \%),{ }^{183} \mathrm{~W}(14.3 \%),{ }^{184} \mathrm{~W}(30.67 \%)$, and ${ }^{186} \mathrm{~W}(28.6 \%)$ (Lassner and Schubert, 2000). The oxidation states of tungsten are $\mathrm{W}^{0}, \mathrm{~W}^{+1}, \mathrm{~W}^{+2}, \mathrm{~W}^{+3}, \mathrm{~W}^{+4}, \mathrm{~W}^{+5}$, and $\mathrm{W}^{+6} ; \mathrm{W}^{+6}$ is the most common during crustal and surficial geochemical processes involving both aqueous and solid tungsten phases (Lassner and Schubert, 2000). Pure tungsten metal is dense $\left(19,254 \mathrm{~kg} / \mathrm{m}^{3}\right.$ at $25^{\circ} \mathrm{C}$ ), has a hardness of 7.5 on Moh's hardness scale, and has the highest melting point of all non-alloyed metals $\left(3422^{\circ} \mathrm{C}\right)$ (Brown and Pitfield, 2014). It also has the lowest coefficient of expansion $\left(4.5 \times 10^{-6} /{ }^{\circ} \mathrm{C}\right)$ and highest tensile strength ( 100 MPa) of all pure metals at temperatures above $1650{ }^{\circ} \mathrm{C}$, which makes it highly desirable for industrial applications involving high temperatures (Lassner and Schubert, 2000; Brown and Pitfield, 2014; Leal-Ayala et al., 2015). Tungsten is the 56th most abundant element in the Earth's crust with an estimated bulk concentration of $1.0 \mathrm{mg} / \mathrm{kg}$ (Rudnick and Gao, 2003). Tungsten behaves incompatibly during magmatic processes, is a lithophile element in the $\mathrm{W}^{+6}$ oxidation state. Tungsten is therefore enriched in the continental crust relative to the mantle, and the upper crust contains on average $1.9 \mathrm{mg} / \mathrm{kg} \mathrm{W}$ whereas the middle and lower crust have on average $0.6 \mathrm{mg} / \mathrm{kg} \mathrm{W}$ (Rudnick and Gao, 2003). Tungsten is also enriched in felsic rocks compared to rocks with mafic compositions.

Scheelite $\left(\mathrm{CaWO}_{4}\right)$ and wolframite $\left[(\mathrm{Fe}, \mathrm{Mn}) \mathrm{WO}_{4}\right]$ are by far the most common tungsten minerals (Lassner and Schubert, 2000). Scheelite is a tetragonal white-brown tungstate mineral, and is isomorphous with powellite $\left(\mathrm{CaMoO}_{4}\right)$. Scheelite is dense (specific gravity $\left.=5.9-6.1\right)$, relatively hard 
(4.5 - 5 on Moh's hardness scale), and fluoresces under short-wave UV light. The fluorescence of scheelite is blueish-white for crystals containing little to no molybdenum, and changes to yellow-orange with increasing molybdenum content (Lassner and Schubert, 2000). These properties, along with its relative insolubility in most natural waters, make scheelite a useful indicator mineral for the exploration of tungsten deposits and also the deposits of other commodities where scheelite is present (McClenaghan et al., 2014). Scheelite occurs as a minor accessory mineral in evolved igneous and metamorphic rocks, with ore-grade occurrences attributed to magmatic/hydrothermal processes (see section 2.1.2).

Wolframite is a solid solution series between huebnerite $\left(\mathrm{MnWO}_{4}\right)$ and ferberite $(\mathrm{FeWO})$, where crystals containing $>80 \% \mathrm{Mn}$ in the cation site are classified as huebnerite, $>80 \% \mathrm{Fe}$ are ferberite, and intermediate compositions are classified as wolframite. Wolframite is monoclinic, denser than scheelite ( specific gravity $=7.1-7.5$ ), is dark grey to black with submetallic to metallic lustre, and has a hardness of $5-5.5$ on Moh's hardness scale. Like scheelite, wolframite occurs in evolved magmatic and metamorphic rocks. Owing to their high abundance relative to other tungsten minerals, scheelite and wolframite are the primary ore minerals for tungsten. Scheelite is the more economically important of the two, accounting for $70 \%$ of global tungsten production (Kwak, 2012).

\subsubsection{Tungsten Deposit Types}

Due to the lithophilic behaviour of tungsten during magmatic processes, tungsten deposits are most commonly associated with highly evolved granitoids. Being an incompatible high field strength element (HFSE), tungsten is retained in the fluid phase during magma crystallization, and anomalous concentrations of tungsten (and other volatile and incompatible elements) are typically associated with the latest stages of crystallization of magma (Newsom et al., 1996). The local lithological contacts, geodynamic setting, and geochemistry of the source fluids (magmatic and/or hydrothermal) dictates the style of tungsten mineralization. The most common and economically important type of tungsten deposit are skarn deposits, which form by intrusion of the source magma into carbonate-rich rocks (e.g. 
limestone, dolostone, marble, and calcareous siliciclastic rocks). Skarn deposits are most common in subduction-related settings, where granitic rocks are emplaced at depths between $1.5-10 \mathrm{~km}$ (Kwak et al., 2012). Like porphyry deposits, W-skarns are temporally rare in Precambrian rocks due to their relatively shallow depth of emplacement resulting in relatively rapid erosion (Kwak et al., 2012). Tungsten mineralization can occur within the metasomatized intrusion (endoskarn facies), or in the hydrothermally altered and/or assimilated country rock (exoskarn facies). The predominant tungsten mineral in skarn deposits is scheelite, owing to the abundance of calcium through dissolution and alteration of calcite and/or dolomite in the limestone/dolostone. The gangue mineralogy of W-skarn deposits is highly variable, but common minerals include calc-silicate minerals (amphibole, pyroxene, garnet, wollastonite), carbonates minerals, and sulfide minerals. Associated elements in W-skarns that may be present in economic quantities are $\mathrm{Mo}, \mathrm{Sn}, \mathrm{Cu}, \mathrm{Zn}, \mathrm{Au}$, and $\mathrm{Bi}$ (Kwak et al., 2012). Tungsten grades range from $0.3-1.5 \% \mathrm{WO}_{3}$, and are some of the largest tungsten deposits in the world (e.g. Cantung and Mactung in Canada, and Tyrnyauz and Vostok-2 in Russia; Werner et al., 2014).

Vein and stockwork-type deposits are associated with late-stage magmatic and hydrothermal fluids that crystallize in pre-existing fractures within the adjacent country rock, or in fractures generated by emplacement of the intrusion (Werner et al., 2014). Wolframite is the primary tungsten mineral associated with this style of deposit although scheelite is not uncommon, and mineralization is accompanied by quartz and commonly $\mathrm{Sn}, \mathrm{Mo}, \mathrm{Bi}, \mathrm{Cu}$, and $\mathrm{Au}$ minerals. Vein and stockwork deposits are typically low-grade $\left(\sim 0.1 \% \mathrm{WO}_{3}\right)$, but can have high tonnage, and therefore open-pit mining is preferred for economic recovery (Brown and Pitfield, 2014). Examples of vein and stockwork style deposits are Verkhne-Kayrakty in Russia, and Mount Carbine in Australia (Werner et al., 2014). Porphyry deposits can have similar morphology to vein and stockwork-type deposits, but are genetically distinct by being related to epizonal and subvolcanic intermediate to felsic intrusions. Porphyry deposits are typically lower grade $\left(0.04-0.4 \% \mathrm{WO}_{3}\right)$, and are less economically important than skarn and vein-type deposits (Brown and Pitfield, 2014). Examples of W-porphyry deposits are the Mount Pleasant and Sisson Brook deposits 
in New Brunswick, Canada. Other deposit types are even less economically important and include breccia, pipe, pegmatite, greisen, and stratabound deposits (Brown and Pitfield, 2014). The common genetic link between these deposits are highly evolved W-rich felsic intrusions, the mechanism of tungsten emplacement is dictated by the local geological setting, and many deposits contain multiple styles of mineralization (Werner et al., 2014). Brine deposits are a unique deposit type, and although not currently economically productive, could be an important source of tungsten in the future (Brown and Pitfield, 2014). Brine deposits are located in continental-sabkha evaporite basins, where tungsten accumulates in the brine after extended periods of hydrothermal leaching from the surrounding bedrock. The most notable deposit is the Searles Lake deposit in California, USA, where tungsten concentrations in the brines are as high as $56 \mathrm{mg} / \mathrm{L}$ (Altringer et al., 1978). The Searles Lake deposit is thought to have formed over thousands of years during the Pleistocene via endoheric termination of rivers eroding Wskarn deposits in the Sierra Nevada mountain range, and tungsten may also have been sourced by hot springs in the Sierra Nevada (Ririe, 1989). A map of the global distribution of tungsten deposits is shown in figure 2.1 . 


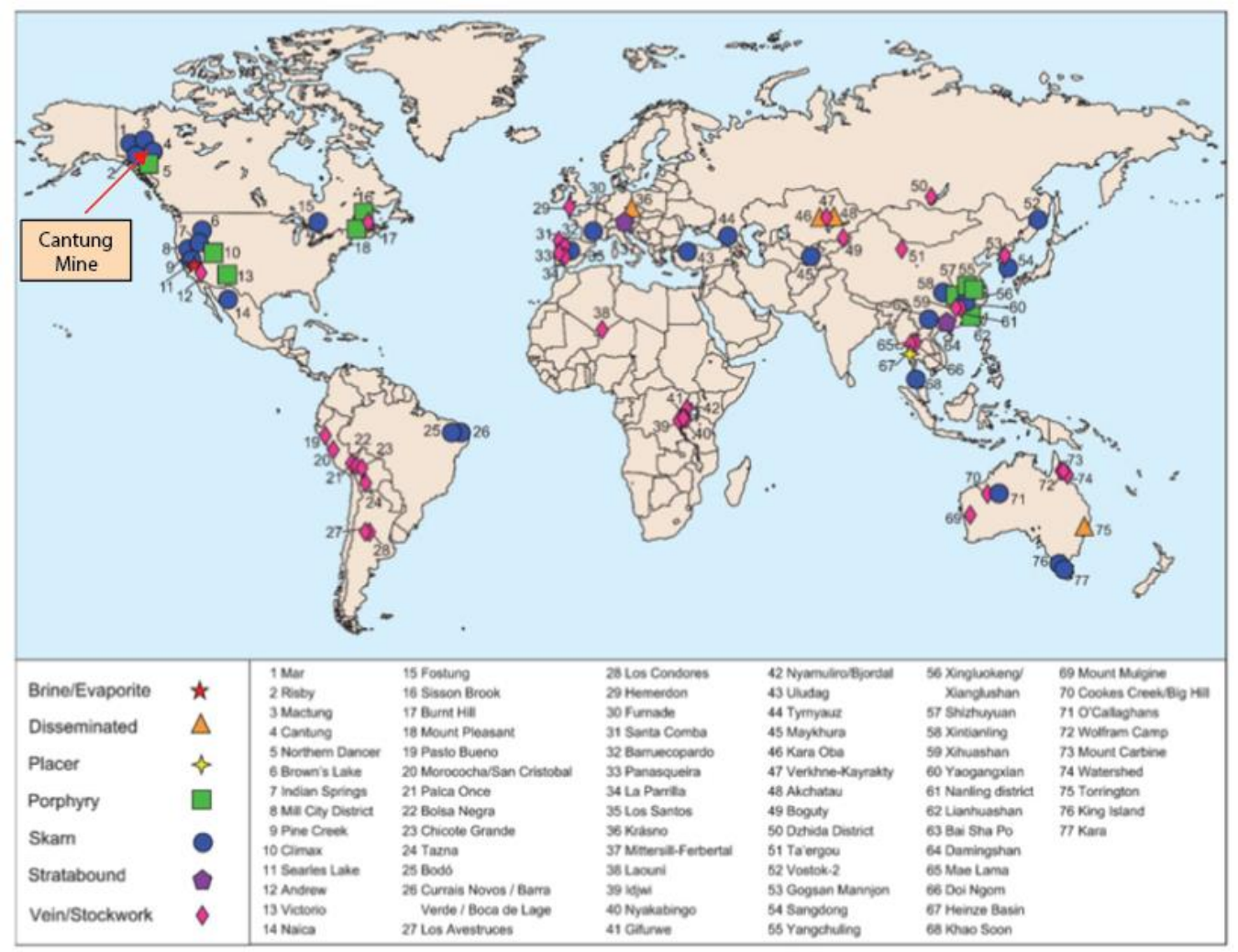

Figure 2.1 The locations of major tungsten deposits worldwide, modified from Brown and Pitfield (2014). Location of the Cantung Mine indicated.

\subsubsection{Secondary Tungsten Mineralogy}

Secondary tungsten minerals are rare, and are almost always found replacing and coating scheelite and wolframite. They form most commonly in hydrothermal environments (Sahama, 1981), although some authors suggest secondary tungsten minerals may form under surface conditions (Tarassov and Tarassova, 2018). Secondary tungsten minerals typically occur as white to yellow, fine-grained, powdery masses that can contain multiple minerals, and macroscopic crystals are rare (Sahama, 1981). Tungstite $\left(\mathrm{WO}_{3} \cdot \mathrm{H}_{2} \mathrm{O}\right)$ has the simplest stoichiometry, and is characterized as a yellow powder most commonly replacing or coating scheelite and wolframite. Tungstite is commonly found with its more hydrated form, hydrotungstite $\left(\mathrm{WO}_{3} \cdot 2 \mathrm{H}_{2} \mathrm{O}\right)$ (Sahama, 1981). Meymacite $\left(\mathrm{WO}_{3} \cdot 2 \mathrm{H}_{2} \mathrm{O}\right)$ is the amorphous precursor to hydrotungstite (Sahama, 1981; Tarassov and Tarassova, 2018). Tungstite precipitates at 
acidic $\mathrm{pH}(<6$ in solutions saturated with respect to scheelite; Marinakis and Kelsall, 1987; Montgomery, 2012; Tarassov and Tarassova, 2018), and is most commonly found coating or replacing scheelite or wolframite (Sahama, 1981). Montgomery (2012) suggested that tungstite coatings on scheelite may decrease the rate of scheelite dissolution in $\mathrm{HCO}_{3}{ }^{-}$dominated groundwaters. Meymacite, tungstite, and hydrotungstite are probably the most likely to form in mine waste due to their simple stoichiometry, and a yellow coating on scheelite (inferred to be tungstite) has been observed in tailings from the Yxsjöberg WCu-F-skarn deposit in Sweden (Hällström et al., 2018).

The formation conditions of secondary tungsten minerals with more complex stoichiometries is less well understood, and proper mineral identification is complicated due to their co-occurrence and fine grain size (Sahama, 1981). The minerals reviewed in this paragraph were chosen because the conditions of their formation have been discussed in literature, and because elements required for their formation (e.g. iron and aluminum) are common in surface waters and porewaters of mine waste (Petrunic and Al, 2005; Hällström et al., 2019; this study). Hydrokenoelsmoreite $\left.\left[\left(\square, \mathrm{Na}, \mathrm{H}_{2} \mathrm{O}\right)_{2}\left(\mathrm{~W}, \mathrm{Fe}^{3+}, \mathrm{Al}\right)_{2}(\mathrm{O}, \mathrm{OH})_{6} \cdot \mathrm{H}_{2} \mathrm{O}\right)\right]$, commonly referred to as ferritungstite (the Fe-bearing variety, where $\mathrm{W}>\mathrm{Fe}$ ) or alumotungstite (the Albearing variety, where $\mathrm{W}>\mathrm{Fe}$ ), is a cubic tungsten mineral with a pyrochlore structure (Shimobayashi et al., 2012; Mills et al., 2016; Tarrasov and Tarassova, 2018). The composition of hydrokenoelsmoreite is inherited by the solution in which it forms, and by the precursor minerals from which it is formed. The genesis of hydrokenoelsmoreite at the Grantcharitza tungsten deposit in Bulgaria was studied by Tarassov and Tarrasova (2018), who postulated that hydrokenoelsmoreite formed at the expense of meymacite in a supergene solution enriched with $\mathrm{Na}, \mathrm{K}$, and $\mathrm{Ca}$, at $\mathrm{pH} 3$ - 4. Hydrokenoelsmoreite from the Hemerdon (Drakelands) W-Sn deposit in the United Kingdom is presumed to have formed from phyllotungstite $\left[\left(\mathrm{H}_{2} \mathrm{O}, \mathrm{M}\right)_{\mathrm{x}}(\mathrm{W}, \mathrm{Fe})(\mathrm{O}, \mathrm{OH})_{3} \cdot \mathrm{yH}_{2} \mathrm{O}(\mathrm{M}=\mathrm{Ca}, \mathrm{Cs}, \mathrm{Pb}\right.$ or $\left.\mathrm{K})\right]$ and/or pittongite $\left(\mathrm{Na}_{0.22}\left(\mathrm{~W}, \mathrm{Fe}^{3+}\right)(\mathrm{O}, \mathrm{OH})_{3} \cdot 0.44 \mathrm{H}_{2} \mathrm{O}\right)$ as precursor minerals (Mills et al., 2016). Anthoinite $\left(\mathrm{AlWO}_{3}(\mathrm{OH})_{3}\right)$ is an aluminian tungsten secondary mineral that is chemically similar to mpororoite $\left(\mathrm{WAlO}_{3}(\mathrm{OH}) \cdot 2 \mathrm{H}_{2} \mathrm{O}\right)$, but the two minerals are structurally different (anthoinite is triclinic, whereas mpororoite is monoclinic; 
Shimobayashi et al., 2012). These minerals are thought to form at the early stages of scheelite alteration (Sahama et al., 1981) in supergene solutions enriched in Al (Matsubara et al., 1984; Shimobayashi et al., 2012). Production from tungsten deposits with secondary mineral coatings on scheelite and wolframite has been avoided due to low recovery efficiencies during froth floatation. One possible reason is that these coatings change the surface properties of these minerals, making them less reactive to froth floatation reagents (Tarassov and Tarassova, 2018).

\subsection{Anthropogenic Sources of Tungsten to the Environment}

Anthropogenic activity can create elevated tungsten concentrations in soils, sediments, and water reservoirs. Activities include the mining, milling, and smelting of tungsten-bearing ores, and the manufacturing and disposal of tungsten products (ATDSR, 2005). Solid mine waste (e.g. tailings, waste rock, slag) can be a source of leached tungsten to water reservoirs directly, and wind may cause particles containing tungsten to become airborne. Dust particles generated during the manufacturing of tungsten products (e.g. tungsten carbide and tungsten alloys) may also become airborne, later to settle in soils and surface waters. Once settled, the W-bearing particles may leach and enter soil porewaters and surface waters, although the amount of leaching is dependent on the solubility and stability of the particle (Huntsman et al., 2018). Treated wastewater (not necessarily exclusive to mining, milling, and smelting operations) may also contain elevated tungsten concentrations, particularly in waters with alkaline $\mathrm{pH}$. Landfills containing tungsten products and metal recycling plants are other potential sources of tungsten (ATDSR, 2005).

\subsection{Tungsten Toxicity and Ecotoxicity}

In recent years, the toxicity of tungsten to humans and other organisms has received increased attention, largely due to the events in Fallon, Nevada (Koutsospyros et al., 2006; Witten et al., 2012; 
Datta et al., 2017). To date, no studies have determined whether exposure to tungsten caused the leukemia cluster, although other adverse clinical manifestations have been associated with tungsten (Witten et al., 2012; Christensen, 2013; Kelly et al., 2013; Menke et al., 2016; Datta et al., 2017; Nigra et al., 2018; VanderSchee et al., 2018). Polytungstate species were found to be more toxic than monotungstate to fish (Strigul et al., 2010), possibly because polytungstate complexes causes higher oxidative stress (Strigul, 2010). It was postulated that tungsten toxicity in humans may also be due to the oxidative properties of tungsten species (Sachdeva et al., 2013). Tungsten may enter the human body via ingestion or inhalation, the latter being more common during occupational exposure (Koutsospyros et al., 2006). A number of studies have observed that once ingested, tungsten compartmentalizes and accumulates in bones (Guandalini et al., 2011; Kelly et al., 2013; Bolt et al., 2015; VanderSchee et al., 2018). An in vivo study exposed mice to $\mathrm{WO}_{4}{ }^{2-}$ via drinking water and analyzed their tibia and femoral bones post-mortem with synchrotron-based $\mu \mathrm{XRF}$ and $\mu \mathrm{XANES}$, and found that tungsten had transformed to polytungstate phases within the bones (VanderSchee et al., 2018). Kelly et al. (2013) suggested that tungsten could act as a tumor promotor in developing bone marrow cells, and that tungsten has a long residence time in bones as it is removed from bones much slower than it is accumulated. Therefore, toxic effects associated with chronic exposure to tungsten is probably more pertinent than acute exposure, as suggested by Witten et al. (2012). Other clinical manifestations associated with tungsten exposure include diabetes (Menke et al., 2016), cardiovascular disease (Nigra et al., 2018), and changes to thyroid function (Christensen, 2013), although the exact mechanisms of the involvement of tungsten with these disorders was not determined. Studies regarding the potential link between tungsten exposure and leukemia (and other illnesses) state that research is still in its infancy, and more research is needed on tungsten's co-toxicity in the presence of other metals (e.g. W-alloys) (Wasel and Freeman, 2018). Tungsten has also been found to bioaccumulate in plants (Pyatt and Pyatt, 2004; Wilson and Pyatt, 2006; Kennedy et al., 2012; Lin et al., 2014), is able to be transferred to higher trophic levels (Kennedy et al., 2012), and has found to be toxic to other organisms including earthworms, (Inouye et al., 2006), snails (Kennedy et al., 2012; Allison et al., 2016), fish (Kühnel et al., 2009; Strigul et al., 2010), and rats (Turkez et al., 2014). 


\subsection{Environmental Mobility of Tungsten}

\subsubsection{Aqueous Tungsten Speciation}

In natural waters, tungsten is similar to molybdenum, forming anionic species strictly in the W(VI) valence state (Datta et al., 2017); However, unlike molybdenum, tungsten cannot be reduced to the $\mathrm{W}(\mathrm{IV})$ state in natural waters (Brookins, 1987). Therefore, a major difference between the two elements is that molybdenum can precipitate as molybdenite $\left(\mathrm{MoS}_{2}\right)$ in sulfidic waters (Brookins, 1987; Vorlicek et al., 2004; Mohajerin et al., 2016), but tungsten cannot precipitate as tungstenite ( $\left.\mathrm{WS}_{2}\right)$. The speciation of aqueous tungsten is dependent on $\mathrm{pH}$, Eh, and ionic strength and composition (Koutospyros et al., 2006; Datta et al., 2017). The most common aqueous tungsten species in natural waters is the monomeric tungstate anion $\left(\mathrm{WO}_{4}{ }^{2-}\right)$, which has tetrahedral coordination and is stable in circumneutral and alkaline waters (Datta et al., 2017). At low $\mathrm{pH}, \mathrm{WO}_{4}{ }^{2-}$ protonates to form $\mathrm{HWO}_{4}{ }^{-}$, and polymerizes at high tungsten concentrations (> 0.184 to $1.84 \mathrm{mg} / \mathrm{L} \mathrm{W}$ ) to form an array of polytungstate species in octahedral coordination such as $\mathrm{W}_{7} \mathrm{O}_{24}{ }^{6-}, \mathrm{HW}_{7} \mathrm{O}_{24}{ }^{5-}$, and $\mathrm{H}_{2} \mathrm{~W}_{12} \mathrm{O}_{42}{ }^{10-}$ (Cruywagen, 2000). Once formed, polytungstates are predicted to be stable at higher pH (Bednar et al., 2008; Bednar et al., 2009). Sun and Bostick (2015) and Bostick et al. (2018) suggested that polyoxometalates (POMs) such as $\mathrm{PW}_{12} \mathrm{O}_{40}{ }^{3-}$ and $\mathrm{SiW}_{12} \mathrm{O}_{40}{ }^{3-}$ may be prevalent alongside polytungstates in acidic soils, and have a lower propensity for adsorption than $\mathrm{WO}_{4}{ }^{2-}$. In circumneutral to alkaline waters with high sulfide concentrations $(>32 \mathrm{mg} / \mathrm{L}$ $\mathrm{S}^{2-}$ ), $\mathrm{WO}_{4}{ }^{2-}$ thiolates to form thiotungstate species (e.g. $\mathrm{WO}_{3} \mathrm{~S}^{2-}, \mathrm{WOS}_{3}{ }^{2-}, \mathrm{WS}_{4}{ }^{2-}$ ) (Mohajerin et al., 2014a; Mohajerin et al., 2016; Cui et al., 2020). Waters conducive for thiotungstate formation include anoxic groundwaters, sulfate-reducing soils, and euxinic oceanwater (e.g. benthic water of the Black Sea) (Mohajerin et al., 2014a).

\subsubsection{Adsorption of Tungsten}

Adsorption-desorption reactions are cited as a major factor in controlling tungsten concentrations in groundwaters (Seiler et al., 2005; Johannesson et al., 2013; Mohajerin et al., 2014b; Watanabe et al., 
2017), soil porewaters (Arnórsson and Óskarsson, 2007; Clausen et al., 2007; Bednar et al., 2008; Bednar et al., 2009; Bostick et al., 2018), seawater (Kashiwabara et al., 2013; Mohajerin et al., 2016; Cui et al., 2020), geothermal waters (Guo et al., 2019), and terrestrial surface waters (Johannesson et al., 2000; Pokrovsky and Schott, 2002; Harita et al., 2005; Gammons et al., 2013). Adsorption reduces the mobility of tungsten in these reservoirs by sequestering it with solid phases (e.g. Fe/Mn-oxyhydroxide minerals), but can also facilitate transport as labile tungsten adsorbed to suspended sediments and colloids. Being anionic, dissolved tungsten species are electrostatically attracted to positively charged surfaces, which depending on the $\mathrm{pH}$ of the point of zero charge $\left(\mathrm{pH}_{\mathrm{pzc}}\right)$ of the mineral, typically occurs at acidic $\mathrm{pH}$ (Dzombak and Morel, 1990; Sposito, 1998). The complex aqueous speciation of tungsten makes thermodynamic modelling of tungsten adsorption difficult (Sen Tuna and Braida, 2014; Bostick et al., 2015; Davantès and Lefèvre, 2015; Hur and Reeder, 2016; Cui and Johannesson, 2017; Bostick et al., 2018; Hur and Reeder, 2018; Sallman et al., 2018), and most studies have addressed only the adsorption behaviour of the $\mathrm{WO}_{4}{ }^{2-}$ anion (Vissenberg et al., 2000; Gustafsson, 2003; Seiler et al., 2005; Xu et al., 2006; Johannesson et al., 2013; Mohajerin et al., 2014a).

Gustafsson (2003) conducted an adsorption experiment comparing the adsorption propensity of $\mathrm{WO}_{4}{ }^{2-}, \mathrm{MoO}_{4}{ }^{2-}$, and $\mathrm{PO}_{4}{ }^{3-}$ on freshly precipitated ferrihydrite across the $\mathrm{pH}$ range of 3 to 10 . Modelling the results with the Diffuse Layer Model (DLM) and the charge-distribution multi-site complexation (CDMUSIC) Model, it was found that the adsorption of both tungsten and molybdenum is best explained by the formation of two monodentate complexes on the ferrihydrite surface, where both species are adsorbed as protonated complexes in tetrahedral coordination (i.e. $\mathrm{HWO}_{4}^{-}$and $\mathrm{HMoO}_{4}{ }^{-}$). It was found that that $\mathrm{HWO}_{4}{ }^{-}$adsorbs more strongly than $\mathrm{HMoO}_{4}^{-}$despite the similar $\mathrm{pKa}$ values for the formation of these species (Gustafsson, 2003). In the absence of competing anions, total adsorption of tungsten was achieved at $\mathrm{pH} 8$ and at $\mathrm{pH} 7$ for molybdenum, and both elements displaced adsorbed $\mathrm{PO}_{4}{ }^{3-}$ at lower $\mathrm{pH}$. The stronger adsorption of $\mathrm{WO}_{4}{ }^{2-}$ to ferrihydrite compared to $\mathrm{MoO}_{4}{ }^{2-}$ is because $\mathrm{WO}_{4}{ }^{2-}$ forms inner-sphere complexes, whereas $\mathrm{MoO}_{4}{ }^{2-}$ forms outer-sphere complexes (Kashiwabara et al., 2010; Kashiwabara et al., 
2011; Kashiwabara et al., 2013). However, Kashiwabara et al. (2013) also found that the adsorption propensity of $\mathrm{WO}_{4}{ }^{2-}$ and $\mathrm{MoO}_{4}{ }^{2-}$ to $\delta-\mathrm{MnO}_{2}$ is similar due to the formation of inner-sphere complexes of both species. Davantès and Lefèvre (2015) investigated the local structure of adsorbed tungsten and molybdenum to hematite $\left(\mathrm{Fe}_{2} \mathrm{O}_{3}\right)$, goethite $(\mathrm{FeOOH})$, akaganeite $(\beta-\mathrm{FeOOH})$, and lepidocrocite $(\gamma-$ $\mathrm{FeOOH}$ ) with attenuated total reflection Fourier-transform infrared spectroscopy (ATR-FTIR) spectroscopy and found that tungsten formed monodentate complexes in tetrahedral coordination on all of the Fe-oxyhydroxide minerals, but not hematite, which allowed the adsorption of polytungstate species in octahedral coordination. On the surface of boehmite $(\gamma-\mathrm{AlOOH})$, tungsten was found to adsorb as polytungstate species even when tungsten was adsorbed at $\mathrm{pH} 8$ where the $\mathrm{WO}_{4}{ }^{2-}$ is the dominant species in solution (Hur and Reeder, 2016).

The speciation of adsorbed tungsten is important for its long-term stability on surfaces. Bednar et al. (2008) calculated partition coefficients for the adsorption of monomeric and polymeric tungsten species in Grenada Loring soil spiked with metallic tungsten. They observed that polytungstate species had lower partition coefficients than monotungstates, and the polytungstate species were found to be primarily $\mathrm{W}_{4} \mathrm{O}_{13}{ }^{-}, \mathrm{PW}_{3} \mathrm{O}_{12}, \mathrm{H}_{3} \mathrm{P}_{4} \mathrm{~W}_{3} \mathrm{O}_{21}{ }^{-}$, and other polytungstates were in minor abundance (Bednar et al., 2008). A follow up study compared monotungstate and polytungstate concentrations in eluents extracted from columns packed with Grenada Loring soil as a function of time (Bednar et al., 2009). When deionized water was used as the eluent, the concentrations of monotungstate and polytungstates was similar, however the concentrations of monotungstates decreased more rapidly due to its higher adsorption propensity. Sun and Bostick (2015) investigated the effects of tungstate polymerization on tungsten adsorption to ferrihydrite. They found that monotungstates have a higher affinity for ferrihydrite than polytungstates, and postulated that adsorbed tungstate may polymerize and become more easily leachable with time. Bostick et al. (2018) suggested the formation of POMs may also increase tungsten mobility in acidic media due to the lower adsorption affinity of POMs relative to monotungstate. Adsorption envelopes for the adsorption of mono and polytungstates to Pahokee Peat, montmorillonite, 
kaolinite, and illite were developed by Sen Tuna and Braida (2014). They found monotungstates have the highest affinity for Pahokee peat, followed by kaolinite, montmorillonite, and illite. For polytungstates, the order is kaolinite, Pahokee peat, montmorillonite, illite, and monotungstates adsorb stronger than polytungstates to all sorbents except illite (Sen Tuna and Braida, 2014). Cui and Johannesson (2017) conducted batch uptake experiments for the adsorption of $\mathrm{WO}_{4}{ }^{2-}$ and $\mathrm{WS}_{4}{ }^{2-}$ to pyrite and goethite. The adsorption of both complexes to pyrite is best explained by the formation of monodentate complexes on a specific site of the pyrite surface, and $\mathrm{WO}_{4}{ }^{2-}$ adsorbed stronger than $\mathrm{WS}_{4}{ }^{2-}$, probably due to the formation of different inner-sphere complexes. Both species adsorbed exhibited stronger adsorption to goethite than pyrite, and $\mathrm{WS}_{4}{ }^{2-}$ adsorbs weaker than $\mathrm{MoS}_{4}{ }^{2-}$ to pyrite (Bostick et al., 2003; Cui and Johannesson, 2017). Overall, tungsten species adsorb strongest at acidic $\mathrm{pH}, \mathrm{WO}_{4}{ }^{2-}$ appears to adsorb stronger than all other tungsten species, and the mechanism for tungsten adsorption is highly dependent on the local structure of adsorbent minerals and tungsten speciation.

\subsubsection{Behaviour of Tungsten in Soils}

In soils, tungsten concentrations typically range from $0.4-5 \mathrm{mg} / \mathrm{kg}$ (Kabata-Pendias and Mukherjee, 2007), and is higher in soils derived from the weathering of rocks with granitic composition. Elevated tungsten concentrations may also occur as a result of anthropogenic contamination, such as in soils adjacent mining or smelting operations (Pyatt and Pyatt, 2004; Koutsospyros et al., 2006; Wilson and Pyatt, 2006; Wilson and Pyatt, 2009; Lin et al., 2014) and in the soils of firing ranges and battlefields where W-bearing ammunition was used (Sadiq et al., 1992; Koutsospyros et al., 2006; Clausen et al., 2007; Bostick et al., 2018). Mineral occurrences of tungsten in soils are scheelite and wolframite, and trace amounts of tungsten can be found in rutile $\left(\mathrm{TiO}_{2}\right)$ and ilmenite $\left(\mathrm{FeTiO}_{3}\right)($ Candela and Bouton, 1990; Cave et al., 2017), which are common in soils due to their high resistance to weathering (Raman and Jackson, 1965). Labile hosts of tungsten in soils are those with high adsorption potential, such as clay minerals, Fe and Al-oxyhydroxide minerals, and organic matter. Secondary minerals of tungsten have 
rarely been reported in soils. Bostick et al. (2018) suggested that tungstite may be present in munitions impacted soils.

In light of the emerging concerns of tungsten toxicity and the replacement of lead with tungsten in ammunition, much of the research regarding tungsten behaviour in soils has been conducted on munitions-impacted soils at firing ranges by the US Army Corps of Engineers (Clausen et al., 2007; Bednar et al., 2008; Bednar et al., 2009; Bostick et al., 2018). At the Camp Edwards Small Arms Ranges in Massachusetts, where W-bearing bullets have accumulated in the troughs and berms behind targets (Clausen et al., 2007), soil samples were collected around the berms and troughs adjacent to targets, and soil porewater was extracted with suction lysimeters. Porewater tungsten concentrations ranged from 0.01 to $400 \mathrm{mg} / \mathrm{L}$, and generally increased with soil depth, whereas the solid tungsten content of the soil decreased with depth. The authors suggested that tungsten was transported downwards in the soil after being leached from oxidized metallic tungsten in the bullets. They also suggested that adsorption is minimal in the soils due to the relatively low clay contents (as determined by XRD analyses), despite the $\mathrm{pH}$ of soil porewaters being mildly acidic (median $\mathrm{pH}=6.7$ ). The high porewater tungsten concentrations is possibly due to the formation of POM species within the soil (Bostick et al., 2018), which have lower adsorption propensities than monotungstate (Sun and Bostick, 2015). Bostick et al. (2018) analyzed munitions-impacted soils using XANES and EXAFS, and found that the dominant solid phase of tungsten was POMs adsorbed to ferrihydrite in the soil. They also conducted tungsten desorption experiments on the soils using river water (with final pHs between $5-7$ ), which yielded high tungsten concentrations (up to $\sim 110 \mathrm{mg} / \mathrm{L}$ ), and found that soils with higher iron concentrations desorbed less tungsten. Whereas the less-easily adsorbed POMs are attributed to the higher mobility of dissolved tungsten in the soils with acidic $\mathrm{pH}$, the anomalously high labile tungsten concentrations are also due to the high solubility of metallic tungsten in the bullets (Clausen et al., 2007; Bostick et al., 2018).

Studies addressing tungsten contamination in soils adjacent to mining operations have focused mostly on the bioavailability of tungsten, with less detail regarding the aqueous behaviour and solid-phase 
speciation of tungsten (Wilson and Pyatt, 2006; Wilson and Pyatt, 2009; Lin et al., 2014). Sequential extractions using acetic acid (for exchangeable and weak-acid soluble phases), followed by hydroxyl ammonium chloride (for easily reducible phases), and then hydrogen peroxide (for oxidizible phases) were conducted on spoil samples taken from nearby an abandoned tungsten mine in the Lake District, United Kingdom, where tungsten is hosted in scheelite and wolframite (Wilson and Pyatt, 2006). The sum of the extraction yields was subtracted from the "pseudototal" element concentrations as determined by aqua regia digestion, which determined that $98.6 \%$ of the tungsten resided in residual phases (most likely relict scheelite and wolframite). The hydroxyl ammonium chloride extracted $0.3-1.2 \%$ of the pseudototal tungsten, whereas yields for arsenic, copper, and zinc were much higher $(18.7-32.5 \%$ of the pseudototals), indicating that a high proportion of arsenic, copper, and zinc is associated with easily reducible phases (i.e. Fe and Mn-oxyhydroxides) more so than tungsten. The same authors conducted a similar study on calcareous soils adjacent to an abandoned polymetallic $(\mathrm{Cu}, \mathrm{Zn}, \mathrm{Ag}, \mathrm{Hg}, \mathrm{W}, \mathrm{Ba})$ mine in the Corbières Area, Southern France, where tungsten is hosted in scheelite (Wilson and Pyatt, 2009). Using the same sequential extraction procedure on spoil samples as their previous study, tungsten yields from the first 3 steps were substantially higher ( 42\% from step 1, 22\% from step 2, 18\% from step 3, and $\sim 18 \%$ in the residual fraction) than spoils from the English Lake District. They suggested the higher yields were due to the higher soil $\mathrm{pH}$ in the Corbières area $(8.0-8.72)$ compared to the acidic soils in the English Lake District (4.09-6.03), however no information was provided with regard to the mineralogical hosts of tungsten. Elevated tungsten concentrations are also reported in agricultural soils and rice nearby the world's largest operating tungsten mine in Jiangxi province, China, where tungsten is extracted from scheelite (Lin et al., 2014). Like the studies by Wilson and Pyatt (2009), Lin et al. (2014) employed a sequential extraction procedure (following Tessier et al., 1979) on the soils, targeting the soluble and exchangeable fraction, followed by the carbonate fraction, the reducible fraction, the organic matter fraction, and the residual fraction. Less than $0.5 \%$ of tungsten was associated with the first three steps of the procedure, $2.9-10 \%$ was associated with the organic matter fraction, and $89-97 \%$ of tungsten was associated with the residual fraction (likely relict wolframite). In both Wilson and Pyatt 
(2006) and Lin et al. (2014), it was suggested that the low yields from the first steps of the extractions is attributed to the acidic $\mathrm{pH}$ of the soils, but no information was given regarding the mineralogical hosts of tungsten at either site. The high sequential extraction yields from alkaline soils from Corbières, France is intriguing, and could be related to not only the high $\mathrm{pH}$ of the soils, but also to the relative age of tungsten contamination (> 1500 years for Corbières, France vs. < 152 years for the Lake District, United Kingdom). The higher yields from Corbières, France may indicate a solid-phase transformation of tungsten related to the aging of the soils in a warmer and more humid climate, albeit speculative. More research addressing tungsten behaviour in both contaminated and natural soils is needed, particularly regarding the mineralogical hosts in soils of varying age and protolith, and their stability under dynamic aqueous conditions.

\subsubsection{Behaviour in Seawater, River Water, and Groundwater}

In the open ocean, tungsten behaves conservatively with an average concentration of $11 \mathrm{ng} / \mathrm{L}$ and a residence time of 20,000 years (Sohrin et al., 1987), but behaves non-conservatively in estuarine waters and reducing marine basins (Kashiwabara et al., 2013; Mohajerin et al., 2016; Bauer et al., 2017; Watanabe et al., 2017). The abundance of tungsten and molybdenum in Earth's upper crust is similar (Mo/W = 3), however the molar ratio of Mo/W in ocean water is $\sim 1,800$ (Kashiwabara et al., 2017), owing to their different behaviour at the seawater-sediment interface (Sohrin et al., 1987; Kashiwabara et al., 2013; Bauer et al., 2017). The sinks for tungsten and molybdenum in the ocean are clay minerals and Fe and Mn-oxyhydroxide crusts and nodules, which host both elements as adsorbed species (Sohrin et al., 1987; Kashiwabara et al., 2013; Bauer et al., 2017). The lower concentration of tungsten relative to molybdenum in seawater is attributed to stronger tungsten adsorption on ferrihydrite by the formation of inner-sphere complexes, whereas molybdenum adsorption is more weakly bound by outer-sphere complexes (Kashiwabara et al., 2013). The different behaviour of tungsten and molybdenum is even more apparent in oxygen-poor seawater (Mohajerin et al., 2016; Watanabe et al., 2017; Cui et al., 2020). The 
instability of Fe and Mn-oxyhydroxide minerals in reducing waters allows for higher tungsten and molybdenum concentrations, and in highly sulfidic waters, tungsten and molybdenum form thiolated species, which adsorb weaker than their oxyanion counterparts (Bostick et al., 2003; Mohajerin et al., 2014a; Mohajerin et al., 2016; Cui and Johannesson, 2017; Cui et al., 2020). The Mo/W value in reducing waters greatly decreases upon molybdenum reduction to $\mathrm{Mo}(\mathrm{IV})$ and precipitation as molybdenite or coprecipitation in polysulfide phases, whereas $\mathrm{W}(\mathrm{VI})$ is much harder to reduce and is more stable in the aqueous phase (Mohajerin et al., 2016).

In rivers, tungsten is transported as dissolved species, and with suspended and colloidal phases (Pokrovsky and Schott, 2002; Viers et al. 2009; Hällström et al. 2019). Viers et al. (2009) calculated the annual flux of tungsten transported to the oceans by the world's rivers, and estimated that 30,000 tonnes of tungsten is transported with suspended sediment and 3,700 tonnes is transported as dissolved species annually (or at least smaller than the 0.22 and $0.45 \mu \mathrm{m}$ filter pore sizes used). Pokrovsky and Schott (2002) measured major and trace element concentrations in small rivers and watersheds in northwest Russia using progressively smaller filter sizes $(5,0.8$ and $0.22 \mu \mathrm{m} ; 100,10$, and $1 \mathrm{kD})$, and noted that tungsten and iron concentrations are similar between the $0.8 \mu \mathrm{m}$ and $5 \mu \mathrm{m}$ filtrates, but sharply decrease with the smaller filter sizes. They suggest that tungsten is mostly transported with colloidal iron (i.e. $<0.8$ $\mu \mathrm{m}$ Fe-oxyhydroxide minerals) in the rivers, with minimal tungsten associated with suspended phases (> $0.8 \mu \mathrm{m})$. It is possible that the high flux of tungsten associated with suspended sediments estimated by Viers et al. (2009) also includes transport by colloids. Hällström et al. (2019) collected water samples (filtered to $0.22 \mu \mathrm{m}$ and unfiltered) from streams downstream of W-Cu-F tailings in Yxsjöberg, Sweden, in May, June, July, August, and October of 2018. Tungsten concentrations (both filtered and unfiltered) generally increased throughout the summer into the fall, with the lower spring concentrations attributed to dilution by higher water fluxes during spring run-off. The unfiltered aliquots generally had higher iron concentrations than filtered aliquots, whereas the proportions of tungsten in the filtered and unfiltered aliquots varied from month to month. No explanation was given regarding the monthly variations, but it 
was interpreted that tungsten in the unfiltered aliquots is adsorbed to Fe-oxyhydroxide phases, although aliquots with smaller filter sizes would be useful in discerning tungsten associated with colloidal or suspended iron phases, as was done by Pokrovsky and Schott (2002).

Factors affecting tungsten concentrations in non-marine surface waters include $\mathrm{pH}$-dependent adsorption by benthic sediments, inputs from weathering of rocks and regolith, input via hydrothermal waters, evaporative concentration, and dilution (Johannesson et al., 2000; Harita et al., 2005; Arnórsson and Óskarsson, 2007; Gammons et al., 2013; Guo et al., 2019; Steenstra et al., 2020). In Eastern Sierra Nevada rivers in Nevada, USA, relatively high tungsten concentrations $(0.147 \mu \mathrm{g} / \mathrm{L}-189 \mu \mathrm{g} / \mathrm{L})$ are attributed to weathering of W-rich soils and rocks, and possibly input by geothermal fluids (Johannesson et al., 2000). Tungsten concentrations in streams, groundwater seeps, and ponds/lakes in Washington state, USA, range from $0.01 \mu \mathrm{g} / \mathrm{L}-2.05 \mu \mathrm{g} / \mathrm{L}$, with average concentrations over two-fold higher in watersheds flowing over W-bearing bedrock (Steenstra et al., 2020). In Icelandic surface waters in contact with basalt, tungsten and molybdenum behave conservatively with concentrations ranging from $0.005-$ $0.342 \mu \mathrm{g} / \mathrm{L}$ and $<0.01-2.71 \mu \mathrm{g} / \mathrm{L}$, respectively, and the $\mathrm{Mo} / \mathrm{W}$ values of surface waters is similar to the basalt (6.3 for the surface waters, 6.4 for basalt; Arnórsson and Óskarsson, 2007). However, in peat soil waters the Mo/W value is 18 , and it was suggested that tungsten is adsorbed or co-precipitated with Feoxyhydroxide minerals and organic matter but molybdenum is not (Arnórsson and Óskarsson, 2007). In the Yunnan-Sichuan-Tibet geothermal belt, China, neutral-alkaline $\mathrm{HCO}_{3}{ }^{-}-\mathrm{Cl}^{-}$dominated geothermal waters have extraordinarily high tungsten concentrations (up to $1103 \mu \mathrm{g} / \mathrm{L}$ ) and very low Mo/W values $(0.0008-0.096)$, whereas tungsten concentrations in acid $\mathrm{SO}_{4}{ }^{2-}$ dominated geothermal waters have much lower tungsten concentrations $(0.05-18.8 \mu \mathrm{g} / \mathrm{L})$ and similar proportions of molybdenum and tungsten (Mo/W values between 1.1 - 10; Guo et al., 2019). In the neutral-alkaline geothermal waters, PHREEQC modelling determined that $>99 \%$ of tungsten is speciated as $\mathrm{WO}_{4}{ }^{2-}$, whereas acidic geothermal waters have significant proportions of polytungstate species, up to $92.8 \%$ in one sampleg. The lithology of the geothermal reservoirs was determined to be the primary factor controlling tungsten concentrations in the 
waters, with the highest tungsten concentrations in waters in contact with granite, however tungsten input from magmatic fluids could not be ruled out (Guo et al., 2019). The low Mo/W values was explained by molybdenite precipitation in the sulfidic neutral-alkaline waters, where W(VI) is less easily reduced to precipitate as tungstenite (Brookins, 1987; Vorlicek et al., 2004; Mohajerin et al., 2016; Guo et al., 2019). Tungsten concentrations in acidic geothermal spring sediments are much higher than neutral-alkaline spring sediments due to higher tungsten adsorption to goethite and pyrite at acidic $\mathrm{pH}$. Therefore, the tungsten input to groundwater and surface waters is higher from the neutral-alkaline geothermal systems than the acidic systems, where tungsten is immobilized in-situ (Guo et al., 2019).

Harita et al. (2005) measured the vertical distribution of tungsten and $\mathrm{pH}$ in three temperate lakes in Japan during periods of thermal stratification. In the epilimnia of the lakes (upper stratified zone; $\mathrm{pH} 8$ -9.5), tungsten concentrations were on average $1.8-2.9$ times higher than in the hypolimnia (lower stratified zone; $\mathrm{pH}<7.5)$. They also conducted a laboratory experiment in which lake sediment was put in a chamber with lake water, and the $\mathrm{pH}$ was controlled by bubbling $\mathrm{CO}_{2}$ gas in the water over a period of 11 days to simulate seasonal $\mathrm{pH}$ variations as a function of photosynthesis (i.e. $\mathrm{CO}_{2}$ uptake by plankton and macrophytes in the warmer seasons). Tungsten concentrations in the lake water increased from 3.7 $\mathrm{ng} / \mathrm{L}$ at $\mathrm{pH} 7$ (during $\mathrm{CO}_{2}$ bubbling) to a maximum of $8 \mathrm{ng} / \mathrm{L}$ at $\mathrm{pH} 8.75$ when bubbling ceased, and tungsten concentrations gradually decreased when the $\mathrm{pH}$ was returned to 7 . The authors suggested that authigenic Fe-oxyhydroxide minerals host adsorbed tungsten in the lake sediment, and that seasonal $\mathrm{pH}$ fluctuations as a function of primary production controlled oxyanion concentrations in the lakes. In a 30 $\mathrm{m}$ deep holomictic pit lake formed after cessation of mining at the open-pit Calvert scheelite Mine in Montana, USA, filtered (to $0.2 \mu \mathrm{m}$ ) tungsten concentrations increase from $14.1 \mu \mathrm{g} / \mathrm{L}$ at $6.1 \mathrm{~m}$ depth to $25.6 \mu \mathrm{g} / \mathrm{L}$ at $24.4 \mathrm{~m}$ depth, and $\mathrm{pH}$ decreases from 8.5 to 7.5 at those depths (Gammons et al., 2013). Iron and manganese concentrations also increase with depth in the lake (from $<2.0$ to $5 \mu \mathrm{g} / \mathrm{L} \mathrm{Fe}$, and 1.0 to $336 \mu \mathrm{g} / \mathrm{L} \mathrm{Mn}$, at 6.1 and $24.4 \mathrm{~m}$ depth, respectively), and the bottom $6 \mathrm{~m}$ of the lake is anoxic. The authors suggested the high manganese concentrations could be due to the reductive dissolution of Mn- 
oxyhydroxide minerals in the benthic sediment, but that reductive dissolution of Fe-oxyhydroxide minerals is restricted by the lack of organic carbon as a reductant. An alternative source of manganese to the benthic waters is the dissolution of rhodochrosite $\left(\mathrm{MnCO}_{3}\right)$, however rhodochrosite is saturated in the bottom $5 \mathrm{~m}$ of the lake and undersaturated in the oxidized waters above (Gammons et al., 2013), suggesting that precipitation of rhodochrosite should be a sink of manganese and not a source. Although it not explicitly stated, it is possible that the higher tungsten concentrations at the bottom of the pit lake is due to lower amounts of adsorbent minerals in the benthic sediment, despite higher tungsten adsorption predicted at lower $\mathrm{pH}$ by Gustafsson (2003).

Like surface and geothermal waters, tungsten concentrations in groundwaters are controlled by the lithology of the groundwater reservoir, $\mathrm{pH}$-dependent adsorption, and the presence of adsorbent minerals (Seiler et al., 2005; Arnórsson and Óskarsson, 2007; Johannesson et al., 2013; Mohajerin et al., 2014b). In Fallon, Nevada, tungsten concentrations in aquifers used for drinking water range from 0.27 to $742 \mu \mathrm{g} / \mathrm{L}$, with the highest concentrations in $\mathrm{Na}^{-} \mathrm{HCO}_{3}$ and $\mathrm{Na}-\mathrm{Cl}$ dominated waters with $\mathrm{pH}$ values $>8$ (Seiler et al., 2005). The groundwaters in the Fallon area are highly reducing [median dissolved oxygen (DO) $<0.2 \mathrm{mg} / \mathrm{L}]$, and it was proposed that the high concentrations are due to lack of adsorption by Feoxyhydroxide minerals in the aquifers, although no mineralogical data is available to confirm this hypothesis. It was suspected the high tungsten concentrations are not anthropogenic in origin, as the aquifers with the highest tungsten concentrations have not received input from surface waters in over 100 years (Seiler et al., 2005). In Icelandic groundwaters in contact with basaltic rocks, tungsten concentrations range from 0.015 to $11.5 \mu \mathrm{g} / \mathrm{L}$, increasing with temperature and water age (Arnórsson and Óskarsson, 2007). The source of tungsten in groundwaters below $30{ }^{\circ} \mathrm{C}$ is predicted to be solely from the dissolution of plagioclase $\left[(\mathrm{Na}, \mathrm{Ca})(\mathrm{Si}, \mathrm{Al})_{4} \mathrm{O}_{8}\right]$, and in groundwaters between $30-90{ }^{\circ} \mathrm{C}$, pyroxene becomes increasingly unstable and partially dissolves to release trace amounts of tungsten. Johannesson et al. (2013) compared dissolved tungsten concentrations between the Aquia aquifer in coastal Maryland, USA and the Carrizo Sand aquifer in southeastern Texas, USA. In the Carrizo Sand aquifer, tungsten 
concentrations increase along the flow gradient from $0.34 \mathrm{ng} / \mathrm{L}$ at $\mathrm{pH} 6.14$ to $237 \mathrm{ng} / \mathrm{L}$ at $\mathrm{pH} 8.5$, correlating also with decreases in Eh and increases in $\mathrm{HCO}_{3}{ }^{-}$and $\mathrm{S}^{2-}$ concentrations. Tungsten concentrations were much lower in the Aquia aquifer $(1.19-33.7 \mathrm{ng} / \mathrm{L})$, and had no correlation with $\mathrm{pH}$, $\mathrm{S}^{2-}$, or $\mathrm{HCO}_{3}{ }^{-}$concentrations. The lower tungsten concentrations in the Aquia aquifer are attributed to its much higher Fe-oxyhydroxide mineral content and lower $\mathrm{pH}$ maxima compared to the Carrizo Sand aquifer, which adsorb tungsten at circumneutral $\mathrm{pH}$ in both aquifers (Johannesson et al., 2013). It was hypothesized that the correlation between dissolved tungsten and $\mathrm{S}^{2-}$ concentrations in the Carrizo Sand aquifer could indicate the presence of thiotungstate species with a lower adsorption propensity than $\mathrm{WO}_{4}{ }^{2-}$ ; However, later modelling of tungsten speciation with thiotungstate equilibrium constants determined by Mohajerin et al. (2014a) suggested that $<0.5 \%$ of tungsten is present as thiotungstates in the aquifer. Adsorption to Fe-oxyhydroxide minerals at circumneutral $\mathrm{pH}$ is also the dominant factor controlling tungsten concentrations in groundwaters in the Murshidabad district of West Bengal, India (Mohajerin et al., 2014b).

\subsubsection{Tungsten Behaviour in Mine Waste}

To date, only two studies have directly addressed the behaviour of tungsten in mine waste (Petrunic and Al, 2005; Petrunic et al., 2006; Petrunic et al., 2009; Hällström et al., 2018; Hällström et al., 2019). The first studies were conducted on tailings from the granitic W-Mo Mount Pleasant mine in New Brunswick, which operated from 1983 - 1985 and hosts $\sim 1$ million tonnes of tailings that have been exposed to the atmosphere since 1997 (Petrunic and Al, 2005). In the Mount Pleasant deposit, tungsten is hosted in wolframite, molybdenum in molybdenite, and the gangue mineralogy consists of over 80 minerals. In one ore body, the most abundant minerals are quartz $\left(\mathrm{SiO}_{2} ; 70 \%\right)$, topaz $\left(\mathrm{Al}_{2} \mathrm{SiO}_{4}(\mathrm{~F}, \mathrm{OH})_{2}\right.$; $10 \%)$, fluorite $\left(\mathrm{CaF}_{2} ; 5 \%\right)$, micas and clays $(4 \%)$, chlorite $(4 \%), \mathrm{K}$-feldspar $\left(\mathrm{KAlSi}_{3} \mathrm{O}_{8} ; 4 \%\right)$, and $3 \%$ opaque minerals including arsenopyrite, sphalerite, native bismuth, galena, pyrite, pyrrhotite, and tin minerals (Parrish, 1977). The top $60 \mathrm{~cm}$ of the tailings are unsaturated and oxidized, and are characterized 
by acidic porewater $(\mathrm{pH}=5.34)$, elevated aqueous $\mathrm{SO}_{4}, \mathrm{As}, \mathrm{Zn}, \mathrm{Cu}, \mathrm{Pb}, \mathrm{Ni}, \mathrm{Co}, \mathrm{Cd}, \mathrm{Fe}, \mathrm{F}$, and $\mathrm{Al}$ concentrations, the widespread formation of Fe-oxyhydroxide minerals and jarosite $\left(\mathrm{KFe}^{3+}{ }_{3}(\mathrm{OH})_{6}\left(\mathrm{SO}_{4}\right)_{2}\right)$, and the depletion of carbonate minerals (Petrunic and Al, 2005). Below the oxidization zone, $\mathrm{pH}$ increases with depth from 8.5 to 10.7 , with decreases in aqueous arsenic and metal concentrations and a dramatic increase in tungsten concentrations from 0.2 to $7.1 \mathrm{mg} / \mathrm{L}$. The anomalously high $\mathrm{pH}$ at depth is attributed to buffering by calcite and the enhanced dissolution of aluminosilicate minerals (namely chlorite) by Al-F complexation. Chlorite alters to kaolinite in the presence of fluorine, in a reaction that has net consumption of $\mathrm{H}^{+}$ions, creating higher $\mathrm{pH}$ values that are unattainable by carbonate buffering alone. They attribute the low tungsten concentrations in the oxidation zone is due to $\mathrm{pH}$-dependent adsorption to Fe-oxyhydroxide minerals, whereas the unsaturated zone lacks Fe-oxyhydroxide minerals due to the stability of sulfide minerals (Petrunic and Al, 2005).

Secondary mineral formation in the Mount Pleasant tailings is diverse, and includes chalcocite $\left(\mathrm{Cu}_{2} \mathrm{~S}\right)$, wulfenite $\left(\mathrm{PbMoO}_{4}\right)$, an unidentified crystalline $\mathrm{Bi}-\mathrm{Pb}-\mathrm{As}-\mathrm{O}$ mineral, a Fe-Zn-As-O phase, and Fe-As-O coatings on arsenopyrite (Petrunic et al., 2006; Petrunic et al., 2009). Of particular interest is the precipitation of wulfenite, which is found within pores of Fe-Zn-As-O and Fe-As-O coatings, and on the surfaces of molybdenite. Wulfenite reached saturation by the leaching of molybdenum and lead from molybdenite and galena, respectively, and is predicted to have precipitated directly from the porewater within the oxidation zone (Petrunic et al., 2006). Using scanning transmission electron microscopy (STEM), they determined that the wulfenite contains up to $\sim 5 \mathrm{~mol} . \% \mathrm{~W}$, As, and $\mathrm{Bi}$, with lesser amounts of $\mathrm{Ca}$ and $\mathrm{Zn}$. Tungsten readily substitutes for molybdenum in wulfenite due to the similar ionic radii of the $\mathrm{WO}_{4}{ }^{2-}$ and $\mathrm{MoO}_{4}{ }^{2-}$ anions ( $\mathrm{r}_{\mathrm{ion}}=0.68, \mathrm{r}_{\mathrm{ion}}=0.62$, respectively; Railsback, 2008), and wulfenite forms a solid solution with stolzite $\left(\mathrm{PbWO}_{4}\right.$; Clark and Sillitoe, 1970). Selected-area electron diffraction (SAED) patterns of the phase match only with wulfenite suggesting that $\mathrm{W}, \mathrm{As}, \mathrm{Bi}, \mathrm{Ca}$, and $\mathrm{Zn}$ are present as substitutions within wulfenite, although the authors state that the presence of minor stolzite, powellite, and scheelite cannot be ruled out (Petrunic et al., 2006). To our knowledge, this is the only 
documented case of tungsten co-precipitating in a secondary mineral in low-temperature geochemical systems. This study highlights the possible importance of co-occurring minerals in tailings that upon dissolution can raise $\mathrm{pH}$, and create highly alkaline waters in which tungsten concentrations can reach $\mathrm{mg} / \mathrm{L}$ concentrations. Furthermore, the oxidative dissolution of molybdenite can result in the precipitation of secondary molybdenum minerals in which aqueous tungsten may be sequestered by substitution, and therefore the behaviour of molybdenum should be considered in conjunction with tungsten when Mobearing minerals are present.

The only other studies addressing tungsten behaviour in mine waste were conducted on historic W-Cu-F skarn tailings at Yxsjöberg, Sweden (Hällström et al., 2018a; Hällström et al., 2018b; Hällström et al., 2019), where 2.8 million tonnes of tailings were deposited in bogs and swamps between 1897 1963. Tungsten is hosted in scheelite, copper in chalcopyrite, and the gangue mineralogy consists of pyrite, pyrrhotite, calc-silicate minerals, quartz, micas, chlorite, calcite, and up to $2 \mathrm{wt} . \%$ fluorite (Hällström et al., 2018a). The top $0.7-2.5 \mathrm{~m}$ of the tailings have completely oxidized, and are characterized by acidic paste $\mathrm{pH}(<4.5$; Hällström et al., 2018b), Fe-oxyhydroxide mineral replacement of pyrrhotite and as coatings on other minerals, and the depletion of carbonate and sulfide minerals (Hällström et al., 2018a). Below the oxidation zone is $\sim 1 \mathrm{~m}$ of variably oxidized tailings, followed by unoxidized tailings beneath. The fluorite content of the tailings decreases with depth from $>2$ wt. $\%$ in the oxidized zone, to $<1 \mathrm{wt} . \%$ below it, whereas tungsten concentrations are consistent with depth at around $0.1 \mathrm{wt} . \%$. Petrographic microscopy identified a yellow rim coating scheelite in a sample from the base oxidized zone, which was interpreted to be tungstic acid $\left(\mathrm{H}_{2} \mathrm{WO}_{4}\right.$, i.e. the mineral tungstite) (Hällström et al., 2018a). To our knowledge, this is the only secondary mineral of tungsten identified outside the supergene zones of ore deposits. The depth of the core that this sample was taken from also has above average tungsten concentrations $(0.5 \mathrm{wt} . \%)$, and the authors state that it is unknown whether this anomaly is due to lower metallurgical recovery of scheelite or represents secondary tungsten precipitation (Hällström et al., 2018a). 
Hällström et al. (2019) studied scheelite weathering in the tailings in more detail by employing a seven-step sequential extraction of the tailings following the method of Dold (2003). The seven steps are: 1) water soluble phases (deionized water at room temperature); 2) exchangeable fraction (1 M ammonium acetate at $\mathrm{pH} 4.5$ ); 3) easily-reducible phases (ammonium-oxalate at $\mathrm{pH}$ 3); 4) resistant reducible phases (ammonium-oxalate in an ultrasonic bath at $80^{\circ} \mathrm{C}$ ); 5) easily oxidizable minerals (35\% hydrogen peroxide); 6) resistant oxidizable minerals (aqua regia digestion); and 7) residues and silicates (4-acid digestion). Neither iron or tungsten was extracted from the first two steps, however steps 3 and 4 had significant tungsten yields. At the redox boundary where the yellow rim on tungsten was identified, the tungsten yield from step 3 was $922 \mathrm{mg} / \mathrm{kg}$ (30\% of the total tungsten at that depth), and tungsten recoveries by steps 3 and 4 from other sample depths were in the hundreds of $\mathrm{mg} / \mathrm{kg}$. Due to the lack of literature regarding the reactivity of scheelite to the acids used, the authors were unsure at which step scheelite dissolved, but suggested that tungsten recoveries from steps 3 and 4 are associated with Feoxyhydroxide minerals which host tungsten via adsorption or structural incorporation. They also suggested that tungsten leaches from scheelite by ion exchange of $\mathrm{WO}_{4}{ }^{2-}$ and $\mathrm{CO}_{3}{ }^{2-}$ on the scheelite surface in the variably oxidized and unoxidized tailings horizons, which is the weathering mechanism proposed by Atademir et al. (1978) for scheelite dissolution during froth floatation. Using this model, scheelite weathering in the oxidized tailings is limited due to low $\mathrm{HCO}_{3}^{-}$concentrations, and is enhanced in the unoxidized tailings by the downward transport of $\mathrm{HCO}_{3}{ }^{-}$during calcite depletion. If it is true that scheelite weathers via ion exchange with $\mathrm{CO}_{3}{ }^{2-}$, then scheelite may have long term stability in acidic $\mathrm{HCO}_{3}{ }^{-}$-depleted waters characteristic of acid rock drainage.

\subsection{Conclusions}

Many studies regarding the low-temperature mobility of tungsten cite $\mathrm{pH}$-dependent adsorption as a primary factor controlling aqueous tungsten concentrations in environmental systems (e.g. Harita et

al., 2005; Petrunic and Al, 2005; Seiler et al., 2005; Arnórsson and Óskarsson, 2007; Clausen et al., 2007; Bednar et al., 2008; Bednar et al., 2009; Gammons et al., 2013; Johannesson et al., 2013; Kashiwabara et 
al., 2013; Mohajerin et al., 2014b; Mohajerin et al., 2016; Bauer et al., 2017; Watanabe et al., 2017; Bostick et al., 2018; Guo et al., 2019; Hällström et al., 2019; Cui et al., 2020). Forming strictly anionic species, tungsten adsorbs to mineral surfaces at acidic $\mathrm{pH}$, and is most mobile in alkaline waters (Gustafsson, 2003). The speciation of tungsten has shown to affect its adsorption propensity, with polymeric and thiolated species adsorbing weaker than $\mathrm{WO}_{4}{ }^{2-}$ (Bednar et al., 2008; Bednar et al., 2009; Cui and Johannesson, 2017; Bostick et al., 2018). High soil porewater tungsten concentrations at acidic $\mathrm{pH}$ values have been attributed to the leaching of tungsten from W-bearing bullets and the relatively weak adsorption polytungstate and POM species (Clausen et al., 2007; Bostick et al., 2018), however aqueous tungsten concentrations generally decrease with decreasing $\mathrm{pH}$ in surface waters, groundwaters, geothermal waters, and mine tailings (Harita et al., 2005; Petrunic and Al, 2005; Johannesson et al., 2013; Guo et al., 2019). More research is needed on the solid-phase hosts of tungsten, both primary and secondary, specifically with regard to their solubility reactivity under different aqueous conditions. In particular, the mechanisms of scheelite and wolframite dissolution are poorly understood, despite these minerals being by far the most common primary hosts of tungsten in Earth's crust (Lassner and Schubert, 2000). As mine waste generated from processing W-rich ores can contain elevated concentrations of these minerals (Petrunic and Al, 2005; Hällström et al., 2018a), it is critical to better understand their weathering behaviour to mitigate the potential for tungsten leaching during the long-term storage of mine waste. Although there has only been one documented case of a secondary tungsten mineral formed in mine tailings (a tungstite rim on scheelite in the W-Cu-F skarn tailings at Yxsjöberg, Sweden; Hällström et al., 2018a), the calculation of thermodynamic data for secondary tungsten minerals would be useful to better predict their formation in mine waste and other environmental systems. Knowledge regarding the toxicity and ecotoxicity of tungsten and the mechanisms by which tungsten may be acutely and chronically toxic is still developing (Witten et al., 2012; Datta et al., 2017), and to date, no definitive link has been established between tungsten exposure and the leukemia clusters in the southwestern United States (Datta et al., 2017). Aqueous concentrations at which tungsten becomes acutely and chronically 
toxic to humans and other organisms would be useful for establishing regulatory limits for tungsten concentrations in both commercial and non-commercial water reservoirs.

\subsection{References}

Allison, P.G., J.M. Seiter, A. Diaz, J.H. Lindsay, R.D. Moser, R.V. Tappero, and A.J. Kennedy. 2016. Gastropod (Otala lactea) shell nanomechanical and structural characterization as a biomonitoring tool for dermal and dietary exposure to a model metal. Journal of the mechanical behavior of biomedical materials. vol. 53, pp. 142-150. https://doi.org/10.1016/j.jmbbm.2015.08.016

Altringer, P.B. 1978. Tungsten Recovery from Searles Lake Brines. Department of the Interior, Bureau of Mines. vol. 8315, pp. 1053-1069. https://doi.org/10.1080/01496398108057599

Arnórsson, S., and N. Óskarsson. 2007. Molybdenum and tungsten in volcanic rocks and in surface and< $100 \mathrm{C}$ ground waters in Iceland. Geochimica et Cosmochimica Acta. vol. 71, no. 2, pp. 284-304. https://doi.org/10.1016/j.gca.2006.09.030

Atademir, M.R., J.A. Kitchener, and H.L. Shergold. 1979. The Surface Chemistry and Floatation of Scheelite I. Solubility and Surface Characteristics of Precipitated Calcium Tungstate. Journal of Colloid and Interface Science. vol. 71, no. 3, pp. 466-476. https://doi.org/10.1016/0021-9797(79)90321-7

Bauer, S., S. Blomqvist, and J. Ingri. 2017. Distribution of dissolved and suspended particulate molybdenum, vanadium, and tungsten in the Baltic Sea. Marine Chemistry. vol. 196, pp. 135-147. https://doi.org/10.1016/j.marchem.2017.08.010

Bednar, A.J., W. T. Jones, R. E. Boyd, D. B. Ringelberg, and S. L. Larson. 2008. Geochemical Parameters Influencing Tungsten Mobility in Soils. Journal of Environment Quality. vol. 37, no. 1, 229233. https://doi.org/10.2134/jeq2007.0305

Bednar, A.J., R.E. Boyd, W.T. Jones, C.J. McGrath, D.R. Johnson, M.A. Chappell, and D.B. Ringelberg. 2009. Investigations of Tungsten Mobility in Soil Using Column Tests. Chemosphere. vol. 75, no. 8, pp. 1049-56. https://doi.org/10.1016/j.chemosphere.2009.01.039

Bolt, A.M., V. Sabourin, M.F. Molina, A.M. Police, L.F. Negro Silva, D. Plourde, ... and K.K. Mann. 2015. Tungsten targets the tumor microenvironment to enhance breast cancer metastasis. Toxicological Sciences. vol. 143, no. 1, pp. 165-177. https://doi.org/10.1093/toxsci/kfu219

Bostick, B.C., S. Fendorf, G.R. and Helz. 2003. Differential adsorption of molybdate and tetrathiomolybdate on pyrite (FeS2). Environmental Science \& Technology. vol. 37, no. 2, pp. 285-291. https://doi.org/10.1021/es0257467 
Bostick, B. C., J. Sun, J. D. Landis, and J.L. Clausen. 2018. Tungsten Speciation and Solubility in Munitions-Impacted Soils. Environmental Science \& Technology. vol. 52, no. 3, pp. 1045-1053. https://doi.org/10.1021/acs.est.7b05406

Brookins, D.G. 1987. Tungsten. In Eh-pH Digrams for Geochemistry. Springer, Berlin, Heidelberg. pp. 106-107. https://doi.org/10.1007/978-3-642-73093-1

Brown, T., and P. Pitfield. 2014. Tungsten. In Critical Metals Handbook. John Wiley \& Sons. pp. 385413. https://doi.org/0.1002/9781118755341.ch16

Candela, P.A., and S.L. Bouton. 1990. The influence of oxygen fugacity on tungsten and molybdenum partitioning between silicate melts and ilmenite. Economic Geology. vol. 85, no. 3, pp. 633-640.

https://doi-org.proxy.queensu.ca/10.2113/gsecongeo.85.3.633

Cave, B.J., I.K. Pitcairn, D. Craw, R.R. Large, J.M. Thompson, and S.C. Johnson. 2017. A metamorphic mineral source for tungsten in the turbidite-hosted orogenic gold deposits of the Otago Schist, New Zealand. Mineralium Deposita. vol. 52, no. 4, pp. 515-537. https://doi.org/10.1007/s00126-016-0677-5

Christensen, K.L.Y. 2013. Metals in blood and urine, and thyroid function among adults in the United States 2007-2008. International journal of hygiene and environmental health. vol. 216, no. 6, pp. 624632. https://doi.org/10.1016/j.ijheh.2012.08.005

Clark, A.H., and R.H. Sillitoe. 1970. Tungstenian wulfenites, Mina San Samuel, Cachiyuyo De Llampos, Chile. American Mineralogist: Journal of Earth and Planetary Materials. vol. 55, no. 11-12, pp. 21142118. Retrieved from https://pubs.geoscienceworld.org/msa/ammin/article/55/1112/2114/540780/Tungstenian-wulfenites-Mina-San-Samuel-Cachiyuyo?casa_token=F_Ou_EytvwAAAAA:qHsM5CiJp1ziHtKEhYLACtfxm3iTE-fUItnIcJZNQLGO3Ul$\underline{\text { r } 0 \mathrm{HqWDLSzE} 2 \mathrm{BcdzBfBeF-U6}}$

Clausen, J.L., S. Taylor, S.L. Larson, A.J. Bednar, M. Ketterer, C.S. Griggs, ... and R.N. Bailey. 2007. Fate and Transport of Tungsten at Camp Edwards Small Arms Ranges. ERDC TR-07-5. In Cold Regions Research and Engineering Laboratory, US Army Engineer Research and Development Center, 72 Lyme Road, Hanover, NH. Retrieved from http://citeseerx.ist.psu.edu/viewdoc/download?doi=10.1.1.169.4648\&rep=rep1\&type=pdf

Cruywagen, J. J. 2000. Protonation, Oligomerization, and Condensation Reactions of Vanadate (V), Molybdate (VI), and Tungstate (VI). Advances in Inorganic Chemistry. vol. 49, pp. 127-182. https://doi.org/10.1016/S0898-8838(08)60270-6

Cui, M., and K.H. Johannesson. 2017. Comparison of tungstate and tetrathiotungstate adsorption onto pyrite. Chemical Geology. vol. 464, pp. 57-68. https://doi.org/10.1016/j.chemgeo.2016.11.034

Cui, M., T.j. Mohajerin, S. Adebayo, S. Datta, and K.H. Johannesson. 2020. Investigation of Tungstate Thiolation Reaction Kinetics and Sedimentary Molybdenum/Tungsten Enrichments: Implication for Tungsten Speciation in Sulfidic Waters and Possible Applications for Paleoredox Studies. Geochimica et Cosmochimica Acta. In press. https://doi.org/10.1016/j.gca.2020.04.004 
Datta, S., Vero, S.E., G.M. Hettiarachchi, and K. Johannesson. 2017. Tungsten Contamination of Soils and Sediments: Current State of Science. Current Pollution Reports. vol. 3, no. 1, pp. 55-64. https://doi.org/10.1007/s40726-016-0046-0

Davantès, A., and G. Lefèvre. 2015. In situ characterization of (poly) molybdate and (poly) tungstate ions sorbed onto iron (hydr) oxides by ATR-FTIR spectroscopy. The European Physical Journal Special Topics. vol. 224, no. 9, pp. 1977-1983. https://doi.org/10.1140/epjst/e2015-02514-8

Dold, B. 2003. Speciation of the Most Soluble Phases in a Sequential Extraction Procedure Adapted for Geochemical Studies of Copper Sulfide Mine Waste. Journal of Geochemical Exploration. vol. 80, no. 1, pp. 55-68. https://doi.org/10.1016/S0375-6742(03)00182-1

Dzombak, D. A., and F.M. Morel, 1990. Surface Complexation Modeling: Hydrous Ferric Oxide. John Wiley \& Sons.

Gammons, C. H., B.L. Pape, S.R. Parker, S.R. Poulson, and C.E. Blank. 2013. Geochemistry, water balance, and stable isotopes of a "clean" pit lake at an abandoned tungsten mine, Montana, USA. Applied geochemistry. vol. 36, pp. 57-69. https://doi.org/10.1016/j.apgeochem.2013.06.011

Guandalini, G.S., L. Zhang, E. Fornero, J.A. Centeno, V.P. Mokashi, P.A. Ortiz, ... and G.G. Chapman. 2011. Tissue distribution of tungsten in mice following oral exposure to sodium tungstate. Chemical research in toxicology. vol. 24, no. 4, pp. 488-493. https://doi.org/10.1021/tx200011k

Guo, Q., Y. Li, and L. Luo. 2019. Tungsten from typical magmatic hydrothermal systems in China and its environmental transport. Science of The Total Environment. vol. 657, pp. 1523-1534.

https://doi.org/10.1016/j.scitotenv.2018.12.146

Gustafsson, J. P. 2003. Modelling Molybdate and Tungstate Adsorption to Ferrihydrite. Chemical Geology. vo. 200, no. 1-2, pp. 105-15. https://doi.org/10.1016/S0009-2541(03)00161-X

Hällström, L., L. Alakangas, and O. Martinsson. 2018a. Geochemical Characterization of W, Cu and F Skarn Tailings at Yxsjöberg, Sweden. Journal of Geochemical Exploration. vol. 194, pp. 266-79. https://doi.org/10.1016/j.gexplo.2018.09.001

Hällström, L., L. Alakangas, and O. Martinsson. 2018b. Metal Release from Acidic and Near-Neutral pHConditions in Historical W, Cu and F Skarn Tailings at Yxsjöberg, Sweden. In 11th ICARD IMWA MWD Conference "Risk to Opportunity" (ICARD 2018), September 10-14, 2018, Pretoria, South Africa. vol. 1, pp. 351-356. Retrieved from https://www.imwa.info/docs/imwa 2018/IMWA2018 Hallstrom 351.pdf

Hällström, L., L. Alakangas, and O. Martinsson. 2019. Scheelite Weathering and Tungsten (W) Mobility in Historical Oxidic-Sulfidic Skarn Tailings at Yxsjöberg, Sweden. Environmental Science and Pollution Research. vol. 27, pp. 6180-6192. https://doi.org/10.1007/s11356-019-07305-1 
Harita, Y., T. Hori, and M. Sugiyama. 2005. Release of trace oxyanions from littoral sediments and suspended particles induced by $\mathrm{pH}$ increase in the epilimnion of lakes. Limnology and Oceanography. vol. 50, no. 2, pp. 636-645. https://doi.org/10.4319/lo.2005.50.2.0636

Huntsman, P., J. Skeaff, M. Pawlak, and R. Beaudoin. 2018. Transformation/dissolution characterization of tungsten and tungsten compounds for aquatic hazard classification. Integrated environmental assessment and management. vol. 14, no. 4, pp. 498-508. https://doi.org/10.1002/ieam.4040

Hur, H., and R.J. Reeder. 2016. Tungstate Sorption Mechanisms on Boehmite: Systematic Uptake Studies and X-Ray Absorption Spectroscopy Analysis. Journal of Colloid and Interface Science. vol. 461, pp. 249-60. https://doi.org/10.1016/j.jcis.2015.09.011

Inouye, L.S., R.P. Jones, and A.J. Bednar. 2006. Tungsten effects on survival, growth, and reproduction in the earthworm, Eisenia fetida. Environmental Toxicology and Chemistry: An International Journal. vol. 25, no. 3, pp. 763-768. https://doi.org/10.1897/04-578R.1

Johannesson, K.H., W.B. Lyons, E.Y. Graham, and K.A. Welch. 2000. Oxyanion Concentrations in Eastern Sierra Nevada Rivers-3. Boron, Molybdenum, Vanadium, and Tungsten. Aquatic Geochemistry. vol. 6, no. 1, pp. 19-46. https://doi.org/10.1023/A:1009622219482

Johannesson, K.H., H.B. Dave, T.J Mohajerin, and S. Datta. 2013. Controls on Tungsten Concentrations in Groundwater Flow Systems: The Role of Adsorption, Aquifer Sediment Fe(III) Oxide/Oxyhydroxide Content, and Thiotungstate Formation. Chemical Geology. vol. 351, 76-94.

https://doi.org/10.1016/j.chemgeo.2013.05.002

Kabata-Pendias, A., and A.B. Mukherjee. 2007. Trace elements from soil to human. Springer Science \& Business Media.

Kashiwabara, T., Y. Takahashi, T. Uruga, H. Tanida, Y. Terada, Y. Niwa, and M. Nomura. 2010. Speciation of tungsten in natural ferromanganese oxides using wavelength dispersive XAFS. Chemistry letters. vol. 39, no. 8, pp. 870-871. https://doi.org/10.1246/cl.2010.870

Kashiwabara, T., Y. Takahashi, M. Tanimizu, and A. Usui. 2011. Molecular-scale mechanisms of distribution and isotopic fractionation of molybdenum between seawater and ferromanganese oxides. Geochimica et Cosmochimica Acta. vol. 75, no. 19, pp. 5762-5784.

https://doi.org/10.1016/j.gca.2011.07.022

Kashiwabara, T., Y. Takahashi, M.A. Marcus, T. Uruga, H. Tanida, Y. Terada, and A. Usui. 2013. Tungsten Species in Natural Ferromanganese Oxides Related to Its Different Behavior from Molybdenum in Oxic Ocean. Geochimica et Cosmochimica Acta. vol. 106, pp. 364-78.

https://doi.org/10.1016/j.gca.2012.12.026

Kelly, A.D., M. Lemaire, Y.K. Young, J.H. Eustache, C. Guilbert, M.F. Molina, and K.K. Mann. 2013. In vivo tungsten exposure alters B-cell development and increases DNA damage in murine bone marrow. toxicological sciences. vol. 131, no. 2, pp. 434-446. https://doi.org/10.1093/toxsci/kfs324 
Kennedy, A.J., D.R. Johnson, J.M. Seiter, J.H. Lindsay, R.E. Boyd, A.J. Bednar, and P.G. Allison. 2012. Tungsten Toxicity, Bioaccumulation, and Compartmentalization into Organisms Representing Two Trophic Levels. Environmental Science \& Technology. vol. 46, no. 17, pp. 9646-52. https://doi.org/10.1021/es300606x

Koutsospyros, A., W. Braida, C. Christodoulatos, D. Dermatas, and N. Strigul. 2006. A Review of Tungsten: From Environmental Obscurity to Scrutiny. Journal of Hazardous Materials. vol. 136, no. 1, pp. 1-19. https://doi.org/10.1016/j.jhazmat.2005.11.007

Kühnel, D., W. Busch, T. Meißner, A. Springer, A. Potthoff, V. Richter, ... and K. Schirmer. 2009. Agglomeration of tungsten carbide nanoparticles in exposure medium does not prevent uptake and toxicity toward a rainbow trout gill cell line. Aquatic Toxicology. vol. 93, no. 2-3, pp. 91-99. https://doi.org/10.1016/j.aquatox.2009.04.003

Kwak, T.A. 2012. W-Sn skarn deposits: and related metamorphic skarns and granitoids. Elsevier.

Lassner, E., W.D. Schubert, E. Lüderitz, and H.U. Wolf. 2000. Tungsten, tungsten alloys, and tungsten compounds. Ullmann's Encyclopedia of Industrial Chemistry. https://doi-

org.proxy.queensu.ca/10.1002/14356007.a27 229

Leal-Ayala, D. R., J.M. Allwood, E. Petavratzi, T.J. Brown, G. Gunn. 2015. Mapping the Global Flow of Tungsten to Identify Key Material Efficiency and Supply Security Opportunities. Resources, Conservation and Recycling. vol. 103, pp. 19-28. https://doi.org/10.1016/j.resconrec.2015.07.003

Lin, C., R. Li, H. Cheng, J. Wang, and X. Shao. 2014. Tungsten distribution in soil and rice in the vicinity of the world's largest and longest-operating tungsten mine in China. PLoS One. vol. 9, no. 3, e91981.

https://doi.org/10.1371/journal.pone.0091981

Marinakis, K.I., and G.H. Kelsall. 1987. The Surface Chemical Properties of Scheelite (CaWO4) I. The Scheelite/Water Interface and CaWO4 Solubility. Colloids and Surfaces. vol. 25, pp. 369-385. https://doi.org/10.1016/0166-6622(87)80315-3

Matsubara, S., A. Kato, and K. Nagashima. 1984. Mpororoite and anthoinite from the Kara mine, Tasmania. Mineralogical Magazine. vol. 48, no. 348, pp. 397-400. https://doi.org/10.1180/minmag.1984.048.348.10

McClenaghan, M.B., A. Plouffe, and D. Layton-Matthews. 2014. Overview of tungsten indicator minerals scheelite and wolframite with examples from the Sisson W-Mo deposit, Canada. Application of Indicator Mineral Methods to Mineral Exploration, 7553, pp. 61-67. Retrieved from https://www.appliedgeochemists.org/images/stories/IAGS_2013/10-McClenaghan-etal.pdf

Menke, A., E. Guallar, and C.C. Cowie. 2016. Metals in urine and diabetes in US adults. Diabetes. vol. 65, no. 1, pp. 164-171. https://doi.org/10.2337/db15-0316 
Mills, S.J., A.G. Christy, M.S. Rumsey, and J. Spratt. 2016. The crystal chemistry of elsmoreite from the Hemerdon (Drakelands) mine, UK: hydrokenoelsmoreite-3 C and hydrokenoelsmoreite-6 R.

Mineralogical Magazine. vol. 80, no. 7, pp. 1195-1203. https://doi.org/10.1180/minmag.2016.080.058

Mohajerin, T.J, G.R. Helz, C.D. White, and K.H. Johannesson. 2014a. Tungsten Speciation in Sulfidic Waters: Determination of Thiotungstate Formation Constants and Modeling Their Distribution in Natural Waters. Geochimica et Cosmochimica Acta. vol. 144, pp. 157-72.

https://doi.org/10.1016/j.gca.2014.08.037

Mohajerin, T.J., A.W. Neal, K. Telfeyan, S.M. Sasihharan, S. Ford, N. Yang, ... and K.H. Johannesson. 2014b. Geochemistry of tungsten and arsenic in aquifer systems: a comparative study of groundwaters from West Bengal, India, and Nevada, USA. Water, Air, \& Soil Pollution. vol. 225, no. 1, 1792. https://doi.org/10.1007/s11270-013-1792-X

Mohajerin, T., G.R. Helz, and K.H. Johannesson. 2016. Tungsten-Molybdenum Fractionation in Estuarine Environments. Geochimica et Cosmochimica Acta. vol. 177, pp. 105-19. https://doi.org/10.1016/j.gca.2015.12.030

Montgomery, S.D. 2012. Kinetics of the Dissolution of Scheelite in Groundwater: Implications for Environmental and Economic Geology. MSc Thesis Dissertation, University of California, Riverside. Retrieved from https://escholarship.org/uc/item/6tp0x6k3

Newsom, H.E., K.W. Sims, P.D. Noll Jr, W.L. Jaeger, S.A. Maehr, and T.B. Beserra. 1996. The depletion of tungsten in the bulk silicate earth: constraints on core formation. Geochimica et Cosmochimica Acta. vol. 60, no. 7, pp. 1155-1169. https://doi.org/10.1016/0016-7037(96)00029-4

Nigra, A.E., B.V. Howard, J.G. Umans, L. Best K.A. Francesconi, W. Goessler, ... and A. Navas-Acien. 2018. Urinary tungsten and incident cardiovascular disease in the Strong Heart Study: An interaction with urinary molybdenum. Environmental research. vol. 166, pp. 444-451.

https://doi.org/10.1016/j.envres.2018.06.015

Parrish, I.S. 1977. Mineral catalog for the Mount Pleasant deposit of Brunswick tin mines. The Canadian Mineralogist. vol. 15, no. 1, pp. 121-126. Retrived from

https://pubs.geoscienceworld.org/canmin/article/15/1/121/11148/Mineral-catalog-for-the-Mount-Pleasant$\underline{\text { deposit-of }}$

Petrunic, B.M., and T.A. Al. 2005. Mineral/Water Interactions in Tailings from a Tungsten Mine, Mount Pleasant, New Brunswick. Geochimica et Cosmochimica Acta. vol. 69, no. 10, pp. 2469-2483. https://doi.org/10.1016/j.gca.2004.10.031

Petrunic, B.M., T.A. Al, and L. Weaver. 2006. A Transmission Electron Microscopy Analysis of Secondary Minerals Formed in Tungsten-Mine Tailings with an Emphasis on Arsenopyrite Oxidation. Applied Geochemistry. vol. 21, no. 8, pp. 1259-1273. https://doi.org/10.1016/j.apgeochem.2006.06.003 
Petrunic, B.M., T.A. Al, L. Weaver and D. Hall. 2009. Identification and characterization of secondary minerals formed in tungsten mine tailings using transmission electron microscopy. Applied Geochemistry. vol. 24, no. 12, pp. 2222-2233. https://doi.org/10.1016/j.apgeochem.2009.09.014

Pokrovsky, O.S., and J. Schott. 2002. Iron Colloids/Organic Matter Associated Transport of Major and Trace Elements in Small Boreal Rivers and their Estuaries (NW Russia). Chemical Geology. vol. 190, no. 1-4, pp. 141-179. https://doi.org/10.1016/S0009-2541(02)00115-8

Pyatt, F.B., and A.J. Pyatt. 2004. The bioaccumulation of tungsten and copper by organisms inhabiting metalliferous areas in North Queensland: an evaluation of potential health effects. Journal of Environmental Health Research. vol. 3, no. 1, pp. 13-18. Retrieved from https://www.semanticscholar.org/paper/The-bioaccumulation-of-tungsten-and-copper-by-areas-PyattPyatt/5ea8d3d88f38477cdc071780dc00e42bedcf02e8

Raman, K.V., and M.L. Jackson. 1965. Rutile and anatase determination in soils and sediments. American Mineralogist: Journal of Earth and Planetary Materials. vol. 50, no. 7-8, pp. 1086-1092. Retrieved from https://pubs.geoscienceworld.org/msa/ammin/article/50/7-8/1086/540124/Rutile-and-anatasedetermination-in-soilsand?casa_token=pdT8WVunmv0AAAAA:0p4tCPle9LylIGduLInvdEDw3F_vQoHfETaaz2uGxuBCX9q x0_BIiS3y26Zd7y9StikpMWZB

Ririe, G.T. 1989. Evaporites and strata-bound tungsten mineralization. Geology. vol. 17, no. 2, pp. 139143. https://doi.org/10.1130/0091-7613(1989)017<0139:EASBTM>2.3.CO;2

Rudnick, R.L., and S. Gao. 2003. Composition of the continental crust. The Crust. vol. 3, pp. 1-64. https://doi.org/10.1016/B0-08-043751-6/03016-4

Sachdeva, S., P. Kushwaha, and S.J.S Flora. 2013. Effects of sodium tungstate on oxidative stress enzymes in rats. Toxicology mechanisms and methods. vol. 23, no. 7, pp. 519-527.

https://doi.org/10.3109/15376516.2013.787132

Sadiq, M., K.M. AlThagafi, and A.A. Mian. 1992. Preliminary evaluation of metal contamination of soils from the Gulf war activities. Bulletin of environmental contamination and toxicology. vol., 49, no. 5, pp. 633-639. https://doi.org/10.1007/BF00200774

Sahama, T.G. 1981. The Secondary Minerals of Tungsten, a Review. The Mineralogical Record. pp. 8187. Retrieved from https://rruff-2.geo.arizona.edu/uploads/MR12 81.pdf

Sallman, B., s. Rakshit, and G. Lefèvre. 2018. Influence of phosphate on tungstate sorption on hematite: A macroscopic and spectroscopic evaluation of the mechanism. Chemosphere. vol. 213, pp. 596-601. https://doi.org/10.1016/j.chemosphere.2018.09.157

Seiler, R.L., K.G. Stollenwerk, and J.R. Garbarino. 2005. Factors Controlling Tungsten Concentrations in Ground Water, Carson Desert, Nevada. Applied Geochemistry. vol. 20, no. 2, pp. 423-41. https://doi.org/10.1016/j.apgeochem.2004.09.002 
Sen Tuna, G., and W. Braida. 2014. Evaluation of the adsorption of mono-and polytungstates onto different types of clay minerals and pahokee peat. Soil and Sediment Contamination: An International Journal. vol. 23, no. 8, pp. 838-849. https://doi.org/10.1080/15320383.2014.809049

Shimobayashi, N., M. Ohnishi, and K. Tsuruta. 2012. Secondary Tungsten Minerals in Quartz Veins in the Ishidera Area, Wazuka, Kyoto Prefecture, Japan: Anthoinite, Mpororoite, and Fe-Free Hydrokenoelsmoreite. Journal of Mineralogical and Petrological Sciences. vol. 107, no. 1, pp. 33-38. https://doi.org/10.2465/jmps.111020f

Sohrin, Y., K. Isshiki, T. Kuwamoto, and E. Nakayama. 1987. Tungsten in north Pacific waters. Marine Chemistry. vol. 22, no. 1, pp. 95-103. https://doi.org/10.1016/0304-4203(87)90051-X

Sposito, G. 1998. On points of zero charge. Environmental science \& technology. vol. 32, no. 19, pp. 2815-2819. https://doi.org/10.1021/es9802347

Steenstra, P., N. Strigul, and J. Harrison. 2020. Tungsten in Washington State surface waters. Chemosphere. vol. 242, 125151. https://doi.org/10.1016/j.chemosphere.2019.125151

Strigul, N. 2010. Does Speciation Matter for Tungsten Ecotoxicology? Ecotoxicology and Environmental Safety. vol. 73, no. 6, pp. 1099-1113. https://doi.org/10.1016/j.ecoenv.2010.05.005

Strigul, N., A. Koutsospyros, and C. Christodoulatos. 2010. Tungsten Speciation and Toxicity: Acute Toxicity of Mono- and Poly-Tungstates to Fish. Ecotoxicology and Environmental Safety. vol. 73, no. 2, pp. 164-171. https://doi.org/10.1016/j.ecoenv.2009.08.016

Sun, J., B.C. Bostick. 2015. Effects of tungstate polymerization on tungsten (VI) adsorption on ferrihydrite. Chemical Geology. vol. 417, no. 21-31. https://doi.org/10.1016/j.chemgeo.2015.09.015

Tarassov, M.P., and E.D. Tarassova. 2018. Structural and Chemical Evolution of Mineral Forms of Tungsten in the Oxidation Zone of the Grantcharitza Deposit (Western Rhodopes, Bulgaria). Bulgarian Chemical Communications. vol. 50, Special Issue J. pp. 270-280. Retrieved from https://www.researchgate.net/publication/327381700 Structural and chemical evolution of mineral for ms of tungsten in the oxidation zone of the Grantcharitza deposit Western Rhodopes Bulgaria

Tessier, A., P.G. Campbell, and M. Bisson. 1979. Sequential extraction procedure for the speciation of particulate trace metals. Analytical chemistry. vol. 51, no. 7, pp. 844-851. https://doi-

org.proxy.queensu.ca/10.1021/ac50043a017

Turkez, H., E. Sonmez, O. Turkez, Y.I. Mokhtar, A.D. Stefano, and G. Turgut. 2014. The risk evaluation of tungsten oxide nanoparticles in cultured rat liver cells for its safe applications in nanotechnology. Brazilian Archives of Biology and Technology. vol. 57, no. 4, pp. 532-541. https://doi.org/10.1590/S1516-89132014005000021

VanderSchee, C.R., D. Kuter, A.M. Bolt, F.C. Lo, R. Feng, J. Thieme, ... and D.S. Bohle. 2018. Accumulation of persistent tungsten in bone as in situ generated polytungstate. Communications Chemistry. vol. 1, no. 1, pp. 1-6. https://doi.org/10.1038/s42004-017-0007-6 
Vissenberg, M. J., L.J. Joosten, M.M. Heffels, A.J. van Welsenes, V.H.J. De Beer, R.A. van Santen, and J.R. van Veen. 2000. Tungstate versus molybdate adsorption on oxidic surfaces: a chemical approach. The Journal of Physical Chemistry B. vol. 104, no. 35, pp. 8456-8461. https://doiorg.proxy.queensu.ca/10.1021/jp993754c

Viers, J., B. Dupré, and J. Gaillardet. 2009. Chemical composition of suspended sediments in World Rivers: New insights from a new database. Science of the total Environment. vol. 407, no. 2, pp. 853-868. https://doi.org/10.1016/j.scitotenv.2008.09.053

Vorlicek, T.P., M.D. Kahn, Y. Kasuya, and G.R. Helz. 2004. Capture of Molybdenum in Pyrite-forming Sediments: Role of Ligand-Induced Reduction by Polysulfides. Geochimica et Cosmochimica Acta. vol. 68, no. 3, pp. 547-556. https://doi.org/10.1016/S0016-7037(00)00444-7

Wasel, O., and J.L. Freeman. 2018. Comparative Assessment of Tungsten Toxicity in the Absence or Presence of Other Metals. Toxics. vol. 6, no. 4, pp. 66. https://doi.org/10.3390/toxics6040066

Watanabe, Y., T. Kashiwabara, J.L. Ishibashi, O. Sekizawa, K. Nitta, T. Uruga, and Y. Takahashi. 2017. Different Partitioning Behaviors of Molybdenum and Tungsten in Sediment-Water System Under Various Redox Conditions. Chemical Geology. vol. 471, pp. 38-51.

https://doi.org/10.1016/j.chemgeo.2017.09.009

Werner, A.B., W.D. Sinclair, and E.B. Amey. 2014. International Strategic Mineral Issues Summary Report--Tungsten. US Government Printing Office. Retrieved from https://pubs.usgs.gov/pdf/circular/pdf/c930-o.pdf

Wilson, B., and F.B. Pyatt. 2006. Bio-availability of tungsten in the vicinity of an abandoned mine in the English Lake District and some potential health implications. Science of the total environment, 370(2-3), 401-408.

Wilson, B., F.B. Pyatt. 2009. Bioavailability of tungsten and associated metals in calcareous soils in the vicinity of an ancient metalliferous mine in the Corbieres area, Southwestern France. Journal of Toxicology and Environmental Health, Part A. vol. 72, no. 13, pp. 807-816. https://doi.org/10.1080/15287390902800389

Witten, M.L., P.R. Sheppard, and B.L. Witten. 2012. Tungsten toxicity. Chemico-biological interactions. vol. 196, no. 3, pp. 87-88. https://doi.org/10.1016/j.cbi.2011.12.002

$\mathrm{Xu}$, N., C. Christodoulatos, and W. Braida. 2006. Modeling the competitive effect of phosphate, sulfate, silicate, and tungstate anions on the adsorption of molybdate onto goethite. Chemosphere. vol. 64, no. 8, pp. 1325-1333. https://doi.org/10.1016/j.chemosphere.2005.12.043 


\section{Chapter 3: Factors Controlling Tungsten Mobility in W-Cu Skarn Tailings from the Cantung Mine, Northwest Territories, Canada}

\subsection{Abstract}

As concerns about the potential toxicity of tungsten have only recently emerged, there is a lack of literature regarding its fate and transport in the environment. In particular, few studies have addressed the mobility of tungsten in mine waste, which could act as a point source for metal leaching. This study examines the behaviour of tungsten in acidic floodplain tailings and circumneutral impoundment tailings at the Cantung Mine in the Northwest Territories, Canada. In the Cantung deposit, tungsten is present as scheelite $\left(\mathrm{CaWO}_{4}\right)$, copper is hosted in chalcopyrite $\left(\mathrm{CuFeS}_{2}\right)$, and gangue mineralogy consists of abundant pyrrhotite $\left(\mathrm{Fe}_{1-\mathrm{x}} \mathrm{S}\right)$, calc-silicate minerals, and carbonate minerals. Nine surface water samples, five tailings porewater samples (collected via suction lysimeters), and thirteen tailings samples were collected from the Cantung Mine's tailings. For surface waters, both filtered $(0.45 \mu \mathrm{m})$ and unfiltered aliquots were collected to compare dissolved and particulate element concentrations.

Water samples have been analyzed by high resolution inductively coupled mass spectrometry (HR-ICP-MS), yielding tungsten concentrations ranging from 5.3 to $26.3 \mu \mathrm{g} / \mathrm{L}$ in samples with $\mathrm{pH}$ values between $7.05-8.05$, whereas samples below $\mathrm{pH} 7.05$ have concentrations below the detection limit of $100 \mathrm{ng} / \mathrm{L}$. Tungsten and iron concentrations are both on average $1.6 \mathrm{x}$ higher in unfiltered aliquots compared to filtered aliquots, suggesting that tungsten is transported as dissolved species but is also adsorbed to suspended Fe-oxyhydroxide minerals at neutral $\mathrm{pH}$. Tailings were analyzed by scanning electron microscopy (SEM) paired with automated mineralogy software (MLA), synchrotron-based micro X-ray diffraction and fluorescence ( $\mu$ XRD-XRF), and partial leach digestions with ICP-MS (cold and hot hydroxylamine hydrochloride, aqua regia, Li-metaborate fusion, and 4-acid digestion). The scheelite content of samples from Tailings Pond 3 (TP3) and the Flat River Tailings (FRT) are similar (0.15 wt.\% 
and $0.21 \mathrm{wt} . \%$, respectively), and scheelite shows no evidence of alteration. Synchrotron-based $\mu$ XRD of Fe-oxyhydroxide minerals in the FRT identified goethite $(\mathrm{FeOOH})$ and lepidocrocite $(\gamma$-FeOOH$)$, whereas $\mu$ XRD spectra of pyrrhotite rims from TP3 do not match Fe-minerals, with the exception of rare rims that match hematite $\left(\mathrm{Fe}_{2} \mathrm{O}_{3}\right)$ and maghemite $\left(\gamma-\mathrm{Fe}_{2} \mathrm{O}_{3}\right)$. The $\mu \mathrm{XRF}$ maps of the hematite-maghemite rims have prominent tungsten peaks, which represent included scheelite grains and possibly structurally incorporated tungsten, likely formed during ore processing. The hydroxylamine leaches yield higher tungsten concentrations in tailings samples from the impoundments than samples from the FRT, suggesting the tailings impoundments have more tungsten that is associated with poorly crystalline and amorphous Fe-oxyhydroxide phases than the FRT. Over time, labile-hosted tungsten in the FRT may have been washed down the Flat River during Fe-oxyhydroxide recrystallization and high energy flooding events.

\subsection{Introduction}

Tungsten is one of the most understudied metals with regard to its geochemical mobility in the environment, in part due to its historical reputation as being environmentally benign (Koutospyros et al., 2006; Petkewich, 2009). Concerns about the potential toxicity of tungsten emerged in the early 2000's, with the United States Centers for Disease Control (CDC) suggesting elevated concentrations of tungsten in groundwater $(0.27-742 \mu \mathrm{g} / \mathrm{L}$; Seiler et al., 2005) and drinking water $(0.25-337 \mu \mathrm{g} / \mathrm{L}$; ATDSR, 2005) as a potential cause of a cluster of childhood leukemia in Fallon, Nevada (Koutospyros et al., 2006). Tungsten was classified as an emerging contaminant by the United States Environmental Protection Agency (EPA) in 2008 (US EPA, 2008), and has been the subject of increased research activity with regards to its toxicity and environmental mobility (Datta et al., 2017; Strigul, 2010; Kennedy et al., 2012). Few studies have addressed tungsten's geochemical mobility in mine waste, which may act as a potential point source for metal leaching into the environment (Petrunic and Al, 2005; Hällström et al., 2018; Hällström et al., 2019). As tungsten has no substitutes for many of its industrial applications, tungsten production by mining is expected to increase (Brown and Pitfield, 2014; Leal-Ayala et al., 2015). 
Understanding the behaviour of tungsten in the mining environment is therefore critical for ensuring responsible development of new and existing mines and for remediation of legacy mines.

Over $70 \%$ of global tungsten production is from mining of skarn deposits (Kwak, 2012), where tungsten is mineralized primarily as scheelite $\left(\mathrm{CaWO}_{4}\right)$, and commonly accompanied by carbonate, sulfide, and calc-silicate minerals. Tailings impoundments can be large surface repositories of tungsten with grades comparable to ore deposits. For example, the average grade of the Cantung Tailings is $\sim 0.3$ wt.\% W (Jamieson et al., 2019), whereas tungsten ore deposits are between $0.06-1.2$ wt.\% W (LealAyala et al., 2015). Highly reactive minerals (e.g. sulfide and carbonate minerals) have a large impact on the $\mathrm{pH}$, redox conditions, and ionic composition of tailings leachate, and the mobility of well-known deleterious elements (e.g. As, $\mathrm{Cu}, \mathrm{Zn}$, and $\mathrm{Pb}$ ) has been thoroughly studied as a function of these reactions (Kimball et al., 2010; Bowell et al., 2014; Gutiérrez et al., 2016). Evidence for mineral-water reactions affecting the mobility of tungsten in tailings is lacking, and can currently only be predicted based on analogues from other environmental systems and laboratory studies.

Tungsten behaves similarly to molybdenum in natural waters, forming anionic species in the $\mathrm{W}(\mathrm{VI})$ valence state. The dominant species in oxidized waters with circumneutral to alkaline $\mathrm{pH}$ is the monomeric tungstate anion $\left(\mathrm{WO}_{4}{ }^{2-}\right)$ (Datta et al., 2017). Tungstate protonates and polymerizes at acidic $\mathrm{pH}$ to form polytungstate species (e.g. $\mathrm{HWO}_{4}^{-}, \mathrm{W}_{7} \mathrm{O}_{24}{ }^{6-}$ ) (Cruywagen, 2000), and in sulfidic waters with neutral to alkaline $\mathrm{pH}$, thiotungstate species (e.g. $\mathrm{WS}_{4}{ }^{2-}$ ) have been observed (Mohajerin et al., 2014; Mohajerin et al., 2016; Cui et al., 2020). Adsorption-desorption reactions have proven to be a primary control on tungsten mobility in natural systems (Johannesson et al., 2000; Pokrovsky and Schott, 2002; Seiler et al., 2005; Bednar et al., 2008; Bednar et al., 2009; Gammons et al., 2013; Johannesson et al., 2013; Kashiwabara et al., 2013; Mohajerin et al., 2014; Mohajerin et al., 2016; Watanabe et al., 2017; Bostick et al., 2018; Guo et al., 2019; Cui et al., 2020). Being anionic, tungsten species adsorb to mineral surfaces at circumneutral to acidic pH (Dzombak and Morel, 1990), making tungsten most mobile in alkaline waters. Scheelite is commonly regarded as relatively stable and insoluble, and no mechanisms 
have been provided as to its weathering behaviour in acidic sulfate-dominated waters characteristic of acid rock drainage (ARD). In order to address the dearth of information regarding tungsten behaviour in mine tailings, we have studied the W-rich tailings from the Cantung Mine, Northwest Territories. Tailings porewaters, surface waters, and tailings samples were sampled from the Cantung tailings and water samples were collected from the adjacent Flat River. This study addresses the geochemical and physiographical factors affecting the behaviour of tungsten and its host mineral scheelite in circumneutral, unoxidized impoundment tailings in contrast to acidic, oxidized floodplain tailings.

\subsection{Methods}

\subsubsection{Study Area}

The Cantung Mine is located within the Mackenzie Mountains in the Northwest Territories, Canada (Fig. 3.1), in a tight U-shaped valley known as the Flat River valley (Appendix D). The region has a subarctic climate (Dfc Köppen climate classification), receiving $650 \mathrm{~mm}$ of annual precipitation split evenly between snow and rain (Environment Canada, 2019). In the center of the valley lies the Flat River and its floodplain, which has headwaters just northwest of the mine. The river has a meandering morphology, with numerous oxbow lakes and abandoned channels. Stream sediment consists of sand to boulder sized clasts. Groundwater flow is perpendicular to the valley's center line with some side sweep in the direction of Flat River flow (O'Kane Consultants Inc. and Geochemistry, 2017). Downstream, the Flat River discharges into the South Nahanni River and eventually the Nahanni River, ultimately joining the Mackenzie River draining to the Arctic Ocean (Parks Canada, 2019). 


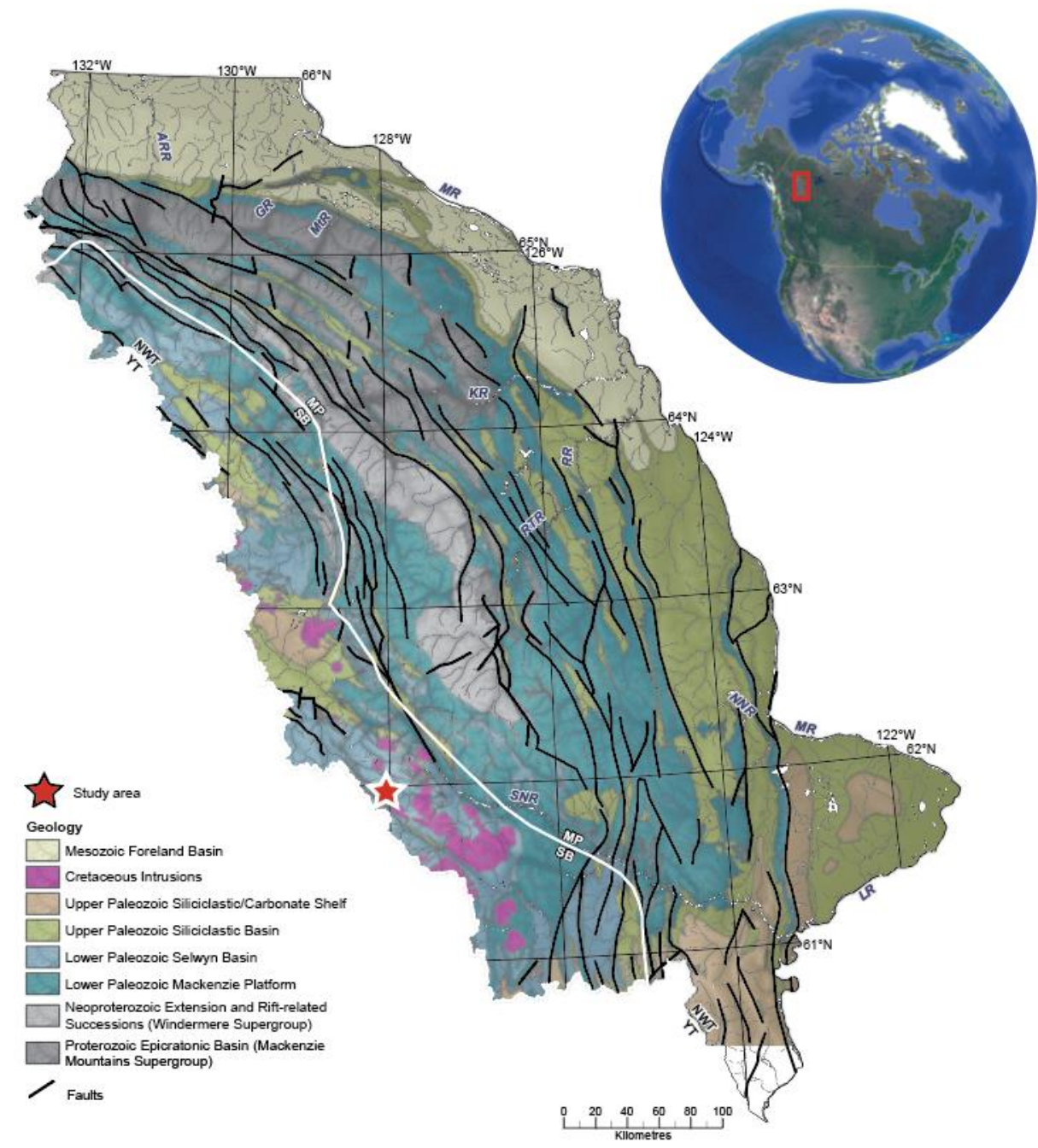

Figure 3.1 Location of the Cantung Mine in the Northwest Territories, Canada, modified from Ootes et al. (2013). ARR = Arctic Red River; GR = Gayna River; KR = Keele River; $L R=$ Liard River; MP = Mackenzie Platform; MR $=$ Mackenzie River; MtR $=$ Mountain River; NNR $=$ North Nahanni River; RR $=$ Redstone River; NWT $=$ Northwest Territories; RTR = Ravensthroat River; SB = Selwyn Basin; SNR = South Nahanni River; YT = Yukon Territory.

The Cantung deposit is a W-Cu skarn hosted within Cambrian carbonate strata of the Selwyn Basin (Ootes et al., 2013), with mineralization occurring in two main ore bodies: The Open Pit orebody, and the underground E-zone orebody (Delaney and Bakker, 2014). Tungsten is present as scheelite in both orebodies, with abundant calcite $\left(\mathrm{CaCO}_{3}\right)$, dolomite $\left(\mathrm{CaMg}\left(\mathrm{CO}_{3}\right)_{2}\right)$, pyrrhotite $\left(\mathrm{Fe}_{1-\mathrm{x}} \mathrm{S}\right)$, mica, and calc-silicate minerals. In the Open Pit orebody, pyrrhotite is hexagonal, whereas pyrrhotite in the E-Zone is predominantly monoclinic (Mesh Environmental, 2008). Copper is hosted in chalcopyrite $\left(\mathrm{CuFeS}_{2}\right)$, 
and accessory minerals include minor sphalerite $(\mathrm{ZnS})$, native bismuth $(\mathrm{Bi})$, apatite $\left(\mathrm{Ca}_{5}\left(\mathrm{PO}_{4}\right)_{3}(\mathrm{Cl}, \mathrm{F}, \mathrm{OH})\right.$, and gold (Mathieson and Clark, 1984; Elongo et al., 2020).

The mine opened in 1962 with production from the Open Pit orebody, using gravity and flotation techniques to concentrate scheelite (Silke, 2009). Tailings were deposited directly into the Flat River during the first three years of production, forming the Flat River Tailings (FRT; Fig. 3.2). Between 1965 - 1973, tailings were deposited in Tailings Pond 1 (TP1) and Tailings Pond 2 (TP2) (pHase Geochemistry, 2014) (Fig. 3.2). The mill was destroyed by a fire in 1966, and replaced with an upgraded milling process that added roasting and magnetic separation of pyrrhotite from scheelite concentrate (Cummings and Bruce, 1977; Silke, 2009). Production from the E-zone started in 1973, with tailings deposition changing to Tailings Pond 3 (TP3) (Cummings and Bruce, 1977). The mine closed due to low tungsten prices in 1986, but reopened in 2001. Tailings were deposited in Tailings Pond 4 (TP4) from 2007 - 2013, and then in Tailings Pond 5 (TP5) until mine closure in 2015 (pHase Geochemistry, 2014; Delaney and Bakker, 2015). The mine site is currently under care and maintenance by the Canadian federal government. Acidic conditions prevail in the FRT as a result of pyrrhotite oxidation and carbonate exhaustion, and are characterized by ochreous Fe-oxyhydroxide minerals, gypsum $\left(\mathrm{CaSO}_{4}\right)$, and jarosite $\left(\mathrm{KFe}_{3}^{3+}(\mathrm{OH})_{6}\left(\mathrm{SO}_{4}\right)_{2}\right)($ Fig. 3.2). Tailings Ponds 1 and 2 have been covered with $1-2 \mathrm{~m}$ of till, whereas TP3, TP4, and TP5 are exposed to atmosphere and are partially oxidized and unsaturated at surface, but are unoxidized and saturated at depth (pHase Geochemistry, 2014).

\subsubsection{Tailings and Water Sampling}

Eleven surface water samples (including two duplicates), five porewater samples, and sixteen tailings samples (including three duplicates) were collected from the Cantung Mine tailings in July 2018 (Appendix B and C). Tailings were sampled from TP3, TP4, TP5, and the FRT (Table 3.1). One porewater sample was extracted from TP3, and five from the FRT. Three surface water samples (and one 
duplicate) were taken from a shallow stream on TP5, which ends as a small pond on TP5. The source of the stream is water that is pumped from the underground mine. Five water samples were taken from the FRT: One from the pond at the base of TP2 (FRT-SW-01), two from an orange pond adjacent to the Flat River (FRT-SW-02 and FRT-SW-02DUP), and two from a shallow ephemeral channel connected to the Flat River (FRT-SW-03 and FRT-SW-04). Two surface water samples were collected from the Flat River: One from $\sim 2 \mathrm{~km}$ upstream of the mine, and one from the river flowing through the FRT. Tailings and water samples were collected from the tailings impoundments and the FRT to contrast the behaviour of tungsten and scheelite in relatively fresh tailings (TP3, TP4, TP5) and tailings which have had prolonged exposure to acidic conditions (FRT). The collection locations of tailings and water samples are shown in figure 2 (Appendix A). 


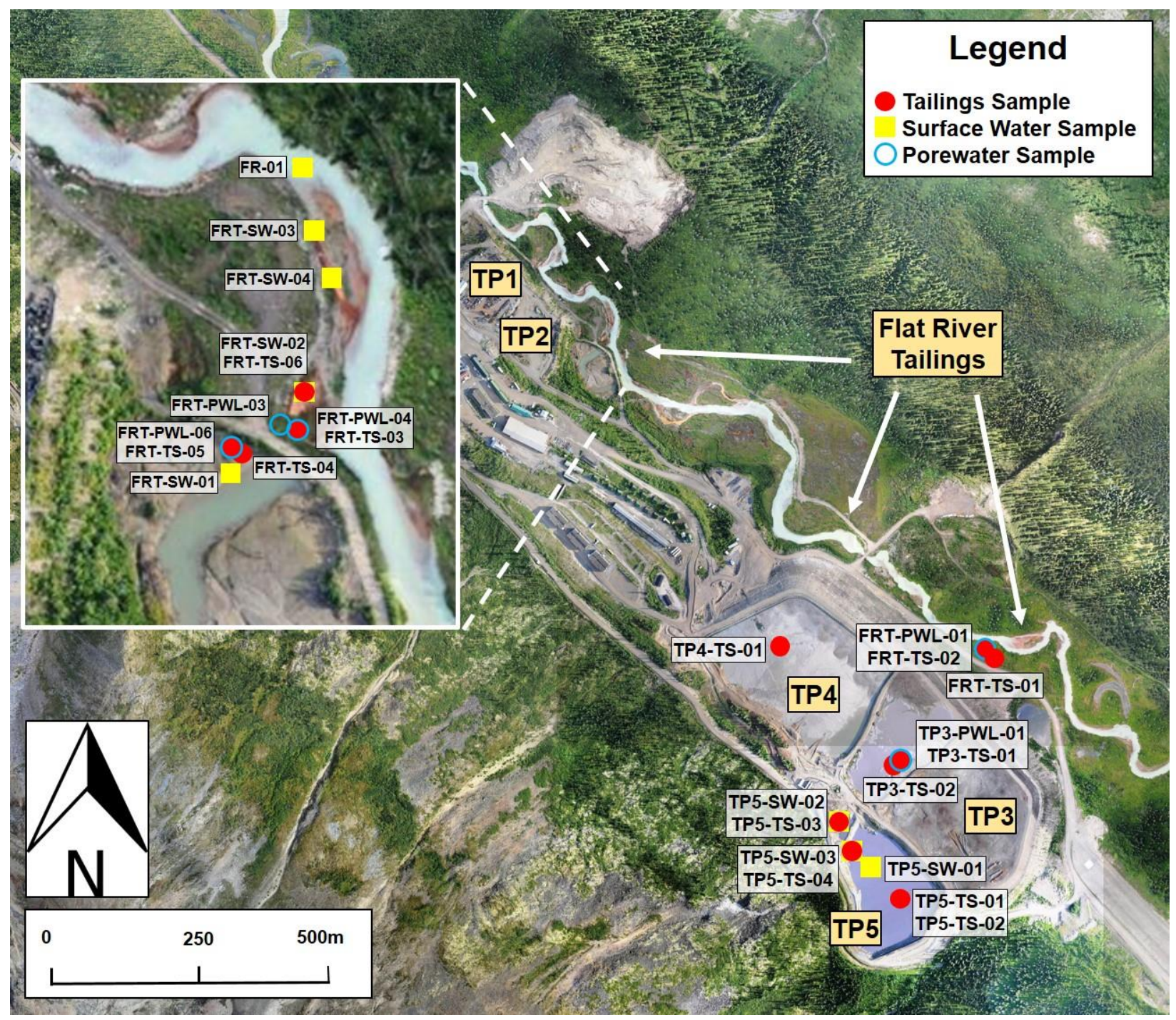

Figure 3.2 Airphoto of the Cantung Mine site with sampling locations. Note that the airphoto was taken in 2014 during active tailings deposition in TP5, which currently has supernatant only on the north side of the pond. The pond at the base of TP2 where FRT-SW-01 was taken was full during sampling, with tailings exposure restricted to small beaches.

Porewaters were collected using Soil Moisture ${ }^{\mathrm{TM}}$ suction lysimeters, which in a study by Rollo (2003) have yielded similar solute concentrations to porewaters extracted by squeezing tailings cores. The benefit of using suction lysimeters is that they sample porewater from a larger volume of tailings than core-squeezing techniques, at the expense of lower spatial resolution (Rollo, 2003). The porous ceramic cup at the base of the lysimeters were soaked and rinsed in DI water for 24 hours before installation. 
Lysimeters were pumped to a vacuum of 30 - 40 centibar and left for four days before water collection. The yield of porewater from the lysimeters was highly variable; some produced no water at all, some produced small amounts $(\sim 30 \mathrm{~mL})$, whereas others produced enough water for all planned analyses $(>60$ $\mathrm{mL}$ ). Water samples were collected in four aliquots where sample volume was sufficient (Appendix C). Three aliquots were collected for elemental analysis in trace metal certified (iChem) Nalgene ${ }^{\mathrm{TM}}$ bottles: filtered and acidified with ultra-high purity $70 \% \mathrm{HNO}_{3}$ (to $1 \%$ by volume), unfiltered and acidified with $\mathrm{HNO}_{3}$, and filtered and acidified with $\mathrm{HNO}_{3}$ and trace $\mathrm{HF}$. Unfiltered aliquots were taken to compare between particulate and "dissolved" tungsten concentrations. Hydrofluoric acid was added upon arrival at the lab to test tungsten preservation during transport. Samples were filtered with $0.45 \mu \mathrm{m}$ Thermo Scientific ${ }^{\mathrm{TM}}$ Target $2^{\mathrm{TM}}$ nylon syringe filters. The fourth aliquot for anion analyses was filtered but not acidified. All bottles and syringes were rinsed three times with sample water before collection. Three field blanks were collected for elemental analysis: one adjacent to the Flat River upstream of the mine, one on the FRT, and one on TP5. Field blanks are 18.2 M $\Omega$ deionized water, and were filtered and acidified. 
Table 3.1 Metadata and field notes for all tailings samples collected. FRT $=$ Flat River Tailings, TP3 = Tailings Pond 3, TP4 = Tailings Pond 4, TP5 = Tailings Pond 5, TS $=$ Tailings Sample.

\begin{tabular}{|c|c|c|c|c|c|c|}
\hline $\begin{array}{l}\text { Tailings } \\
\text { Sample ID }\end{array}$ & Location & Sample Depth & Color & $\begin{array}{c}\text { Water } \\
\text { Content }\end{array}$ & Oxidation & Notes \\
\hline FRT-TS-01 & $\begin{array}{l}\text { FRT near base } \\
\quad \text { of TP3 }\end{array}$ & $10 \mathrm{~cm}$ depth & Orange & Dry & Yes & Yellow clumps in tailings. \\
\hline FRT-TS-02 & $\begin{array}{l}\text { FRT near base } \\
\text { of TP3 }\end{array}$ & $60 \mathrm{~cm}$ depth & Orange & Moist & Yes & Two metres from bank of Flat River. \\
\hline FRT-TS-03 & $\begin{array}{l}\text { FRT adjacent } \\
\text { to stagnant } \\
\text { orange pond }\end{array}$ & $70 \mathrm{~cm}$ depth & Grey and orange & Saturated & $\begin{array}{l}\text { Oxidized with some } \\
\text { unoxidized pods. } \\
\text { Heterogeneous }\end{array}$ & $\begin{array}{c}\text { On bank } 1 \mathrm{~m} \text { above orange pond adjacent to } \\
\text { Flat River. Lots of organic material. Coarse } \\
\text { material at bottom of auger hole }\end{array}$ \\
\hline $\begin{array}{l}\text { FRT-TS- } \\
\text { 03DUP }\end{array}$ & $\begin{array}{l}\text { FRT adjacent } \\
\text { to stagnant } \\
\text { orange pond }\end{array}$ & $70 \mathrm{~cm}$ depth & Grey and orange & Saturated & $\begin{array}{l}\text { Oxidized with some } \\
\text { unoxidized pods. } \\
\text { Heterogeneous }\end{array}$ & $\begin{array}{c}\text { Duplicate of FRT-TS-03. Duplicate taken from } \\
\text { new auger hole due to lack of material in first } \\
\text { hole. }\end{array}$ \\
\hline FRT-TS-04 & $\begin{array}{l}\text { FRT pond at } \\
\text { base of TP1 }\end{array}$ & $15 \mathrm{~cm}$ depth & Red & Moist & Yes & $\begin{array}{l}\text { Lots of organics, sample taken } 1 \mathrm{~m} \text { from } \\
\text { surface water. }\end{array}$ \\
\hline FRT-TS-05 & $\begin{array}{l}\text { FRT pond at } \\
\text { base of TP1 }\end{array}$ & $70 \mathrm{~cm}$ depth & Grey and green & Saturated & Yes & - \\
\hline FRT-TS-06 & $\begin{array}{l}\text { FRT stagnant } \\
\text { orange pond }\end{array}$ & $\begin{array}{l}\text { Benthic tailings, } \\
\text { under } 6 \text { inches of } \\
\text { water }\end{array}$ & $\begin{array}{l}\text { Orange-red with } \\
\text { grey pods }\end{array}$ & Saturated & Yes & $\begin{array}{l}\text { Bottom of pond had organic matter and coarser } \\
\text { material, heterogeneous. Surface of pond had } \\
\text { extensive biofilm, pond water was cloudy }\end{array}$ \\
\hline $\begin{array}{l}\text { FRT-TS- } \\
\text { 06DUP }\end{array}$ & $\begin{array}{l}\text { FRT stagnant } \\
\text { orange pond }\end{array}$ & $\begin{array}{l}\text { Benthic tailings, } \\
\text { under } 6 \text { inches of } \\
\text { water }\end{array}$ & $\begin{array}{l}\text { Orange-red with } \\
\text { grey pods }\end{array}$ & Saturated & Yes & Duplicate of FRT-TS-06. \\
\hline TP3-TS-01 & TP3 & $70 \mathrm{~cm}$ depth & Grey & Saturated & No & - \\
\hline TP3-TS-02 & TP3 & $10 \mathrm{~cm}$ depth & Orange & Moist & Yes & - \\
\hline TP4-TS-01 & TP4 & $10 \mathrm{~cm}$ depth & Orange and grey & Moist & Some & $\begin{array}{c}\text { Some pods of unoxidized tailings, } \\
\text { heterogeneous. }\end{array}$ \\
\hline TP5-TS-01 & TP5 & $80 \mathrm{~cm}$ depth & Grey & Saturated & None & - \\
\hline TP5-TS-02 & TP5 & $10 \mathrm{~cm}$ depth & $\begin{array}{l}\text { Grey to light } \\
\text { brown }\end{array}$ & Moist & Some & - \\
\hline TP5-TS-03 & $\begin{array}{l}\text { TP5 pond inlet } \\
\text { stream }\end{array}$ & $\begin{array}{l}\text { Under } \sim 10 \mathrm{~cm} \text { of } \\
\text { water }\end{array}$ & $\begin{array}{l}\text { Grey with some } \\
\text { orange }\end{array}$ & Saturated & On surface & $\begin{array}{l}\text { Benthic sediment was orange on surface, grey } \\
\text { underneath with some organics. Water was } \\
\text { green-orange and turbid. Sample taken } \sim 10 \mathrm{~m}\end{array}$ \\
\hline $\begin{array}{l}\text { TP5-TS- } \\
\text { 03DUP }\end{array}$ & $\begin{array}{l}\text { TP5 pond inlet } \\
\text { stream }\end{array}$ & $\begin{array}{l}\text { Under } \sim 10 \mathrm{~cm} \text { of } \\
\text { water }\end{array}$ & $\begin{array}{l}\text { Grey with some } \\
\text { orange }\end{array}$ & Saturated & On surface & Duplicate of TP5TS03. \\
\hline TP5-TS-04 & $\begin{array}{l}\text { TP5 pond inlet } \\
\text { stream }\end{array}$ & $\begin{array}{l}\text { Under } \sim 10 \mathrm{~cm} \text { of } \\
\text { water }\end{array}$ & Orange and grey & Saturated & On surface & $\begin{array}{l}\text { Thin oxidation veneer on surface, completely } \\
\text { grey underneath. Downstream of TP5-SW- } 02 \\
\text { by about } 40 \mathrm{~m} \text {. Shallow, flowing water. }\end{array}$ \\
\hline
\end{tabular}

Field parameters [pH, oxidation-reduction potential (ORP), temperature, and conductivity] of surface waters were measured with a YSI ${ }^{\mathrm{TM}} 556$ Handheld multiparameter instrument, and the parameters of porewaters were measured with an Accumet ${ }^{\mathrm{TM}}$ AP 115 Portable Meter. The $\mathrm{pH}$ and ORP modules of both instruments used $\mathrm{Ag} / \mathrm{AgCl}$ reference electrodes saturated with $\mathrm{KCl}$. The $\mathrm{pH}$ probes were calibrated 
with standard buffer solutions of $\mathrm{pH}$ 4, 7, and 10, and the ORP sensors were tested using ZoBell's solution following the method of Nordstrom and Wilde (2005) (Appendix G). Each probe was calibrated and tested each morning before sampling. Alkalinity was measured using a $\mathrm{HACH}^{\mathrm{TM}}$ alkalinity kit Model AL-AP. Alkalinity measurements are reported to every $20 \mathrm{mg} / \mathrm{L} \mathrm{CaCO}_{3}$ for concentrations above 100 $\mathrm{mg} / \mathrm{L}$, and to $5 \mathrm{mg} / \mathrm{L}$ for concentrations between 5 - $100 \mathrm{mg} / \mathrm{L}$ (Appendix C).

Tailings were sampled from the bottom of holes augered during lysimeter installation, and from the bottom of supernatant ponds coincident with surface water collection sites (Table 3.1; Appendix D). Samples were collected in Ziploc ${ }^{\mathrm{TM}}$ bags and frozen for transport to Queen's University. Upon arrival, it was noticed that the tailings had variably thawed during transport, but were placed in a freezer to be refrozen. A thin veneer of oxidation was noticed on some tailings, but care was given to avoid these during subsequent subsampling. The locations of all water and tailings samples collected are shown in figure 2 .

\subsubsection{Aqueous Geochemistry}

Water samples were analyzed for 60 elements using a Thermo Scientific ${ }^{\mathrm{TM}}$ Element $2^{\mathrm{TM}}$ high resolution inductively coupled plasma mass spectrometer (HR-ICP-MS) at Queen's Facility for Isotope Research (QFIR) at Queen's University in Kingston, Ontario. All samples were diluted with 0.32 M $\mathrm{HNO}_{3}$ spiked with $2 \mathrm{ppb} \mathrm{Rh}$. Rhodium was used an internal standard to correct for matrix differences and signal suppression, and was chosen because no mass interferences were expected or observed. Certified reference materials used were NASS-7, SLRS-6, SLEW-2, and AQUA-1. Two lab blanks were analyzed to test for contamination during sample preparation, and all reported values are blank subtracted. Most elements, including $\mathrm{W}$, were analyzed using multiple resolutions to test for mass interferences. If it was found there was no mass interferences, the lowest resolution results are reported. The relative standard deviations (RSDs) of each measurement based on the average counts per second over a ten second 
measurement window are less than $5 \%$ for most measurements and analytes. Detection limits were set based on a $20 \%$ RSD cutoff (e.g. for tungsten, the lowest concentration after blank subtraction was 123 ng/L with a RSD of $20 \%$, so the detection limit was set at $100 \mathrm{ng} / \mathrm{L}$ ) (Appendix O).

The concentrations of $\mathrm{SO}_{4}{ }^{2-}, \mathrm{PO}_{4}^{2-}, \mathrm{NO}_{3}^{-}, \mathrm{Cl}^{-}$and $\mathrm{F}^{-}$in the waters was determined using a Dionex ${ }^{\mathrm{TM}}$ ICS-3000 ${ }^{\mathrm{TM}}$ ion chromatograph at the Analytical Services Unit (ASU) at Queen's University. Samples were pumped at a constant flow rate of $2 \mathrm{~mL} / \mathrm{min}$ through a Dionex ${ }^{\mathrm{TM}}$ AG4A-SC ${ }^{\mathrm{TM}}$ guard column with an AS4A-SC ${ }^{\mathrm{TM}}$ analytical column in an aqueous $1.8 \mathrm{mM} \mathrm{CO}_{3}{ }^{2-1} / 1.7 \mathrm{mM} \mathrm{HCO}_{3}{ }^{-}$eluent, and measured using a conductivity detector in suppressed conductivity mode. Certified reference material Cranberry-05 was used (Appendix N).

\subsubsection{Mineralogy}

Prior to all analyses, tailings samples were thawed and dried in an Erlab Captair Pyramid 2200 glove bag under ultra-high purity 4.8 grade $\mathrm{N}_{2(\mathrm{~g})}$ atmosphere for 36 - 48 hours to prevent sulfide oxidation. Nine 30 x $10 \mathrm{~mm}$ cylindrical epoxy grain mounts were prepared at SGS Laboratories in Lakefield, Ontario for analysis by scanning electron microscopy coupled with automated mineralogy analysis software (SEM-MLA) and synchrotron-based micro X-ray diffraction and fluorescence ( $\mu \mathrm{XRD}$ XRF) (Appendix E). Grain mounting was done without the use of water or heat treatment to prevent phase changes of secondary minerals. Samples were chosen for SEM-MLA based on having ICP-MS data for their coincident porewater or surface waters (Appendix F). Samples were unsieved to preserve grain size distributions.

The SEM-MLA was used to characterize mineral textures and determine modal mineralogy. Analyses were done at QFIR using a Thermo Scientific ${ }^{\mathrm{TM}}$ (formerly FEI) Quanta ${ }^{\mathrm{TM}} 650$ Field Emission Gun (FEG) environmental (E)SEM. Automated mineralogy data was collected in sparse phase liberation (SPL-Lt) mode to search for bright phases (ones with high average atomic numbers, e.g. scheelite and 
sulfide minerals), and in extended backscatter electron (XBSE) mode to calculate modal mineralogy. During both analyses, the SEM was operated under $25 \mathrm{kV}$ voltage, $6 \mu \mathrm{m}$ spot size, and $10-15 \mathrm{~mm}$ working distance. The SPL-Lt measurements were taken under 464 x magnification, and XBSE measurements were taken under 232 x magnification. The BSE images were standardized to Au to search for bright phases.

Spectra from individual energy-dispersive x-ray spectroscopy (EDS) measurements were matched with a mineral reference library for mineral identification. The initial library used was compiled by Jamieson et al. (2019), and contained minerals known to occur at the Cantung deposit and secondary minerals commonly formed as products of ARD [gypsum, Fe-oxide minerals, and native sulfur (S)]. Jarosite was added to the mineral reference library after initially being classified as unknowns by the MLA software. For FRT samples, "Fe-oxides" in the mineral library was replaced by goethite (FeOOH) because goethite was identified in FRT-TS-01 and FRT-TS-03 by $\mu$ XRD (this study) and in the FRT by previous XRD analyses (Mesh Environmental, 2008). Modal mineralogy was finalized by identifying grains initially identified as unknowns, and assigning their spectra to a new or existing mineral phase. Modal mineralogy was calculated using the weight percent distribution of each mineral, and minerals were grouped based on mineral groupings (e.g. pyroxene, amphibole) for representation (Appendix H).

\subsubsection{Partial Leaches}

Partial and whole-rock digestion techniques were employed to provide additional information on the mineralogical hosts of tungsten. Tailings subsamples were sent to ALS Geochemistry in North Vancouver, British Columbia, for the following leaches: Sequential cold and hot hydroxylamine hydrochloride $\left(\mathrm{NH}_{2} \mathrm{OH} \cdot \mathrm{HCl}\right.$; ALS Code ME-MS05 and ME-MS06, respectively) to attack amorphous and crystalline Fe-oxyhydroxide minerals; ultra-trace aqua regia $\left(1: 3 \mathrm{HNO}_{3}-\mathrm{HCl}\right.$; ALS Code MEMS41L) to attack sulfide, oxide, and carbonate minerals; and total digestion by Li-metaborate fusion 
(ALS Code ME-MS81) and ultra-trace 4-acid digestion ( $\mathrm{HNO}_{3}-\mathrm{HClO}_{4}-\mathrm{HF}-\mathrm{HCl}$; ALS Code ME-MS61L). Only the cold and hot hydroxylamine hydrochloride leaches were sequential, whereas the aqua regia, 4acid and Li-metaborate digestions were subsampled separately but from the same subsample. Therefore, heterogeneity produced by subsampling is considered in data interpretation.

For the cold hydroxylamine leach, $1 \mathrm{~g}$ of sample was mixed with $25 \mathrm{~mL}$ of $\mathrm{NH}_{2} \mathrm{OH} \cdot \mathrm{HCl}$ solution and agitated at room temperature for two hours. The residual solids were centrifuged, and the supernatant solution was decanted for analysis. The hot leach followed the same procedure, but samples were digested at $60{ }^{\circ} \mathrm{C}$ for two hours in an ultrasonic bath. Solutions after both leaches were analyzed for 63 elements by ICP-MS. The $\mathrm{pH}$ of the solutions was measured after each leach. One blank was run, and the certified reference materials used were OREAS-25a, STSD-1, OREAS-46, and OREAS-45d. Photos of samples were taken before and after leaching to track color changes (Appendix K). Eluents after aqua regia digestion were analyzed by ICP-MS for 53 elements. One blank was run, and certified reference material OREAS 920 was used. Eluents after 4-acid digestion were analyzed for 48 elements by ICP-MS. The melt produced by Li-metaborate fusion was dissolved in nitric acid and analyzed for 30 trace elements by ICPMS, and 13 major elements by inductively coupled plasma atomic emission spectroscopy (ICP-AES) (ALS Code ME-ICP06). Two blanks were run per digestion technique, and certified reference materials used were CDN-W-4, SRM 88B, AMIS0286, GS 310-10, GS 313-8, AMIS0185, OREAS 146, DS-1, MA-1b, OREAS 920, AMIS067, and EMOG-17. For all analyses, concentrations were converted to ppm, and concentrations below detection limit were assigned a value one half of the detection limit (Appendix M).

\subsubsection{Synchrotron-based $\mu$ XRD-XRF}

Iron-oxyhydroxide minerals from TP3 and the FRT were identified using SEM and targeted for analysis by synchrotron-based $\mu \mathrm{XRD}-\mathrm{XRF}$ to determine their mineralogy and potential for hosting 
tungsten (Appendix J). Synchrotron analyses were performed using a monochromatic beam at undulator beamline 13-IDE at the Advanced Photon Source (APS), National Argonne Laboratory, Chicago, Illinois. Two-dimensional XRF maps and XRD patterns were collected using an incident beam of $18 \mathrm{kV}$ with a spot size of $2 \mu \mathrm{m}$, with a dwell time of $50 \mathrm{~ms}$ per pixel. Specific pixels of interest were targeted for longer duration XRD measurements at 10,000 ms per pixel. Fluoresced X-rays were measured using a Hitachi 4element Vortex ME4 silicon drift diode detector positioned at $90^{\circ}$ to the incident beam and connected to a Xspress 3 digital X-ray multi-channel analyzer system. Diffracted X-rays were measured using a Perkin Elmer XRD1621 digital flat panel detector placed $400 \mathrm{~mm}$ from the sample operating in transmission mode. Processing and analysis of $\mu$ XRF maps was performed using Larch software (Version 0.9.46; Newville, 2019). Tungsten was identified using fluoresced $\mathrm{L}_{\alpha}$ and $\mathrm{L}_{\beta} \mathrm{X}$-rays. Two-dimensional XRD data was calibrated and integrated using Dioptas software (Prescher and Prakapenka, 2015), and phase identification was done on extracted 1D patterns using X'Pert HighScore Plus.

\subsection{Results}

\subsubsection{Aqueous Geochemistry}

\subsubsection{General Water Chemistry}

Tailings Pond 5 surface waters have similar compositions, with $\mathrm{Ca}, \mathrm{Mg}, \mathrm{SO}_{4}$, and $\mathrm{HCO}_{3}$ being the dominant solutes (Table 3.2; Fig. 3.2; Appendix N and O). The $\mathrm{pH}$ and total dissolved solids (TDS) of TP5 surface waters increase down gradient $(\mathrm{pH}=7.35-7.91$, TDS $=844-1065 \mathrm{mg} / \mathrm{L})$, with slight increases in unfiltered $\mathrm{Ca}(143-174 \mathrm{mg} / \mathrm{L}), \mathrm{Mg}(30-35 \mathrm{mg} / \mathrm{L}), \mathrm{SO}_{4}(510-630 \mathrm{mg} / \mathrm{L})$, and $\mathrm{HCO}_{3}(120$ $-140 \mathrm{mg} / \mathrm{L}$ ). Iron in the filtered aliquots is below the detection limit of $0.001 \mathrm{mg} / \mathrm{L}$, but unfiltered samples have iron concentrations between 1 and $3 \mathrm{mg} / \mathrm{L}$, which decrease down gradient. Flat River Tailings samples have more variable water chemistry, and range from slightly acidic to alkaline $(\mathrm{pH}=$ $5.63-8.05)$ with a larger range of TDS $(817-2015 \mathrm{mg} / \mathrm{L})$. Sample FRT-SW-01 was taken from the 
pond at the base of TP2, and its composition is similar to TP5 surface waters. Sample FRT-SW-02 was taken from an orange, turbid pond on the FRT, and has the lowest $\mathrm{pH}$ (5.63) and highest TDS (2015 $\mathrm{mg} / \mathrm{L}$ ) of all surface water samples. This sample has the highest filtered iron and sulfate concentrations (221 and $1400 \mathrm{mg} / \mathrm{L}$, respectively), the lowest alkalinity of all surface water samples $(10 \mathrm{mg} / \mathrm{L})$, and the highest unfiltered iron concentrations (294 mg/L). Samples FRT-SW-03 and FRT-SW-04 were taken from turbid, orange ponds in a channel that is commonly connected to the Flat River, but was stagnant when sampled. The two samples are acidic ( $\mathrm{pH}=5.91$ and 6.23), although FRT-SW-04 has higher dissolved concentrations of all major solutes except iron (Table 3.2). Flat River samples are circumneutral $(\mathrm{pH}=7.10$ and 7.19) with low TDS (141 and $163 \mathrm{mg} / \mathrm{L})$, and are $\mathrm{Ca}-\mathrm{HCO}_{3}$ dominated with much lower $\mathrm{SO}_{4}(58$ and $63 \mathrm{mg} / \mathrm{L})$ than tailings surface waters. Sample FR01, taken $\sim 2 \mathrm{~km}$ upstream of the mine, has slightly lower $\mathrm{pH}$ and TDS than FR02, which was sampled from the Flat River flowing through the FRT, and FR02 has low iron concentrations in the unfiltered aliquot $(0.2 \mathrm{mg} / \mathrm{L})$. 
Table 3.2 Water parameters and concentrations of major elements for all water samples. Filtered concentrations reported are from the FA aliquot, with the exception of the porewater samples and FR01 which are from the FA + HF aliquot. TP3 = Tailings Pond 3, TP5 = Tailings Pond 5, FRT = Flat River Tailings, FR = Flat River Surface Water, PWL = Porewater, $\mathrm{SW}=$ Surface Water. *Values are elemental S reported by ICP-MS, converted to $\mathrm{SO}_{4}$. A value of "-“ indicates the parameter was not measured or the sample was not collected.

\begin{tabular}{|c|c|c|c|c|c|c|c|c|c|c|c|c|c|c|c|c|c|c|c|c|c|c|}
\hline \multirow[t]{2}{*}{ Water Sample ID } & \multirow[t]{2}{*}{$\begin{array}{c}\text { Tailings } \\
\text { Sample ID } \\
\end{array}$} & \multirow[t]{2}{*}{$\mathrm{pH}$} & \multirow[t]{2}{*}{ Eh } & \multirow[t]{2}{*}{$\begin{array}{c}\mathbf{E C} \\
(\mathrm{mS}) \\
\end{array}$} & \multirow[t]{2}{*}{$\begin{array}{c}\begin{array}{c}\text { Alkalinity } \\
(\mathrm{mg} / \mathrm{L} \\
\mathrm{CaCO})\end{array} \\
\end{array}$} & \multirow[t]{2}{*}{$\begin{array}{c}\mathrm{SO}_{4} \\
(\mathrm{mg} / \mathbf{L})\end{array}$} & \multicolumn{2}{|c|}{$\mathrm{Al}(\mathrm{mg} / \mathbf{L})$} & \multicolumn{2}{|c|}{$\mathrm{Ca}(\mathrm{mg} / \mathrm{L})$} & \multicolumn{2}{|c|}{$\mathrm{Fe}(\mathrm{mg} / \mathrm{L})$} & \multicolumn{2}{|c|}{ Mn (mg/L) } & \multicolumn{2}{|c|}{$\mathrm{K}(\mathrm{mg} / \mathbf{L})$} & \multicolumn{2}{|c|}{$\mathrm{Mg}(\mathrm{mg} / \mathrm{L})$} & \multicolumn{2}{|c|}{$\mathrm{Na}(\mathrm{mg} / \mathrm{L})$} & \multicolumn{2}{|c|}{$\mathrm{Si}(\mathrm{mg} / \mathbf{L})$} \\
\hline & & & & & & & Fil. & Unf. & Fil. & Unf. & Fiil. & Unf. & Fiil. & Unf. & Fiil. & Unf. & Fil. & Unf. & Fil. & Unf. & Fiil. & Unf. \\
\hline TP3-PWL-01 & TP3-TS-01 & 7.05 & 0.34 & 1.970 & 180 & 1200 & $<1$ & - & 402 & - & 4.051 & - & 1.3 & - & 11 & - & 51.9 & - & 16 & - & 26.3 & - \\
\hline FRT-PWL-01 & FRT-TS-02 & 5.46 & 0.39 & - & 20 & $1691^{*}$ & 1.5 & - & 419 & - & 9.227 & - & 6.1 & - & 4 & - & 186.1 & - & 10 & - & 15.1 & - \\
\hline FRT-PWL-03 & - & 2.2 & 0.72 & - & 0 & $3444 *$ & 72 & - & 433 & - & 645.4 & - & 4.8 & - & 7 & - & 65.1 & - & 15 & - & 78.4 & - \\
\hline FRT-PWL-04 & FRT-TS- 03 & 3.02 & 0.63 & 1.920 & 0 & 2200 & 51 & - & 390 & - & 252.8 & - & 3 & - & 1 & - & 111 & - & 55 & - & 21 & - \\
\hline FRT-PWL-06 & FRT-TS-05 & 7.61 & 0.48 & - & - & $456^{*}$ & $<1$ & - & 139 & - & 0.050 & - & $<0.5$ & - & 2 & - & 30 & - & 44 & - & 7 & - \\
\hline TP5-SW-01 & - & 7.91 & 0.37 & 1.296 & 140 & 630 & $<1$ & $<1$ & 168 & 168 & $<0.001$ & 1.057 & $<0.5$ & $<0.5$ & 1 & 1 & 35 & 34 & 84 & 77 & 7 & 8 \\
\hline TP5-SW-02 & TP5-TS-03 & 7.35 & 0.43 & 1.060 & 120 & 510 & $<1$ & $<1$ & 147 & 143 & $<0.001$ & 2.743 & $<0.5$ & $<0.5$ & 1 & 1 & 31 & 30 & 67 & 61 & 7 & 7 \\
\hline TP5-SW-02DUP & TP5-TS-03 & 7.35 & 0.43 & 1.060 & 120 & 530 & $<1$ & $<1$ & 151 & 142 & $<0.001$ & 2.814 & 0.5 & $<0.5$ & 1 & 1 & 32 & 30 & 70 & 60 & 7 & 8 \\
\hline TP5-SW-03 & TP5-TS-04 & 7.75 & 0.36 & 1.319 & 140 & 610 & $<1$ & $<1$ & 162 & 174 & $<0.001$ & 3.031 & 0.6 & 0.6 & 2 & 1 & 34 & 35 & 75 & 82 & 8 & 9 \\
\hline FRT-SW-01 & - & 8.05 & 0.42 & 1.027 & 120 & 460 & $<1$ & $<1$ & 146 & 147 & $<0.001$ & 1.085 & $<0.5$ & $<0.5$ & 1 & 1 & 31 & 31 & 54 & 56 & 6 & 6 \\
\hline FRT-SW-02 & FRT-TS-06 & 5.63 & 0.26 & 2.805 & 10 & 1400 & $<1$ & $<1$ & 262 & 261 & 221.2 & 294.3 & 3 & 3 & 2 & 2 & 77 & 83 & 35 & 28 & 5 & 6 \\
\hline FRT-SW-02DUP & FRT-TS-06 & 5.69 & 0.25 & 2.890 & 10 & 1400 & $<1$ & $<1$ & 254 & 297 & 230.7 & 376.0 & 3 & 4 & 1 & 1 & 80 & 89 & 29 & 41 & 5 & 8 \\
\hline FRT-SW-03 & - & 6.23 & 0.19 & 1.382 & 140 & 510 & $<1$ & $<1$ & 167 & 163 & 56.20 & 61.64 & 1 & 1 & $<1$ & $<1$ & 47 & 45 & 4 & 4 & 2 & 3 \\
\hline FRT-SW-04 & - & 5.91 & 0.26 & 2.162 & 140 & 1300 & $<1$ & 4 & 334 & 332 & 10.69 & 24.46 & 1 & 1 & 1 & 1 & 178 & 176 & 3 & 3 & 4 & 5 \\
\hline FR01 & - & 7.1 & 0.44 & 0.191 & 60 & 66 & $<1$ & - & 23 & - & 0.012 & - & $<0.5$ & - & $<1$ & - & 7.8 & - & 1 & - & 5 & - \\
\hline FR02 & - & 7.19 & 0.32 & 0.222 & 45 & 58 & $<1$ & $<1$ & 27 & 27 & 0.027 & 0.228 & $<0.5$ & $<0.5$ & $<1$ & $<1$ & 9 & 9 & 0 & 0 & 2 & 2 \\
\hline
\end{tabular}


Porewater from TP3 was extracted from a lysimeter installed at $70 \mathrm{~cm}$ depth in tailings that were saturated and appeared unoxidized. The porewater has neutral $\mathrm{pH}$ (7.05), high dissolved Ca (402 mg/L), $\mathrm{Mg}(51.9 \mathrm{mg} / \mathrm{L}), \mathrm{Fe}(4.05 \mathrm{mg} / \mathrm{L}), \mathrm{K}(11 \mathrm{mg} / \mathrm{L}), \mathrm{SO}_{4}(1200 \mathrm{mg} / \mathrm{L})$, and the highest alkalinity of all water samples (180 mg/L). Like FRT surface waters, the chemistry of FRT porewater is variable, ranging from acidic to slightly alkaline $(\mathrm{pH}=2.2-7.61)$. Sample FRT-PWL-01 was extracted from $60 \mathrm{~cm}$ depth in highly oxidized tailings, and has slightly acidic pH (5.41), low alkalinity (20 mg/L), and elevated concentrations of Fe (9.23 mg/L), Al (1.50 mg/L), and Mg (186 mg/L). Sample FRT-PWL-03 was extracted at $15 \mathrm{~cm}$ depth from highly oxidized tailings, and has the most acidic $\mathrm{pH}$ (2.20), no alkalinity, and the highest $\mathrm{SO}_{4}(3444 \mathrm{mg} / \mathrm{L}), \mathrm{Fe}(645 \mathrm{mg} / \mathrm{L})$, and $\mathrm{Al}$ concentrations $(72.0 \mathrm{mg} / \mathrm{L})$ of all water samples. Sample FRT-PWL-04, extracted at $70 \mathrm{~cm}$ depth from a hole adjacent to FRT-PWL-03, is slightly less acidic (3.02) and has high concentrations of Fe (253 mg/L) and Al (51.0 mg/L). Sample FRT-PWL-06 was extracted at $70 \mathrm{~cm}$ depth from saturated, grey tailings on the tailings beach at the base of TP2. It has the highest $\mathrm{pH}$ (7.61) of all porewater samples and the lowest concentrations of major solutes (Table 3.2).

\subsubsection{Tungsten and Copper Concentrations}

Aliquots were spiked with HF to prevent the formation of insoluble tungstic acid on the walls of sample bottles (Gaines, 2018), which has been observed previously (Gustafsson, 2003). The aliquots spiked with HF have comparable tungsten concentrations to aliquots without HF, and all aliquot pairs have concentrations within 2 standard deviations of their ICP-MS measurements (Fig. 3.3). The HF was added and the samples were analyzed approximately two weeks and eight months after sample collection, respectively, so it cannot be concluded that the addition of $\mathrm{HF}$ affected tungsten preservation during transport. It is possible that if any tungstic acid precipitated, the HF added was insufficient to re-dissolve tungsten into solution, and is also possible that the $\mu \mathrm{g} / \mathrm{L} \mathrm{W}$ concentrations in the samples are too low to reach saturation of tungstic acid. All further surface water concentrations are reported from the aliquots without HF for internal consistency. Trace element concentrations for samples TP3-PWL-01, FRT-PWL- 
01, and FRT-PWL-03 are reported from the aliquots with HF added, as lysimeter yield was not sufficient for the collection of multiple aliquots.

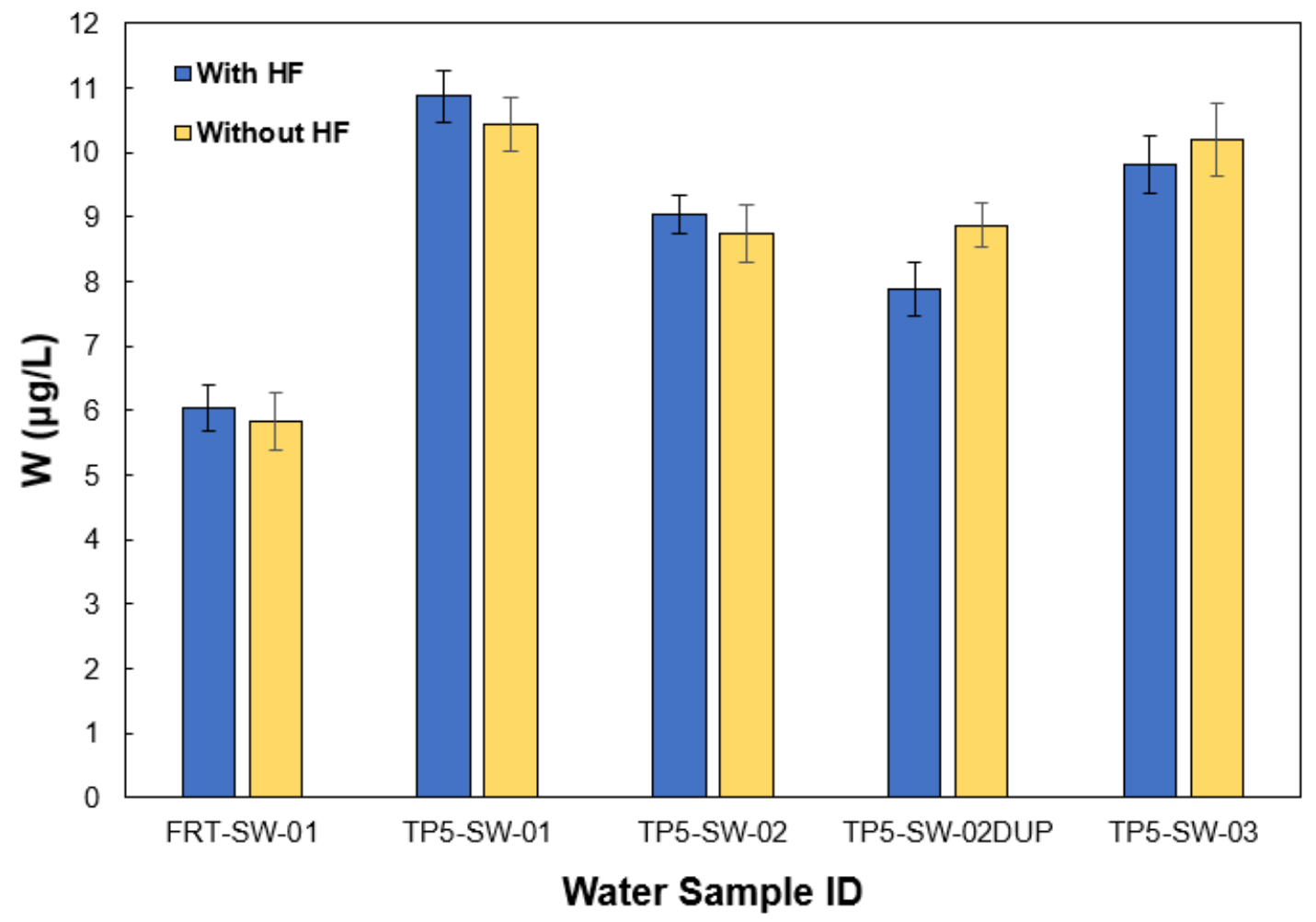

Figure 3.3 Tungsten concentrations in water samples with tungsten above detection limit, and only samples that have been filtered are shown. Error bars are 2 standard deviations of the ICP-MS measurement.

Copper was chosen to compare to tungsten in this study due to the similar abundances of chalcopyrite and scheelite in fresh Cantung tailings (see section 3.2.1; Fig. 3.5), and are expected to have opposite behaviour during $\mathrm{pH}$-dependent adsorption because tungsten and copper form anionic and cationic species, respectively (Dzombak and Morel, 1990). Furthermore, the Canadian Council of Ministers of the Environment (CCME) guidelines suggest maximum copper concentrations of $2 \mu \mathrm{g} / \mathrm{L}$ for the protection of aquatic life, but there are currently no guidelines for tungsten (CCME, 2008). Detectable tungsten concentrations ( $>100 \mathrm{ng} / \mathrm{L}$ ) are restricted to TP5 surface waters, one surface water from the FRT, and TP3 porewater. Filtered tungsten concentrations in surface waters range from 5.8 to $10 \mu \mathrm{g} / \mathrm{L}$, and unfiltered concentrations are on average 1.4 times higher $(7.3-19 \mu \mathrm{g} / \mathrm{L})$. The highest tungsten 
concentrations are in TP3 porewater at $26 \mu \mathrm{g} / \mathrm{L}$, and all water samples below $\mathrm{pH} 7$ are below the detection limit. In contrast to tungsten, filtered copper concentrations are above the detection limit of $100 \mathrm{ng} / \mathrm{L}$ in all water samples with the exception of TP5-SW-03, FR01, and TP3-TS-01 (Fig. 3.4). In tailings surface waters, filtered copper concentrations range from 0.5 to $157 \mu \mathrm{g} / \mathrm{L}$, and increase with decreasing $\mathrm{pH}$, and unfiltered concentrations are on average four times higher than filtered concentrations $(1.9-505 \mu \mathrm{g} / \mathrm{L})$. Copper concentrations in FRT porewater range from 3.1 to $10767 \mu \mathrm{g} / \mathrm{L}$, and also increase with decreasing pH (Fig. 3.4). Sample FR02 has $0.3 \mu \mathrm{g} / \mathrm{L}$ in the filtered aliquot and $0.6 \mu \mathrm{g} / \mathrm{L}$ in the unfiltered aliquot, whereas FR01 has copper concentrations below the detection limit.
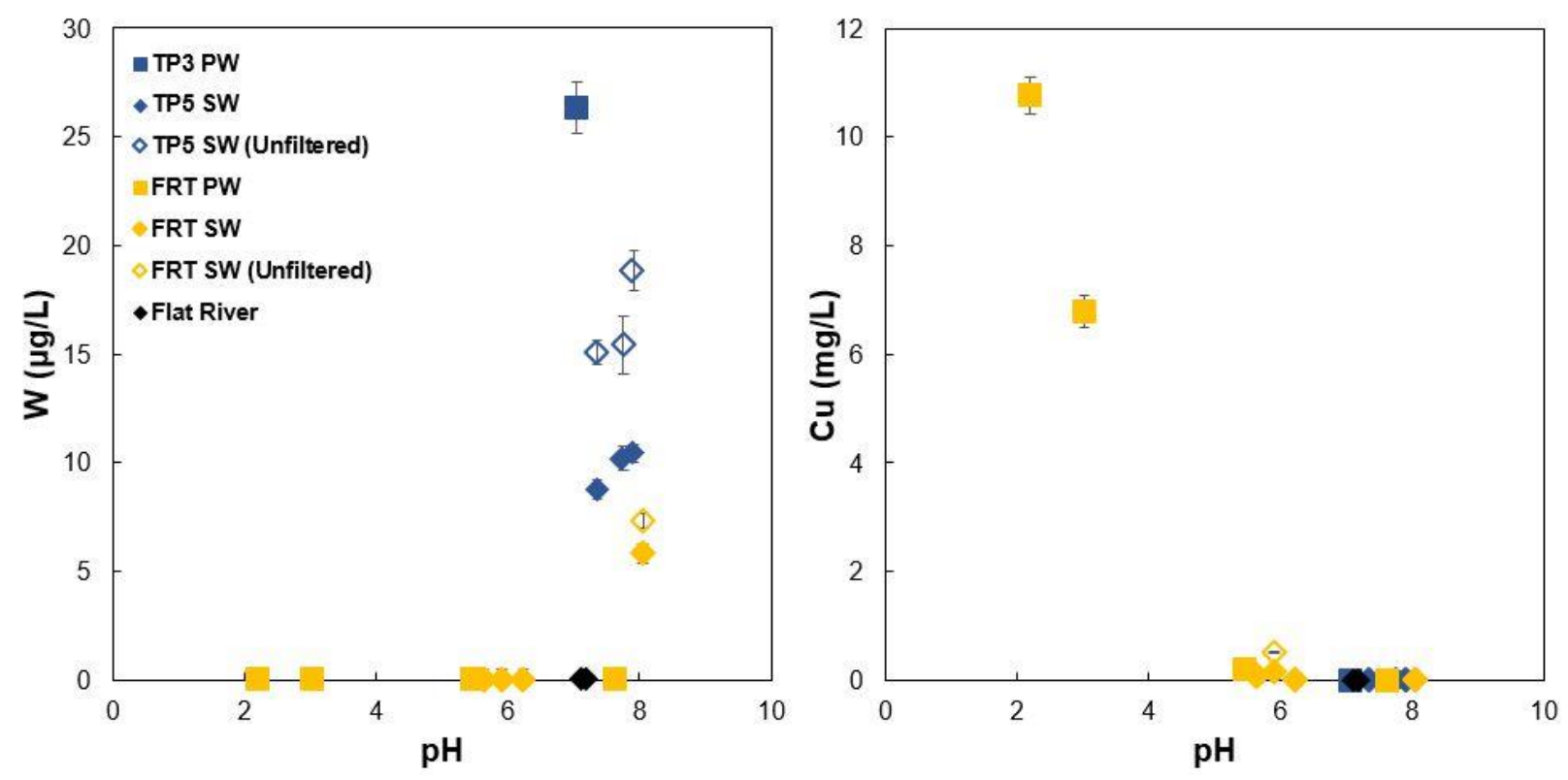

Figure 3.4 Tungsten and copper concentrations vs. pH for all surface waters and porewaters collected in this study. Error bars are two standard deviations of the mean of each ICP-MS measurement. All samples are filtered to 0.45 micron unless stated otherwise.

\subsubsection{Tailings Mineralogy}

\subsubsection{Modal Mineralogy}

Samples representative as endmembers of tailings alteration were chosen to show important mineralogical differences between fresh, mostly unoxidized tailings in the tailings impoundments, and 
tailings that have been extensively oxidized in the FRT (Fig. 3.5; Appendix L). Sample TP3-TS-01 was taken from saturated, unoxidized tailings at $70 \mathrm{~cm}$ depth in TP3, and FRT-TS-01 was taken from the top $10 \mathrm{~cm}$ of dry, oxidized tailings on the FRT. Sample TP3-TS-01 has abundant sulfide minerals, consisting of pyrrhotite (17 wt.\%), pyrite $\left(\mathrm{FeS}_{2} ; 1\right.$ wt.\%), chalcopyrite (0.6 wt.\%), and sphalerite (0.1 wt.\%), and carbonate minerals dolomite (16 wt.\%), calcite (14 wt.\%), and ankerite $\left(\mathrm{Ca}(\mathrm{Fe}, \mathrm{Mg}, \mathrm{Mn})\left(\mathrm{CO}_{3}\right)_{2} ; 0.2\right.$ wt.\%). Secondary minerals are limited with only 0.4 wt.\% Fe-oxide minerals, which are found as rims on, and as partial replacements of, pyrrhotite grains (Fig. 3.6). In contrast, sample FRT-TS-01 has no carbonate minerals, and the only sulfide mineral is chalcopyrite. Secondary minerals common to ARD are in high abundance, and consist of gypsum (21 wt.\%), goethite (20 wt.\%), jarosite (1 wt.\%), and native sulfur. Silicate mineralogy for both samples is similar, consisting of quartz, amphibole (actinolite and hornblende), pyroxene (hedenbergite, diopside, clinozoisite), feldspar (K-feldspar and plagioclase), mica (biotite and muscovite), chlorite, and minor garnet. Scheelite is present in both samples in similar proportions $(0.1-0.2 \mathrm{wt} . \%)$. The proportions of secondary minerals in FRT-TS-01 may be misrepresented due to heterogeneities at the $\mu \mathrm{m}$ scale of pseudomorphed pyrrhotite grains where they are most commonly found (see section 3.2.2; Fig. 3.6). The centroid method by which XBSE mode collects EDS spectra (Sandmann, 2015) commonly resulted in entire grains being identified as a single phase due to similarities between their grey scale colors (i.e. the average atomic numbers of goethite and jarosite is close; 22.25 and 19.27, respectively). For example, grain-by-grain EDS analysis of some grains identified native sulfur that was not identified as a separate phase by automated mineralogy. Native sulfur is an expected oxidation product of pyrrhotite (Belzile et al., 2004), and up to $14 \mathrm{wt} . \%$ native sulfur was detected by Rietveld XRD analysis in grab samples from the FRT (Mesh Environmental, 2008), so it is possible native sulfur is underreported by automated mineralogy. Moreover, modal mineralogy varies within the tailings impoundments due to heterogeneities within the Cantung orebody and hydrologic sorting of grains during tailings deposition (Jamieson et al., 2019). The modal mineralogies presented in figure 5 are comparable to our previous calculations for 37 samples from the tailings impoundments (not used in this study), which have an average pyrrhotite content of 14 wt.\% and an average scheelite content 
from TP3, scheelite, chalcopyrite, and sphalerite appear unaltered, and Fe-oxyhydroxide phases were not found coating non-sulfide grains. An obvious contrast in tailings saturation was observed at around $50 \mathrm{~cm}$ depth of the hole augered in TP3, and it is probable that tailings saturation has limited oxygen ingress at depth, and therefore the oxidation of sulfide minerals as well. The sample selected from TP5 for SEM and automated mineralogy was very fine-grained and unfortunately, agglomeration of fine-grained minerals during sample preparation prevented adequate estimate of modal mineralogy (Appendix L). However, the tailings were grey and appeared unoxidized, except for samples taken from the stream, which had an orange veneer indicative of Fe-oxyhydroxide minerals (Appendix D). The grey sediment and relatively young age ( $<5$ years; pHase Geochemistry, 2014) suggests these tailings have not undergone significant oxidation. 

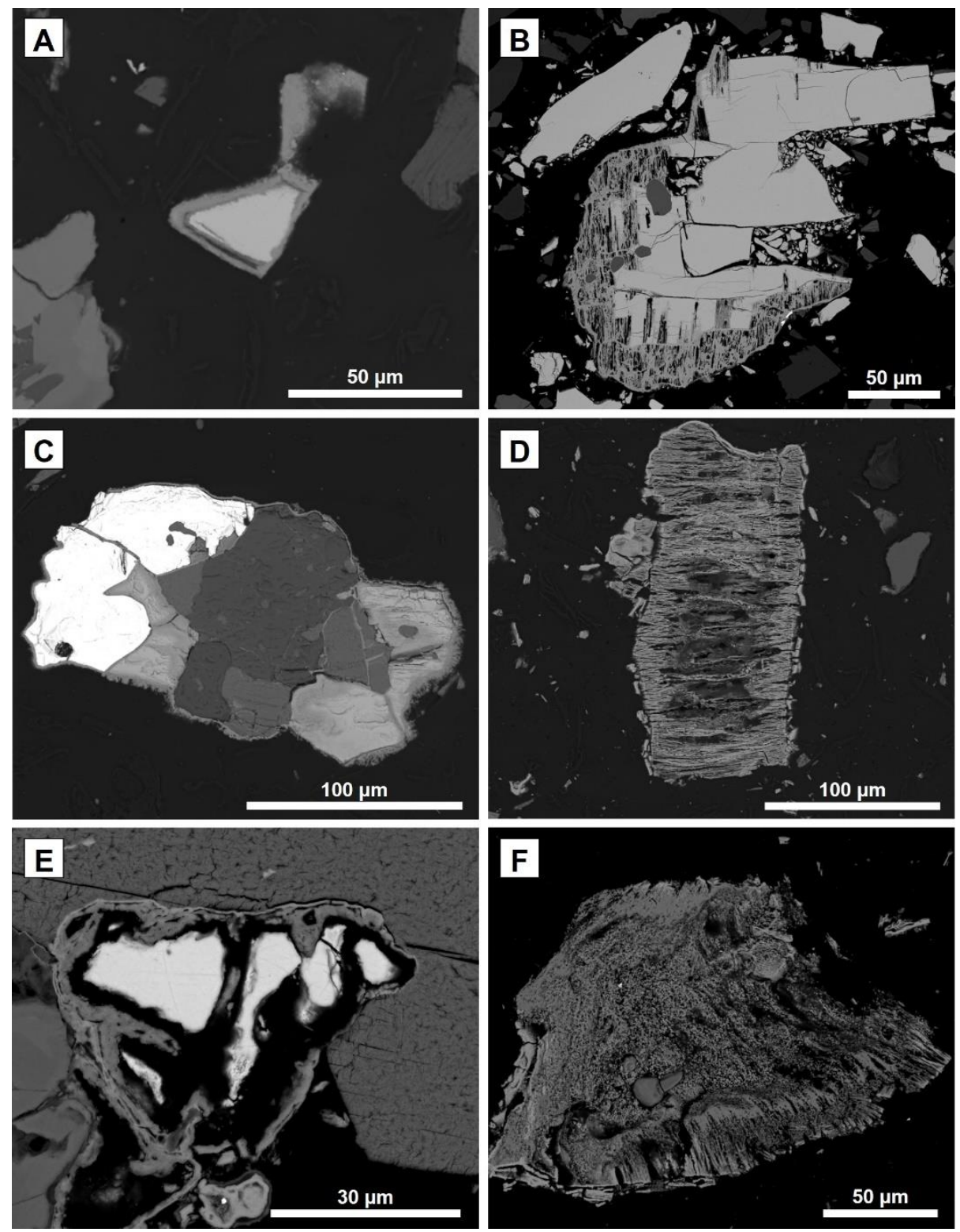

Figure 3.6 SEM-BSE images of alteration textures observed in the FRT and TP3. A: Pyrrhotite grain from TP3-TS01 showing early stages of oxidation with etching along the grain boundary and a rim of Fe-oxyhydroxide. B: More aggressively altered pyrrhotite grain from TP3-TS-01 with parallel bands of Fe-oxyhydroxide replacing pyrrhotite along cleavage planes, encased by a rim of Fe-oxyhydroxide. Note the unaltered pyrrhotite grain in the top left of the image. C: Lithic fragment from FRT-TS-05 consisting of scheelite, pyrrhotite, plagioclase, and biotite, enveloped by acicular goethite. D: Pseudomorph of pyrrhotite from FRT-TS-01 with parallel bands of goethite. Note the porous texture. E: Relict core of chalcopyrite cemented by gypsum from FRT-TS-01. Weathering rind identified as jarosite by the prominent K peak in its EDS spectrum. F: Pseudomorph of pyrrhotite from FRT-TS-01 with equant, pseudocubic crystals of jarosite sheathed by a rind of goethite. The bottom of the grain shows parallel bands of goethite (bright grey) being replaced by jarosite (darker grey). 
Tailings from the FRT have been extensively oxidized, with nearly complete exhaustion of carbonate and sulfide minerals in the most altered samples (FRT-TS-01 and FRT-TS-02) (Appendix I and L). In these samples, pyrrhotite has been completely dissolved and replaced by Fe-oxyhydroxide and Fehydroxysulfate minerals (chiefly goethite and jarosite). Pyrrhotite pseudomorph grains appear porous and most consist solely of goethite, as determined by $\mu$ XRD (Fig. 3.6D; Fig. 3.8), but are heterogeneous at the grain scale. For example, EDS spectra collected across a single grain may show the presence or absence of minor peaks of $\mathrm{Si}, \mathrm{Al}, \mathrm{K}$, and $\mathrm{S}$, with no compositional consistency between grain morphologies (e.g. spectra collected on the rims or interiors). Virtually all minerals in both of these samples have rims of goethite, with the exception of some gypsum grains. Jarosite has partially replaced goethite within pseudomorph grains, is present as tabular crystals growing in spaces between goethite in pseudomorphs, and as rims on other minerals. Jarosite that has replaced goethite in pseudomorphs appears to have done so from the inside out (Fig. 3.6F). The only sulfide mineral remaining in these samples is chalcopyrite, which occurs as relict cores with a gap between the cores and their weathered rinds, suggesting partial dissolution (Fig. 3.6E). Scheelite grains appear unweathered, and have Fe-oxyhydroxide coatings that are compositionally and texturally similar to coatings on other non-sulfide grains. Euhedral gypsum is abundant and cements many grains. However, some gypsum crystals lack Fe-oxyhydroxide rims, suggesting that some gypsum might have formed during drying of the samples and are not authigenic to the FRT. Nonetheless, gypsum is a common secondary mineral in acid mine drainage environments (Lindsay et al., 2015), and was identified in previous Cantung tailings characterization reports (Mesh Environmental, 2008). Although FRT-TS-01 and FRT-TS-02 represent the most altered tailings samples collected in this study, other FRT samples exhibit intermediate degrees of alteration. Common to all FRT samples is the coating of non-sulfide grains with goethite displaying both acicular and massive textures (Fig. 3.6C). 


\subsubsection{Partial Leach Extractions}

The partial leach extractions were used to determine the potential labile tungsten content of $\mathrm{Fe}$ oxyhydroxide minerals (Appendix M). Total iron concentrations reported by Li-metaborate fusion are on average higher in the FRT samples than those from the tailings impoundments $(18 \mathrm{wt} . \%$ and $11 \mathrm{wt} . \%$, respectively; Fig. 3.7). However, iron recovered by aqua regia as a percentage of the total iron (by Limetaborate fusion) is on average $79 \%$ for FRT samples and $76 \%$ for tailings impoundment samples. This suggests that similar proportions of iron reside in phases digestible by aqua regia (e.g. sulfide and Fe-oxyhydroxide minerals) and that the residual is hosted in less reactive minerals (i.e. Fe-bearing silicate minerals). The cold and hot hydroxylamine leaches recovered significantly more iron from the FRT samples than those from the tailings impoundments (Fig. 3.7). The cold leach returned on average 1240 ppm iron from the FRT samples and $70 \mathrm{ppm}$ from the tailings impoundment samples, and the hot hydroxylamine leach returned on average $2 \mathrm{wt} . \%$ iron from the FRT samples and $1 \mathrm{wt} . \%$ from the tailings impoundments. 


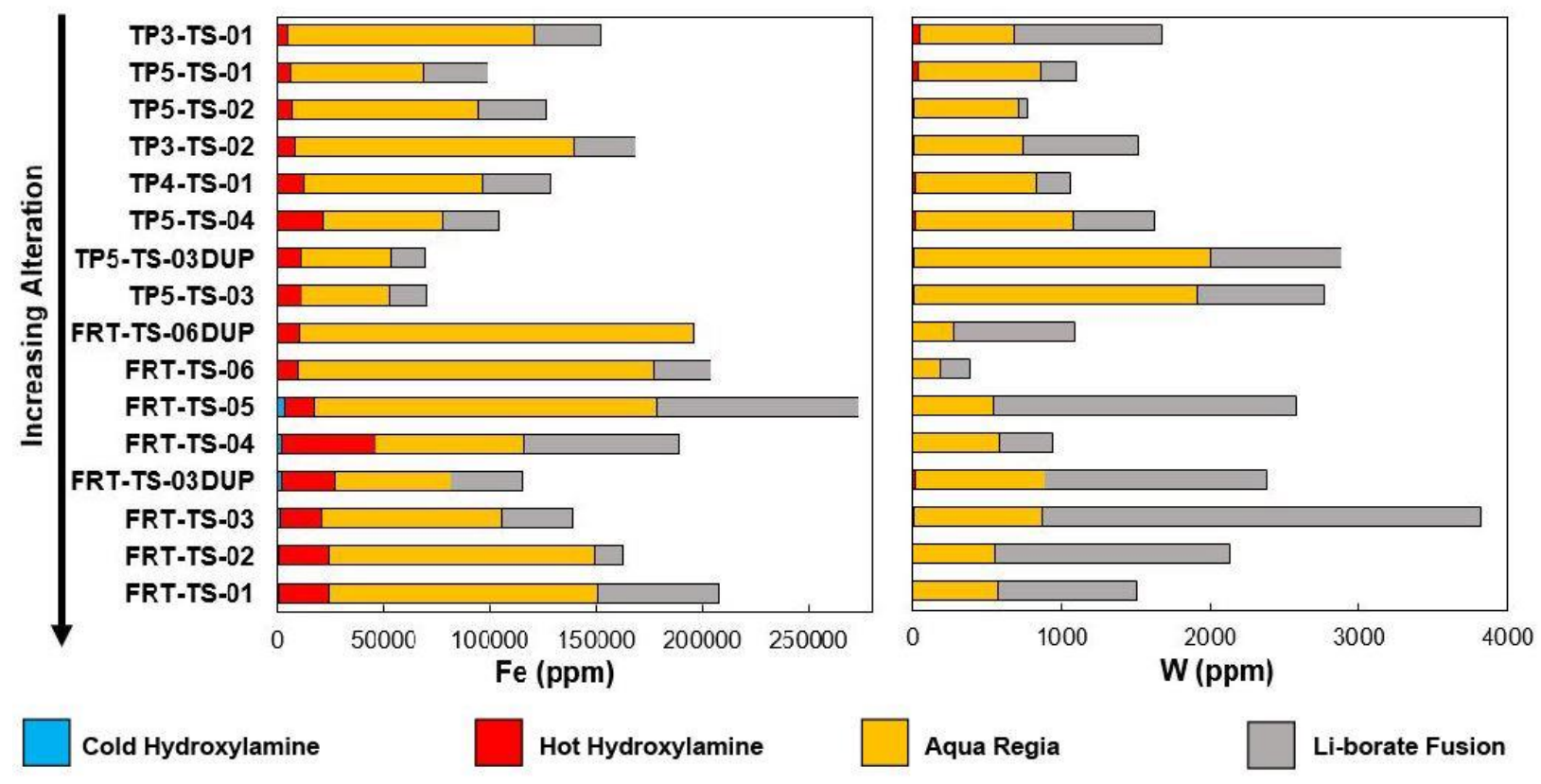

Figure 3.7 Bar charts showing the partial leach recoveries of iron and tungsten. Samples are ordered by their relative degree of alteration as determine by SEM-MLA, with the least-altered samples at the top and most altered at the bottom. Note that only the cold and hot hydroxylamine hydrochloride leaches were sequential so the width of their bars represents the amount extracted. The recoveries by aqua regia and Li-metaborate fusion are plotted as residual values as if they were sequential, however their bar maxima represent the amount extracted (i.e. their true bar width starts from 0 ).

Tungsten recovery by Li-metaborate fusion is similar between samples from the tailings impoundments $($ average $=1674 \mathrm{ppm})$ and samples from the FRT $($ average $=1854 \mathrm{ppm})$, but aqua regia recovered more tungsten from the tailings impoundment samples than the FRT samples (averages of 1102 and $557 \mathrm{ppm}$, respectively). The hot hydroxylamine leach yielded on average $16 \mathrm{ppm}$ from the tailings impoundments and $3 \mathrm{ppm}$ from the FRT, whereas the cold hydroxylamine hydrochloride returned negligible tungsten from both populations $(0.02 \mathrm{ppm}$ from the tailings impoundments and $0.04 \mathrm{ppm}$ from the FRT). Samples FRT-TS-03 and FRT-TS-03DUP recovered 5.5 and $15.7 \mathrm{ppm}$ tungsten from the hot hydroxylamine leach, respectively, which is anomalously high for FRT samples. 


\subsubsection{Synchrotron-based $\mu$ XRD-XRF}

Pyrrhotite grains at different stages of oxidation were targeted for synchrotron-based $\mu$ XRD-XRF analysis to determine their mineralogy and potential for hosting W (Appendix J). Analyses were done on epoxy grain mounts sliced to $1-2 \mathrm{~mm}$ thickness, and due to penetration of the incident beam, $\mathrm{X}$-rays potentially diffracted from phases at depth were considered during interpretation. For example, some peaks appearing as spots on the $2 \mathrm{D} \mu \mathrm{XRD}$ images also appear in $\mu \mathrm{XRD}$ patterns distal from the grains shown in figure 8 , and are probably sourced from Laue diffraction of coarser crystallites at depth in the epoxy (Appendix J). Pyrrhotite pseudomorph grains in sample FRT-TS-01, FRT-TS-02, and FRT-TS-03 have $\mu \mathrm{XRD}$ patterns that match well with goethite, and in some patterns lepidocrocite $(\gamma$-FeOOH) was identified (Fig. 3.8). Goethite appears as distinct Debye-Scherrer bands on the 2D $\mu$ XRD images, whereas Debye-Scherrer bands of lepidocrocite are discontinuous, possibly due to coarser grain size. Goethite was also identified in Fe-oxyhydroxide rims on quartz in sample FRT-TS-03 (not shown in Fig. 3.8). In sample TP3-TS-01, rims on two pyrrhotite grains have $\mu$ XRD patterns matching hematite $\left(\mathrm{Fe}_{2} \mathrm{O}_{3}\right)$ and maghemite $\left(\gamma-\mathrm{Fe}_{2} \mathrm{O}_{3}\right)$ that appear as Debye-Scherrer bands on the 2D $\mu$ XRD images (Fig. 3.8). Micro xray fluorescence analysis of these two grains indicates the presence of tungsten, and the BSE-SEM images of these grains show small scheelite particles along the rim, however tungsten on the XRF map also traces the rim in places with no visible scheelite. Tungsten fluorescing within the boundaries of the grain are interpreted to be sourced from buried scheelite, as higher energy X-rays fluoresced from tungsten are less likely to be reabsorbed by the surrounding media. Other Fe-oxyhydroxide rims analyzed in this sample do not have detectable $\mathrm{W}$, nor do they have $\mu$ XRD patterns that match with any Feoxyhydroxide minerals (Appendix J). 

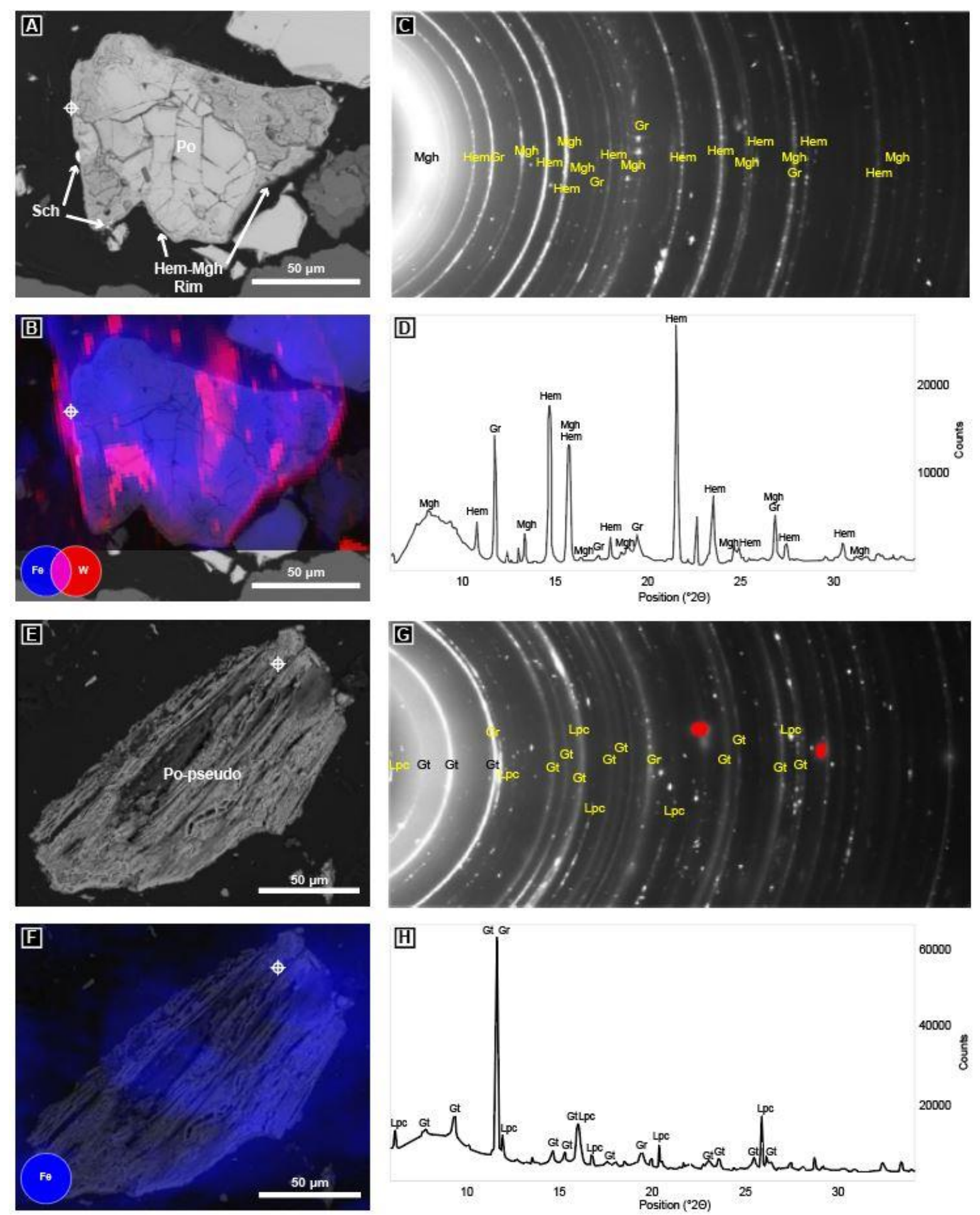

Figure 3.8 Synchrotron-based $\mu \mathrm{XRF}$ maps and $\mu \mathrm{XRD}$ patterns of a partially oxidized pyrrhotite grain from TP3 (panels A-D) and a pyrrhotite pseudomorph from the FRT (panels E-H). Micro-XRD measurements in panels C, D, $\mathrm{G}$, and $\mathrm{H}$ were done with a spot size of $2 \mu \mathrm{m}$ and a dwell time of 10,000 ms. The center of the bullseyes in panels A, $\mathrm{B}, \mathrm{E}$, and $\mathrm{F}$ mark the exact location of the $\mu \mathrm{XRD}$ measurements. A: Pyrrhotite enveloped by a hematite-maghemite rim with fragments of scheelite. B: Micro-XRF map of the grain in panel A, note that the color intensity does not 
reflect exact tungsten and iron concentrations. C: Two-dimensional $\mu$ XRD image showing Debye-Scherrer bands of hematite (Hem), maghemite (Mgh), and graphite (Gr). Samples were carbon coated to create a conductive surface during SEM analyses but was not removed before the synchrotron-based analyses, so graphite is present in all $\mu \mathrm{XRD}$ patterns. D: Integrated $\mu \mathrm{XRD}$ pattern showing relative peak intensities. E: Pyrrhotite completely replaced by goethite and lepidocrocite. F: Micro-XRF map of grain in panel E. G: Two-dimensional $\mu X R D$ image showing Debye-Scherrer bands of goethite (Gt), lepidocrocite (Lpc), and graphite (Gr). Artefacts were masked by the red circles on the image before 1D pattern integration. H: Integrated $\mu$ XRD pattern showing relative peak intensities, note that the large peak at $11.7^{\circ} 2 \Theta$ is due to overlap between goethite and graphite.

\subsection{Discussion}

\subsubsection{Mineralogical Characteristics of the Cantung Tailings}

The sulfidic ore processed at Cantung has generated tailings that contain an assemblage of minerals characteristic of ARD and metal leaching processes (Jambor et al., 2005; Moncur et al., 2009; Lindsay et al., 2015). At Cantung, pyrrhotite is the dominant acid generator and in the presence of $\mathrm{O}_{2}$ (likely catalyzed by Fe-oxidizing bacteria and abiotically by ferrous iron) is readily oxidized, generating acid and releasing $\mathrm{Fe}^{2+}$ to solution. Ferrous iron is then rapidly oxidized to $\mathrm{Fe}^{3+}$, which is insoluble in oxidized waters and precipitates as ferrihydrite and/or goethite. Ferrihydrite is the more favorable precipitate of $\mathrm{Fe}^{3+}$ due to the lower energy required for its nucleation, but is less thermodynamically stable than goethite and in hydrous conditions with lower temperatures will transform to goethite with time (Cornell and Schwertmann, 2000). Despite the abundance of carbonate minerals available to neutralize acid generated during pyrrhotite oxidation, most tailings from the impoundments are considered net acid generating according to acid-base accounting (Mesh Environmental; 2008; Jamieson et al., 2019), although with a significant lag time of 20 years as determined by a humidity cell kinetic test conducted on fresh mill tailings sampled in 2007 (Mesh Environmental, 2008). The tailings ponds remain mostly unoxidized with circumneutral porewater as a result of maintenance of saturation and limited oxygen ingress, whereas acidic conditions exist in the FRT as a result of over 50 years of exposure to oxygenated waters on the Flat River floodplain. The mineralogical, geochemical, and physiological 
contrasts between the FRT and the tailings impoundments provides insight as to how tungsten and its host mineral scheelite behave after prolonged exposure to acidic conditions.

\subsubsection{The Tailings Impoundments}

In relatively unoxidized tailings from TP3, carbonate and sulfide minerals are abundant, scheelite appears unaltered, and the precipitation of secondary minerals is, for the most part, limited to $\mathrm{Fe}$ oxyhydroxide rims on pyrrhotite. Two of these rims analyzed by $\mu$ XRD and $\mu$ XRF contain small $(<5$ $\mu \mathrm{m})$ particles of scheelite, and have diffraction patterns matching hematite and maghemite (Fig. 3.8), whereas other Fe-oxyhydroxide rims analyzed do not have any peaks matching Fe-oxyhydroxide minerals. In low temperature neutral waters, ferrihydrite and goethite are more thermodynamically favorable precipitates of $\mathrm{Fe}^{3+}$ than hematite and maghemite (Cornell and Schwertmann, 2003) and are expected oxidation products of pyrrhotite in tailings (Belzile et al., 2004; Jambor et al., 2005; Moncur et al., 2009; Lindsay et al., 2015). Some Fe-oxyhydroxide rims did not diffract, and are likely amorphous metastable precursors of goethite (Cornell and Schwertmann, 2003). Hematite and maghemite are not expected to have formed in-situ in tailings due to the high temperatures required for their formation (Jambor and Dutrizac, 1998; Cornell and Schwertmann, 2003). These minerals have not been reported as present in the ore at Cantung (Mathieson and Clark, 1984), but may have formed during the milling process.

At Cantung, scheelite was concentrated via two stages of floatation followed by gravity separation, roasting, and magnetic separation of excess pyrrhotite and magnetite (Delaney and Bakker, 2014). It is plausible that during floatation, some pyrrhotite was oxidized and formed Fe-oxyhydroxide rims which were transformed to hematite and maghemite during roasting. Scheelite concentrate was roasted at temperatures between $260-430{ }^{\circ} \mathrm{C}$ (Cummings and Bruce, 1977; Delaney and Bakker, 2014), temperatures at which amorphous Fe-oxyhydroxide and ferrihydrite minerals dehydrate and transform to 
hematite (Jambor and Dutrizac, 1998; Cornell and Schwertmann, 2003), and may also transform to maghemite as a metastable intermediate phase (Eggleton and Fitzpatrick, 1988). Roaster-derived hematite and maghemite has previously been identified in tailings and soils adjacent to the abandoned Giant and Con gold mines in Yellowknife, Northwest Territories, Canada (Walker et al., 2005; Walker et al., 2015; Bromstad et al., 2017). The small fragments of scheelite identified within these rims may have been included during this process, although the uniform distribution of tungsten on the rims in places with no visible scheelite is intriguing (Fig. 3.8). We propose three scenarios to explain the presence of tungsten on these rims: 1) The rims contain scheelite fragments below the field of view of the SEM images, and the apparent uniform distribution of tungsten is caused by X-rays fluoresced radially from scheelite; 2)

Tungsten has been adsorbed to these rims after tailings deposition. This explanation is not favored due to the lack of observable tungsten on other Fe-oxyhydroxide rims analyzed from this sample, which would likely have a much higher surface capacity for adsorption due to being poorly crystalline or amorphous (Cornell and Schwertmann, 2003); and 3) Tungsten is structurally incorporated in the hematite and/or maghemite. Tungsten that is adsorbed to ferrihydrite can be incorporated into the structure of hematite during solid transformation by heterovalent substitution (Kreissl et al., 2016), and up to $1.72 \mathrm{wt} . \% \mathrm{WO}_{3}$ is reported in supergene hematite from the Grantcharitza tungsten deposit in Bulgaria (Tarassov et al., 2002). Using this model, tungsten leached from scheelite in the floatation cells would adsorb to ferrihydrite rims on pyrrhotite and then be incorporated into hematite by solid transformation within the roaster. Although the potential presence of scheelite below the field of view on the SEM image is a simpler explanation for the tungsten distribution observed on the $\mu$ XRF maps (Fig. 3.8), the possibility that tungsten is structurally incorporated within hematite may have implications for the mobility of tungsten within the tailings impoundments. Two other pyrrhotite grains with scheelite included in their rims were found in thin sections of TP3-TS-01 in December 2019. These rims are brighter than the grain interiors, and have tungsten and calcium peaks in their EDS spectra in places on the rim with no visible scheelite (Appendix I). The rarity of hematite-maghemite rims within TP3 may be due to the removal of most pyrrhotite by the sulfide floatation circuit, resulting in a low volume of pyrrhotite that was roasted. 
Roaster-derived hematite and maghemite are not observed or expected in the FRT because roasting was not added to the metallurgical process at Cantung until after tailings deposition in the Flat River ceased (Cummings and Bruce, 1977; Delaney and Bakker, 2014).

\subsubsection{The Flat River Tailings}

Prolonged exposure to oxygenated waters in the Flat River floodplain has extensively oxidized sulfide minerals and created acidic conditions within the FRT. Calcite and dolomite have been completely exhausted in the most altered tailings samples, and the only sulfide mineral remaining is chalcopyrite likely due to its relatively higher resistance to oxidation (Moncur et al., 2009). Iron released from the dissolution of Fe-sulfide minerals has precipitated in-situ as Fe-oxyhydroxide pseudomorphs of pyrrhotite, and as Fe-oxyhydroxide rims on virtually all non-sulfide grains. Synchrotron $\mu$ XRD patterns of all Fe-oxyhydroxide minerals analyzed match with goethite and in some cases lepidocrocite, and are characterized by Debye-Scherrer bands in the 2D XRD images that indicate they are microcrystalline (Fig. 3.8). Sulfur and calcium released from the dissolution of sulfide and carbonate minerals have precipitated as gypsum. The samples with the most acidic porewater have euhedral pseudocubic crystals of jarosite replacing goethite in pseudomorph grains and as rims on non-sulfide grains, that are texturally similar to jarosite precipitated in mud inside the Richmond Mine at Iron Mountain, California (Jamieson et al., 2005). Conditions required for jarosite growth require acidic $\mathrm{pH}(1-2)$, elevated aqueous $\mathrm{Fe}^{3+}$, and a source of monovalent cations $\left(\mathrm{K}^{+}, \mathrm{Na}^{+}\right.$, and/or $\mathrm{H}_{3} \mathrm{O}^{+}$) (Alpers et al., 1989; Jamieson et al., 2005). Potassium is likely sourced from the weathering of biotite and K-feldspar (Jambor et al., 2005; Bhatti et al., 2011), whereas $\mathrm{Fe}^{3+}$ is sourced from the oxidation of Fe-sulfide minerals and acidic dissolution of $\mathrm{Fe}$ oxyhydroxide minerals (Cornell and Schwertmann, 2003). Scheelite is abundant in the FRT and shows no evidence of alteration other than being coated by goethite, and no secondary tungsten minerals were identified. Furthermore, the total tungsten concentration of FRT samples is comparable to samples from the tailings impoundments (Fig. 3.7), indicating that little tungsten has been transported downstream. 


\subsubsection{Behaviour of Aqueous Tungsten}

The sulfate-rich waters of the Cantung tailings are characteristic of ARD, with $\mathrm{pH}$ and alkalinity reflecting the relative degree of tailings alteration. Surface waters on TP5 are circumneutral due to buffering by the dissolution of carbonate minerals in the tailings, whereas most FRT surface waters are slightly acidic with no alkalinity due to carbonate exhaustion. The Flat River waters upstream of the mine (FR01) and flowing through the FRT (FR02) have similar TDS and lower $\mathrm{SO}_{4}$ concentrations than tailings surface waters. However, boulders and cobbles in the river are stained by Fe-oxyhydroxide minerals in the FRT area but not upstream of the mine. Tailings at the bottom of the stream on TP5 also have an orange veneer of Fe-oxyhydroxide minerals with unoxidized tailings beneath, and all tailings in contact with FRT surface waters are oxidized.

In all surface waters at Cantung including the Flat River, unfiltered aliquots have higher iron concentrations than their filtered counterparts (Table 3.2), most likely due to the presence of suspended Fe-oxyhydroxide minerals, supported by the orange turbidity of the waters during sampling. Although iron is below detection limit in filtered aliquots from TP5, filtered FRT surface waters have iron concentrations as high as $221 \mathrm{mg} / \mathrm{L}$. The iron in these samples is likely a mixture of dissolved $\mathrm{Fe}^{2+}$ and suspended Fe-oxyhydroxide minerals smaller than $0.45 \mu \mathrm{m}$. The measured $\mathrm{pH}$ and Eh of these waters plot in the $\mathrm{FeOOH}_{(\mathrm{am})}$ field on an Fe-Pourbaix diagram, but close to the boundary between $\mathrm{Fe}^{2+}{ }_{(\mathrm{aq})}$ and $\mathrm{Fe}^{3+}{ }_{(\mathrm{s})}$. Field Eh measurements commonly disagree with measured redox couples (Langmuir, 1997), and in this case the reason is likely the sluggish oxidation of $\mathrm{Fe}^{2+}$ to $\mathrm{Fe}^{3+}$. Some of the iron in the filtered aliquot is probably freshly nucleated Fe-oxyhydroxide minerals, as they can be as small as 0.001 to $0.01 \mu \mathrm{m}$ (Cornell and Schwertmann, 2003) and thus can pass through the $0.45 \mu \mathrm{m}$ filters used in this study. Detectable tungsten concentrations in surface waters are restricted to waters with circumneutral $\mathrm{pH}$, and like iron, concentrations are highest in the unfiltered aliquots (Fig. 3.9). Copper concentrations are also higher in the unfiltered aliquots, and copper concentrations are highest in acidic FRT surface waters (Fig. 
3.9). Both the filtered and unfiltered aliquots of sample FR02 have detectable copper concentrations, but not tungsten.
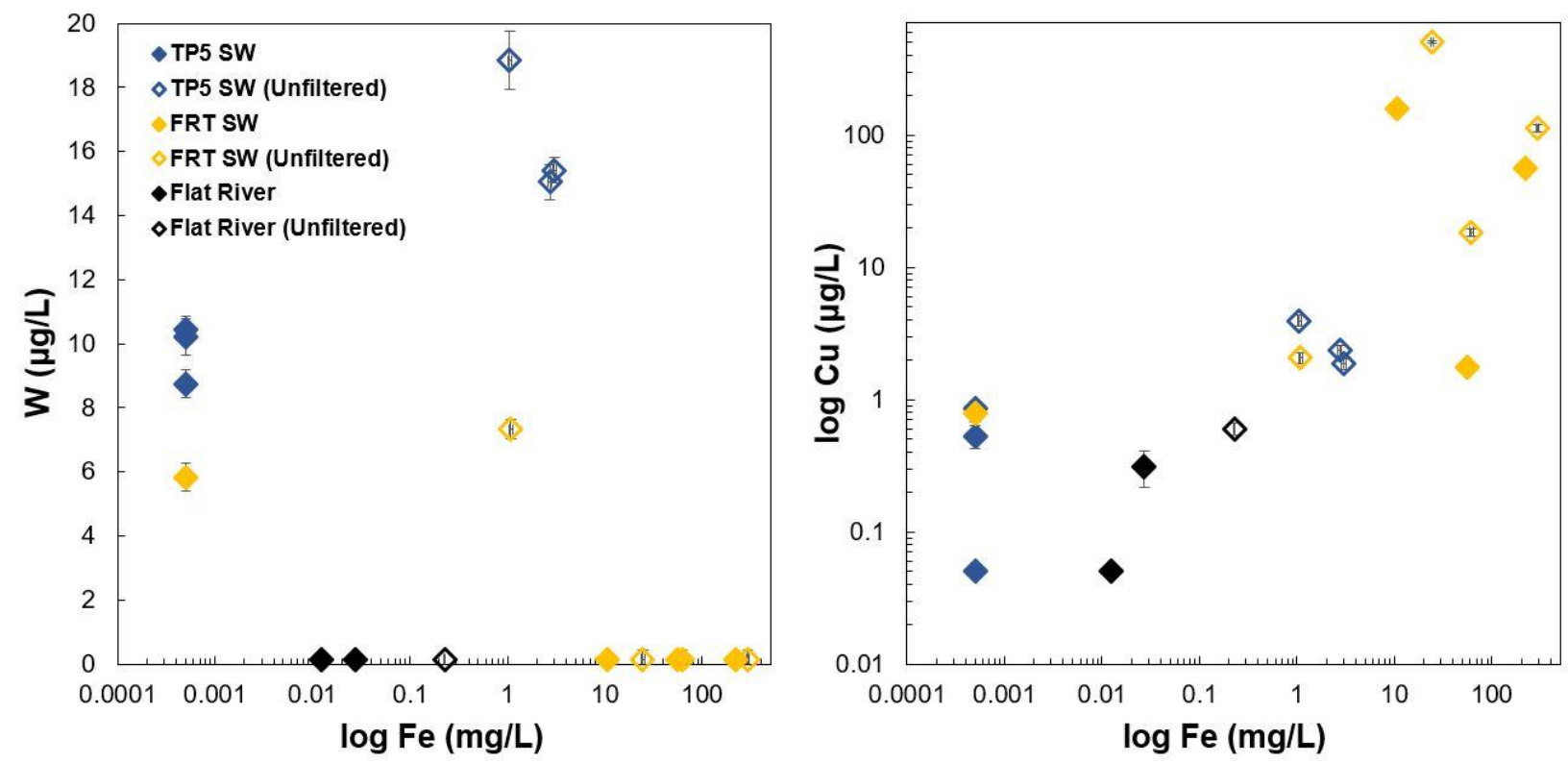

Figure 3.9 Tungsten and copper vs. iron concentrations for all surface waters collected in this study. Note that iron and copper concentrations are plotted on a log scale. Samples below the detection limit were assigned a value one half of the detection limit. Error bars are two standard deviations of the mean value of each ICP-MS measurement.

The higher tungsten concentrations in the unfiltered aliquots are likely due to adsorption on suspended Fe-oxyhydroxide minerals. A similar mechanism has also been suggested for tungsten transport in streams downstream of the historic W-Cu-F skarn tailings in Yxsjöberg, Sweden (Hällström et al., 2019). Tungsten forms anionic species in solution, most commonly $\mathrm{WO}_{4}{ }^{2-}$ in oxidized waters with neutral to alkaline $\mathrm{pH}$, and strongly adsorbs to mineral surfaces with decreasing $\mathrm{pH}$ (Gustafsson, 2003; Kashiwabara et al., 2013; Sun and Bostick, 2015; Hur and Reeder, 2016; Datta et al., 2017). Laboratory studies measuring $\mathrm{WO}_{4}{ }^{2-}$ adsorption to ferrihydrite report that near $100 \%$ of $\mathrm{WO}_{4}{ }^{2-}$ is adsorbed at $\mathrm{pH} 7$ (Gustafsson, 2003; Sun and Bostick, 2015) At the Mount Pleasant granitic tungsten mine in New Brunswick, Canada, tungsten concentrations as high as $7.1 \mathrm{mg} / \mathrm{L}$ are reported in tailings porewater with $\mathrm{pH}=10.5$ and decrease with decreasing $\mathrm{pH}$ (Petrunic and Al, 2005). Tungsten concentrations along groundwater gradients in Maryland and Texas, USA, were also found to decrease with $\mathrm{pH}$ and increasing 
Fe-oxyhydroxide mineral content (Johannesson et al., 2013). It is therefore probable that the relatively low tungsten concentrations in surface waters at Cantung is due to scavenging by $\mathrm{Fe}$-oxyhydroxide minerals formed from pyrrhotite oxidation, although waters with a broader $\mathrm{pH}$ range are needed to observe an adsorption envelope indicative that $\mathrm{pH}$-dependent adsorption is the primary factor controlling dissolved tungsten concentrations. We would expect that the acidic FRT surface waters would also have elevated tungsten concentrations in the unfiltered aliquots (indicative of tungsten adsorbed to suspended Fe-oxyhydroxide minerals); however, tungsten is below the detection limit of $100 \mathrm{ng} / \mathrm{L}$ in these samples, whereas unfiltered copper concentrations are as high as $505 \mu \mathrm{g} / \mathrm{L}$ (Fig. 3.9). The morphology of stagnant FRT ponds suggests that they are sometimes connected to the Flat River and the pond waters probably have low residence times, so a kinetic effect associated with the solubility and/or reactivity of their host minerals may explain the contrasting concentrations of tungsten and copper. We propose that reason the unfiltered aliquots have high copper concentrations but not tungsten is because chalcopyrite is dissolving faster than scheelite in these ponds.

The weathering rates of scheelite in different aqueous solutions are largely unknown, whereas the dissolution rates of chalcopyrite in oxygenated waters are well documented (Kimball et al., 2010). Scheelite is commonly regarded as insoluble and non-reactive, and a broad range of Ksp values for scheelite exists in the literature making thermodynamic modelling of scheelite weathering difficult (Atademir et al., 1978; Marinakis and Kelsall, 1987; Wood and Samson, 2000; Pina et al., 2000; Seiler et al., 2005; Montgomery, 2012). Furthermore, the mechanism of scheelite dissolution remains undocumented for natural systems. A metallurgical study investigating the surface properties of scheelite during froth floatation by Atademir et al. (1978) suggested ion exchange of $\mathrm{WO}_{4}{ }^{2-}$ by $\mathrm{CO}_{3}{ }^{2-}$ on scheelite surfaces as an important reaction i.e.:

$$
\mathrm{CaWO}_{4(\mathrm{~s})}+\mathrm{CO}_{3}{ }^{2-}{ }_{(\mathrm{aq})} \rightarrow \mathrm{CaCO}_{3(\mathrm{~s})}+\mathrm{WO}_{4}{ }^{2-}{ }_{(\mathrm{aq})}
$$

This reaction is postulated to occur in $\mathrm{HCO}_{3}{ }^{-}$dominated groundwaters (Montgomery, 2012) and in W-Cu-F skarn tailings at Yxsjöberg, Sweden (Hällström et al., 2019), but to our knowledge no other 
mechanisms for scheelite weathering have been suggested. The abundance of scheelite in the FRT suggests that it is stable in acidic, sulfate-rich waters, and therefore the leachability of scheelite is low in ARD environments. It is possible that the lack of $\mathrm{HCO}_{3}{ }^{-}$in FRT porewaters prevents scheelite from weathering, however more studies are needed to constrain the solubility and reactivity of scheelite.

The aqueous speciation of tungsten in surface waters is of interest as some species have been found to be more toxic than others. Strigul et al. (2010) found polytungstate species (e.g. $\mathrm{W}_{7} \mathrm{O}_{24}{ }^{-6}$ and $\mathrm{H}_{2} \mathrm{~W}_{12} \mathrm{O}_{43}{ }^{-10}$ ) to be more toxic to fish than $\mathrm{WO}_{4}{ }^{2-}$, and polytungstate species have been shown to be bioavailable to plants and accumulate in higher trophic levels (Kennedy et al., 2012). Polytungstate species form at high tungsten concentrations (>0.184 to $1.84 \mathrm{mg} / \mathrm{L}$ ) at low $\mathrm{pH}$ (Cruywagen, 2000), and are predicted to persist as stable species in neutral waters (Bednar et al., 2008; Bednar et al., 2009). However, due to the strong adsorption of tungsten at acidic $\mathrm{pH}$, it is unlikely tungsten would reach high enough concentrations to polymerize in Cantung surface waters and porewaters. Thiotungstate species (e.g. $\mathrm{WS}_{4}{ }^{2-}$ ) are also expected to form in anoxic, highly sulfidic waters (Johannesson et al., 2013; Mohajerin et al., 2014; Mohajerin et al., 2016; Cui et al., 2020), although the toxicity of these species is currently unknown. Surface waters and porewaters at Cantung are $\mathrm{SO}_{4}$-rich so thiotungstate species are not expected. It is therefore likely that $\mathrm{WO}_{4}{ }^{2-}$ is the only tungsten species in Cantung surface waters and porewaters.

\subsubsection{Tungsten Mobility in the Flat River Tailings}

Processes including secondary mineral precipitation and adsorption are known to attenuate metals in ARD environments (Jamieson et al., 2015; Lindsay et al., 2015). The abundance of scheelite in the FRT suggests that it is relatively immune to dissolution in acidic sulfate waters, and FRT porewater has probably not had tungsten concentrations high enough to reach saturation of secondary tungsten minerals. To our knowledge, other naturally occurring secondary tungsten minerals such as anthoinite 
$\left(\mathrm{AlWO}_{3}(\mathrm{OH})_{3}\right)$, hydrokenoelsmoreite $\left((\mathrm{W}, \mathrm{Fe})_{2}(\mathrm{O}, \mathrm{OH})_{6} \cdot \mathrm{H}_{2} \mathrm{O}\right)$, and tungstite $\left(\mathrm{WO}_{3} \cdot \mathrm{H}_{2} \mathrm{O}\right)$ have only been observed in the supergene zones of ore deposits (Sahama, 1981; Shimobayashi et al., 2012; Tarassov et al., 2018) with the exception of a yellow rim on scheelite in W-Cu-F skarn tailings at Yxsjöberg, Sweden, which was inferred to be secondary tungstite (Hällström et al., 2018). However, tungsten can substitute in primary and secondary molybdenum minerals due to the same charge and similar ionic radii of the $\mathrm{WO}_{4}{ }^{2-}$ and $\mathrm{MoO}_{4}{ }^{2-}$ anions ( $\mathrm{r}_{\text {ion }}=0.68, \mathrm{r}_{\text {ion }}=0.62$, respectively; Railsback, 2008). For example, solid solutions exist between stolzite $\left(\mathrm{PbWO}_{4}\right)$ and wulfenite $\left(\mathrm{PbMoO}_{4}\right)$ and secondary wulfenite with up to $\sim 5$ mol.\% W is reported in the Mount Pleasant tungsten tailings in New Brunswick, Canada (Petrunic et al., 2006). Molybdenite was not identified in any tailings samples, and the molybdenum content of the Cantung tailings is low $(0.99-28.2 \mathrm{ppm}$, determined by 4-acid digestion), so it is unlikely that and secondary molybdenum minerals have precipitated in the Cantung tailings. Secondary minerals in the FRT that might be candidates to host tungsten are gypsum and jarosite, which can host trace amounts of other elements such as $\mathrm{Cu}, \mathrm{Pb}$, and $\mathrm{Zn}$ (Alpers and Nordstrom, 1994; Jamieson et al., 2005). It is unlikely that gypsum and jarosite host tungsten due to $\mathrm{WO}_{4}{ }^{2-}$ being too large to substitute for $\mathrm{SO}_{4}{ }^{2-}\left(\mathrm{r}_{\text {ion }}=0.68, \mathrm{r}_{\text {ion }}=\right.$ 0.29 , respectively; Railsback, 2008) in these minerals. Therefore, the most likely secondary host of tungsten in the FRT is tungsten that is adsorbed to or structurally incorporated within Fe-oxyhydroxide minerals.

The partial leach extractions were employed to determine the tungsten content of Feoxyhydroxide minerals within the tailings impoundments and the FRT. We predicted that due to the strong adsorption propensity of tungsten at acidic $\mathrm{pH}$, the hydroxylamine leaches would recover significant amounts of tungsten by dissolving Fe-oxyhydroxide minerals in the FRT samples. It is likely that a large portion of Fe-oxyhydroxide minerals in the FRT samples were not dissolved by the hydroxylamine leaches, supported by their orange residues after leaching. Iron is dominantly hosted within pyrrhotite in the tailings impoundments and within Fe-oxyhydroxide minerals in the FRT (Fig. 3.5), so it is not surprising that the hydroxylamine leaches yield more iron from the FRT samples than 
tailings impoundment samples (Fig. 3.7). However, for both the FRT and tailings impoundment samples, the amount of iron recovered by the hydroxylamine leaches is only a fraction of the iron leached by aqua regia (average of $18 \%$ for the FRT and $13 \%$ for the tailings impoundments; Fig. 3.7). The effectiveness of hydroxylamine hydrochloride in dissolving Fe-oxyhydroxide minerals has been the subject of much debate (Chao et al., 1984; Hall et al., 1996; Cardoso Fonseca and da Silva, 1998; McCarty et al., 1998; Dold et al., 2003). Although proven to be effective at reductively dissolving amorphous and poorly crystalline Mn-oxyhydroxides (Chao et al., 1984 and references therein; Leybourne et al., 2003), hydroxylamine hydrochloride dissolves Fe-oxyhydroxide minerals less readily, with their resistance increasing with crystallinity and grain size (Hall et al., 1996; Leybourne et al., 2003). At weak acid strengths and lower temperatures, amorphous Mn and Fe-oxyhydroxide phases dissolve, leaving crystalline Fe-oxyhydroxide minerals unaffected with the exception of their surfaces. By increasing the acid strength and raising the temperature, crystalline Fe-oxyhydroxide minerals may dissolve to a greater extent (Hall et al., 1996). With these precautions in mind, the low iron yields by the cold hydroxylamine leach suggests that a very small portion of the Fe-oxyhydroxide minerals are amorphous, and iron recovered by the hot hydroxylamine leach is probably associated with the most thermodynamically unstable Fe-oxyhydroxide minerals; i.e., those that are poorly crystalline and/or have the highest surface area.

The tungsten recovered from the hydroxylamine leaches is therefore also associated with the least stable Fe-oxyhydroxide minerals, but no conclusion can be made as to the tungsten content of Feoxyhydroxide minerals that were not dissolved. Although aqua regia digests all Fe-oxyhydroxide phases regardless of crystallinity, the high tungsten recovery from aqua regia (Fig. 3.7) is probably due to the partial dissolution of scheelite and may not represent tungsten associated with Fe-oxyhydroxide minerals. Atademir et al. (1978) reported that $40 \%$ of scheelite was dissolved by repeated treatments with 1:1 $\mathrm{HNO}_{3}$ and $\mathrm{HCl}$, which is similar to the $1: 3 \mathrm{HNO}_{3}$ and $\mathrm{HCl}$ mixture used in this study. The lower recoveries by aqua regia from the FRT samples compared to the tailings impoundment samples is likely 
because FRT scheelite is generally coarser grained than scheelite in the tailings impoundments (Jamieson et al., 2019), and therefore has a lower surface area for reaction.

Although we are unable to conclude whether tungsten is associated with Fe-oxyhydroxide minerals not dissolved by the hydroxylamine leaches, comparisons can be made between the recoveries from samples from the tailings impoundments and the FRT. The FRT samples have higher iron recoveries by the hydroxylamine leaches, however more tungsten was recovered from the tailings impoundment samples (Fig. 3.7). This suggests that more tungsten is associated with amorphous and/or poorly crystalline Fe-oxyhydroxide minerals in the tailings impoundments than the FRT. Fe-oxyhydroxide minerals within the tailings impoundments are relatively immature compared to FRT, where most Feoxyhydroxide minerals have recrystallized to goethite or jarosite. We suggest that dynamic fluvial and geochemical processes within the Flat River floodplain may have transported Fe-oxyhydroxide minerals with adsorbed tungsten downstream. During deposition of the FRT, tungsten leached from scheelite was likely adsorbed to amorphous or poorly crystalline Fe-oxyhydroxide minerals formed from pyrrhotite oxidation, and was either immediately washed downstream or was left in-situ. As the FRT matured, the dissolution of Fe-oxyhydroxide phases to form goethite (and ultimately jarosite) likely released tungsten to solution, at least temporarily, decreasing the overall content of labile tungsten over time. Furthermore, high energy flooding events have been recorded by a stream hydrograph installed in the Flat River between 1973 - 1988 (Environment Canada, 2020). These events may have enhanced this process by mechanically reworking tailings otherwise sheltered from transport by the Flat River. Although these processes could act as a transport mechanism for labile W, the apparent stability of scheelite appears to be the dominant control on tungsten mobility within the FRT. The total tungsten concentrations of the FRT compared to the tailings impoundments (Fig. 3.7) suggests that low amounts of tungsten have been lost to the Flat River. 


\subsubsection{Considerations for Tungsten Behaviour in Mine Waste}

This study shows that tungsten concentrations in mine leachate is controlled by $\mathrm{pH}$, the presence of adsorbents (i.e. Fe-oxyhydroxide minerals), and by the low reactivity of scheelite. More research is needed on the reactivity and solubility of scheelite (and wolframite) in different aqueous solutions, particularly in acidic sulfate-dominated waters, as most global tungsten production is from skarn deposits with potentially acid generating mineralogies similar to Cantung (Kwak, 2012; Brown and Pitfield, 2014). The other most common deposit types where tungsten is mined are associated with evolved granitic intrusions that mineralize scheelite and/or wolframite alongside a diverse assemblage of gangue minerals not typically present in skarn deposits (Werner et al., 2014). Mine waste generated by processing ore from these deposits may or may not contain Fe-sulfide and carbonate minerals and can therefore have wide ranges of leachate $\mathrm{pH}$, and can contain minerals that upon dissolution may enhance or inhibit tungsten mobility. For example, the dissolution of fluorite in tailings from the Mount Pleasant tungsten deposit has enhanced silicate mineral dissolution and created highly alkaline porewaters in which tungsten is most mobile, and some tungsten is attenuated by incorporation within secondary wulfenite (Petrunic et al, 2006). Production from tungsten deposits containing secondary tungsten minerals has been avoided due to these minerals causing issues with metallurgical recoveries (Schmidt, 2012), but these deposits may become more important sources of tungsten as deposits containing solely scheelite and/or wolframite are depleted (Brown and Pitfield, 2014). Further study of the solubility and reactivity of secondary tungsten minerals is important to increase the production efficiency from these deposits, and to better predict the formation of these minerals in mine waste and other environmental systems. Although dissolved tungsten is not currently a regulated contaminant in Canada, the United States, or the European Union (Canadian Council of Ministers of the Environment, 2008; Strigul et al., 2009; Datta et al., 2017), the release of Wbearing mine effluent to alkaline and Fe-reducing water reservoirs should be avoided. 


\subsection{Conclusions}

- Acidic conditions prevail in the FRT as a result of extensive sulfide oxidation and exhaustion of carbonate minerals. The tailings impoundments remain mostly unoxidized as a result of limited oxygen ingress due to sustained water saturation.

- Scheelite appears stable after over 50 years of exposure to acidic sulfate dominated porewaters within the FRT, and shows no signs of alteration. Secondary tungsten minerals were not observed in the FRT or the tailings impoundments, probably because porewaters have not had tungsten concentrations high enough to reach saturation of these phases.

- Circumneutral surface waters on TP5 transport tungsten adsorbed to suspended Feoxyhydroxide phases, and as dissolved species, likely $\mathrm{WO}_{4}{ }^{2-}$.

- Tungsten concentrations are below the detection limit in FRT porewaters and surface waters due the low reactivity of scheelite and strong tungsten adsorption to $\mathrm{Fe}$ oxyhydroxide minerals.

- Labile tungsten associated with Fe-oxyhydroxide phase $s$ in the FRT may have been flushed to the Flat River during Fe-oxyhydroxide recrystallization and during high energy flooding events.

- More research is needed regarding the solubility and reactivity of primary and secondary tungsten minerals in different aqueous solutions, particularly acidic sulfatedominated waters as most tungsten mining is from skarn deposits with potentially acid generating mineralogies. 


\subsection{References}

Agency for Toxic Substances and Disease Registry (ATSDR). 2005. Toxicological profile for Tungsten. Atlanta, GA: U.S. Department of Health and Human Services, Public Health Service. Retrieved from https://www.atsdr.cdc.gov/ToxProfiles/tp.asp?id=806\&tid=157

Alpers, C.N., D.K. Nordstrom, and J.W. Ball. 1989. Solubility of Jarosite Solid Solutions Precipitated from Acid Mine Waters, Iron Mountain, California, USA. Sciences Geologiques, Bulletin. vol. 42, no. 4, pp. 281-298.

Alpers, C.N., D.W. Blowes, D.K. Nordstrom, and J.L. Jambor and Nordstrom. 1994. Secondary Minerals and Acid Mine-water Chemistry. In J.L. Jambor, D.W. Blowes, Environmental Geochemistry of Sulfide Mine-Wastes. Mineralogical Association of Canada. pp. 247-270.

Atademir, M.R., J.A. Kitchener, and H.L. Shergold. 1979. The Surface Chemistry and Floatation of Scheelite I. Solubility and Surface Characteristics of Precipitated Calcium Tungstate. Journal of Colloid and Interface Science. vol. 71, no. 3, pp. 466-476. https://doi.org/10.1016/0021-9797(79)90321-7

Bednar, A.J., W. T. Jones, R. E. Boyd, D. B. Ringelberg, and S. L. Larson. 2008. Geochemical Parameters Influencing Tungsten Mobility in Soils. Journal of Environment Quality. vol. 37, no. 1, 229233. https://doi.org/10.2134/jeq2007.0305

Bednar, A.J., R.E. Boyd, W.T. Jones, C.J. McGrath, D.R. Johnson, M.A. Chappell, and D.B. Ringelberg. 2009. Investigations of Tungsten Mobility in Soil Using Column Tests. Chemosphere. vol. 75, no. 8, pp. 1049-56. https://doi.org/10.1016/j.chemosphere.2009.01.039

Belzile, N., Y. Chen, M. Cai, and Y. Li. 2004. A Review on Pyrrhotite Oxidation. Journal of Geochemical Exploration. vol. 84, no. 2, pp. 65-76. https://doi.org/10.1016/j.gexplo.2004.03.003

Bhatti, T.M., J.M. Bigham, L. Carlson, and O.H. Tuovinen. 1993. Mineral Products of Pyrrhotite Oxidation by Thiobacillus Ferrooxidans. Applied and Environmental Microbiology. vol. 59, no. 6 pp. 1984-90. https://doi.org/10.1128/AEM.59.6.1984-1990.1993

Bostick, B. C., J. Sun, J. D. Landis, and J.L. Clausen. 2018. Tungsten Speciation and Solubility in Munitions-Impacted Soils. Environmental Science \& Technology. vol. 52, no. 3, pp. 1045-1053. https://doi.org/10.1021/acs.est.7b05406

Bowell, R. J., C.N. Alpers, H.E. Jamieson, D.K. Nordstrom, \& J. Majzlan. 2014. The Environmental Geochemistry of Arsenic - an Overview-. Reviews in Mineralogy and Geochemistry. vol. 79, no. 1, pp. 1-16. https://doi.org/10.2138/rmg.2014.79.1

Bromstad, M.J., L.A. Wrye, and H.E. Jamieson. 2017. The Characterization, Mobility, and Persistence of Roaster-Derived Arsenic in Soils at Giant Mine, NWT. Applied Geochemistry. vol. 82, pp. 102-118. https://doi.org/10.1016/j.apgeochem.2017.04.004 
Brookins, D.G. 1987. Tungsten. In Eh-pH Digrams for Geochemistry. Springer, Berlin, Heidelberg. pp. 106-107. https://doi.org/10.1007/978-3-642-73093-1

Brown, T., and P. Pitfield. 2014. Tungsten. In Critical Metals Handbook. John Wiley \& Sons. pp. 385413. https://doi.org/0.1002/9781118755341.ch16

Canadian Council of Ministers of the Environment. 2008. Canadian Water Quality Guidelines. Retrieved from https://www.ccme.ca/files/Resources/supporting_scientific_documents/cwqg_pn_1040.pdf

Cardoso Fonseca, E., and E. F. da Silva. 1998. Application of Selective Extraction Techniques in MetalBearing Phases Identification: A South European Case Study. Journal of Geochemical Exploration. vol. 61, no. 1-3, pp. 203-12. https://doi.org/10.1016/S0375-6742(97)00051-4

Chao, T.T. 1984. Use of Partial Dissolution Techniques in Geochemical Exploration. Journal of Geochemical Exploration. vol. 20, no. 2, pp.101-35. https://doi.org/10.1016/0375-6742(84)90078-5

Cornell, R. M., and U. Schwertmann. 2003. The Iron Oxides: Structure, Properties, Reactions, Occurrences and Uses. John Wiley \& Sons. https://doi.org/10.1002/3527602097

Cruywagen, J. J. 2000. Protonation, Oligomerization, and Condensation Reactions of Vanadate (V), Molybdate (VI), and Tungstate (VI). Advances in Inorganic Chemistry. vol. 49, pp. 127-182.

https://doi.org/10.1016/S0898-8838(08)60270-6

Cui, M., T.j. Mohajerin, S. Adebayo, S. Datta, and K.H. Johannesson. 2020. Investigation of Tungstate Thiolation Reaction Kinetics and Sedimentary Molybdenum/Tungsten Enrichments: Implication for Tungsten Speciation in Sulfidic Waters and Possible Applications for Paleoredox Studies. Geochimica et Cosmochimica Acta. In press. https://doi.org/10.1016/j.gca.2020.04.004

Cummings, W.W., and D.E. Bruce. 1977. Canada Tungsten - Change to Underground Mining \& Description of Mine-Mill Procedures. CIM Bulletin. vol. 70, no. 784, pp. 94-101.

Datta, S., Vero, S.E., G.M. Hettiarachchi, and K. Johannesson. 2017. Tungsten Contamination of Soils and Sediments: Current State of Science. Current Pollution Reports. vol. 3, no. 1, pp. 55-64.

https://doi.org/10.1007/s40726-016-0046-0

Delaney, B., and F.J. Bakker. 2014. Technical Report on the Cantung Mine, Northwest Territories, Canada. Report for NI 43-101. Retrieved from http://www.natungsten.com/i/pdf/Tech-Report-CanTungMine-Northwest.pdf

Dold, B. 2003. Speciation of the Most Soluble Phases in a Sequential Extraction Procedure Adapted for Geochemical Studies of Copper Sulfide Mine Waste. Journal of Geochemical Exploration. vol. 80, no. 1, pp. 55-68. https://doi.org/10.1016/S0375-6742(03)00182-1

Dzombak, D. A., and F.M. Morel, 1990. Surface Complexation Modeling: Hydrous Ferric Oxide. John Wiley \& Sons. 
Eggleton, R.A., and R.W. Fitzpatrick. 1988. New Data and a Revised Structural Model for Ferrihydrite. Clays Clay Minerals. vol. 36, pp. 111-124. https://doi.org/10.1346/CCMN.1988.0360203

Elongo, V., P. Lecumberri-Sanchez, H. Legros, H. Falck, E. Adlakha, and A. Roy-Garand. 2020. Paragenetic Constraints on the Cantung, Mactung and Lened Tungsten Skarn Deposits, Canada: Implications for Grade Distribution. Ore Geology Reviews. In press.

https://doi.org/10.1016/j.oregeorev.2020.103677

Environment Canada. 2019. Canadian Climate Normals 1961-1990, Tungsten Station, Northwest Territories. Retrieved from https://climate.weather.gc.ca/climate_normals/results_1961_1990_e.html?searchType=stnName\&txtStati onName $=$ tungsten $\&$ searchMethod $=$ contains $\&$ txtCentralLatMin $=0 \&$ txtCentralLatSec $=0 \&$ txtCentralLong Min $=0 \&$ txtCentralLong $S e c=0 \& \operatorname{stn} I D=786 \&$ dispBack $=1$

Environment Canada. 2020. Monthly Discharge for Flat River at Cantung Camp (10EA002) [NT]. Retrieved from https://wateroffice.ec.gc.ca/report/historical e.html?stn=10EA002\&dataType=Monthly\&parameterType= $\underline{\text { Level \&year }=2010 \& \text { mode }=\text { Graph }}$

Gaines, P. 2018. Sample Preparation Guide: Part 16. Samples Containing Tungsten. Inorganic Ventures. Retrieved from: https://www.inorganicventures.com/sample-preparation-guide/samples-containingtungsten

Gammons, C. H., B.L. Pape, S.R. Parker, S.R. Poulson, and C.E. Blank. 2013. Geochemistry, Water Balance, and Stable Isotopes of a "Clean" Pit Lake at an Abandoned Tungsten Mine, Montana, USA. Applied Geochemistry. vol. 36, pp. 57-69. https://doi.org/10.1016/j.apgeochem.2013.06.011

Gunsinger, M.R., C.J. Ptacek, D.W. Blowes, and J.L. Jambor. 2006. Evaluation of Long-Term Sulfide Oxidation Processes within Pyrrhotite-Rich Tailings, Lynn Lake, Manitoba. Journal of Contaminant Hydrology. vol. 83, no. 3-4, pp. 149-70. https://doi.org/10.1016/j.jconhyd.2005.10.013

Guo, Q., Y. Li, and L. Luo. 2019. Tungsten from Typical Magmatic Hydrothermal Systems in China and its Environmental Transport. Science of The Total Environment. vol. 657, pp. 1523-1534.

https://doi.org/10.1016/j.scitotenv.2018.12.146

Gustafsson, J. P. 2003. Modelling Molybdate and Tungstate Adsorption to Ferrihydrite. Chemical Geology. vo. 200, no. 1-2, pp. 105-15. https://doi.org/10.1016/S0009-2541(03)00161-X

Gutiérrez, M., K. Mickus, and L.M. Camacho. 2016. Abandoned PbZn Mining Wastes and their Mobility as Proxy to Toxicity: A review. Science of the Total Environment. vol. 565, pp. 392-400.

https://doi.org/10.1016/j.scitotenv.2016.04.143

Hall, G.E.M., J.E. Vaive, R. Beer, and M. Hoashi. 1996. Selective Leaches Revisited, with Emphasis on the Amorphous Fe Oxyhydroxide Phase Extraction. Journal of Geochemical Exploration. vol. 56, no. 1, pp. 59-78. https://doi.org/10.1016/0375-6742(95)00050-X 
Hällström, L., L. Alakangas, and O. Martinsson. 2018. Geochemical Characterization of W, Cu and F Skarn Tailings at Yxsjöberg, Sweden. Journal of Geochemical Exploration. vol. 194, pp. 266-79. https://doi.org/10.1016/j.gexplo.2018.09.001

Hällström, L., L. Alakangas, and O. Martinsson. 2019. Scheelite Weathering and Tungsten (W) Mobility in Historical Oxidic-Sulfidic Skarn Tailings at Yxsjöberg, Sweden. Environmental Science and Pollution Research. vol. 27, pp. 6180-6192. https://doi.org/10.1007/s11356-019-07305-1

Hur, H., and R.J. Reeder. 2016. Tungstate Sorption Mechanisms on Boehmite: Systematic Uptake Studies and X-Ray Absorption Spectroscopy Analysis. Journal of Colloid and Interface Science. vol. 461, pp. 249-60. https://doi.org/10.1016/j.jcis.2015.09.011

Jambor, J.L., C.J. Ptacek, D.W. Blowes, and M.C. Moncur. 2005. Acid drainage from the oxidation of iron sulfides and sphalerite in mine wastes. Proceedings from: Lead \& Zinc '05, Vol. 1, The Mining and Materials Processing Institute of Japan, T. Fujisawa, (Ed.). pp. 715-737. Retrieved from https://www.researchgate.net/profile/Michael_Moncur/publication/329161911_Acid_drainage_from_the oxidation of iron sulfides and sphalerite/links/5bf8aa5f458515a69e374e82/Acid-drainage-from-theoxidation-of-iron-sulfides-and-sphalerite.pdf

Jambor, J.L., and J.E. Dutrizac. 1988. Occurrence and Constitution of Natural and Synthetic Ferrihydrite, a Widespread Iron Oxyhydroxide. Chemical Reviews. vol. 98, no. 7, pp. 2549-86. https://doi.org/10.1021/cr970105t

Jamieson. H.E., B.G. Kazamel, M.I. Leybourne, and A. Dobosz. 2019. Increasing Value and Decreasing Envrionmental Risk by Reprocessing and Stabilizing Tungsten Tailings at Cantung Mine, NT, Canada. Life with Ore Deposits on Earth - 15th SGA Biennial Meeting 2019. vol. 4, pp. 1607-1610. Retrieved from https://www.researchgate.net/publication/342610845 Increasing value and decreasing environmental r isk by reprocessing and stabilizing tungsten tailings at Cantung Mine NT Canada

Jamieson, H. E., C. Robinson, C.N. Alpers, D.K. Nordstrom, A. Poustovetov, and H.A. Lowers. 2005. The Composition of Coexisting Jarosite-group Minerals and Water from the Richmond Mine, Iron Mountain, California. The Canadian Mineralogist. vol. 43, no. 4, pp. 1225-1242.

https://doi.org/10.2113/gscanmin.43.4.1225

Johannesson, K.H., W.B. Lyons, E.Y. Graham, and K.A. Welch. 2000. Oxyanion Concentrations in Eastern Sierra Nevada Rivers-3. Boron, Molybdenum, Vanadium, and Tungsten. Aquatic Geochemistry. vol. 6, no. 1, pp. 19-46. https://doi.org/10.1023/A:1009622219482

Johannesson, K.H., H.B. Dave, T.J Mohajerin, and S. Datta. 2013. Controls on Tungsten Concentrations in Groundwater Flow Systems: The Role of Adsorption, Aquifer Sediment Fe(III) Oxide/Oxyhydroxide Content, and Thiotungstate Formation. Chemical Geology. vol. 351, 76-94.

https://doi.org/10.1016/j.chemgeo.2013.05.002 
Johnson, R.H, D.W Blowes, W.D Robertson, and J.L Jambor. 2000. The Hydrogeochemistry of the Nickel Rim Mine Tailings Impoundment, Sudbury, Ontario. Journal of Contaminant Hydrology. vol. 41, no. 1-2, pp. 49-80. https://doi.org/10.1016/S0169-7722(99)00068-6

Jeong, G. Y., and B.Y. Lee. 2003. Secondary Mineralogy and Microtextures of Weathered Sulfides and Manganoan Carbonates in Mine Waste-rock Dumps, with Implications for Heavy-metal Fixation. American Mineralogist. vol. 88, no. 11-12, pp. 1933-1942. https://doi.org/10.1007/978-3-642-23327-2_3

Kashiwabara, T., Y. Takahashi, M.A. Marcus, T. Uruga, H. Tanida, Y. Terada, and A. Usui. 2013. Tungsten Species in Natural Ferromanganese Oxides Related to Its Different Behavior from Molybdenum in Oxic Ocean. Geochimica et Cosmochimica Acta. vol. 106, pp. 364-78.

https://doi.org/10.1016/j.gca.2012.12.026

Kennedy, A.J., D.R. Johnson, J.M. Seiter, J.H. Lindsay, R.E. Boyd, A.J. Bednar, and P.G. Allison. 2012. Tungsten Toxicity, Bioaccumulation, and Compartmentalization into Organisms Representing Two Trophic Levels. Environmental Science \& Technology. vol. 46, no. 17, pp. 9646-52. https://doi.org/10.1021/es300606x

Kimball, B. E., J.D. Rimstidt, and S.L. Brantley. 2010. Chalcopyrite Dissolution Rate Laws. Applied Geochemistry. vol. 25, no. 7, pp. 972-983. https://doi.org/10.1016/j.apgeochem.2010.03.010

Koutsospyros, A., W. Braida, C. Christodoulatos, D. Dermatas, and N. Strigul. 2006. A Review of Tungsten: From Environmental Obscurity to Scrutiny. Journal of Hazardous Materials. vol. 136, no. 1, pp. 1-19. https://doi.org/10.1016/j.jhazmat.2005.11.007

Kreissl, S., R. Bolanz, J. Göttlicher, R. Steininger, M. Tarassov, and G. Markl. 2016. Structural Incorporation of $\mathrm{W}^{6+}$ into Hematite and Goethite: A Combined Study of Natural and Synthetic Iron Oxides Developed from Precursor Ferrihydrite and the Preservation of Ancient Fluid Compositions in Hematite. American Mineralogist. vol. 101, no. 12, pp. 2701-15. https://doi.org/10.2138/am-2016-5690

Kwak, T.A. 2012. W-Sn Skarn Deposits: and Related Metamorphic Skarns and Granitoids. Elsevier.

Langmuir, D. 1997. Aqueous Environmental Geochemistry. Prentice Hall, NJ.

Leal-Ayala, D. R., J.M. Allwood, E. Petavratzi, T.J. Brown, G. Gunn. 2015. Mapping the Global Flow of Tungsten to Identify Key Material Efficiency and Supply Security Opportunities. Resources, Conservation and Recycling. vol. 103, pp. 19-28. https://doi.org/10.1016/j.resconrec.2015.07.003

Leybourne, M.I., D.R. Boyle, W.D. Goodfellow, S.R. McCutcheon, and J.M. Peter. 2003. Interpretation of Stream Water and Sediment Geochemistry in the Bathurst Mining Camp, New Brunswick: Applications to Mineral Exploration. Massive Sulphide Deposits of the Bathurst Mining Camp, New Brunswick, and Northern Maine. vol. 11, pp. 741-762. https://doi-org.proxy.queensu.ca/10.5382/Mono.11 
Lindsay, M., M.C. Moncur, J.G. Bain, J.L. Jambor, C.J. Ptacek, and D.W. Blowes. 2015. Geochemical and Mineralogical Aspects of Sulfide Mine Tailings. Applied Geochemistry. vol. 57, pp. 157-77. https://doi.org/10.1016/j.apgeochem.2015.01.009

Majzlan, J., K. Grevel, and A. Navrotsky. 2003. Thermodynamics of Fe Oxides: Part II. Enthalpies of Formation and Relative Stability of Goethite (a-FeOOH), Lepidocrocite (g-FeOOH), and Maghemite (gFe2O3). American Mineralogist. vol. 88, pp. 855-859. https://doi.org/10.2138/am-2003-5-614

Marinakis, K.I., and G.H. Kelsall. 1987. The Surface Chemical Properties of Scheelite $\left(\mathrm{CaWO}_{4}\right)$ I. The Scheelite/Water Interface and $\mathrm{CaWO}_{4}$ Solubility. Colloids and Surfaces. vol. 25, pp. 369-385. https://doi.org/10.1016/0166-6622(87)80315-3

Mathieson, G.A., and A.H. Clark. 1984. The Cantung E Zone Scheelite Skarn Orebody, Tungsten, Northwest Territories; a Revised Genetic Model. Economic Geology. vol. 79, no. 5, pp. 883-901. https://doi.org/10.2113/gsecongeo.79.5.883

McCarty, D.K., J.N. Moore, and W.A. Marcus. 1998. Mineralogy and Trace Element Association in an Acid Mine Drainage Iron Oxide Precipitate; Comparison of Selective Extractions. Applied Geochemistry. vol. 13, no. 2, pp. 165-76. https://doi.org/10.1016/S0883-2927(97)00067-X

Mesh Environmental. 2008. Geochemical Characterization of the Cantung Mine Tailings, NWT. Prepared for: North American Tungsten Corp. Ltd. Retrieved from http://registry.mvlwb.ca/Documents/MV2002L2-0019/MV2002L2-0019\%20-\%20NATCL\%20\%20Renewal\%20-\%20Application\%20-\%20Final\%20Tailings\%20Characterization\%20Jan.03-08.pdf

Mohajerin, T.J, G.R. Helz, C.D. White, and K.H. Johannesson. 2014. Tungsten Speciation in Sulfidic Waters: Determination of Thiotungstate Formation Constants and Modeling Their Distribution in Natural Waters. Geochimica et Cosmochimica Acta. vol. 144, pp. 157-72. https://doi.org/10.1016/j.gca.2014.08.037

Mohajerin, T., G.R. Helz, and K.H. Johannesson. 2016. Tungsten-Molybdenum Fractionation in Estuarine Environments. Geochimica et Cosmochimica Acta. vol. 177, pp. 105-19. https://doi.org/10.1016/j.gca.2015.12.030

Moncur, M.C., J.L. Jambor, C.J. Ptacek, and D.W. Blowes. 2009. Mine Drainage from the Weathering of Sulfide Minerals and Magnetite. Applied Geochemistry. vol. 24, no. 12, pp. 2362-2373. https://doi.org/10.1016/j.apgeochem.2009.09.013

Montgomery, S.D. 2012. Kinetics of the Dissolution of Scheelite in Groundwater: Implications for Environmental and Economic Geology. MSc Thesis Dissertation, University of California, Riverside. Retrieved from https://escholarship.org/uc/item/6tp0x6k3

Morin, K.A., N.M. Hutt. 1999. Geochemical Characterization of Molybdenum Leaching from Rock and Tailings at the Brenda Minesite, British Columbia. Proceedings of the 1999 Workshop on Molybdenum 
Issues in Reclamation, September 24, Kamloops, British Columbia, pp. 76-85. Retrieved from https://www.mdag.com/MDAG\%20Paper\%20Database/M0004\%20\%20Morin\%20and\%20Hutt\%201999\%20-\%20Molybdenum\%20at\%20Brenda.PDF

Newville, M. 2019. Larch: An Analysis Package For XAFS And Related Spectroscopies. Journal of Physics Conference Series. vol. 430. https://doi.org/10.1088/1742-6596/430/1/012007

Nordstrom, D.K., and F.D. Wilde. 2005. Reduction-oxidation Potential (Electrode Method). In: U.S. Geological Survey Techniques of Water-Resources Investigations, Book 9, Chapter 6.5. https://doi.org/10.3133/twri09A6.5

O'Kane Consultants Inc. and pHase Geochemistry, 2017. Updated Geochemical Load Balance and Risk Assessment, Cantung Mine, NWT. Prepared for: North American Tungsten Corp. Ltd http://registry.mvlwb.ca/Documents/MV2015L2-0003/MV2015L2-0003\%20-\%20NATCL\%20\%20Integrated\%20Geochemical\%20Load\%20Balance\%20and\%20Risk\%20Assessment\%20Report\%20\%20Jan27-17.pdf

Ootes, L., S.A. Gleeson, E. Turner, K. Rasmussen, S. Gordey, H. Falck, E. Martel, and K. Pierce. 2013. Metallogenic Evolution of the Mackenzie and Eastern Selwyn Mountains of Canada's Northern Cordillera, Northwest Territories: A Compilation and Review. Geoscience Canada. vol.40, no. 1, pp. 4069. https://doi.org/10.12789/geocanj.2013.40.005

Parks Canada. 2019. Nahanni National Park Reserve: Hydrology. Retrieved from https://www.pc.gc.ca/en/pn-np/nt/nahanni/decouvrir-discover/natculld

Petkewich, R. 2009. Unease Over Tungsten. Chemical \& Engineering News. vol. 87, no. 3, pp. 63-65. https://doi.org/10.1021/cen-v087n003.p063

Petrunic, B.M., and T.A. Al. 2005. Mineral/Water Interactions in Tailings from a Tungsten Mine, Mount Pleasant, New Brunswick. Geochimica et Cosmochimica Acta. vol. 69, no. 10, pp. 2469-2483. https://doi.org/10.1016/j.gca.2004.10.031

Petrunic, B.M., T.A. Al, and L. Weaver. 2006. A Transmission Electron Microscopy Analysis of Secondary Minerals Formed in Tungsten-Mine Tailings with an Emphasis on Arsenopyrite Oxidation. Applied Geochemistry. vol. 21, no. 8, pp. 1259-1273. https://doi.org/10.1016/j.apgeochem.2006.06.003

pHase Geochemistry. 2014. Geochemical Risk Assessment, Cantung Mine, NWT. Prepared for: North American Tungsten Corp. Ltd. http://registry.mvlwb.ca/Documents/MV2015L2-0003/MV2015L20003\%20-\%20NATCL\%20-\%20Geochemical\%20Risk\%20Assessment\%20Report\%20-\%20May3014.pdf

Pina, C. M., L. Fernández-Díaz, and J.M. Astilleros. 2000. Nucleation and Growth of Scheelite in a Diffusing-Reacting System. Crystal Research and Technology: Journal of Experimental and Industrial 
Crystallography. vol. 35. no. 9, pp. 1015-1022. https://doi.org/10.1002/1521-

4079(200009)35:9<1015::AID-CRAT1015>3.0.CO;2-L

Pokrovsky, O.S., and J. Schott. 2002. Iron Colloids/Organic Matter Associated Transport of Major and Trace Elements in Small Boreal Rivers and their Estuaries (NW Russia). Chemical Geology. vol. 190, no. 1-4, pp. 141-179. https://doi.org/10.1016/S0009-2541(02)00115-8

Prescher, C., and V.B. Prakapenka. 2015. DIOPTAS: A Program for Reduction of Two-dimensional Xray Diffraction Data and Data Exploration. High Pressure Research. vol. 35, no. 3, pp. 223-230.

https://doi.org/10.1080/08957959.2015.1059835

Railsback, B. 2008. An Earth Scientist's Periodic Table of the Elements and their Ions, version 4.8d.

Retrieved from http://railsback.org/PT/815PeriodicTable48d013600.jpg

Sahama, T.G. 1981. The Secondary Minerals of Tungsten, a Review. The Mineralogical Record. pp. 81 87. Retrieved from https://rruff-2.geo.arizona.edu/uploads/MR12_81.pdf

Sandmann, D. 2015. Method Development in Automated Mineralogy. Phd Thesis Dissertation. Division of Economic Geology and Petrology of the Department of Mineralogy, TU Bergakademie Freiberg. Retrieved from https://pdfs.semanticscholar.org/6c7d/fc4f887906a3c987f47277981fbec453538f.pdf

Seiler, R.L., K.G. Stollenwerk, and J.R. Garbarino. 2005. Factors Controlling Tungsten Concentrations in Ground Water, Carson Desert, Nevada. Applied Geochemistry. vol. 20, no. 2, pp. 423-41. https://doi.org/10.1016/j.apgeochem.2004.09.002

Shimobayashi, N., M. Ohnishi, and K. Tsuruta. 2012. Secondary Tungsten Minerals in Quartz Veins in the Ishidera Area, Wazuka, Kyoto Prefecture, Japan: Anthoinite, Mpororoite, and Fe-Free Hydrokenoelsmoreite. Journal of Mineralogical and Petrological Sciences. vol. 107, no. 1, pp. 33-38. https://doi.org/10.2465/jmps.111020f

Silke, R. 2009. The Operational History of Mines in the Northwest Territories, Canada. NWT Geoscience Office. Retrieved from www.miningnorth.com/ rsc/sitecontent/library/NWT Mines History RSilke2009.pdf

Strigul, N., A. Koutsospyros, and C. Christodoulatos. 2009. Tungsten in the Former Soviet Union: Review of Environmental Regulations and Related Research. Land Contamination and Reclamation. vol. 17, no. 1, 189-215.https://doi.org/10.2462/09670513.923

Strigul, N. 2010. Does Speciation Matter for Tungsten Ecotoxicology? Ecotoxicology and Environmental Safety. vol. 73, no. 6, pp. 1099-1113. https://doi.org/10.1016/j.ecoenv.2010.05.005

Strigul, N., A. Koutsospyros, and C. Christodoulatos. 2010. Tungsten Speciation and Toxicity: Acute Toxicity of Mono- and Poly-Tungstates to Fish. Ecotoxicology and Environmental Safety. vol. 73, no. 2, pp. 164-171. https://doi.org/10.1016/j.ecoenv.2009.08.016

Tarassov, M., B. Mihailova, E. Tarassova, and L. Konstantinov. 2002. Chemical Composition and Vibrational Spectra of Tungsten-Bearing Goethite and Hematite from Western Rhodopes, Bulgaria. 
European Journal of Mineralogy. vol. 14, no. 5, 977-986. https://doi.org/10.1127/0935-1221/2002/0014$\underline{0977}$

Tarassov, M.P., and E.D. Tarassova. 2018. Structural and Chemical Evolution of Mineral Forms of Tungsten in the Oxidation Zone of the Grantcharitza Deposit (Western Rhodopes, Bulgaria). Bulgarian Chemical Communications. vol. 50, Special Issue J. pp. 270 - 280. Retrieved from https://www.researchgate.net/publication/327381700_Structural_and_chemical_evolution_of_mineral_for ms_of_tungsten_in_the_oxidation_zone_of_the_Grantcharitza_deposit_Western_Rhodopes_Bulgaria

United States Environmental Protection Agency. 2008. Emerging Contaminant - Tungsten. National Service Center for Environmental Publications. Retrieved from https://nepis.epa.gov/Exe/ZyNET.exe/P1000L3K.TXT?ZyActionD=ZyDocument\&Client=EPA\&Index= $2006+$ Thru $+2010 \&$ Docs $=\&$ Query $=\&$ Time $=\&$ EndTime $=\&$ SearchMethod $=1 \&$ TocRestrict $=$ n $\&$ Toc $=\&$ Toc Entry $=\& Q$ Field $=\& Q$ FieldYear $=\& Q$ FieldMonth $=\& Q$ FieldDay $=\&$ IntQFieldOp $=0 \&$ ExtQFieldOp $=0 \& X m \mathrm{~m}$ Query $=\&$ File $=$ D\%3A\%5Czyfiles\%5CIndex\%20Data\%5C06thru10\%5CTxt\%5C00000002\%5CP1000L3

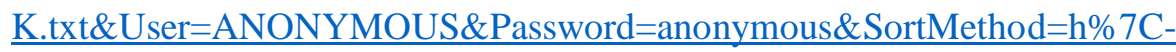
\&MaximumDocuments=1\&FuzzyDegree=0\&ImageQuality=r75g8/r75g8/x150y 150g16/i425\&Display=h pfr \&DefSeekPage $=x \&$ SearchBack $=$ ZyActionL\&Back $=$ ZyActionS $\&$ BackDesc $=$ Results\%20page $\&$ Maxim umPages $=1 \&$ ZyEntry $=1 \&$ SeekPage $=x \& Z y P U R L$

Vorlicek, T.P., M.D. Kahn, Y. Kasuya, and G.R. Helz. 2004. Capture of Molybdenum in Pyrite-forming Sediments: Role of Ligand-Induced Reduction by Polysulfides. Geochimica et Cosmochimica Acta. vol. 68, no. 3, pp. 547-556. https://doi.org/10.1016/S0016-7037(00)00444-7

Walker, S. R., H.E. Jamieson, A. Lanzirotti, C.F. Andrade, and G.E.M. Hall. 2005. The Speciation of Arsenic in Iron Oxides in Mine Wastes from the Giant Gold Mine, N.W.T.: Application of Synchrotron Micro-XRD and microXANES at the Grain Scale. The Canadian Mineralogist. vol. 43, no. 4, pp.1205-24. https://doi.org/10.2113/gscanmin.43.4.1205

Watanabe, Y., T. Kashiwabara, J.L. Ishibashi, O. Sekizawa, K. Nitta, T. Uruga, and Y. Takahashi. 2017. Different Partitioning Behaviors of Molybdenum and Tungsten in Sediment-Water System Under Various Redox Conditions. Chemical Geology. vol. 471, pp. 38-51.

https://doi.org/10.1016/j.chemgeo.2017.09.009

Werner, A.B., W.D. Sinclair, and E.B. Amey. 2014. International Strategic Mineral Issues Summary Report--Tungsten. US Government Printing Office. Retrieved from https://pubs.usgs.gov/pdf/circular/pdf/c930-o.pdf

Wood, S.A., and I.M. Samson. 2000. The Hydrothermal Geochemistry of Tungsten in Granitoid Environments: I. Relative Solubilities of Ferberite and Scheelite as a Function of T, P, pH, and $\mathrm{m} \mathrm{NaCl}$. Economic Geology. vol. 95, no. 1, pp. 143-182. https://doi.org/10.2113/gsecongeo.95.1.143 


\section{Chapter 4: Conclusions}

\subsection{Conclusions}

This study investigated the mobility of tungsten in the acidic Flat River Tailings (FRT) and the circumneutral tailings impoundments at the Cantung Mine. Scheelite contents of both the FRT and tailings impoundments are similar and show no evidence of alteration, suggesting that scheelite is stable under both acidic and circumneutral tailings conditions. In contrast, chalcopyrite is depleted in the FRT compared to the tailings impoundments and relict chalcopyrite in the FRT shows significant dissolution due to its instability in oxidized waters. Calcium and tungsten in scheelite are in their highest and most stable oxidation states $\left(\mathrm{Ca}^{2+}\right.$ and $\left.\mathrm{W}^{6+}\right)$, and are therefore not susceptible to oxidative dissolution. No secondary minerals of tungsten were identified in this study, probably because not enough tungsten has been leached from scheelite to reach saturation of secondary tungsten minerals.

Detectable aqueous tungsten concentrations are restricted to waters with $\mathrm{pH}$ values $>7$, and are below the detection limit in the Flat River. More water samples across a wider $\mathrm{pH}$ range are needed to determine whether $\mathrm{pH}$-dependent adsorption is the primary control on aqueous tungsten concentrations at Cantung. In particular, previous studies have noted marked increases in tungsten concentrations in waters with $\mathrm{pH}>8.5$ in the presence of adsorbent minerals (e.g. Fe-oxyhydroxide minerals). Nonetheless, it is probable that the lack of aqueous tungsten in acidic water samples is due to adsorption to Feoxyhydroxide minerals. In surface waters, both tungsten and iron concentrations are highest in unfiltered samples. It is likely that tungsten is adsorbed to suspended Fe-oxyhydroxide phases in surface waters, and is also present as dissolved species. Tungsten is probably speciated as $\mathrm{WO}_{4}{ }^{2-}$, which is the most common tungsten species in circumneutral, non-sulfidic waters. Aqueous copper concentrations are up to an order of magnitude higher than tungsten concentrations, and in contrast to tungsten, are highest in acidic porewaters and lowest in circumneutral waters. The opposing behaviour to tungsten is because copper 
forms cationic species in solution and adsorbs to mineral surfaces with increasing $\mathrm{pH}$, whereas anions adsorb more with decreasing $\mathrm{pH}$. The higher copper concentrations relative to tungsten is due to the higher solubility and reactivity of chalcopyrite than scheelite, and because cation desorption is high in the acidic FRT porewater where the $\mathrm{pH}$ is as low as 2.2.

One of the objectives of this study was to identify potential secondary hosts of tungsten within the FRT and tailings impoundments. Early in this study, the most likely candidate was determined to be Feoxyhydroxide minerals due to their abundance within the tailings, and because they are commonly cited as secondary hosts in other environmental systems. Synchrotron-based $\mu$ XRD was employed to determine the mineralogy of Fe-oxyhydroxide minerals in the FRT and tailings impoundments, and $\mu$ XRF was used to determine the potential presence of tungsten. Interestingly, tungsten was found to be associated with Fe-oxyhydroxide mineral rims in TP3 (with circumneutral porewater), but not in Fe-oxyhydroxide minerals from the FRT which has acidic porewater. Diffraction patterns of the W-bearing rims match those of hematite and maghemite, which are not expected to form in low-temperature geochemical systems. It is possible that hematite and maghemite may have transformed from a ferrihydrite precursor within the roaster at Cantung before being magnetically separated and rejected to the tailings. Upon leaching from scheelite during froth floatation, tungsten was adsorbed to ferrihydrite and may have been structurally incorporated within hematite and/or maghemite during thermal transformation, which has been observed in supergene hematite from the Grantcharitza W-deposit in Bulgaria (Tarassov et al., 2002; Kreissl et al., 2016; Tarassov and Tarassova, 2018). The apparent rarity of these rims within TP3 is probably because a low volume of pyrrhotite was roasted at Cantung, as most sulfide minerals should have been removed from the scheelite concentrate during the sulfide floatation stage of scheelite beneficiation. Without any data regarding the co-deposition of tailings generated from different stages of beneficiation, it cannot be concluded whether there is a homogeneous or heterogeneous distribution of these rims in the tailings impoundments. Iron-oxyhydroxide mineral rims in TP3 without tungsten do not have diffraction patterns matching any Fe-oxyhydroxide mineral, and are likely amorphous or poorly 
crystalline. All Fe-oxyhydroxide minerals in the FRT samples analyzed by $\mu$ XRD-XRF match with goethite and/or jarosite, and in one pattern, lepidocrocite was identified. The identification of goethite and jarosite in the FRT is expected, as the tailings are more than 50 years old and these minerals are thermodynamically stable in acidic $\mathrm{SO}_{4}$-dominated waters (Cornell and Schwertmann, 2000; Lindsay et al., 2015).

With no tungsten detectable by $\mu$ XRF in FRT Fe-oxyhydroxide minerals, partial leach extractions were employed to determine if tungsten is hosted in these phases. It was predicted that the FRT samples would have higher tungsten recoveries from the hydroxylamine hydrochloride leaches than the impoundment samples, due to the acidic $\mathrm{pH}$ of the FRT. In fact, tungsten recoveries from FRT samples were lower than from the impoundment samples, and it is likely that not all Fe-oxyhydroxide minerals were successfully dissolved. Without complete (and exclusive) dissolution of all Fe-oxyhydroxide phases, it cannot be determined whether tungsten is hosted by these phases in the FRT, either as adsorbed labile species or by structural incorporation. However, it can be concluded that tungsten is not associated with the most thermodynamically unstable Fe-oxyhydroxide phases (i.e. by being amorphous or poorly crystalline) or partially reacted Fe-oxyhydroxide mineral surfaces, which hydroxylamine hydrochloride is known to dissolve effectively (Chao et al., 1984; Hall et al., 1996; Leybourne et al., 2003). It is possible that the dissolution of poorly crystalline Fe-oxyhydroxide phases to recrystallize as goethite and jarosite, coupled with over 50 years of dynamic fluvial events may have flushed labile tungsten downstream.

This study shows that scheelite is stable in both circumneutral $\mathrm{HCO}_{3}$-dominated and acidic $\mathrm{SO}_{4}$ dominated tailings porewater, and that $\mathrm{pH}$-dependent adsorption is likely the main factor controlling aqueous tungsten concentrations. The stability of scheelite during acid rock drainage (ARD) and strong tungsten adsorption at acidic $\mathrm{pH}$ implies that the risk of tungsten leaching during tailings acidification is low. One of the risks associated with moving TP1, TP2, TP3, TP4, and TP5 to more geotechnically stable dry-stack impoundments is oxygen ingress into unsaturated tailings, and therefore the generation of acidic leachate as a result of sulfide oxidation. The risk of tungsten mobilization during this scenario is low, but 
the dry-stack storage of the Cantung tailings does increase the risk of cation leaching, notably $\mathrm{Cu}, \mathrm{Zn}, \mathrm{Fe}$, and $\mathrm{Al}$.

\subsection{Recommendations for Future Work}

The following is a list of recommendations for future research regarding tungsten mobility within the Cantung tailings and other $\mathrm{W}$-rich mine waste:

- Core sampling and stratigraphic logging of the Cantung tailings to determine whether there are redox and $\mathrm{pH}$ boundaries within the tailings that could act as a source or sink of tungsten.

- The use of non-procedural partial extractions to fully and exclusively digest Fe-oxyhydroxide minerals within the FRT tailings to determine the amount of tungsten associated with crystalline $\mathrm{Fe}$ oxyhydroxide minerals.

- Spectroscopic studies on the W-bearing hematite-maghemite rims in TP3 to determine whether tungsten is present as scheelite or if it is structurally incorporated within or adsorbed to the rims. Techniques that would be useful in answering this question would be those that determine the local atomic structure of tungsten such as Raman spectroscopy and X-ray Absorption Spectroscopy (XAS).

- Mechanisms for scheelite and wolframite weathering should be studied in detail, particularly acidic $\mathrm{SO}_{4}$-dominated waters characteristic of ARD.

- Micro-X-ray Diffraction ( $\mu \mathrm{XRD}$ ) analysis of the W-bearing Fe-oxyhydroxide rims on pyrrhotite pseudomorphs found in December 2019 (Appendix J). Analysis of these rims would be useful for confirming the identification of hematite and maghemite on the TP3 Fe-oxyhydroxide rims by the synchrotron-based $\mu$ XRD analyses in August 2019.

- Laboratory studies on the synthesis of secondary tungsten minerals that may form in tailings environments, particularly those containing iron and aluminum, which are commonly present in 
elevated concentrations in ARD. Solubility products and reaction enthalpies should be calculated to enable accurate prediction of the formation of these phases using geochemical modelling software.

- Molybdenum is commonly contrasted with tungsten in environmental studies due to their similar geochemical behaviour. Such comparisons would be useful in mine waste containing both molybdenum and tungsten, particularly as secondary molybdenum minerals may be a sink for aqueous tungsten via elemental substitution and co-precipitation.

\subsection{References}

Chao, T.T. 1984. Use of Partial Dissolution Techniques in Geochemical Exploration. Journal of Geochemical Exploration. vol. 20, no. 2, pp.101-35. https://doi.org/10.1016/0375-6742(84)90078-5

Cornell, R. M., and U. Schwertmann. 2003. The Iron Oxides: Structure, Properties, Reactions, Occurrences and Uses. John Wiley \& Sons. https://doi.org/10.1002/3527602097

Kreissl, S., R. Bolanz, J. Göttlicher, R. Steininger, M. Tarassov, and G. Markl. 2016. Structural Incorporation of W 6+ into Hematite and Goethite: A Combined Study of Natural and Synthetic Iron Oxides Developed from Precursor Ferrihydrite and the Preservation of Ancient Fluid Compositions in Hematite. American Mineralogist. vol. 101, no. 12, pp. 2701-15. https://doi.org/10.2138/am-2016-5690

Leybourne, M.I., D.R. Boyle, W.D. Goodfellow, S.R. McCutcheon, and J.M. Peter. 2003. Interpretation of Stream Water and Sediment Geochemistry in the Bathurst Mining Camp, New Brunswick: Applications to Mineral Exploration. Massive Sulphide Deposits of the Bathurst Mining Camp, New Brunswick, and Northern Maine. vol. 11, pp. 741-762. https://doi-org.proxy.queensu.ca/10.5382/Mono.11

Lindsay, M., M.C. Moncur, J.G. Bain, J.L. Jambor, C.J. Ptacek, and D.W. Blowes. 2015. Geochemical and Mineralogical Aspects of Sulfide Mine Tailings. Applied Geochemistry. vol. 57, pp. 157-77. https://doi.org/10.1016/j.apgeochem.2015.01.009

Tarassov, M., B. Mihailova, E. Tarassova, and L. Konstantinov. 2002. Chemical Composition and Vibrational Spectra of Tungsten-Bearing Goethite and Hematite from Western Rhodopes, Bulgaria. European Journal of Mineralogy. vol. 14, no. 5, 977-986. https://doi.org/10.1127/0935-1221/2002/0014$\underline{0977}$

Tarassov, M.P., and E.D. Tarassova. 2018. Structural and Chemical Evolution of Mineral Forms of Tungsten in the Oxidation Zone of the Grantcharitza Deposit (Western Rhodopes, Bulgaria). Bulgarian Chemical Communications. vol. 50, Special Issue J. pp. 270 - 280. Retrieved from

https://www.researchgate.net/publication/327381700 Structural and chemical evolution of mineral for ms of tungsten in the oxidation zone of the Grantcharitza deposit Western Rhodopes Bulgaria 


\section{Appendix A: Tailings Sample GPS Coordinates}

The following table contains the gps coordinates (latitude and longitude) for all tailings samples utilized in this study.

\begin{tabular}{|c|c|c|}
\hline Sample ID & Northing & Easting \\
\hline FRT-TS-01 & 61.96506 & 128.21689 \\
\hline FRT-TS-02 & 61.96506 & 128.21689 \\
\hline FRT-TS-03 & 61.9629 & 128.22734 \\
\hline FRT-TS-03DUP & 61.9629 & 128.22734 \\
\hline FRT-TS-04 & 61.96934 & 128.22766 \\
\hline FRT-TS-05 & 61.96934 & 128.22766 \\
\hline FRT-TS-06 & 61.96929 & 128.22734 \\
\hline FRT-TS-06DUP & 61.96929 & 128.22734 \\
\hline TP3-TS-01 & 61.96209 & 128.21991 \\
\hline TP3-TS-02 & 61.96218 & 128.21812 \\
\hline TP4-TS-01 & 61.96451 & 128.22137 \\
\hline TP5-TS-01 & 61.96048 & 128.21693 \\
\hline TP5-TS-02 & 61.96048 & 128.21693 \\
\hline TP5-TS-03 & 61.96146 & 128.22023 \\
\hline TP5-TS0-3DUP & 61.96146 & 128.22023 \\
\hline TP5-TS-04 & 61.96106 & 128.21965 \\
\hline
\end{tabular}




\section{Appendix B: Tailings Sample Metadata}

The following table contains the field notes for all tailings samples utilized in this study.

\begin{tabular}{|c|c|c|c|c|c|c|c|c|c|}
\hline $\begin{array}{c}\text { Tailings Sample } \\
\text { ID }\end{array}$ & $\begin{array}{l}\text { Water } \\
\text { Sample } \\
\text { ID }\end{array}$ & Location & $\begin{array}{c}\text { Micro- } \\
\text { environment }\end{array}$ & $\begin{array}{l}\text { Sampling } \\
\text { Method }\end{array}$ & Colour & $\begin{array}{c}\text { Water } \\
\text { Content }\end{array}$ & Oxidation & $\begin{array}{c}\text { Photo } \\
\#\end{array}$ & Field Notes \\
\hline FRT-TS-01 & $\begin{array}{l}\text { FRT- } \\
\text { PWC-01 }\end{array}$ & $\begin{array}{l}\text { FRT near } \\
\text { base of } \\
\text { TP3 }\end{array}$ & $10 \mathrm{~cm}$ depth & Shovel & Orange & Dry & Yes & $\begin{array}{l}657 \\
659\end{array}$ & $\begin{array}{l}\text { Taken from same pit as } \\
\text { FRTPWC01. Yellow clumps in } \\
\text { tailings (jarosite?). Adjacent to } \\
\text { FRTPWL02. }\end{array}$ \\
\hline FRT-TS-02 & $\begin{array}{l}\text { FRT- } \\
\text { PWL-01 }\end{array}$ & $\begin{array}{l}\text { FRT near } \\
\text { base of } \\
\text { TP3 }\end{array}$ & $60 \mathrm{~cm}$ depth & Auger & Orange & Moist & Yes & $\begin{array}{l}658 \\
659\end{array}$ & $\begin{array}{l}\text { On river bank ( } 2 \mathrm{~m} \text { away, } 1 \mathrm{~m} \\
\text { vertical). Taken from lysimeter } \\
\text { hole FRTPWL01. }\end{array}$ \\
\hline FRT-TS-03 & $\begin{array}{l}\text { FRT- } \\
\text { PWC- } \\
02, \\
\text { FRT- } \\
\text { PWL-04 }\end{array}$ & $\begin{array}{l}\text { FRT } \\
\text { adjacent } \\
\text { to } \\
\text { stagnant } \\
\text { orange } \\
\text { pond }\end{array}$ & $70 \mathrm{~cm}$ depth & Auger & $\begin{array}{l}\text { Grey and } \\
\text { orange }\end{array}$ & Saturated & $\begin{array}{l}\text { Oxidized with } \\
\text { some } \\
\text { unoxidized } \\
\text { pods. } \\
\text { Heterogeneous }\end{array}$ & $\begin{array}{l}669 \\
670\end{array}$ & $\begin{array}{l}\text { On bank of tailings adjacent to } \\
\text { orange pond. Bank height } 1 \mathrm{~m} \\
\text { above water, lots of yellow } \\
\text { minerals on wall of bank. Pond is } \\
\text { adjacent to flat river. Lots of } \\
\text { organic material. Coarse material } \\
\text { at bottom of auger hole, may be } \\
\text { underlying till? }\end{array}$ \\
\hline $\begin{array}{l}\text { FRT-TS- } \\
\text { O3DUP }\end{array}$ & & $\begin{array}{l}\text { FRT } \\
\text { adjacent } \\
\text { to } \\
\text { stagnant } \\
\text { orange } \\
\text { pond } \\
\end{array}$ & $70 \mathrm{~cm}$ depth & Auger & $\begin{array}{l}\text { Grey and } \\
\text { orange }\end{array}$ & Saturated & $\begin{array}{l}\text { Oxidized with } \\
\text { some } \\
\text { unoxidized } \\
\text { pods. } \\
\text { Heterogeneous }\end{array}$ & $\begin{array}{l}669 \\
670\end{array}$ & $\begin{array}{c}\text { Duplicate of FRTTS03. Duplicate } \\
\text { taken from new auger hole due to } \\
\text { lack of material in first hole. Holes } \\
\text { looked identical. }\end{array}$ \\
\hline FRT-TS-04 & $\begin{array}{c}\text { FRT- } \\
\text { PWC-03 }\end{array}$ & $\begin{array}{l}\text { FRT pond } \\
\text { at base of } \\
\text { TP1 }\end{array}$ & $15 \mathrm{~cm}$ depth & Auger & $\begin{array}{l}\text { Hematite } \\
\text { red }\end{array}$ & Moist & Yes & $\begin{array}{l}675 \\
677\end{array}$ & $\begin{array}{l}\text { Lots of organics, roots. Had what } \\
\text { looked like a soil profile. } 2 \mathrm{~mm} \\
\text { grey material }->2 \mathrm{~cm} \text { black } \\
\text { material }->10 \mathrm{~cm} \text { hematite red } \\
\text { material (silt and fine sand sized) - } \\
>\text { brown/orange material below. } \\
\text { Sampled hematite red matieral. } \\
\text { Same hole as FRTPWL05. Talen } \\
\text { 1m from surface water. }\end{array}$ \\
\hline FRT-TS-05 & $\begin{array}{c}\text { FRT- } \\
\text { PWL-06 }\end{array}$ & $\begin{array}{l}\text { FRT pond } \\
\text { at base of } \\
\text { TP1 }\end{array}$ & $70 \mathrm{~cm}$ depth & Auger & $\begin{array}{l}\text { Grey and } \\
\text { green }\end{array}$ & Saturated & Yes & $\begin{array}{l}676 \\
677\end{array}$ & $\begin{array}{l}\text { Same hole as FRTPWL06. } \\
\text { saturated. Smelled like algae, or } \\
\text { ocean. Green could be algae? Pond } \\
\text { water is green. }\end{array}$ \\
\hline FRT-TS-06 & $\begin{array}{l}\text { FRT- } \\
\text { SW-02 }\end{array}$ & $\begin{array}{l}\text { FRT } \\
\text { stagnant } \\
\text { orange } \\
\text { pond }\end{array}$ & $\begin{array}{l}\text { Benthic tailings, } \\
\text { under } 6 \text { inches of } \\
\text { water }\end{array}$ & Shovel & $\begin{array}{l}\text { Orange- } \\
\text { red with } \\
\text { grey pods }\end{array}$ & Saturated & Yes & $\begin{array}{l}670 \\
684 \\
685\end{array}$ & $\begin{array}{l}\text { Bottom of pond had gravel and } \\
\text { cobbles. Had organic material, } \\
\text { some yellow spots, some green } \\
\text { spots. Heterogeneous. Surface of } \\
\text { pond had extensive biofilm, pond } \\
\text { water was cloudy orange. }\end{array}$ \\
\hline $\begin{array}{l}\text { FRT-TS- } \\
\text { O6DUP }\end{array}$ & $\begin{array}{l}\text { FRT- } \\
\text { SW-02 }\end{array}$ & $\begin{array}{l}\text { FRT } \\
\text { stagnant } \\
\text { orange } \\
\text { pond }\end{array}$ & $\begin{array}{l}\text { Benthic tailings, } \\
\text { under } 6 \text { inches of } \\
\text { water }\end{array}$ & Shovel & $\begin{array}{l}\text { Orange- } \\
\text { red with } \\
\text { grey pods }\end{array}$ & Saturated & Yes & $\begin{array}{l}670 \\
684 \\
685\end{array}$ & Duplicate of FRTTS06. \\
\hline
\end{tabular}




\begin{tabular}{|c|c|c|c|c|c|c|c|c|c|}
\hline TP3-TS-01 & $\begin{array}{c}\text { TP3- } \\
\text { PWC- } \\
\text { 01, TP3- } \\
\text { PWL-01 } \\
\end{array}$ & TP3 & $70 \mathrm{~cm}$ depth & Auger & Grey & Saturated & No & 653 & $\begin{array}{l}\text { Taken from lysimeter hole } \\
\text { TP3PWL01. Adjacent to } \\
\text { TP3PWC01 }\end{array}$ \\
\hline TP3-TS-02 & & TP3 & $10 \mathrm{~cm}$ depth & Shovel & Orange & Moist & Yes & 655 & \\
\hline TP4-TS-01 & & TP4 & $10 \mathrm{~cm}$ depth & Shovel & $\begin{array}{l}\text { Orange } \\
\text { and grey }\end{array}$ & Moist & Some & 667 & $\begin{array}{c}\text { Oxidation in local area is highly } \\
\text { variable - this sample was a good } \\
\text { average. Some pods of unoxidized } \\
\text { tailings. }\end{array}$ \\
\hline TP5-TS-01 & & TP5 & $80 \mathrm{~cm}$ depth & Auger & Grey & Saturated & None & $\begin{array}{l}663, \\
664, \\
666\end{array}$ & $\begin{array}{c}40 \mathrm{~m} \text { from pond. } 40 \mathrm{~m} \text { from active } \\
\text { sprinklers on other side. Bagged } \\
\text { by HJ. }\end{array}$ \\
\hline TP5-TS-02 & & TP5 & $10 \mathrm{~cm}$ depth & Shovel & $\begin{array}{l}\text { Grey to } \\
\text { light } \\
\text { brown }\end{array}$ & Moist & Some & $\begin{array}{l}662, \\
664, \\
666\end{array}$ & Taken adjacent to TP5TS01. \\
\hline TP5-TS-03 & $\begin{array}{c}\text { TP5- } \\
\text { SW-02, } \\
\text { TP5- } \\
\text { SW- } \\
02 \text { DUP }\end{array}$ & $\begin{array}{l}\text { TP5 pond } \\
\text { inlet } \\
\text { stream }\end{array}$ & $\begin{array}{l}\text { Benthic tailings, } \\
\text { under } 6 \text { inches of } \\
\text { water }\end{array}$ & Hand & $\begin{array}{l}\text { Grey with } \\
\text { some } \\
\text { orange }\end{array}$ & Saturated & On surface & $\begin{array}{l}744, \\
745\end{array}$ & $\begin{array}{l}\text { Benthic sediment appeared orange } \\
\text { on surface. Muddy, some organics. } \\
\text { Water was green-orange and } \\
\text { turbid. Sample taken } \sim 10 \mathrm{~m} \text { from } \\
\text { outlet pipe. Took sample while } \\
\text { sitting on waste rock. Lots of } \\
\text { vegetation in water, macrophytes } \\
\text { too. Two days earlier water } \\
\text { appeared murky brown. }\end{array}$ \\
\hline TP5-TS-03DUP & $\begin{array}{c}\text { TP5- } \\
\text { SW-02, } \\
\text { TP5- } \\
\text { SW- } \\
\text { 02DUP }\end{array}$ & $\begin{array}{l}\text { TP5 pond } \\
\text { inlet } \\
\text { stream }\end{array}$ & $\begin{array}{l}\text { Benthic tailings, } \\
\text { under } 6 \text { inches of } \\
\text { water }\end{array}$ & Hand & $\begin{array}{l}\text { Grey with } \\
\text { some } \\
\text { orange }\end{array}$ & Saturated & On surface & $\begin{array}{l}744, \\
745\end{array}$ & Duplicate of TP5TS03. \\
\hline TP5-TS-04 & $\begin{array}{l}\text { TP5- } \\
\text { SW-03 }\end{array}$ & $\begin{array}{l}\text { TP5 pond } \\
\text { inlet } \\
\text { stream }\end{array}$ & $\begin{array}{l}\text { Benthic tailings, } \\
\text { under } 6 \text { inches of } \\
\text { water }\end{array}$ & Hand & $\begin{array}{l}\text { Orange } \\
\text { and grey }\end{array}$ & Saturated & On surface & $\begin{array}{l}749, \\
751\end{array}$ & $\begin{array}{l}\text { Thin } \sim 1 \mathrm{~cm} \text { orange oxidation on } \\
\text { surface. Completely grey } \\
\text { underneath. Tailings on bank had } \\
\text { lots of algae and organics, } \\
\text { macrophytes growing in creek. } \\
\text { Avoided all organics when } \\
\text { sampling. Downstream of TP5- } \\
\text { SW-02 by about } 40 \text { m. Shallow, } \\
\text { flowing water. }\end{array}$ \\
\hline
\end{tabular}




\section{Appendix C: Water Sample Metadata}

The following table contains the field notes, aliquots collected, and field $\mathrm{pH}$ and ORP of all water samples utilized in this study. A value of “_“ indicates the aliquot wasn't collected, parameters weren’t measured, or notes weren't taken.

\begin{tabular}{|c|c|c|c|c|c|c|c|c|c|c|}
\hline $\begin{array}{c}\text { Water } \\
\text { Sample ID }\end{array}$ & $\begin{array}{l}\text { Tailings } \\
\text { Sample ID }\end{array}$ & FA & $\begin{array}{c}\text { FA } \\
+ \\
\text { HF }\end{array}$ & NFA & $\begin{array}{c}\text { Field } \\
\text { pH }\end{array}$ & $\begin{array}{l}\text { Field } \\
\text { ORP } \\
\text { (V) }\end{array}$ & $\begin{array}{l}\text { Sample } \\
\text { Depth } \\
\text { (cm) }\end{array}$ & Tailings Colour & $\begin{array}{l}\text { Tailings } \\
\text { Saturation }\end{array}$ & Notes \\
\hline $\begin{array}{l}\text { FRT-PWC- } \\
01\end{array}$ & FRT-TS-01 & - & $X$ & - & 1.92 & 0.63 & 15 & $\begin{array}{l}\text { red-orange with } \\
\text { yellow pods }\end{array}$ & dry & - \\
\hline $\begin{array}{l}\text { FRT-PWC- } \\
02\end{array}$ & FRT-TS-03 & - & $\mathrm{X}$ & - & 3.19 & 0.39 & 70 & $\begin{array}{l}\text { red-orange with } \\
\text { yellow pods }\end{array}$ & saturated & Same site and depth as FRT-PWL-04 \\
\hline $\begin{array}{l}\text { FRT-PWC- } \\
03\end{array}$ & FRT-TS-04 & - & $\mathrm{X}$ & - & 7.68 & 0.24 & 15 & red & moist & Sampled 1 m from FRT-SW-01 \\
\hline TP3-PWC-01 & TP3-TS-01 & - & $X$ & - & 7.24 & -0.04 & 70 & metallic grey & saturated & - \\
\hline TP3-PWL-01 & TP3-TS-01 & - & $X$ & - & 7.05 & 0.11 & 70 & metallic grey & saturated & $\begin{array}{l}\text { Water was very turbid, brown/orange before } \\
\text { filtering }\end{array}$ \\
\hline $\begin{array}{l}\text { FRT-PWL- } \\
01 \\
\end{array}$ & FRT-TS-02 & - & $\mathrm{X}$ & - & 5.46 & 0.19 & 60 & $\begin{array}{l}\text { red-orange with } \\
\text { yellow pods }\end{array}$ & moist & On bank $1 \mathrm{~m}$ above and $2 \mathrm{~m}$ away from Flat River \\
\hline $\begin{array}{c}\text { FRT-PWL- } \\
03 \\
\end{array}$ & - & - & $\mathrm{X}$ & - & 2.20 & 0.51 & 15 & red-orange & dry & - \\
\hline $\begin{array}{l}\text { FRT-PWL- } \\
\quad 04\end{array}$ & FRT-TS-03 & $X$ & $X$ & - & 3.02 & 0.43 & 70 & $\begin{array}{l}\text { orange-red with } \\
\text { yellow pods and } \\
\text { grey pods }\end{array}$ & saturated & $\begin{array}{l}\text { Heterogeneous mix of oxidized and unoxidized } \\
\text { tailings. Same site and depth as FRT-PWC- } 02\end{array}$ \\
\hline $\begin{array}{l}\text { FRT-PWL- } \\
\text { 06 } \\
\end{array}$ & FRT-TS-05 & $\mathrm{X}$ & - & - & 7.61 & 0.28 & 70 & grey-green & saturated & - \\
\hline FRT-SW-01 & - & $\mathrm{X}$ & $\mathrm{X}$ & $\mathrm{X}$ & 8.05 & 0.21 & - & - & - & Water was green coloured \\
\hline FRT-SW-02 & FRT-TS-06 & $\mathrm{X}$ & $\mathrm{X}$ & $\mathrm{X}$ & 5.63 & 0.04 & - & $\begin{array}{l}\text { orange-red with } \\
\text { grey pods }\end{array}$ & saturated & $\begin{array}{c}\text { Sampled from shallow, stagnant, orange coloured } \\
\text { pond adjacent to Flat River. Extensive biofilm } \\
\text { covering surface }\end{array}$ \\
\hline $\begin{array}{l}\text { FRT-SW- } \\
\text { O2DUP }\end{array}$ & FRT-TS-06 & $X$ & $\mathrm{X}$ & $\mathrm{X}$ & 5.69 & 0.04 & - & $\begin{array}{l}\text { orange-red with } \\
\text { grey pods }\end{array}$ & saturated & Duplicate of FRT-SW-02 \\
\hline FRT-SW-03 & - & $\mathrm{X}$ & $\mathrm{X}$ & $\mathrm{X}$ & 6.23 & -0.03 & - & $\begin{array}{l}\text { benthic sediment } \\
\text { boulder-cobble } \\
\text { sized }\end{array}$ & - & $\begin{array}{l}\text { Sampled from shallow, orange-yellow coloured } \\
\text { pond adjacent to Flat River. Creek morphology } \\
\text { suggests ephemeral connection to Flat River }\end{array}$ \\
\hline FRT-SW-04 & - & $\mathrm{X}$ & $\mathrm{X}$ & $\mathrm{X}$ & 5.91 & 0.05 & - & $\begin{array}{l}\text { benthic sediment } \\
\text { boulder-cobble } \\
\text { sized }\end{array}$ & - & $\begin{array}{l}\text { Sampled from shallow, orange-yellow coloured } \\
\text { pond adjacent to Flat River. Creek morphology } \\
\text { suggests ephemeral connection to Flat River }\end{array}$ \\
\hline TP5-SW-01 & - & $\mathrm{X}$ & $X$ & $\mathrm{X}$ & 7.91 & 0.17 & - & $\begin{array}{l}\text { Grey with orange } \\
\text { surface veneer }\end{array}$ & saturated & Water was clear \\
\hline TP5-SW-02 & TP5-TS-03 & $X$ & $X$ & $X$ & 7.35 & 0.22 & - & $\begin{array}{l}\text { Grey with orange } \\
\text { surface veneer }\end{array}$ & saturated & $\begin{array}{l}\text { Sampled from turbid green-orange stream, } 10 \mathrm{~m} \\
\text { from outlet pipe of water pumped from } \\
\text { underground mine. Macrophytes growing in stream }\end{array}$ \\
\hline $\begin{array}{l}\text { TP5-SW- } \\
\text { 02DUP }\end{array}$ & TP5-TS-03 & $\mathrm{X}$ & $\mathrm{X}$ & $\mathrm{X}$ & 7.35 & 0.22 & - & $\begin{array}{l}\text { Grey with orange } \\
\text { surface veneer }\end{array}$ & saturated & Duplicate of TP5-SW-02 \\
\hline
\end{tabular}




\begin{tabular}{|c|c|c|c|c|c|c|c|c|c|c|}
\hline TP5-SW-03 & TP5-TS-04 & $\mathrm{X}$ & $\mathrm{X}$ & $\mathrm{X}$ & 7.75 & 0.16 & - & $\begin{array}{c}\text { Grey with orange } \\
\text { surface veneer }\end{array}$ & saturated & $\begin{array}{c}\text { Sampled 40 m downstream of TP5-SW-02. } \\
\text { Shallow, clear water }\end{array}$ \\
\hline FR-01 & - & - & $\mathrm{X}$ & - & 7.10 & 0.23 & - & - & $\begin{array}{c}\text { Sampled from Flat River 2 km upstream of Flat } \\
\text { River Tailings. No iron-staining on river sediment }\end{array}$ \\
\hline FR-02 & - & $\mathrm{X}$ & $\mathrm{X}$ & $\mathrm{X}$ & 7.19 & 0.10 & - & - & $\begin{array}{c}\text { Sampled from Flat River flowing through Flat } \\
\text { River Tailings. Iron-staining on river } \\
\text { boulders/cobbles. }\end{array}$ \\
\hline
\end{tabular}




\section{Appendix D: Field Photographs}

The following are photographs of sampling sites and of the Cantung Mine, taken in July 2018.

Photo ID's are from the camera, and correspond to the Photo \#s in the table in Appendix B.
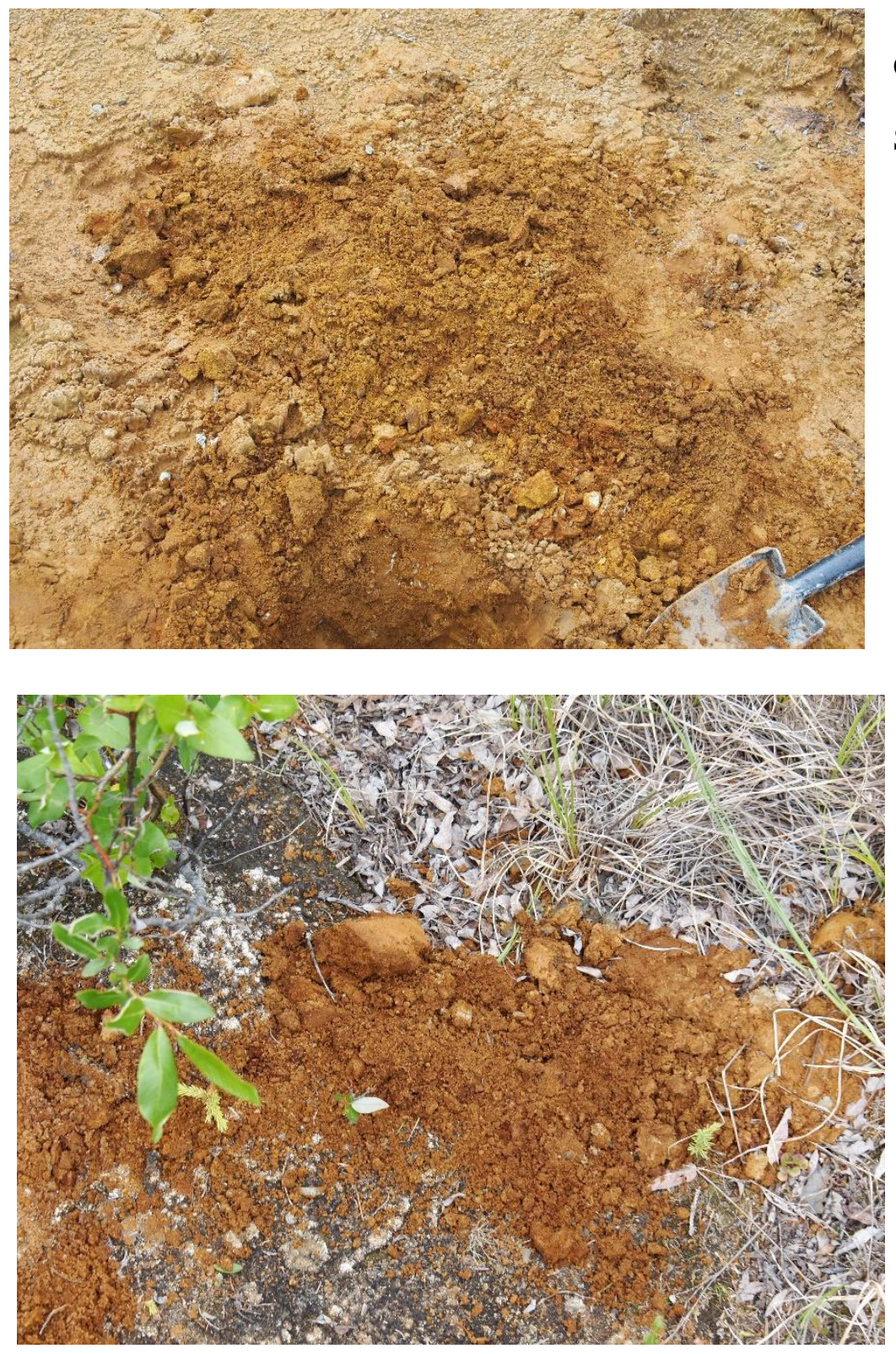

657: Sample FRT-TS-01 in the field.

Sample collected with a shovel.

658: Sample FRT-TS-02 in the

field. Samples collected with auger. 


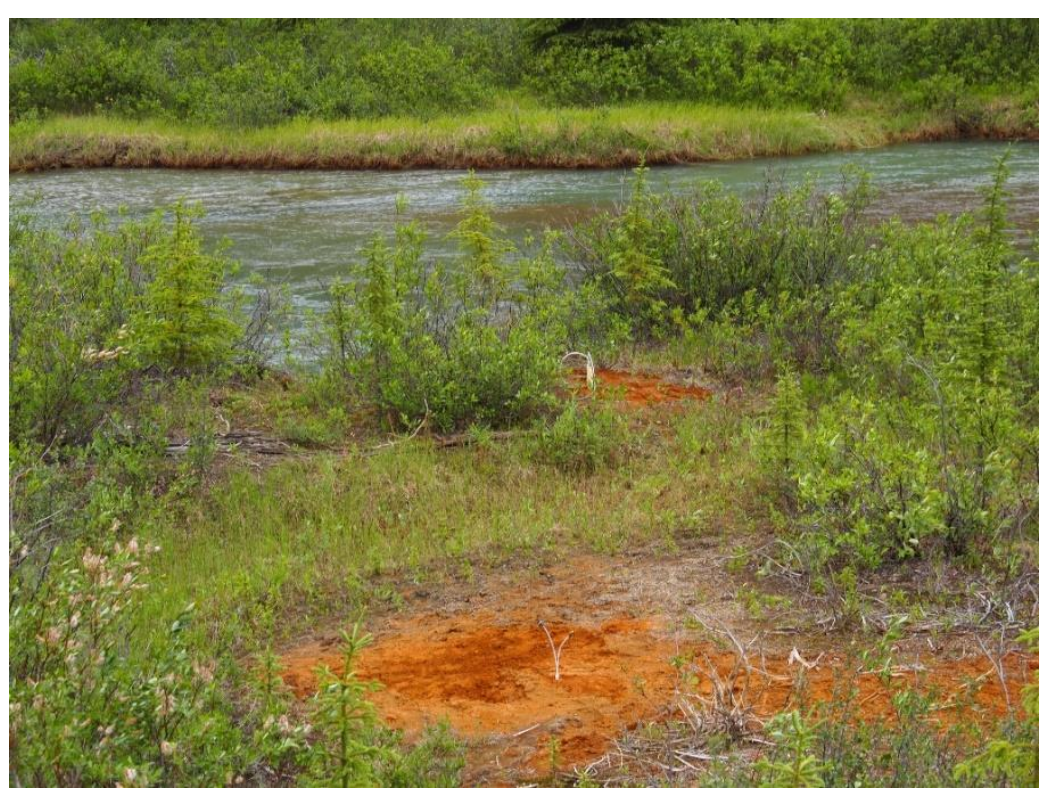

659: Sample sites for FRT-TS-01

(close) and FRT-TS-02 (far) with

suction lysimeters. Flat River in

background.

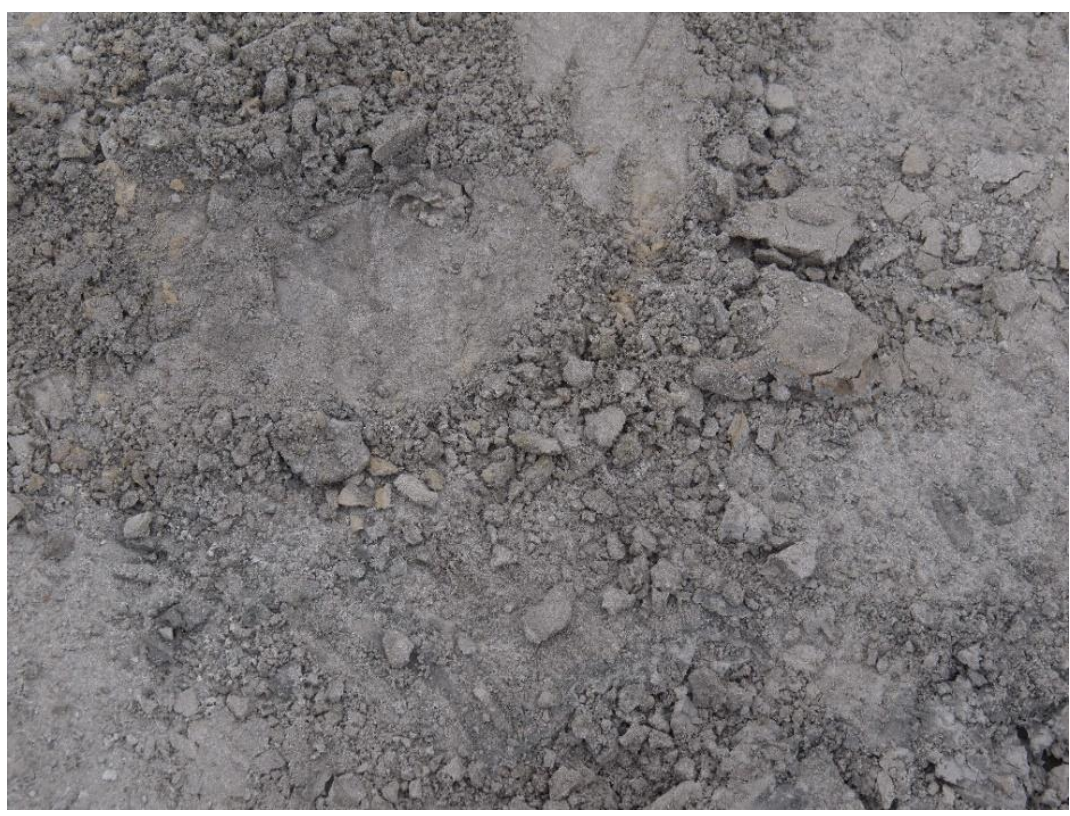

662: Sample TP5-TS-02 in the field. 

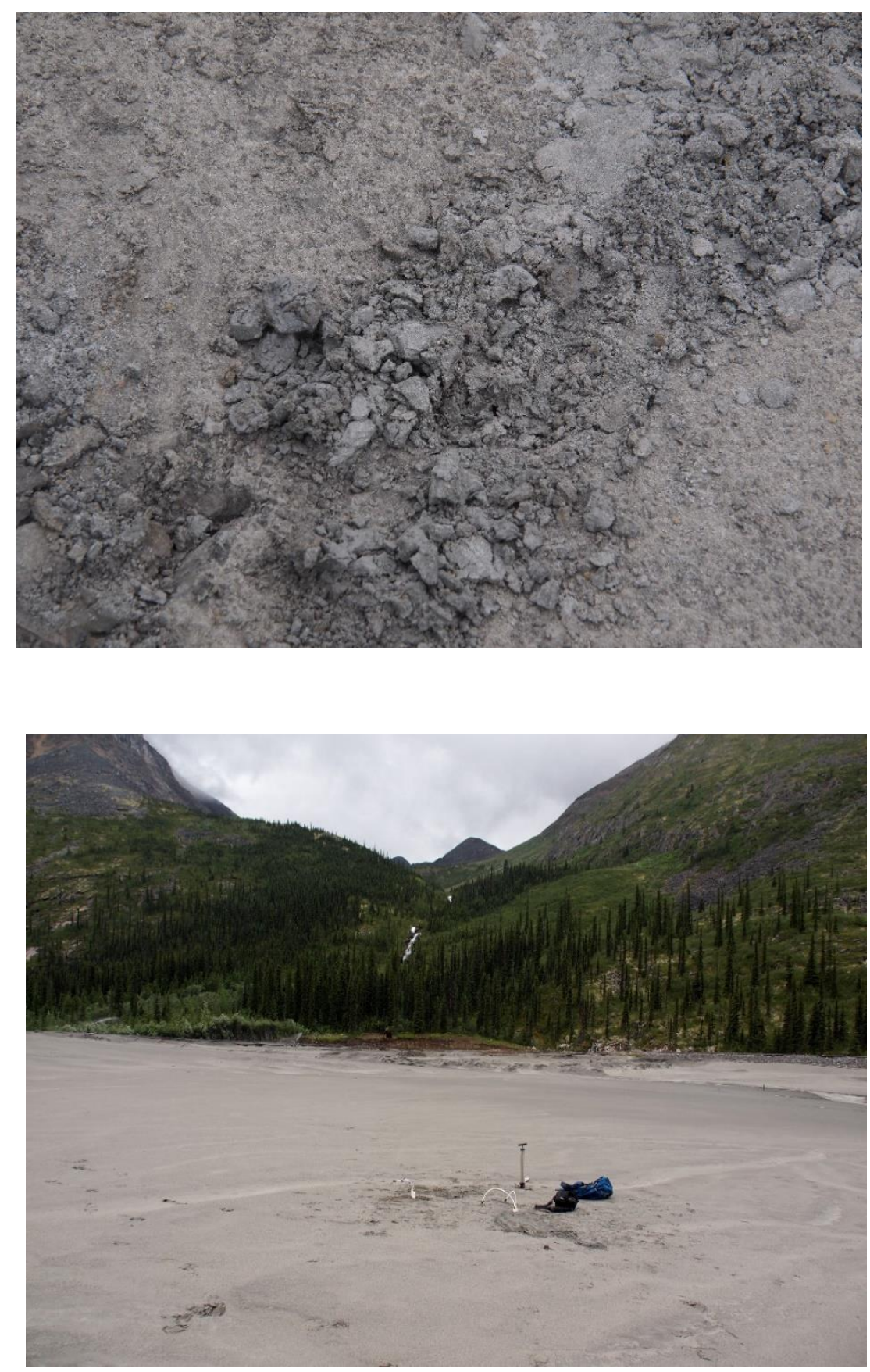

663: Sample TP5-TS-01 in the field.

664: Sample sites for TP5-TS-01 and TP5-TS-02 with lysimeters installed. 


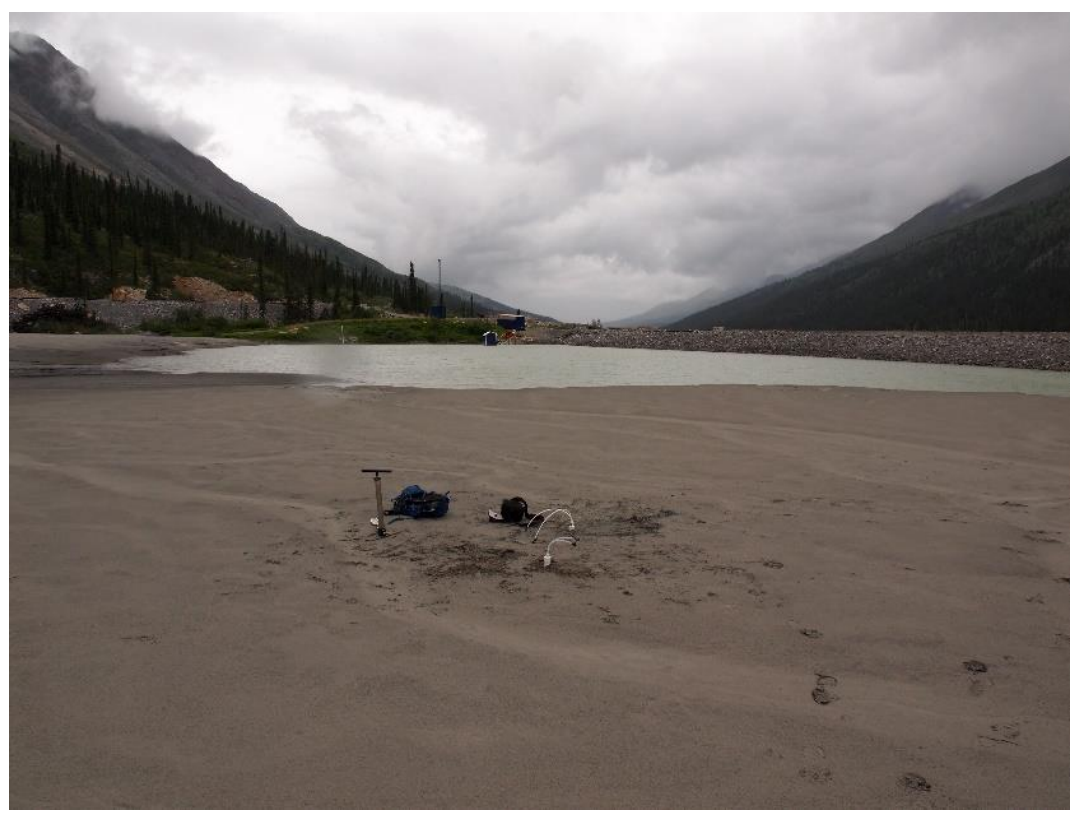

666: Sample sites for TP5-TS-01 and TP5-TS-02 showing pond on TP5.

Sample site for TP5-SW-01 is $30 \mathrm{~cm}$

from bank on left of pond

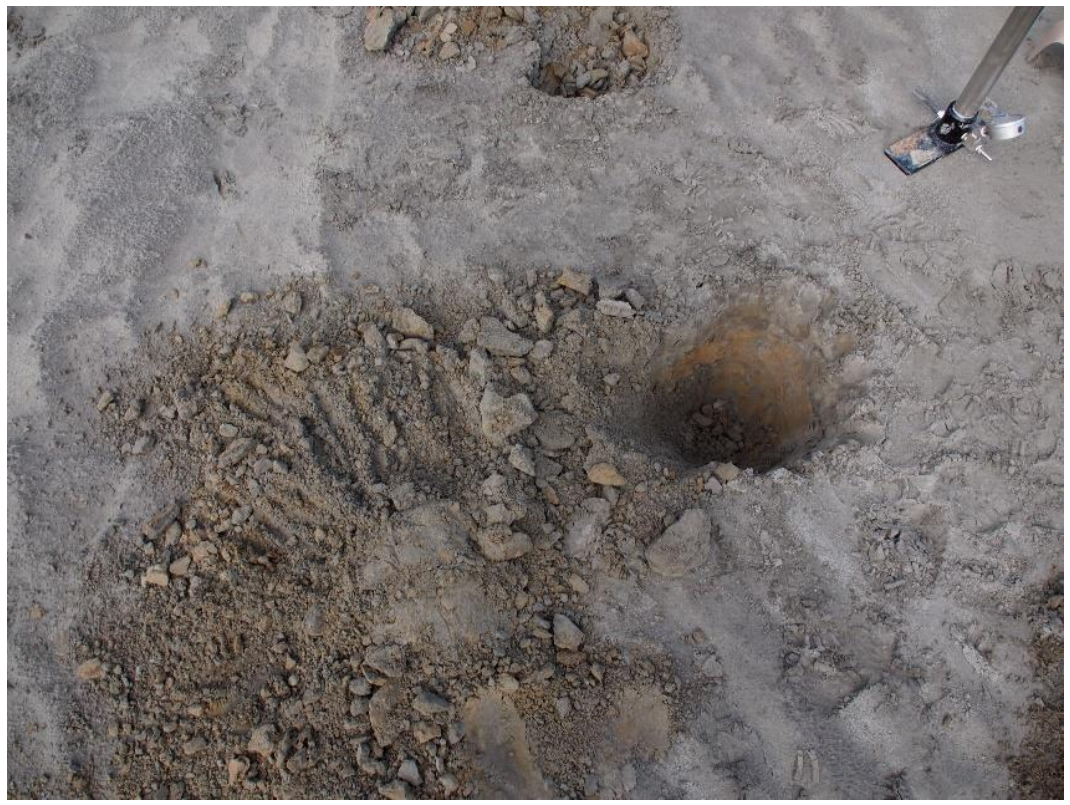

667: Sample TP4-TS-01. Note the variable degree of oxidation. 


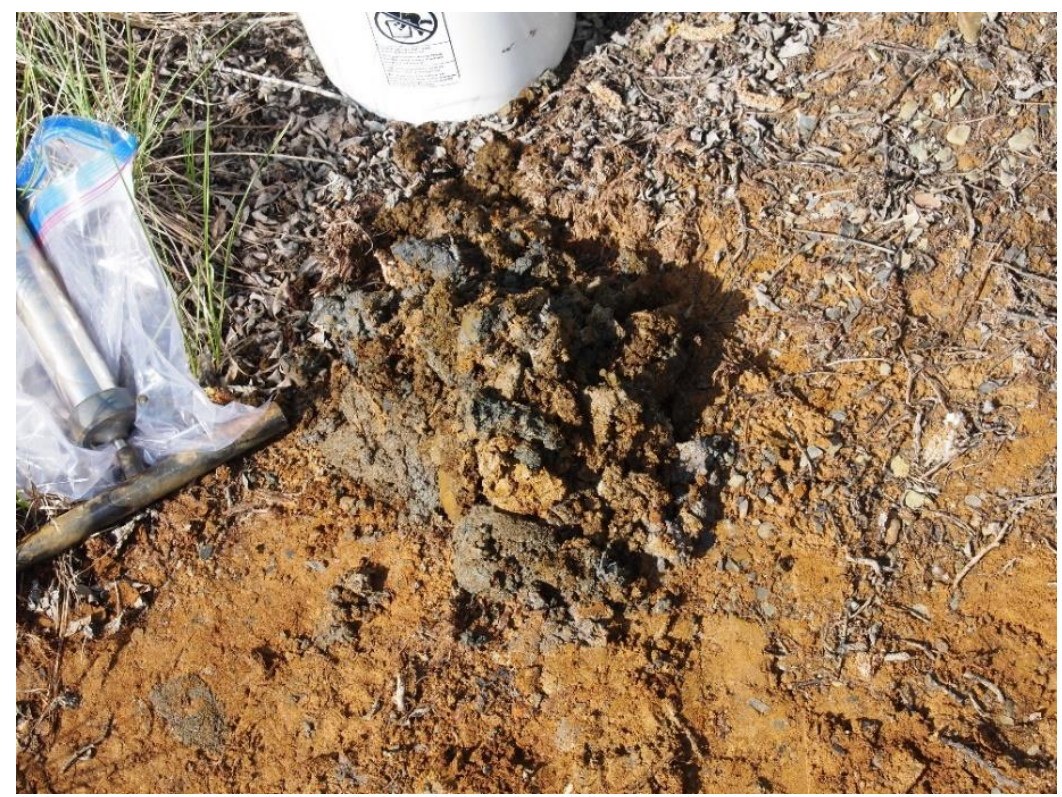

669: Sample FRT-TS-03. Note the heterogeneous mix of oxidized and unoxidized tailings.

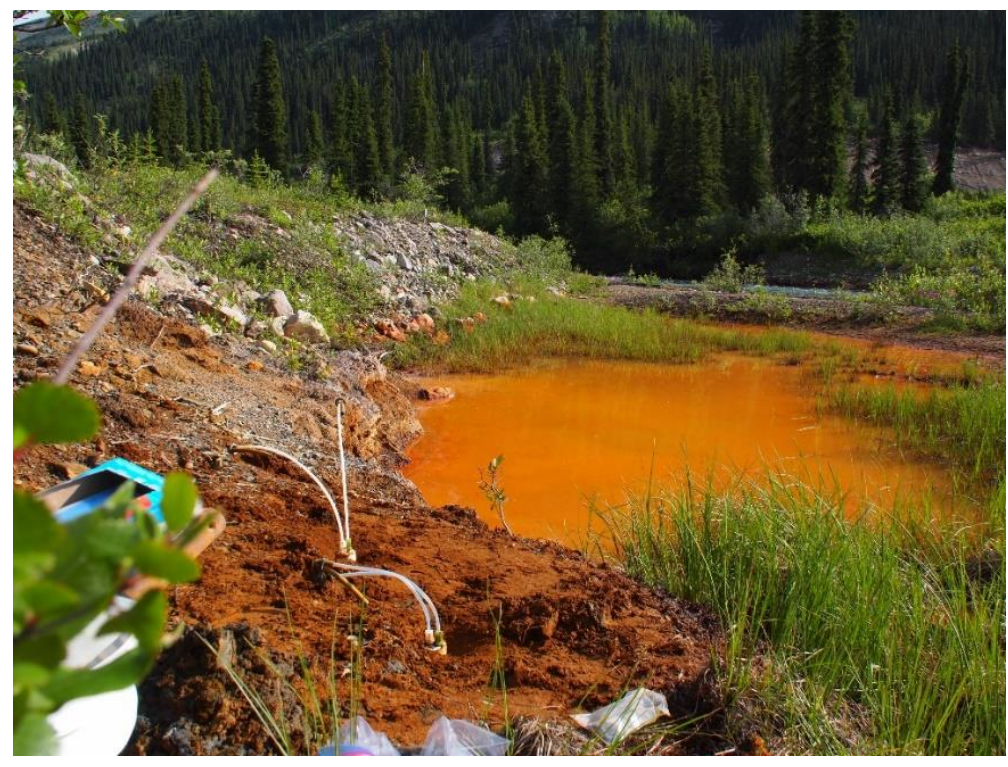

670: Orange pond on bank of the Flat River. Samples FRT-TS-03, FRT-TS03DUP sampled from lysimeter hole (water sample FRT-PWL-04). Samples FRT-TS-06 and FRT-TS-06DUP taken from bottom of pond, FRT-SW-02 and FRT-SW-02DUP taken from surface of orange pond, $30 \mathrm{~cm}$ from bank. Flat River in background. 


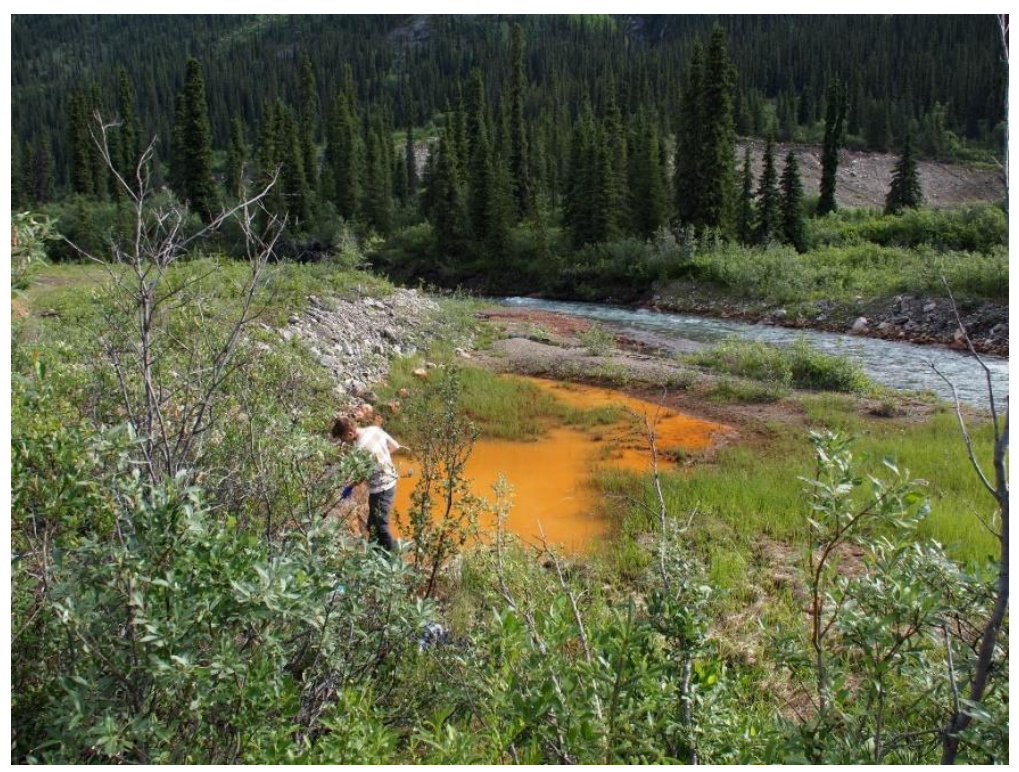

674: Orange pond on the FRT with

the Flat River in the background.

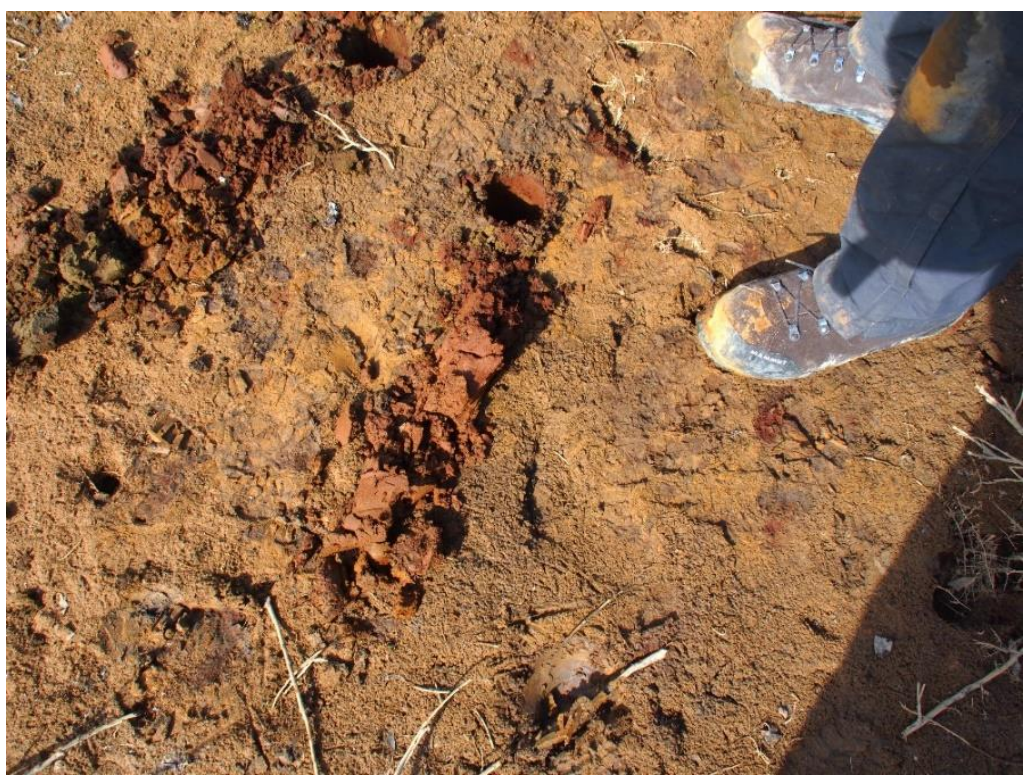

675: Sample FRT-TS-04 in the field.

Note the brick red colour. 


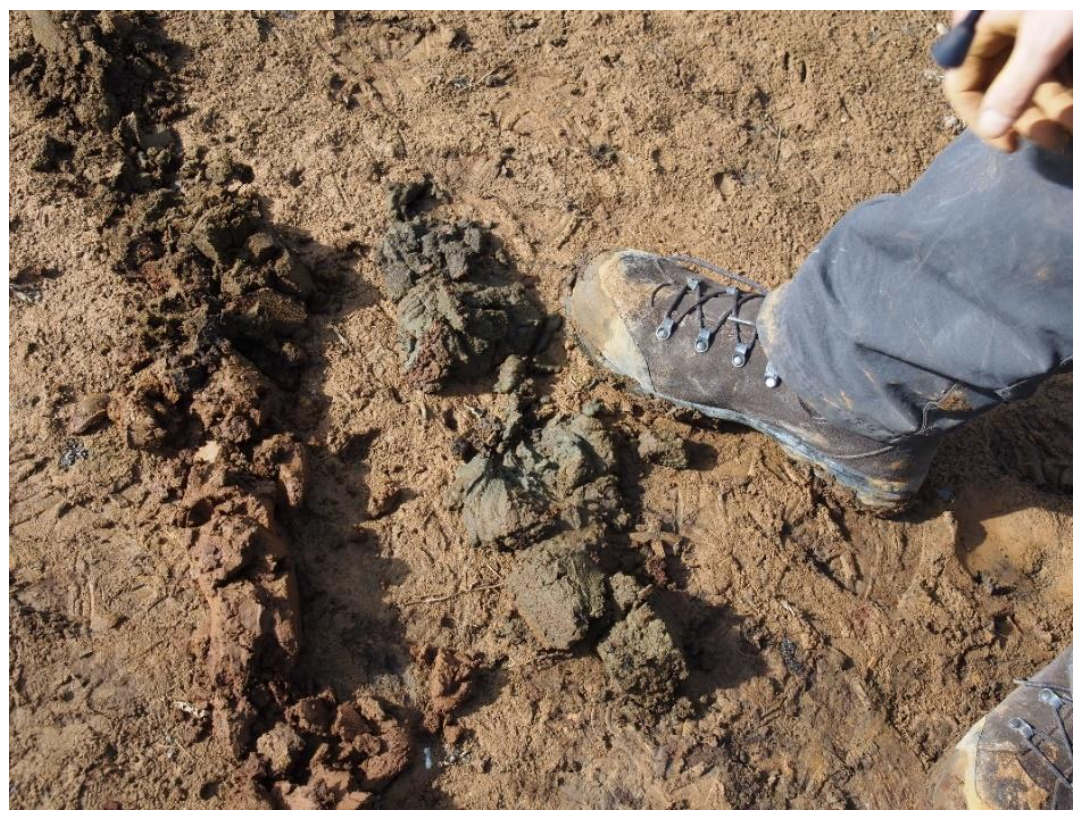

676: Sample FRT-TS-05 in the field.

Note the grey-green colour.

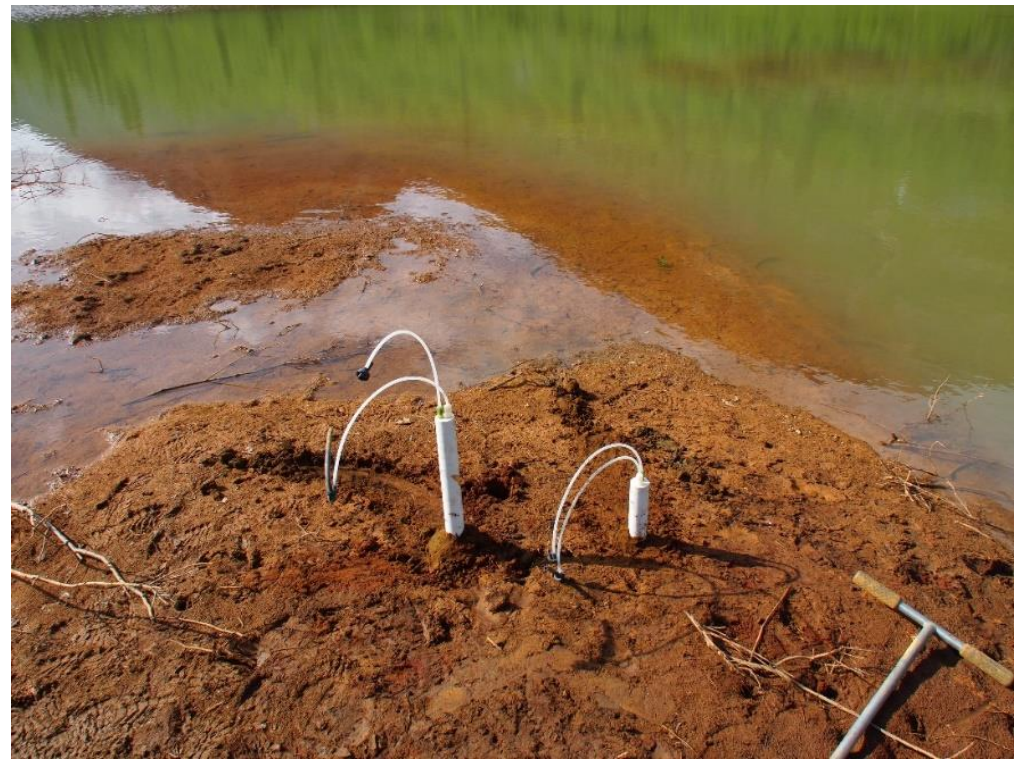

677: Sample sites for FRT-TS-04,

FRT-TS-05, FRT-SW-01, and

lysimeter for FRT-PWL-06. 


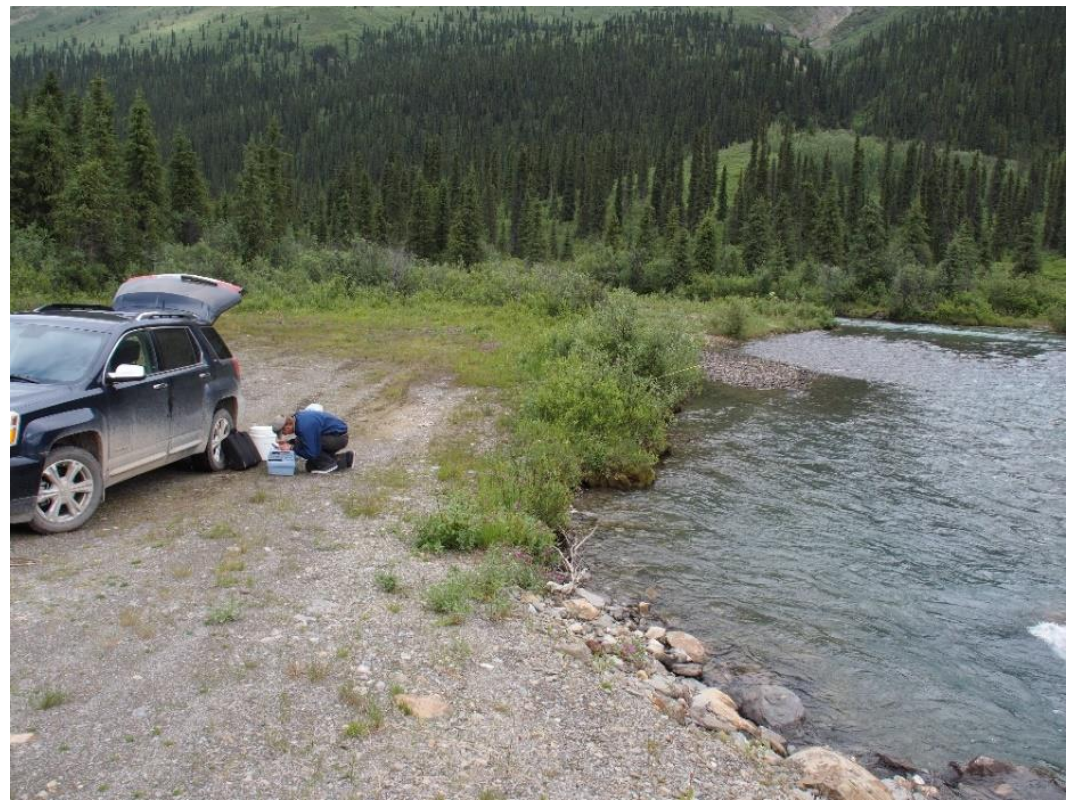

679: Sample site for water sample

FR-01.

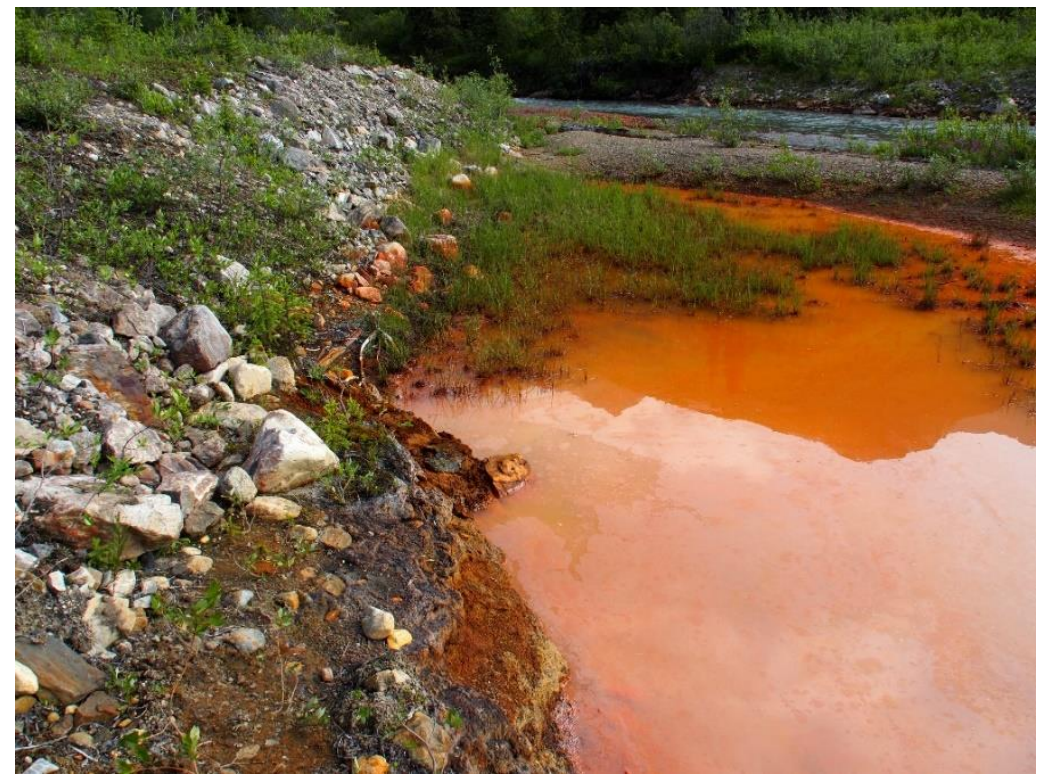

685: Biofilm on surface of orange pond on FRT. Flat River in the background. 


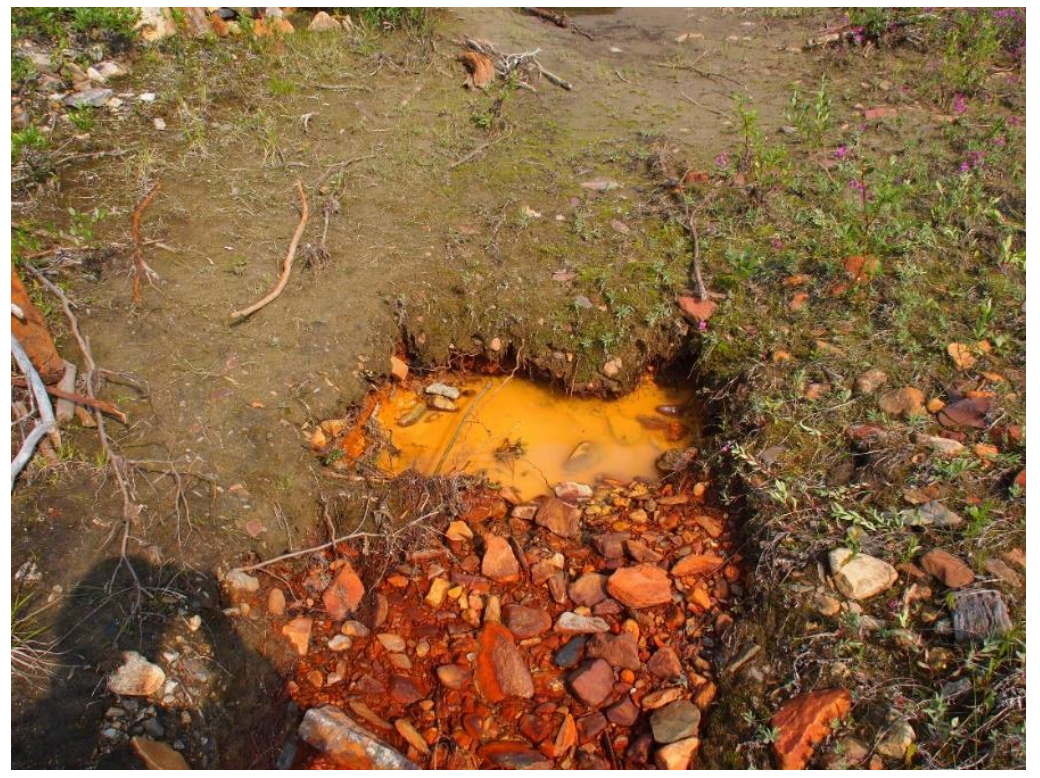

687: Sample site for FRT-SW-04.

Stagnant yellow-orange water.

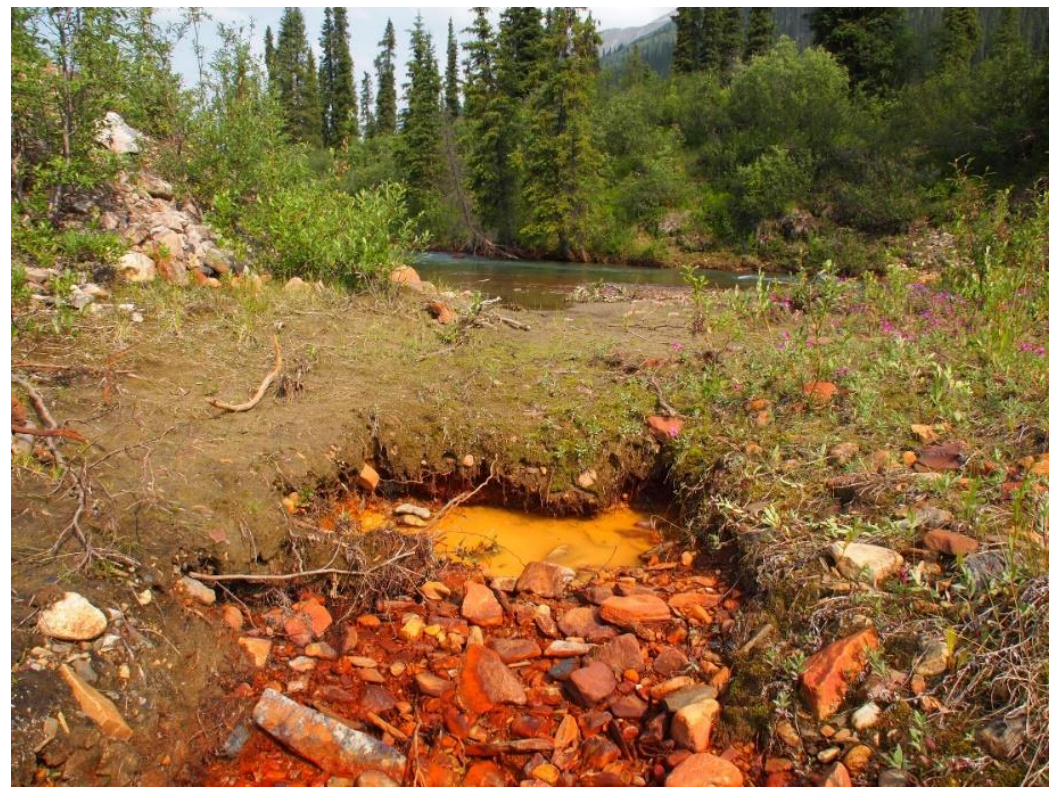

688: Sample site for FRT-SW-04

with Flat River in the background. 


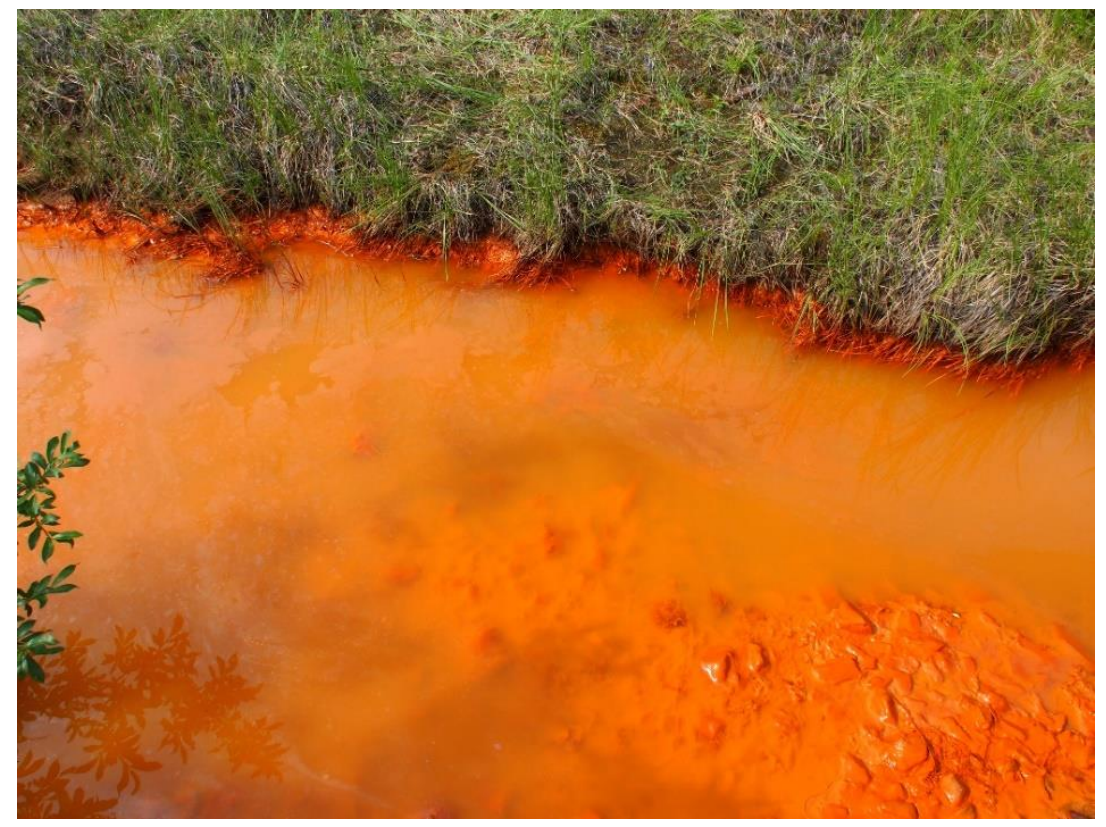

692: Sample site for FRT-SW-03.

Linear creek morphology suggests it was dug out with an excavator, and sometimes connected to Flat River.

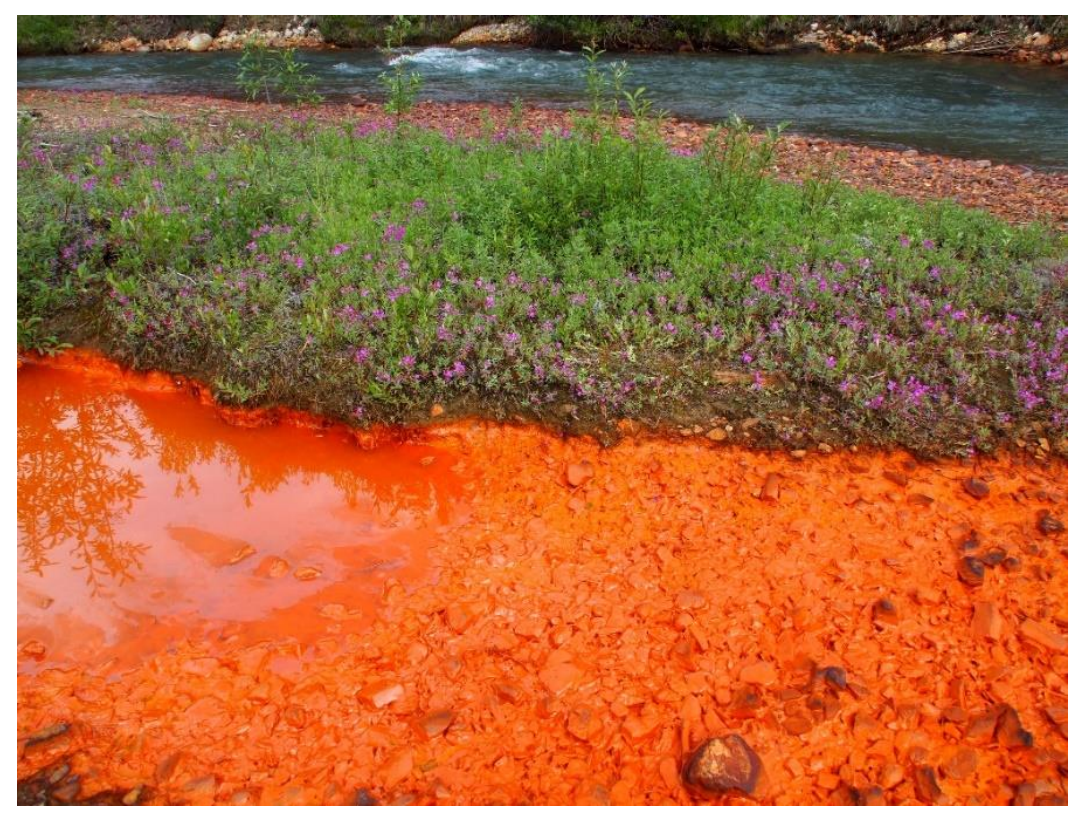

695: Sample site for FRT-SW-03, with sample site for FR-02 in background. 


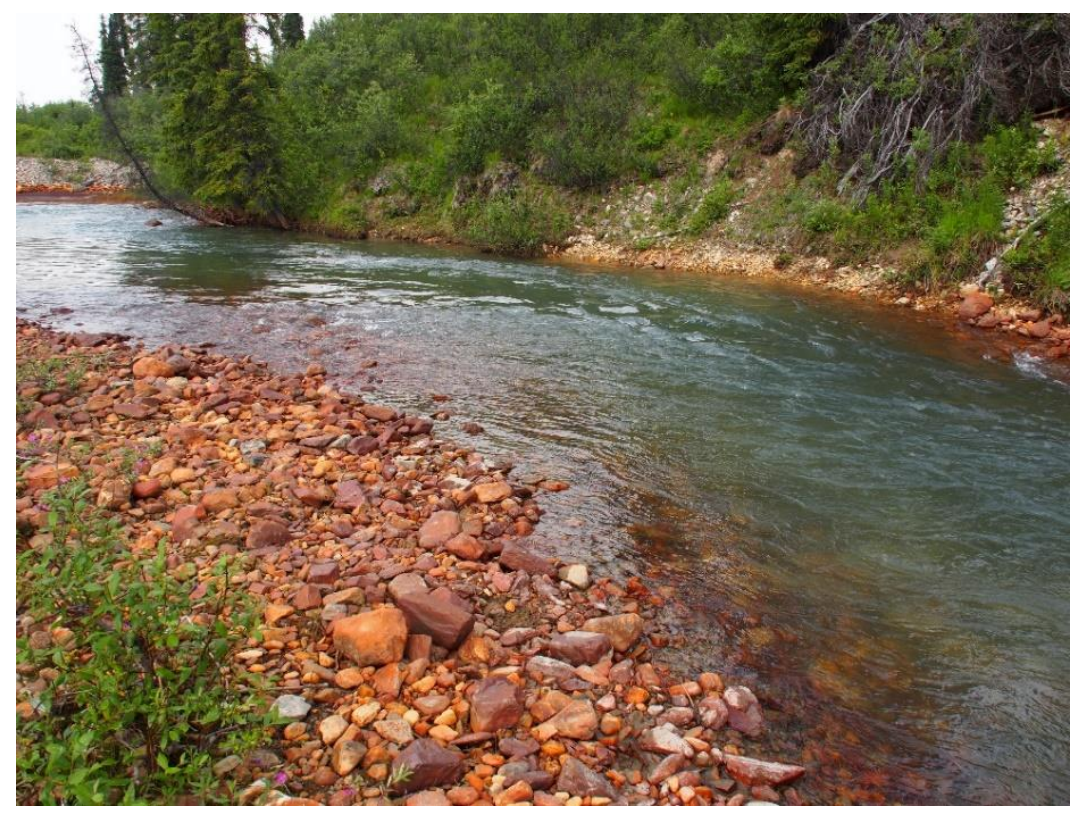

699: Flat River flowing through

the Flat River tailings. Sample site for FR-02. Note the Fe-staining on cobbles and boulders.

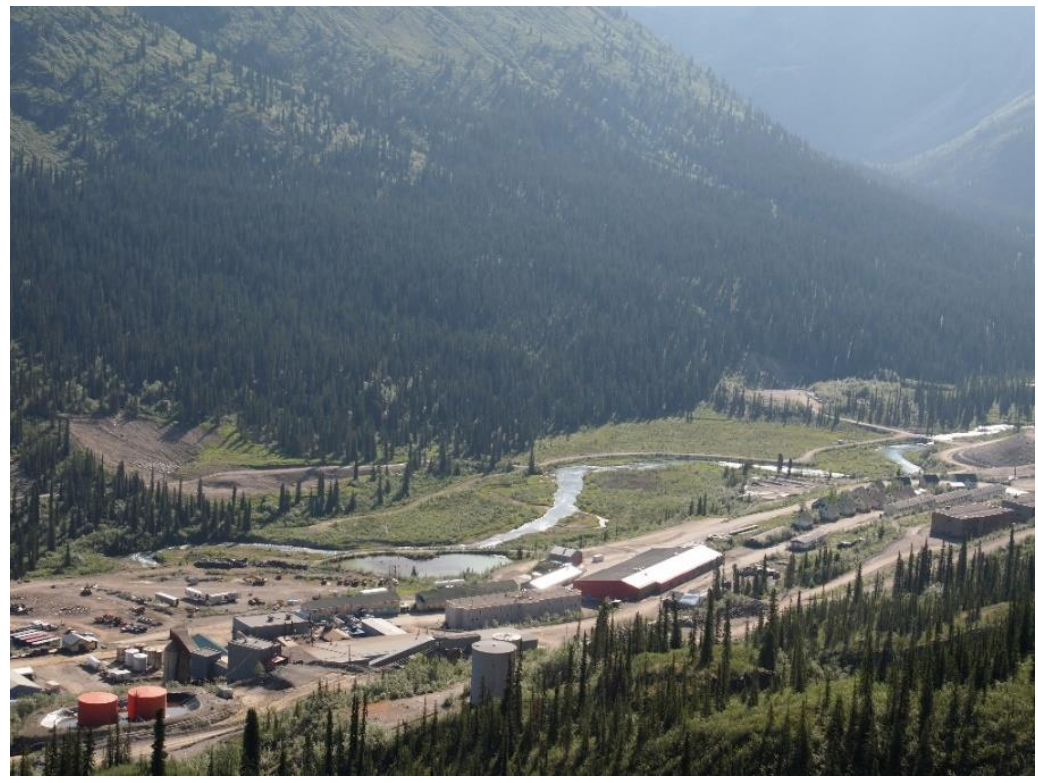

719: Photo of the Flat River flowing through the Flat River tailings. Note the ephemeral meandering channel. Photo taken from the open pit. 


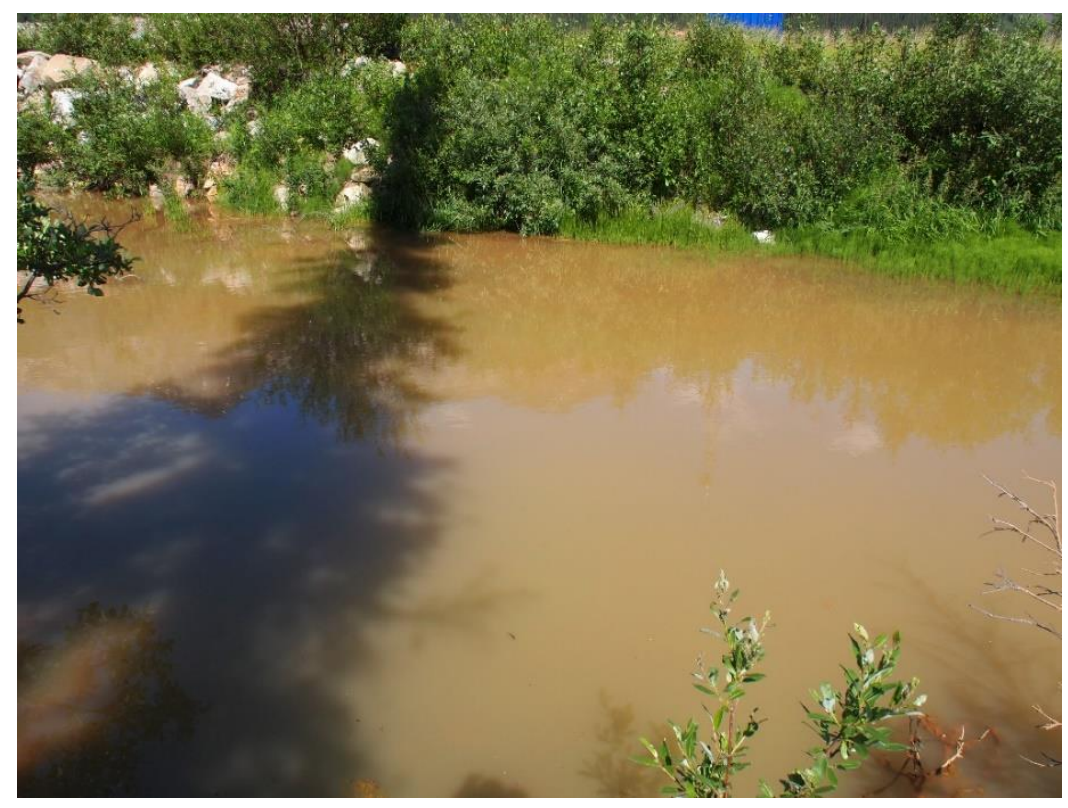

744: Sample site for TP5-TS-03, TP5-TS-03DUP, TP5-SW-02, and TP5-SW-02DUP. TP5 pond inlet, water pumped from underground. Note the high turbidity of the water.

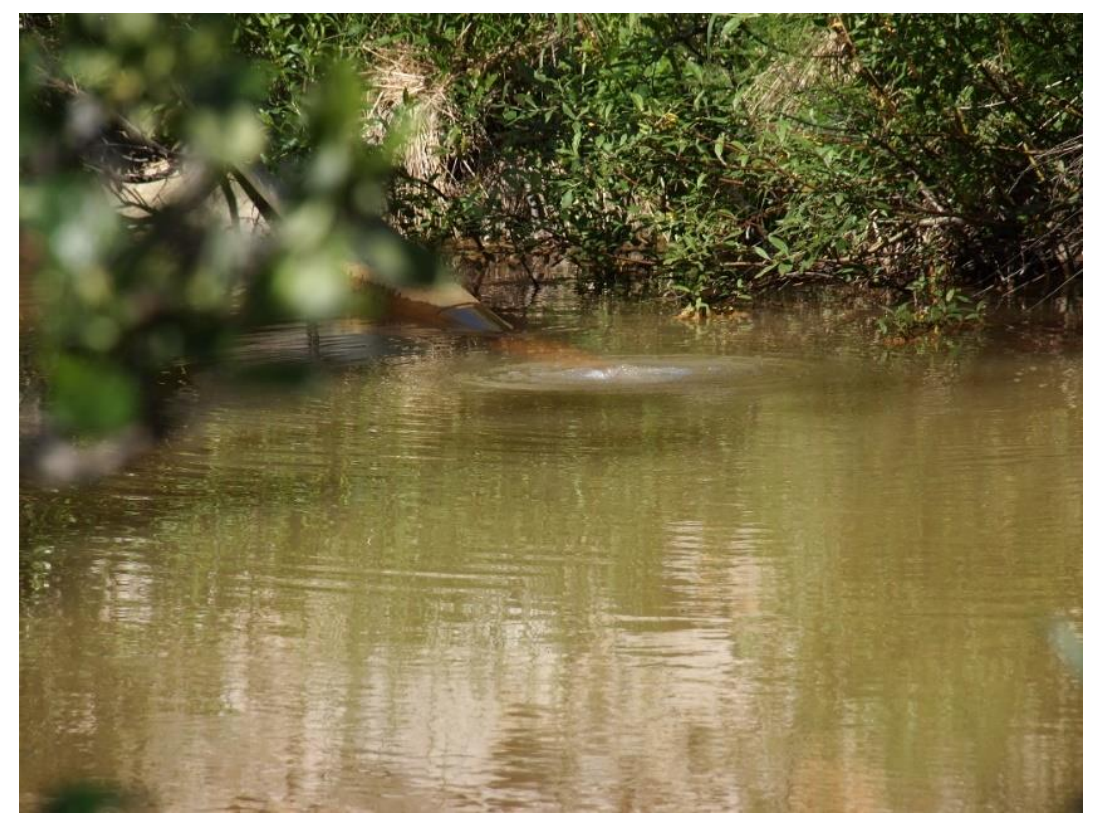

745: Outlet pipe for water pumped from underground to TP5. 


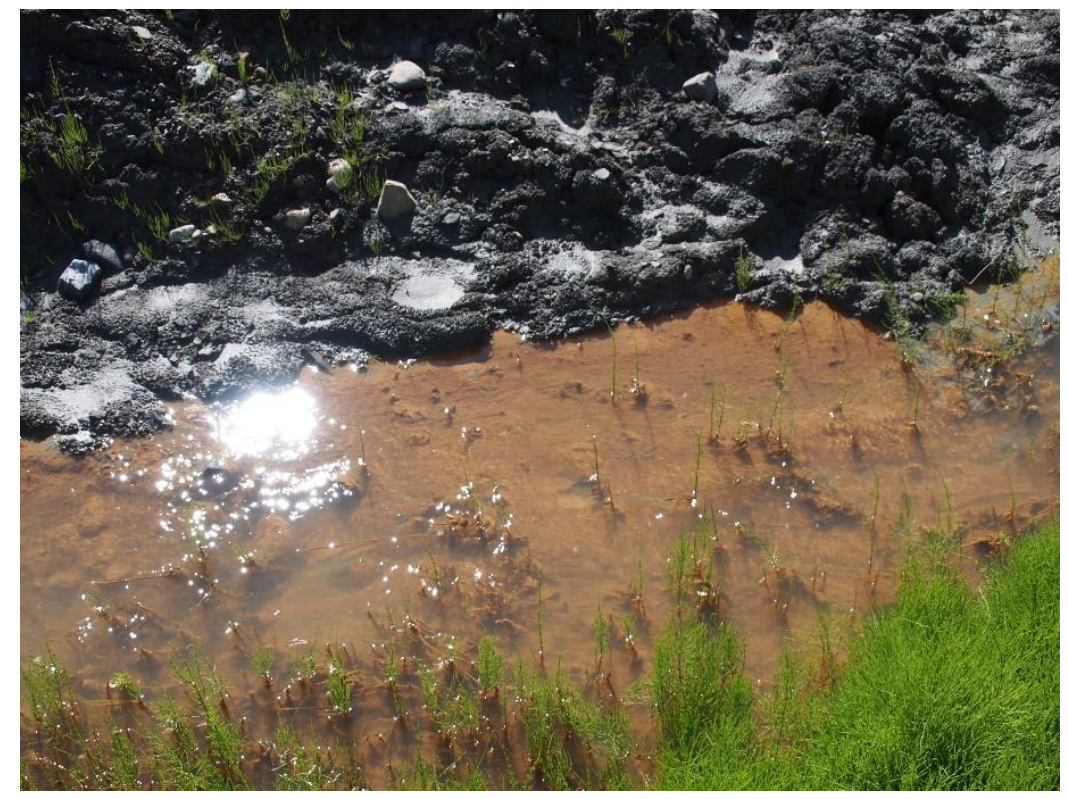

749: Sample site for TP5-TS-04 and TP5-SW-03. Note the unoxidized tailings on bank, and orange staining on creek bed. Downstream from TP5TS-03 sampling site.

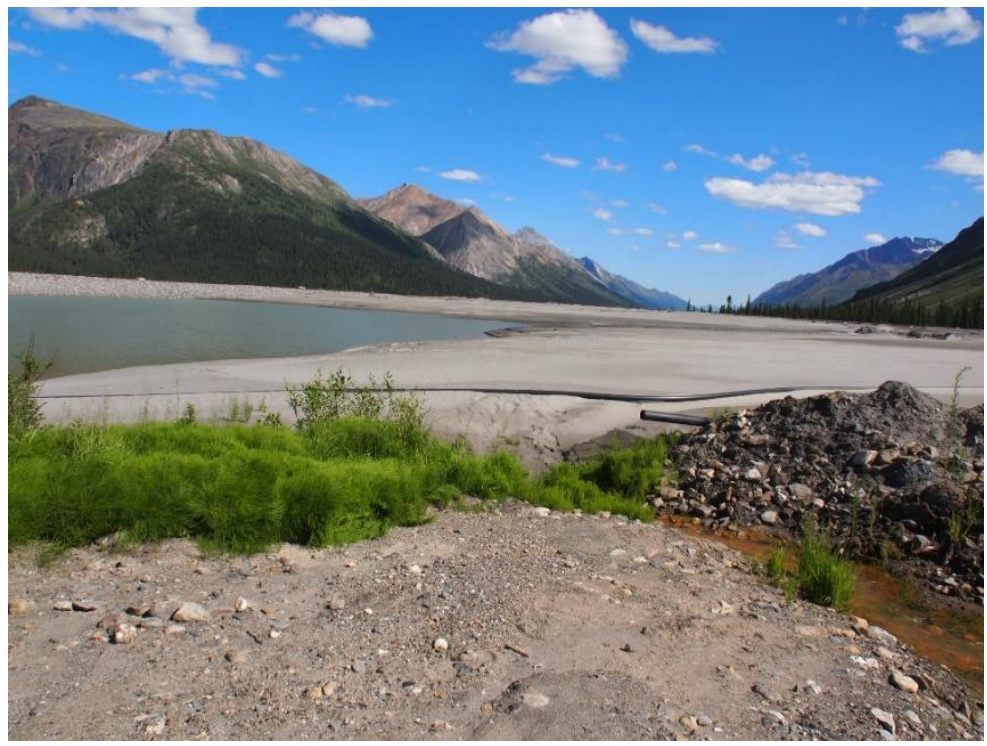

751: Sample site for TP5-TS-04 and TP5SW-03 is the creek in the bottom right. Sample site for TP5-SW-01 is on right side of pond. 


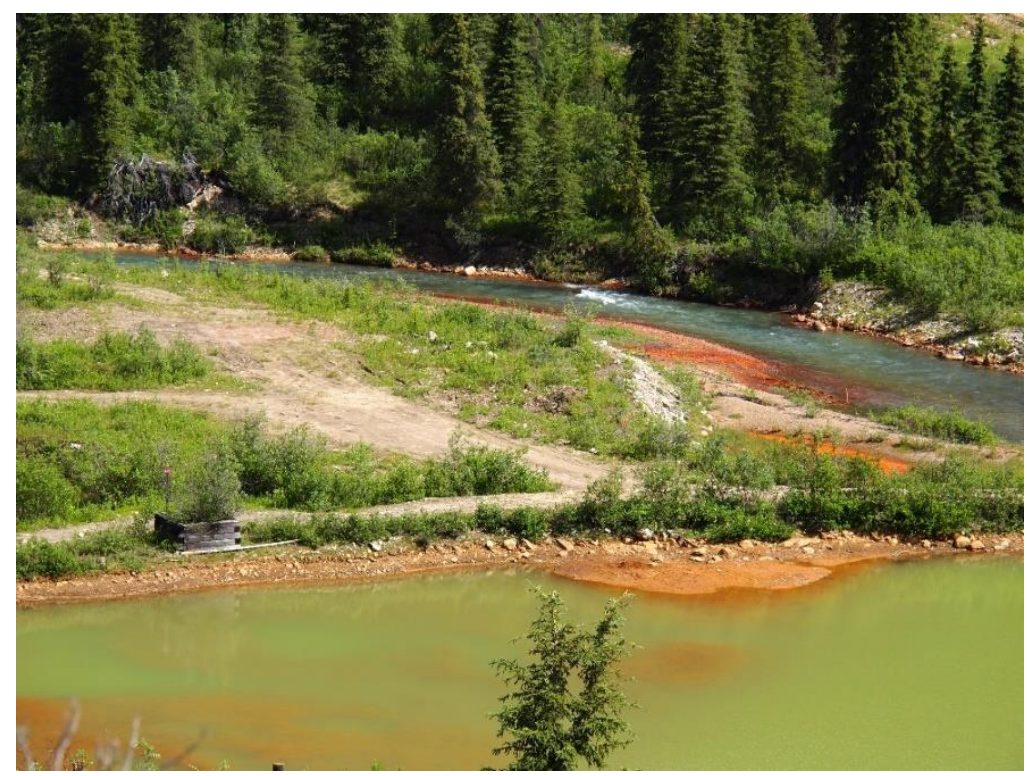

764: Photo of Flat River flowing through the FRT.

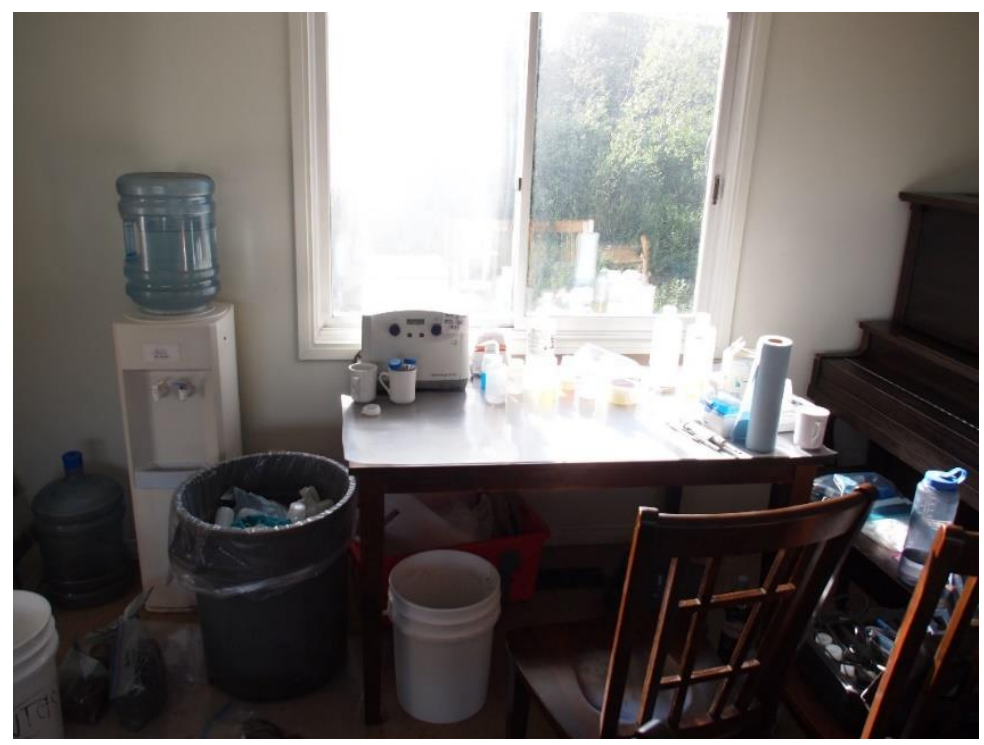

755: Photo of lab setup in the field where portable meters were calibrated and samples were acidified. 


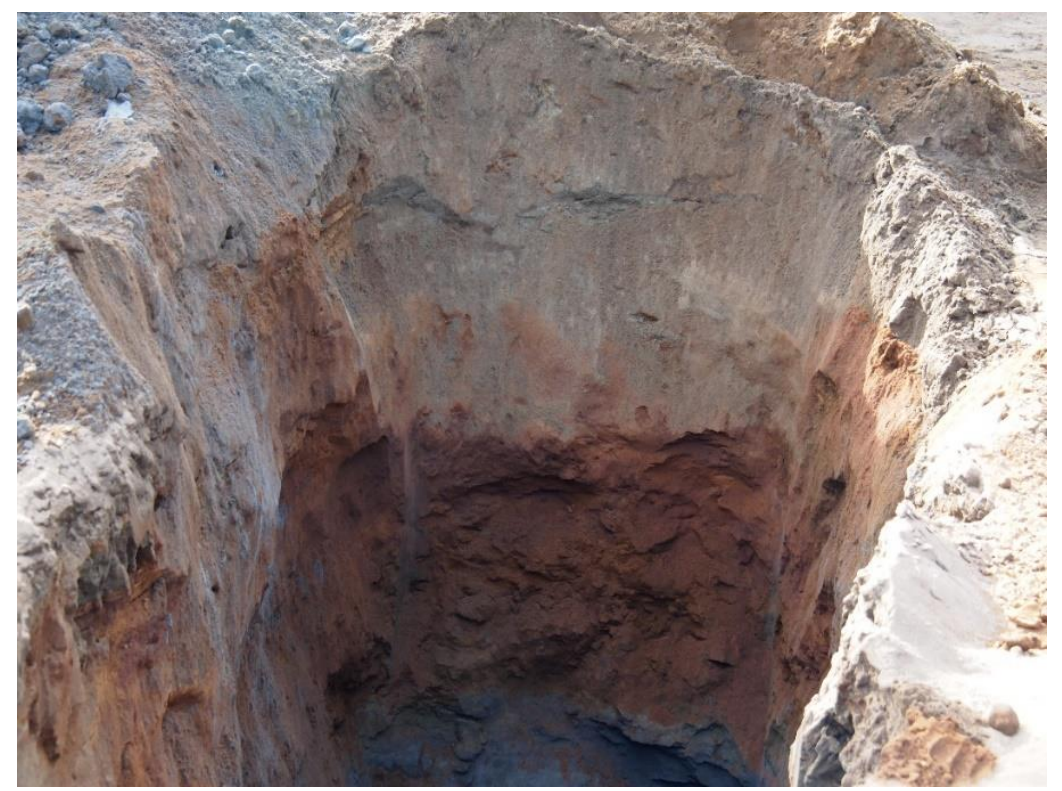

760: Excavated hole on TP3. Note the large contrast in colour indicating variable oxidation with depth.

Tailings at bottom of hole appear unoxidized, capped by extensively oxidized tailings. 


\section{Appendix E: Tailings Sample Analysis List}

The following table is a list of all analyses done on tailings samples for this thesis.

\begin{tabular}{|c|c|c|c|c|c|c|c|c|}
\hline $\begin{array}{c}\text { Tailings } \\
\text { Sample ID }\end{array}$ & $\begin{array}{l}\text { Epoxy Grain } \\
\text { Mount (SGS) }\end{array}$ & $\begin{array}{c}\text { Automated } \\
\text { Mineralogy (SEM- } \\
\text { MLA) }\end{array}$ & $\begin{array}{l}\text { Thin Section } \\
\text { (Vancouver } \\
\text { Petrographics) }\end{array}$ & $\begin{array}{l}\text { Synchrotron } \\
\mu \text { XRD-XRF }\end{array}$ & $\begin{array}{l}\text { Li-Borate } \\
\text { Fusion } \\
\text { ICP-MS } \\
\text { (ALS) }\end{array}$ & $\begin{array}{l}\text { 4-Acid } \\
\text { ICP- } \\
\text { MS } \\
\text { (ALS) }\end{array}$ & $\begin{array}{c}\text { Aqua } \\
\text { Regia ICP- } \\
\text { MS (ALS) }\end{array}$ & $\begin{array}{l}\text { Hydroxylamine } \\
\text { Sequential Leach } \\
\text { ICP-MS (ALS) }\end{array}$ \\
\hline FRT-TS-01 & $X$ & $X$ & $X$ & $X$ & $\mathrm{X}$ & $\mathrm{X}$ & $X$ & $X$ \\
\hline FRT-TS-02 & $\mathrm{X}$ & $\mathrm{X}$ & $\mathrm{X}$ & & $X$ & $X$ & $X$ & $X$ \\
\hline FRT-TS-03 & $X$ & $X$ & $\mathrm{X}$ & $\mathrm{X}$ & $\mathrm{X}$ & $\mathrm{X}$ & $\mathrm{X}$ & $\mathrm{X}$ \\
\hline $\begin{array}{c}\text { FRT-TS- } \\
\text { 03DUP }\end{array}$ & $\mathrm{X}$ & $\mathrm{X}$ & - & - & $X$ & $X$ & $\mathrm{X}$ & $\mathrm{X}$ \\
\hline FRT-TS-04 & $\mathrm{X}$ & $\mathrm{X}$ & - & - & $\mathrm{X}$ & $\mathrm{X}$ & $X$ & $\mathrm{X}$ \\
\hline FRT-TS-05 & $\mathrm{X}$ & $\mathrm{X}$ & - & $X$ & $X$ & $X$ & $X$ & $\mathrm{X}$ \\
\hline FRT-TS-06 & $X$ & $X$ & - & $X$ & $\mathrm{X}$ & $\mathrm{X}$ & $X$ & $X$ \\
\hline $\begin{array}{c}\text { FRT-TS- } \\
\text { 06DUP }\end{array}$ & - & - & - & - & $\mathrm{X}$ & $\mathrm{X}$ & $\mathrm{X}$ & $\mathrm{X}$ \\
\hline TP3-TS-01 & $\mathrm{X}$ & $\mathrm{X}$ & $X$ & $X$ & $\mathrm{X}$ & $\mathrm{X}$ & $\mathrm{X}$ & $\mathrm{X}$ \\
\hline TP3-TS-02 & - & - & $\mathrm{X}$ & - & $\mathrm{X}$ & $\mathrm{X}$ & $\mathrm{X}$ & $\mathrm{X}$ \\
\hline TP4-TS-01 & - & - & - & - & $X$ & $X$ & $X$ & $X$ \\
\hline TP5-TS-01 & - & - & - & - & $\mathrm{X}$ & $\mathrm{X}$ & $X$ & $\mathrm{X}$ \\
\hline TP5-TS-02 & - & - & - & - & $\mathrm{X}$ & $\mathrm{X}$ & $\mathrm{X}$ & $\mathrm{X}$ \\
\hline TP5-TS-03 & $\mathrm{X}$ & $\mathrm{X}$ & - & - & $\mathrm{X}$ & $\mathrm{X}$ & $X$ & $\mathrm{X}$ \\
\hline $\begin{array}{l}\text { TP5-TS- } \\
\text { 03DUP }\end{array}$ & - & - & - & - & $\mathrm{X}$ & $\mathrm{X}$ & $\mathrm{X}$ & $\mathrm{X}$ \\
\hline TP5-TS-04 & - & - & - & - & $X$ & $X$ & $X$ & $X$ \\
\hline
\end{tabular}




\section{Appendix F: SEM-MLA Sample Picking Rationale}

The following table explains the rationale behind picking select tailings samples for analysis by SEM-MLA.

\begin{tabular}{|c|c|}
\hline SampleID & Reason for SEM-MLA \\
\hline FRT-TS-01 & $\begin{array}{l}\text { Lowest porewater } \mathrm{pH}(\mathrm{pH}=2.2) \text { Shallow tailings sample to be compared } \\
\text { with deeper tailings sample taken nearby (FRT-TS-02). }\end{array}$ \\
\hline FRT-TS-02 & $\begin{array}{l}\text { High porewater } \mathrm{pH} \text { for FRT }(\mathrm{pH}=5.46 \text {, extracted by lysimeter). Deep } \\
\text { tailings sample to be compared with shallow tailings sample taken nearby } \\
\text { (FRT-TS-01). }\end{array}$ \\
\hline FRT-TS-03 & $\begin{array}{l}\text { Low porewater } \mathrm{Ph}(\mathrm{Ph}=3.02 \text {, extracted by lysimeter }) \text {. Deep tailings, field } \\
\text { notes suggested near base of tailings based on coarse material in auger hole. } \\
\text { Yellow pods were observed in adjacent bank of orange pond. }\end{array}$ \\
\hline $\begin{array}{l}\text { FRT-TS- } \\
\text { O3DUP }\end{array}$ & $\begin{array}{l}\text { Field duplicate for FRT-TS-03. Chosen to check for spatial heterogeneity in } \\
\text { the field. }\end{array}$ \\
\hline FRT-TS-04 & $\begin{array}{c}\text { Colour of tailings were "hematite red" in the field. Analyzed to check for } \\
\text { unique mineralogy. }\end{array}$ \\
\hline FRT-TS-05 & $\begin{array}{l}\text { High porewater } \mathrm{pH} \text { for FRT, but below detection limit for } \mathrm{W}(\mathrm{Ph}=7.6 \text {, } \\
\text { extracted by lysimeter). Deep tailings sample to be compared with shallow } \\
\text { tailings sample from same auger hole (FRT-TS-04). }\end{array}$ \\
\hline FRT-TS-06 & $\begin{array}{l}\text { Benthic tailings of orange pond, chosen to compare the unique } \\
\text { microenvironment with other tailings samples. }\end{array}$ \\
\hline TP3-TS-01 & $\begin{array}{l}\text { Only tailings sample from TP3, TP4, or TP5 with a coincident porewater } \\
\text { sample. Porewater sample had the highest W concentration of all water } \\
\text { samples. Used to represent fresh, unaltered tailings. }\end{array}$ \\
\hline TP5-TS-03 & $\begin{array}{l}\text { Only other tailings sample from TP3, TP4, or TP5 with water data to } \\
\text { compare with. Benthic stream sediment with visible oxidation in top } 1 \mathrm{~cm} \text {. }\end{array}$ \\
\hline
\end{tabular}




\section{Appendix G: Field ORP to Eh Conversions}

The Eh of the waters was calculated using the following formula (from Nordstrom and Wilde, 2005):

$$
\text { Eh }=\text { Emf }+ \text { Eref }
$$

Where,

$\mathrm{Eh}=$ potential of sample solution relative to the standard hydrogen electrode (SHE)

$\mathrm{Emf}=$ electromotive force of the water at the measured temperature

Eref $=$ reference electrode temperature corrected for sample temperature.

The temperature correction for Eref was determined using Table 6.5-2 from Nordstrom and Wilde (2005) for $\mathrm{Ag} / \mathrm{AgCl}$ reference electrodes saturated with $\mathrm{KCl}$, where:

$$
\operatorname{Eref}(V)=-0.001 T+0.224
$$

$\mathrm{T}=$ sample temperature $\left({ }^{\circ} \mathrm{C}\right)$

The following table lists the calculated Eh for each water sample utilized in this study.

\begin{tabular}{|c|c|c|}
\hline $\begin{array}{c}\text { Water Sample } \\
\text { ID }\end{array}$ & $\begin{array}{c}\text { ORP } \\
(\mathbf{m V})\end{array}$ & Eh $(\mathbf{m V})$ \\
\hline TP3-PWC-01 & -38.5 & 161 \\
\hline TP3-PWL-01 & 114.1 & 325 \\
\hline FRT-PWL-01 & 189.1 & 393 \\
\hline FRT-PWC-01 & 630 & 831 \\
\hline FRT-PWL-03 & 512.6 & 716 \\
\hline FRT-PWL-04 & 429.9 & 632 \\
\hline FRT-PWL-06 & 275 & 477 \\
\hline FRT-PWC-O2 & 387.7 & 588 \\
\hline FR01 & 225 & 439 \\
\hline FRT-SW-01 & 206.2 & 416 \\
\hline FRT-SW-02 & 42 & 261 \\
\hline FRT-SW-2DUP & 36.9 & 254 \\
\hline FR02 & 103 & 316 \\
\hline \multicolumn{2}{|c}{}
\end{tabular}




\begin{tabular}{|c|c|c|}
\hline FRT-SW-03 & -25 & 191 \\
\hline FRT-SW-O4 & 50.4 & 255 \\
\hline TP5-SW-01 & 167 & 374 \\
\hline TP5-SW-02 & 217 & 430 \\
\hline $\begin{array}{c}\text { TP5-SW- } \\
\text { 02DUP }\end{array}$ & 217 & 430 \\
\hline TP5-SW-03 & 155.9 & 364 \\
\hline FRT-PWC-03 & 244.5 & 441 \\
\hline
\end{tabular}




\section{Appendix H: SEM-MLA Mineral Reference Library}

Two separate mineral reference libraries were used for the FRT and tailings impoundments samples. The only difference between the two, is the FRT samples have goethite (FeOOH) in the library, whereas the tailings impoundment samples have Fe-oxides $\left(\mathrm{Fe}_{2} \mathrm{O}_{3}\right)$ in the library.

\section{FRT Samples Mineral Reference Library:}

\begin{tabular}{|c|c|c|c|}
\hline Mineral Name & Density & Formula & Grouping \\
\hline Actinolite & 3.04 & $\mathrm{Ca} 2 \mathrm{Mg} 3 \mathrm{Fe} 2+2 \mathrm{Si} 8 \mathrm{O} 22(\mathrm{OH}) 2$ & Amphiboles \\
\hline Albite & 2.62 & NaAlSi3O8 & Feldspars \\
\hline Ankerite & 3.05 & $\mathrm{Ca}(\mathrm{Fe}, \mathrm{Mg}, \mathrm{Mn})(\mathrm{CO} 3) 2$ & \\
\hline Apatite & 3.19 & $\mathrm{Ca} 5(\mathrm{PO} 4)(\mathrm{F}, \mathrm{Cl}, \mathrm{OH})$ & Other \\
\hline Arsenopyrite & 6.07 & $\mathrm{Fe} 3+\mathrm{AsS}$ & Other \\
\hline Augite & 3.4 & $(\mathrm{Ca}, \mathrm{Na})(\mathrm{Mg}, \mathrm{Fe}, \mathrm{Al})(\mathrm{Si}, \mathrm{Al}) 2 \mathrm{O} 6$ & Pyroxenes and Epidote \\
\hline Barite & 4.48 & $\mathrm{Ba}(\mathrm{SO} 4)$ & Other \\
\hline Biotite & 3.1 & $\mathrm{KMg} 2.5 \mathrm{Fe} 2+0.5 \mathrm{AlSi} 3 \mathrm{O} 10(\mathrm{OH}) 1.75 \mathrm{~F} 0.25$ & Micas \\
\hline Bismuthinite & 6.8 & $\mathrm{Bi} 2 \mathrm{~S} 3$ & Other \\
\hline Bornite & 5.1 & $\mathrm{Cu} 5 \mathrm{Fe} 2+\mathrm{S} 4$ & Other \\
\hline Calcite & 2.71 & $\mathrm{Ca}(\mathrm{CO} 3)$ & \\
\hline Carbon & 1 & $\mathrm{C}$ & Other \\
\hline Celsian & 3.15 & $\mathrm{BaA} 2 \mathrm{SiO} 8$ & Other \\
\hline Chalcopyrite & 4.2 & $\mathrm{CuFe} 2+\mathrm{S} 2$ & \\
\hline Chlorite & 2.95 & $(\mathrm{Mg}, \mathrm{Fe}) 3(\mathrm{Si}, \mathrm{Al}) 4 \mathrm{O} 10(\mathrm{OH}) 2 \cdot(\mathrm{Mg}, \mathrm{Fe}) 3(\mathrm{OH}) 6$ & Micas \\
\hline Chromite & 4.8 & $\mathrm{Fe} 2+\mathrm{Cr} 2 \mathrm{O} 4$ & Other \\
\hline Clinozoisite & 3.35 & $\mathrm{Ca} 2 \mathrm{Al} 3(\mathrm{SiO} 4) 3(\mathrm{OH})$ & Pyroxenes and Epidote \\
\hline Covellite & 4.68 & $\mathrm{CuS}$ & Other \\
\hline Cuprite & 6.1 & $\mathrm{Cu} 2 \mathrm{O}$ & Other \\
\hline Diopside & 3.4 & $\mathrm{CaMg}(\mathrm{Si2O})$ & Pyroxenes and Epidote \\
\hline Dolomite & 2.85 & $\mathrm{CaMg}(\mathrm{CO} 3) 2$ & \\
\hline Electrum $15 \%$ & 12.2 & $\mathrm{Au} 2 \mathrm{Ag} 0.7$ & Other \\
\hline Electrum $30 \%$ & 12.2 & $\mathrm{Au} 2 \mathrm{Ag} 1.5$ & Other \\
\hline Enargite & 4.45 & $\mathrm{Cu} 3 \mathrm{AsS} 4$ & Other \\
\hline Enstatite & 3.2 & $\mathrm{Mg} 2 \mathrm{Si} 2 \mathrm{O} 6$ & Pyroxenes and Epidote \\
\hline Epidote & 3.45 & $\mathrm{Ca} 2 \mathrm{Al} 2(\mathrm{Fe} 3+, \mathrm{Al})(\mathrm{SiO} 4)(\mathrm{Si} 2 \mathrm{O} 7) \mathrm{O}(\mathrm{OH})$ & Pyroxenes and Epidote \\
\hline Ferberite & 7.45 & $\mathrm{Fe} 2+(\mathrm{WO} 4)$ & Other \\
\hline
\end{tabular}




\begin{tabular}{|c|c|c|c|}
\hline Fluorapatite & 3.15 & $\mathrm{Ca} 5(\mathrm{PO} 4) 3 \mathrm{~F}$ & Other \\
\hline Fluorite & 3.13 & $\mathrm{CaF} 2$ & Other \\
\hline Galena & 7.4 & $\mathrm{PbS}$ & Other \\
\hline $\begin{array}{c}\text { Garnet }(\mathbf{C a}> \\
\mathrm{Fe}=\mathrm{Mn})\end{array}$ & 4.04 & $(\mathrm{Ca}, \mathrm{Fe}, \mathrm{Mn}) 3 \mathrm{Al} 2(\mathrm{SiO} 4) 3$ & Other \\
\hline Goethite & 3.8 & $\mathrm{Fe} 3+\mathrm{O}(\mathrm{OH})$ & \\
\hline Gold & 17.65 & $\mathrm{Au}$ & Other \\
\hline Gypsum & 2.3 & $\mathrm{Ca}(\mathrm{SO} 4) \cdot 2(\mathrm{H} 2 \mathrm{O})$ & \\
\hline Hedenbergite & 3.4 & $(\mathrm{Ca}, \mathrm{Na})(\mathrm{Mg}, \mathrm{Fe}, \mathrm{Al})(\mathrm{Si}, \mathrm{Al}) 2 \mathrm{O} 6$ & Pyroxenes and Epidote \\
\hline Hornblende & 2.9 & $\mathrm{Ca} 2(\mathrm{Mg}, \mathrm{Fe}, \mathrm{Al}) 5(\mathrm{Al}, \mathrm{Si}) 8 \mathrm{O} 22(\mathrm{OH}) 2$ & Amphiboles \\
\hline Ilmenite & 4.72 & $\mathrm{Fe} 2+\mathrm{TiO} 3$ & Other \\
\hline Jarosite & 3.06 & $\mathrm{KFe} 3(\mathrm{SO} 4) 2(\mathrm{OH}) 6$ & \\
\hline Molybdenite & 5.5 & MoS2 & Other \\
\hline Monazite & 5.15 & $\mathrm{Ce} 0.5 \mathrm{La} 0.25 \mathrm{Nd} 0.2 \mathrm{Th} 0.05(\mathrm{PO} 4)$ & Other \\
\hline Native Bi & 9.78 & $\mathrm{Bi}$ & Other \\
\hline Orthoclase & 2.56 & KAlSi3O8 & Feldspars \\
\hline Pentlandite & 4.8 & $\mathrm{Fe} 2+4.5 \mathrm{Ni} 4.5 \mathrm{~S} 8$ & Other \\
\hline Plagioclase & 2.69 & $\mathrm{Na} 0.5 \mathrm{Ca} 0.5 \mathrm{Si} 3 \mathrm{AlO} 8$ & Feldspars \\
\hline Pyrite & 5.01 & $\mathrm{Fe} 2+\mathrm{S} 2$ & \\
\hline Pyrrhotite & 4.62 & $\mathrm{Fe} 2+0.95 \mathrm{~S}$ & \\
\hline Quartz & 2.63 & $(\mathrm{SiO} 2)$ & \\
\hline Rutile & 4.25 & $\mathrm{TiO} 2$ & Other \\
\hline Scheelite & 6.01 & $\mathrm{Ca}(\mathrm{WO} 4)$ & \\
\hline Sphalerite & 4.05 & $(\mathrm{Zn}, \mathrm{Fe}) \mathrm{S}$ & \\
\hline Spinel & 3.59 & $\mathrm{MgAl} 2 \mathrm{O} 4$ & Other \\
\hline Stibnite & 4.63 & $\mathrm{Sb} 2 \mathrm{~S} 3$ & Other \\
\hline Sulfur & 2 & $\mathrm{~S}$ & \\
\hline Ti-Muscovite & 2.83 & KAl3Si3O10(OH)1.9F0.1Ti0.7 & Micas \\
\hline Titanite & 3.48 & CaTiSiO5 & Other \\
\hline Wolframite & 7.3 & $\mathrm{Fe} 2+0.5 \mathrm{Mn} 2+0.5(\mathrm{WO} 4)$ & Other \\
\hline Zircon & 4.65 & $\mathrm{ZrSiO} 4$ & Other \\
\hline
\end{tabular}

Tailings Impoundment Samples Mineral Reference Library:

\begin{tabular}{|c|c|c|c|}
\hline Mineral Name & Density & Formula & Grouping \\
\hline Actinolite & 3.04 & $\mathrm{Ca} 2 \mathrm{Mg} 3 \mathrm{Fe} 2+2 \mathrm{Si} 8 \mathrm{O} 22(\mathrm{OH}) 2$ & Amphiboles \\
\hline Albite & 2.62 & $\mathrm{NaAlSi} 3 \mathrm{O} 8$ & Feldspars \\
\hline Ankerite & 3.05 & $\mathrm{Ca}(\mathrm{Fe}, \mathrm{Mg}, \mathrm{Mn})(\mathrm{CO} 3) 2$ & \\
\hline Apatite & 3.19 & $\mathrm{Ca} 5(\mathrm{PO} 4)(\mathrm{F}, \mathrm{Cl}, \mathrm{OH})$ & Other \\
\hline Arsenopyrite & 6.07 & $\mathrm{Fe} 3+\mathrm{AsS}$ & Other \\
\hline Augite & 3.4 & $(\mathrm{Ca}, \mathrm{Na})(\mathrm{Mg}, \mathrm{Fe}, \mathrm{Al})(\mathrm{Si}, \mathrm{Al}) 2 \mathrm{O} 6$ & Pyroxenes and Epidote \\
\hline Barite & 4.48 & $\mathrm{Ba}(\mathrm{SO} 4)$ & Other \\
\hline
\end{tabular}




\begin{tabular}{|c|c|c|c|}
\hline Biotite & 3.1 & $\mathrm{KMg} 2.5 \mathrm{Fe} 2+0.5 \mathrm{AlSi} 3 \mathrm{O} 10(\mathrm{OH}) 1.75 \mathrm{~F} 0.25$ & Micas \\
\hline Bismuthinite & 6.8 & $\mathrm{Bi} 2 \mathrm{~S} 3$ & Other \\
\hline Bornite & 5.1 & $\mathrm{Cu} 5 \mathrm{Fe} 2+\mathrm{S} 4$ & Other \\
\hline Calcite & 2.71 & $\mathrm{Ca}(\mathrm{CO} 3)$ & \\
\hline Carbon & 1 & $\mathrm{C}$ & Other \\
\hline Celsian & 3.15 & $\mathrm{BaAl2SiO8}$ & Other \\
\hline Chalcopyrite & 4.2 & $\mathrm{CuFe} 2+\mathrm{S} 2$ & \\
\hline Chlorite & 2.95 & $(\mathrm{Mg}, \mathrm{Fe}) 3(\mathrm{Si}, \mathrm{Al}) 4 \mathrm{O} 10(\mathrm{OH}) 2 \cdot(\mathrm{Mg}, \mathrm{Fe}) 3(\mathrm{OH}) 6$ & Micas \\
\hline Chromite & 4.8 & $\mathrm{Fe} 2+\mathrm{Cr} 2 \mathrm{O} 4$ & Other \\
\hline Clinozoisite & 3.35 & $\mathrm{Ca} 2 \mathrm{Al} 3(\mathrm{SiO} 4) 3(\mathrm{OH})$ & Pyroxenes and Epidote \\
\hline Covellite & 4.68 & $\mathrm{CuS}$ & Other \\
\hline Cuprite & 6.1 & $\mathrm{Cu} 2 \mathrm{O}$ & Other \\
\hline Diopside & 3.4 & $\mathrm{CaMg}(\mathrm{Si} 2 \mathrm{O} 6)$ & Pyroxenes and Epidote \\
\hline Dolomite & 2.85 & $\mathrm{CaMg}(\mathrm{CO} 3) 2$ & \\
\hline Electrum $15 \%$ & 12.2 & $\mathrm{Au} 2 \mathrm{Ag} 0.7$ & Other \\
\hline Electrum 30\% & 12.2 & $\mathrm{Au} 2 \mathrm{Ag} 1.5$ & Other \\
\hline Enargite & 4.45 & $\mathrm{Cu} 3 \mathrm{AsS} 4$ & Other \\
\hline Enstatite & 3.2 & $\mathrm{Mg} 2 \mathrm{Si} 2 \mathrm{O} 6$ & Pyroxenes and Epidote \\
\hline Epidote & 3.45 & $\mathrm{Ca} 2 \mathrm{Al} 2(\mathrm{Fe} 3+, \mathrm{Al})(\mathrm{SiO} 4)(\mathrm{Si} 2 \mathrm{O} 7) \mathrm{O}(\mathrm{OH})$ & Pyroxenes and Epidote \\
\hline Fe Oxides & 4.9 & $\mathrm{Fe} 3+2 \mathrm{O} 3$ & \\
\hline Ferberite & 7.45 & $\mathrm{Fe} 2+(\mathrm{WO} 4)$ & Other \\
\hline Fluorapatite & 3.15 & $\mathrm{Ca} 5(\mathrm{PO} 4) 3 \mathrm{~F}$ & Other \\
\hline Fluorite & 3.13 & $\mathrm{CaF} 2$ & Other \\
\hline Galena & 7.4 & $\mathrm{PbS}$ & Other \\
\hline $\begin{array}{c}\text { Garnet }(\mathbf{C a}> \\
\text { Fe }=M n)\end{array}$ & 4.04 & $(\mathrm{Ca}, \mathrm{Fe}, \mathrm{Mn}) 3 \mathrm{Al} 2(\mathrm{SiO} 4) 3$ & Other \\
\hline Gold & 17.65 & $\mathrm{Au}$ & Other \\
\hline Gypsum & 2.3 & $\mathrm{Ca}(\mathrm{SO} 4) \cdot 2(\mathrm{H} 2 \mathrm{O})$ & \\
\hline Hedenbergite & 3.4 & $(\mathrm{Ca}, \mathrm{Na})(\mathrm{Mg}, \mathrm{Fe}, \mathrm{Al})(\mathrm{Si}, \mathrm{Al}) 2 \mathrm{O} 6$ & Pyroxenes and Epidote \\
\hline Hornblende & 2.9 & $\mathrm{Ca} 2(\mathrm{Mg}, \mathrm{Fe}, \mathrm{Al}) 5(\mathrm{Al}, \mathrm{Si}) 8 \mathrm{O} 22(\mathrm{OH}) 2$ & Amphiboles \\
\hline Ilmenite & 4.72 & $\mathrm{Fe} 2+\mathrm{TiO} 3$ & Other \\
\hline Jarosite & 3.06 & $\mathrm{KFe} 3(\mathrm{SO} 4) 2(\mathrm{OH}) 6$ & \\
\hline Molybdenite & 5.5 & MoS2 & Other \\
\hline Monazite & 5.15 & Ce0.5La0.25Nd0.2Th0.05(PO4) & Other \\
\hline Native Bi & 9.78 & $\mathrm{Bi}$ & Other \\
\hline K-Feldspar & 2.56 & KAlSi3O8 & Feldspars \\
\hline Pentlandite & 4.8 & $\mathrm{Fe} 2+4.5 \mathrm{Ni} 4.5 \mathrm{~S} 8$ & Other \\
\hline Plagioclase & 2.69 & $\mathrm{Na} 0.5 \mathrm{Ca} 0.5 \mathrm{Si} 3 \mathrm{AlO} 8$ & Feldspars \\
\hline Pyrite & 5.01 & $\mathrm{Fe} 2+\mathrm{S} 2$ & \\
\hline Pyrrhotite & 4.62 & $\mathrm{Fe} 2+0.95 \mathrm{~S}$ & \\
\hline Quartz & 2.63 & $(\mathrm{SiO} 2)$ & \\
\hline Rutile & 4.25 & $\mathrm{TiO} 2$ & Other \\
\hline
\end{tabular}




\begin{tabular}{|c|c|c|c|}
\hline Scheelite & 6.01 & $\mathrm{Ca}(\mathrm{WO} 4)$ & \\
\hline Sphalerite & 4.05 & $(\mathrm{Zn}, \mathrm{Fe}) \mathrm{S}$ & \\
\hline Spinel & 3.59 & $\mathrm{MgAl} 2 \mathrm{O} 4$ & Other \\
\hline Stibnite & 4.63 & $\mathrm{Sb} 2 \mathrm{~S} 3$ & Other \\
\hline Sulfur & 2 & $\mathrm{~S}$ & Micas \\
\hline Muscovite & 2.83 & $\mathrm{KAl} 3 \mathrm{Si} 3 \mathrm{O} 10(\mathrm{OH}) 1.9 \mathrm{~F} 0.1 \mathrm{Ti} 0.7$ & Other \\
\hline Titanite & 3.48 & $\mathrm{CaTiSiO} 5$ & Other \\
\hline Wolframite & 7.3 & $\mathrm{Fe} 2+0.5 \mathrm{Mn} 2+0.5(\mathrm{WO} 4)$ & Other \\
\hline Zircon & 4.65 & $\mathrm{ZrSiO} 4$ & \\
\hline
\end{tabular}




\section{Appendix I: SEM-BSE Images and EDS Spectra}

The following images are SEM-BSE images and sample EDS spectra used to choose targets for synchrotron-based $\mu$ XRD-XRF. Working voltage of the SEM and the scale is included in the images. Example images and spectra were chosen for: 1) Fe-oxyhydroxide rims from TP3-TS-01 containing fragments of scheelite; 2) Fe-oxyhydroxide rims without scheelite from TP3-TS-01; 3) Goethite and jarosite in a pyrrhotite "pseudomorph grain" from FRT-TS-02; and 4) Goethite rim on a lithic fragment from FRT-TS-05.

\section{TP3-TS-01 Fe-oxyhydroxide Rims with Included Scheelite}
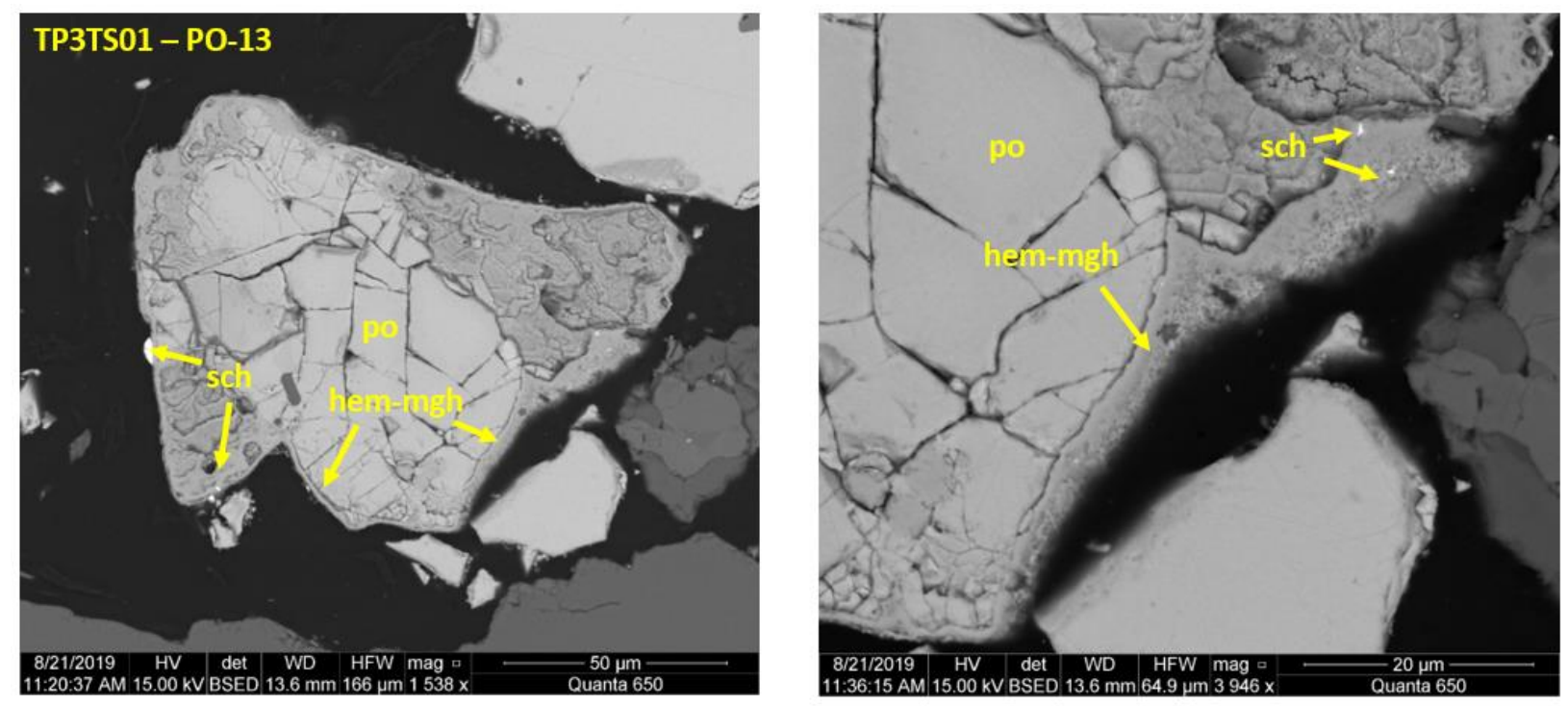

Sample ID: TP3TS01 - Epoxy Grain Mount

Notes: Pyrrhotite grain with scheelite fragments included within hematite-maghemite rim (as determined by synchrotron-based $\mu \mathrm{XRD}$ ). No EDS spectra were saved for this grain. EDS spectra look similar to the one shown for TP3TS01 - RIM-1 

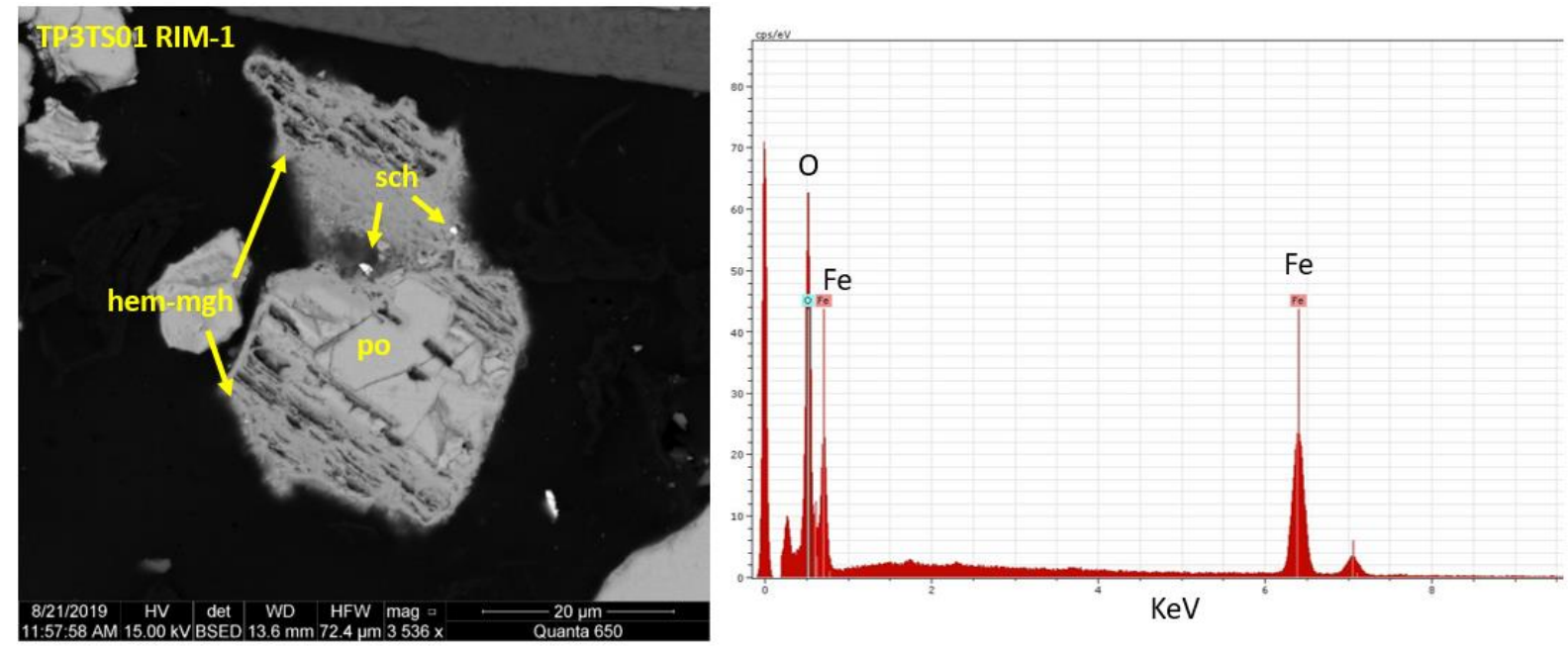

Sample ID: TP3TS01 - Epoxy Grain Mount

Notes: Pyrrhotite grain with scheelite fragments included within hematite-maghemite rim (determined by synchrotron-based $\mu \mathrm{XRD})$. EDS spectrum was taken from top rim of grain. Spectra on other parts of rim are similar.
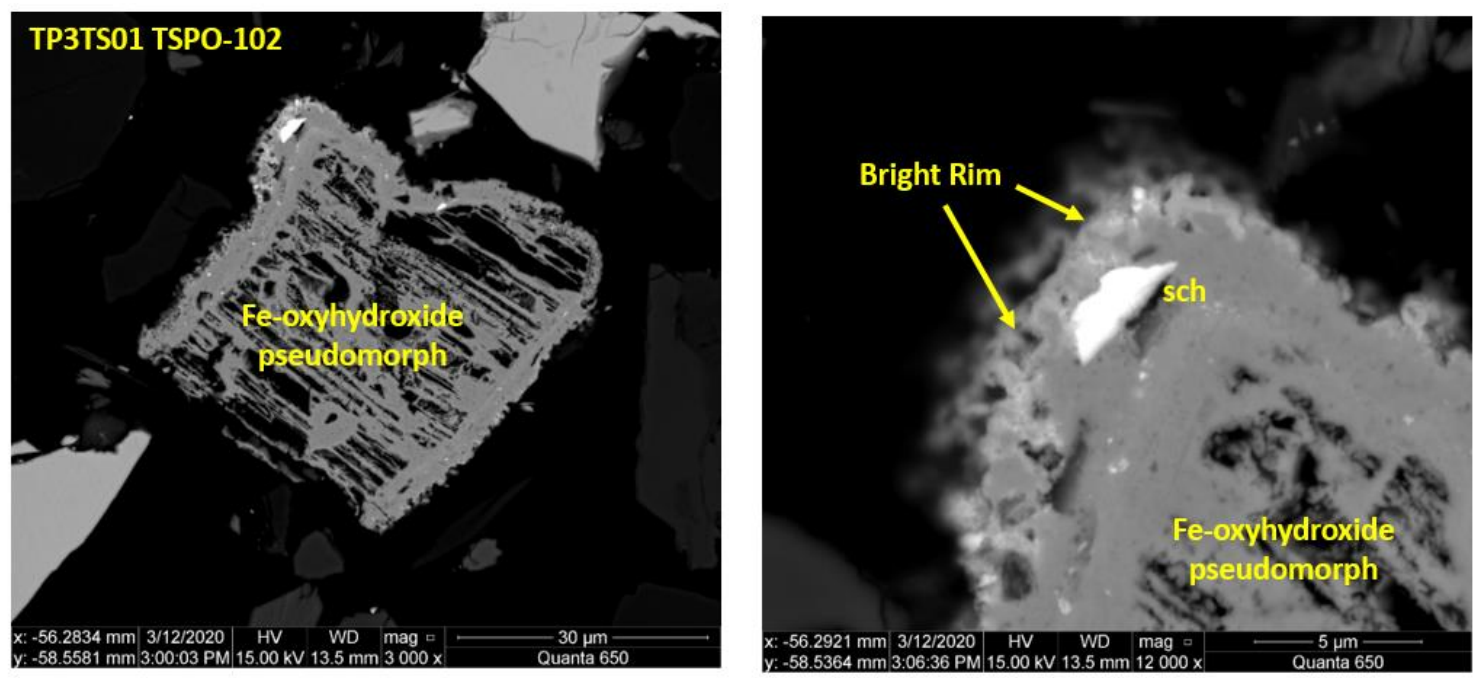

Sample ID: TP3TS01 - Thin Section

Notes: Pyrrhotite "pseudomorph" grain with small scheelite fragments included on exterior rim. Note that parts of the rim are slightly brighter than the grain interior, possible due to the presence of tungsten. EDS spectra below. No XRD data for this grain. 

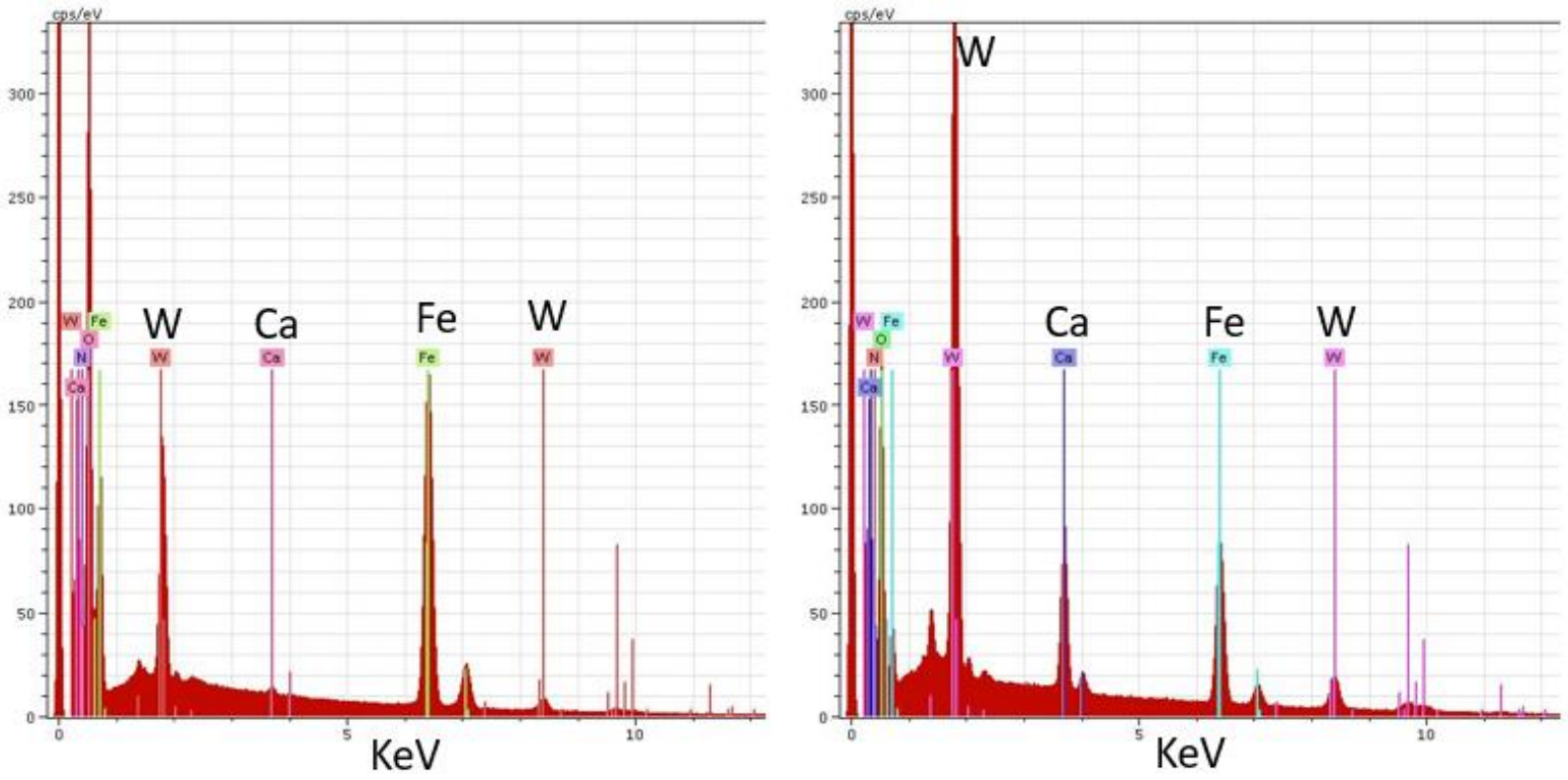

Notes: EDS spectra for TP3-TS-01 TSPO-102. No spectrum available from grain interior.

Left: Spectrum from bright exterior rim, distal from visible scheelite.

Right: Spectrum from the scheelite fragment on top of the SEM-BSE image.
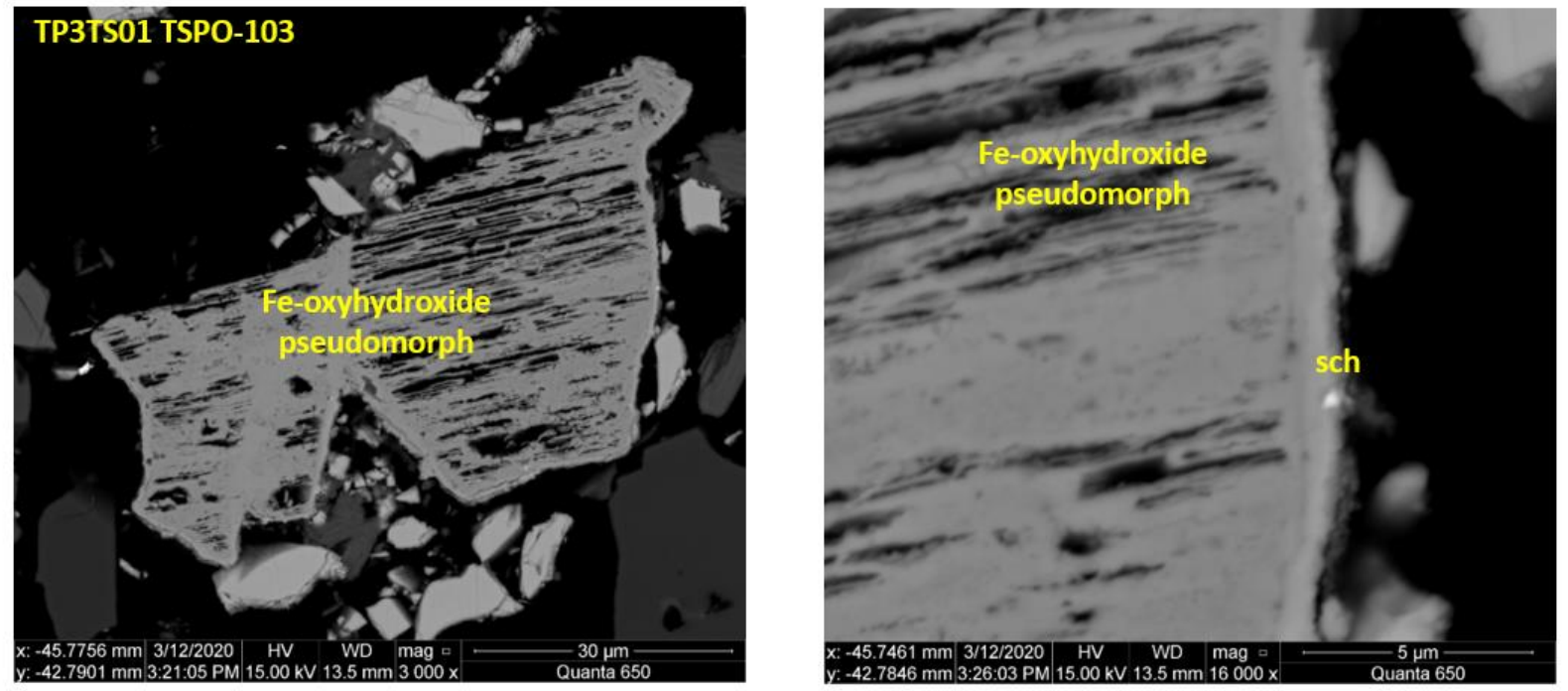

Sample ID: TP3TS01 - Thin Section

Notes: Pyrrhotite "pseudomorph" grain with small scheelite fragments included on exterior rim. Note that the rim is slightly brighter than the grain interior, possible due to the presence of tungsten. EDS spectra below. No XRD data for this grain. 

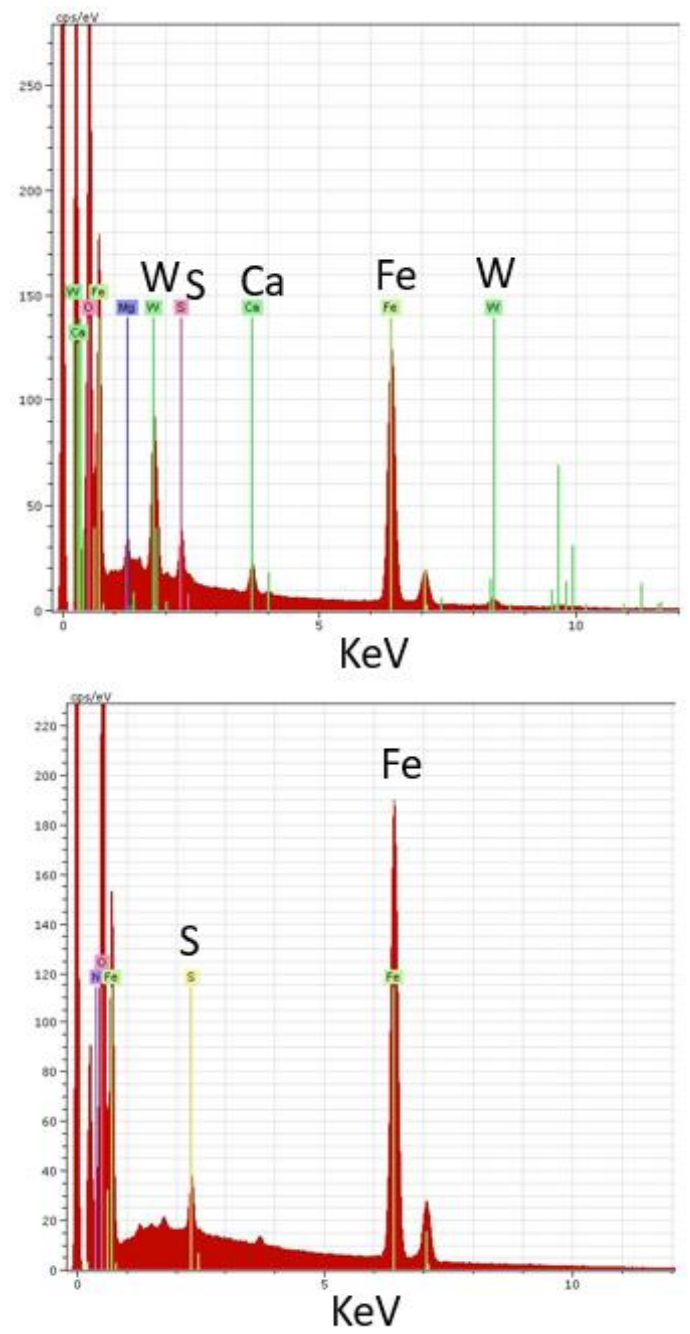

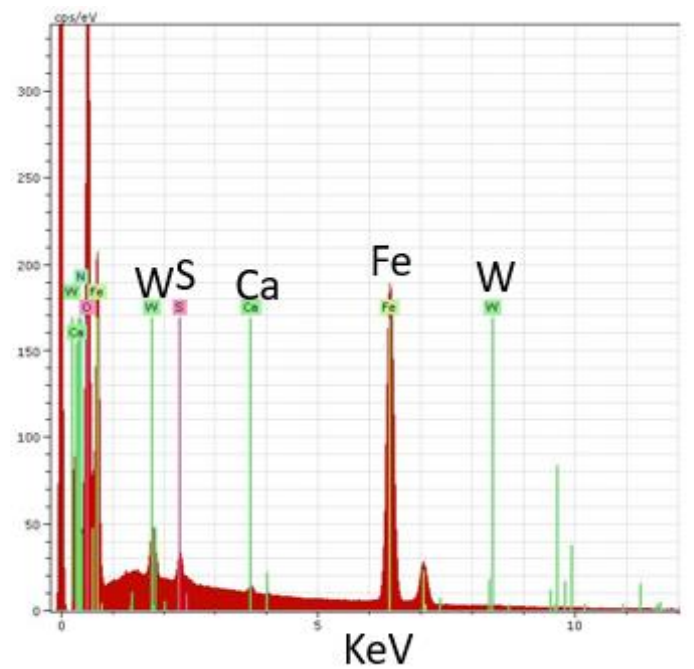

Notes: EDS spectra for TP3-TS-01 TSPO-103. Top Left: Spectrum from the scheelite fragment on the SEM-BSE image.

Top Right: Spectrum from bright exterior rim, $\sim 10$ um from scheelite fragment.

Bottom Left: Spectrum from interior of pseudomorph. 


\section{TP3-TS-01 Fe-oxyhydroxide Rims without Scheelite}
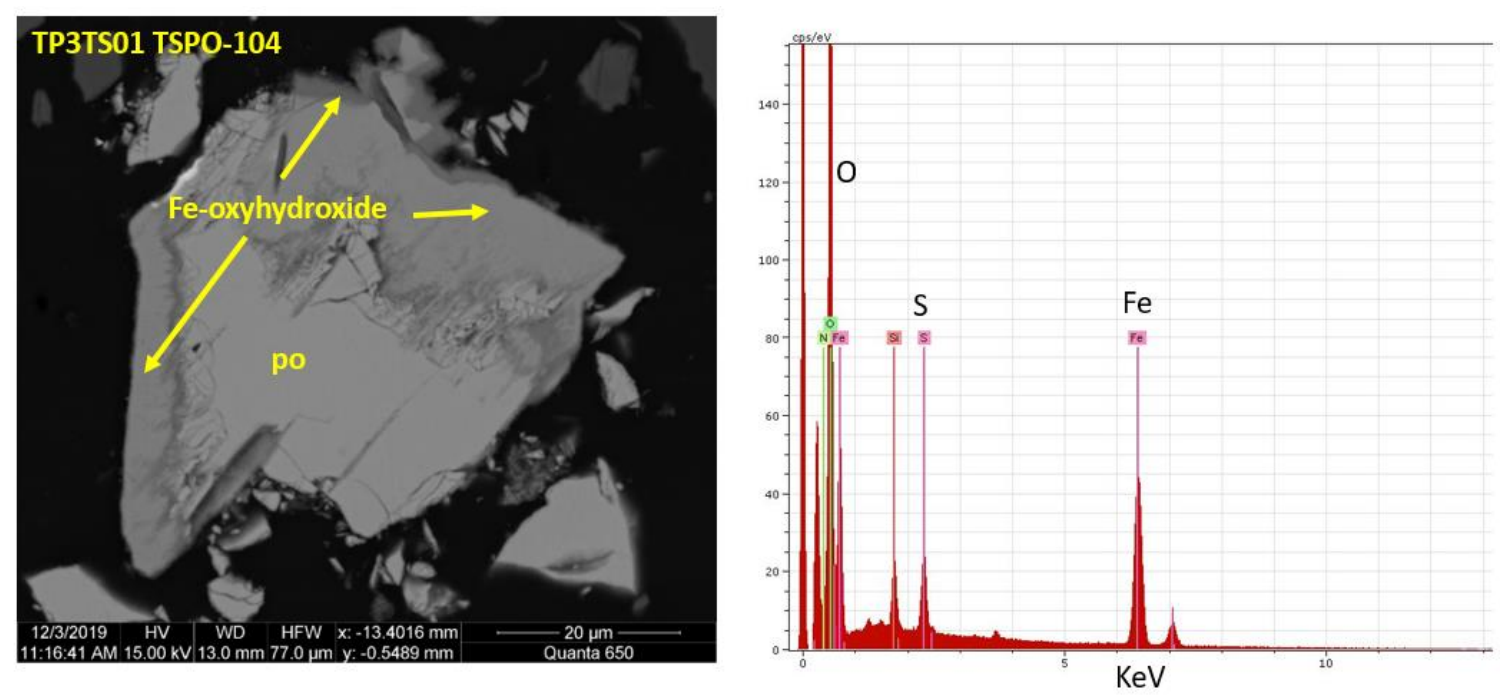

Sample ID: TP3TS01 - Thin Section

Notes: Pyrrhotite grain exhibiting early stages of oxidation. The bright interior is pyrrhotite, whereas the darker regions are Fe-oxyhydroxide with spectra similar to the one shown. EDS spectra is from top rim of grain. Note that the spectra has S and $\mathrm{Si}$, which is typical for Fe-oxyhydroxide rims in TP3-TS-01 and FRT samples. No XRD data for this grain.
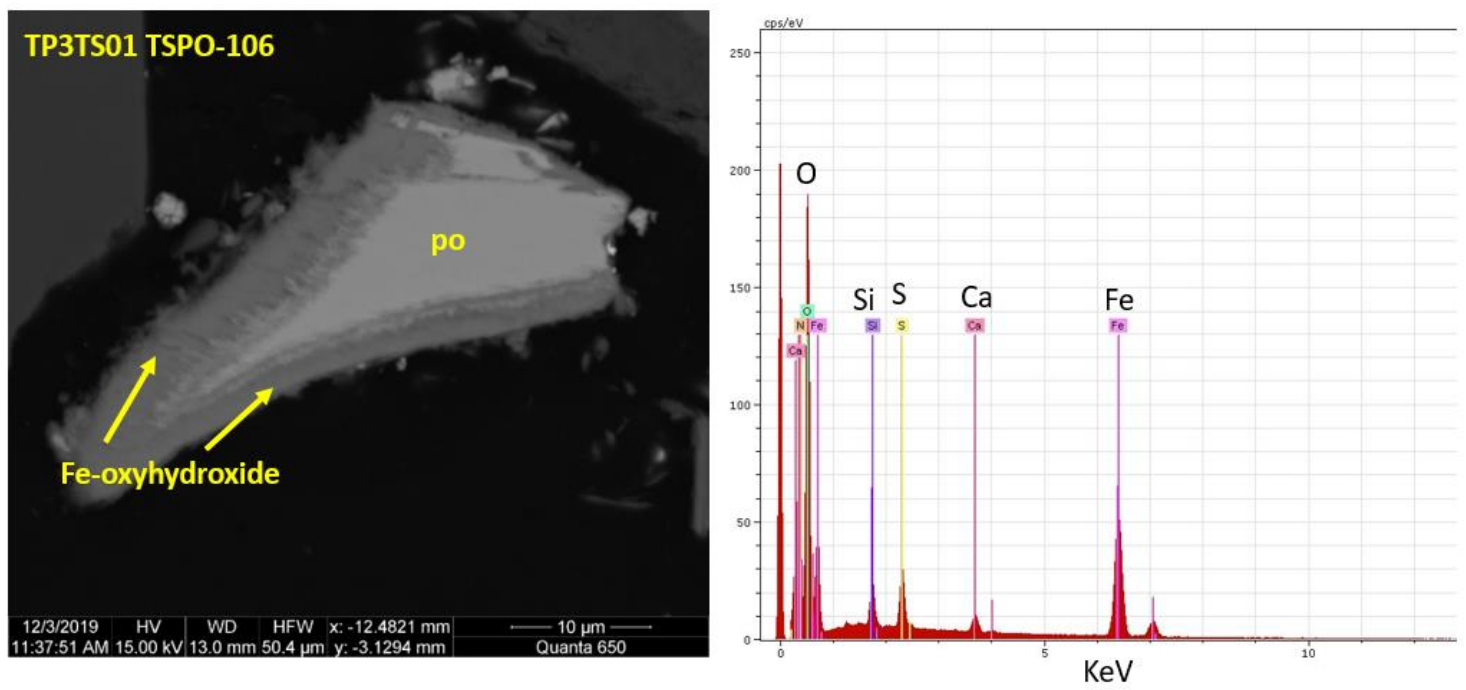

Sample ID: TP3TS01 - Thin Section

Notes: Pyrrhotite grain exhibiting early stages of oxidation. The bright interior is pyrrhotite, whereas the darker regions are

Fe-oxyhydroxide with spectra similar to the one shown. EDS spectra is from the rim of the grain, and contains $\mathrm{Si}$, $\mathrm{S}$, and Ca. No XRD data for this grain. 


\section{Goethite and Jarosite from the FRT}
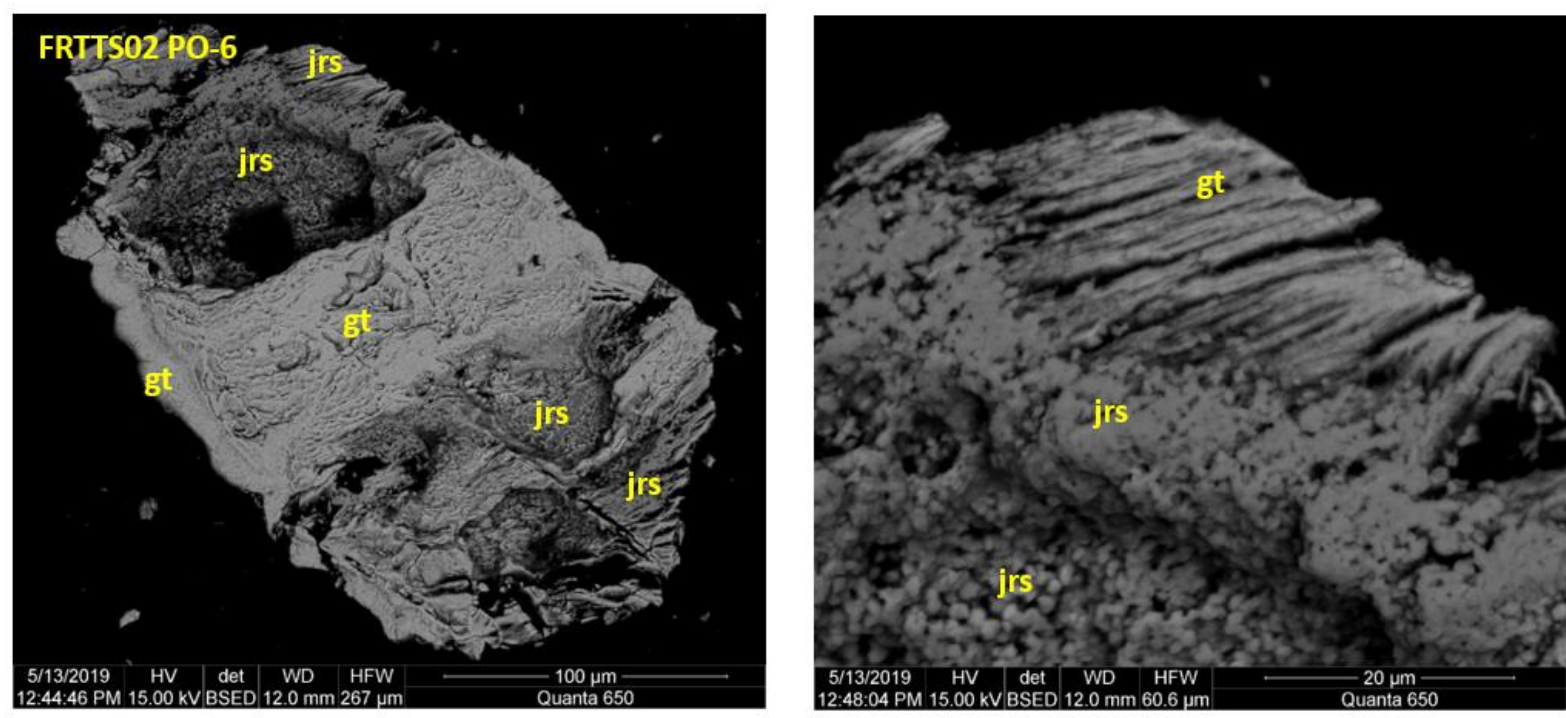

Sample ID: FRT-TS-02 - Epoxy Grain Mount

Notes: Pyrrhotite pseudomorphed by goethite and jarosite. Note that the grain is pitted on the top and bottom of the left image, where jarosite is dominant as pseudocubic crystals. Goethite is restricted to the exterior of the grain and grain margins. EDS spectra for the center of the grain and of the jarosite cubes below. No XRD data for this grain identification of goethite is based off other grains analyzed by $\mu \mathrm{XRD}$.
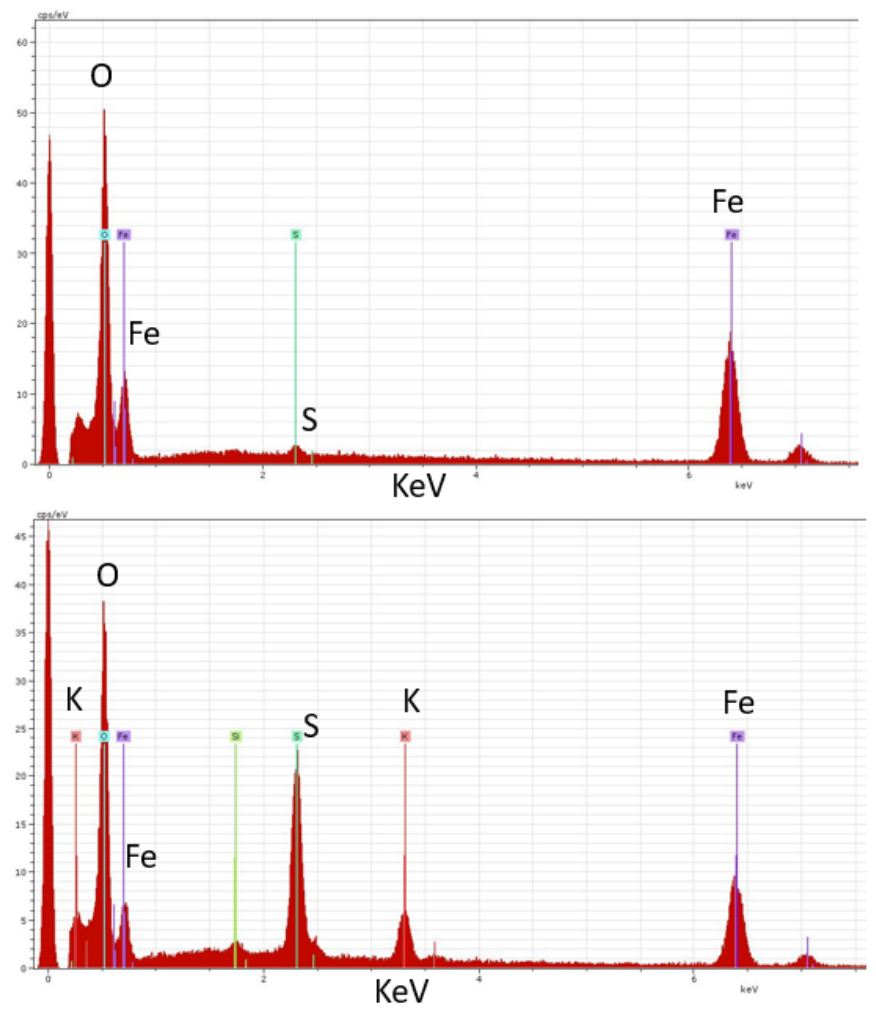

Notes: EDS spectra for FRT-TS-02 PO-6.

Top: Spectrum from center of grain, with only $\mathrm{Fe}$, and $\mathrm{O}$ peaks, and a small S peak.

Bottom: Spectrum from the jarosite pit at the top of the BSE-SEM image. Note the prominent $\mathrm{Fe}, \mathrm{S}, \mathrm{O}$, and $\mathrm{K}$ peaks. 


\section{Goethite Rims in the FRT}
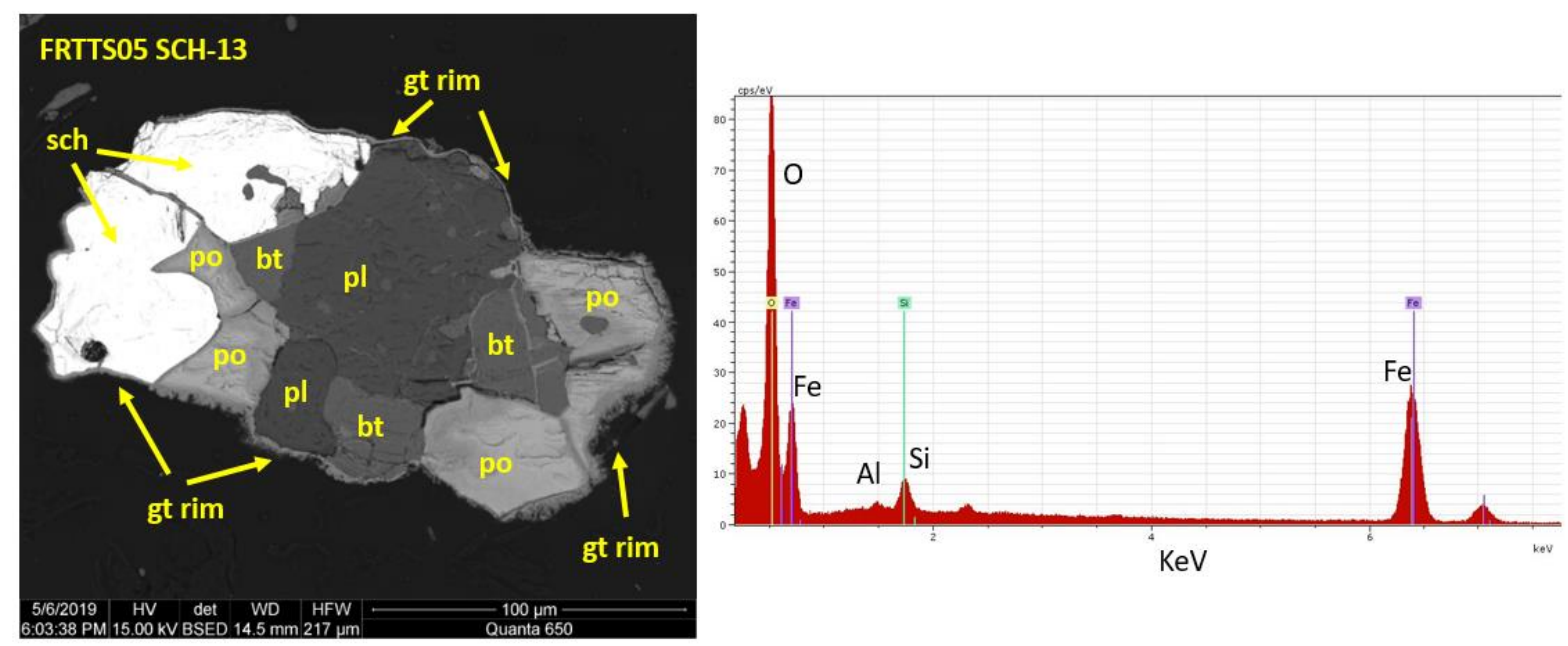

Sample ID: FRT-TS-05 - Epoxy Grain Mount

Notes: Acicular goethite rim enveloping a lithic fragment containing scheelite, pyrrhotite, plagioclase, and biotite. EDS spectra is from goethite rim on scheelite. EDS spectra from other parts of the rim are similar, with varying peak heights of $\mathrm{Al}$ and Si. No XRD data for this grain - identification of goethite is based off other grains analyzed by $\mu$ XRD. 


\section{Appendix J: Synchrotron XRD-XRF Data}

This appendix contains $\mu$ XRF maps, $\mu$ XRD patterns, SEM images, and $\mu$ XRF spectra of Feoxyhydroxide mineral rims on pyrrhotite and non-sulfide grains. Background $\mu$ XRD spectra were collected by "lassoing" areas on the $\mu \mathrm{XRF}$ maps. The $1 \mathrm{D} \mu \mathrm{XRD}$ spectra was generated by integrating the patterns of each pixel in the lassoed area, which were collected with a dwell time of $50 \mathrm{~ms}$. The $\mu \mathrm{XRF}$ spectra correspond to lassoed areas on the $\mu \mathrm{XRF}$ map, and were also generated by integrating the spectra of each pixel in the lassoed areas. Note that the $\mu$ XRF maps have not been overlain on the SEM images, and some rotation is needed for the images to match perfectly. Graphite was identified in every Mxrd pattern, due to the epoxy grain mounts having a carbon coat during analyses. Note that the counts on the $y$-axis of both the $\mu$ XRD patterns and $\mu$ XRF spectra are strongly affected by the size of the lasso area, where larger lassos have more counts. 

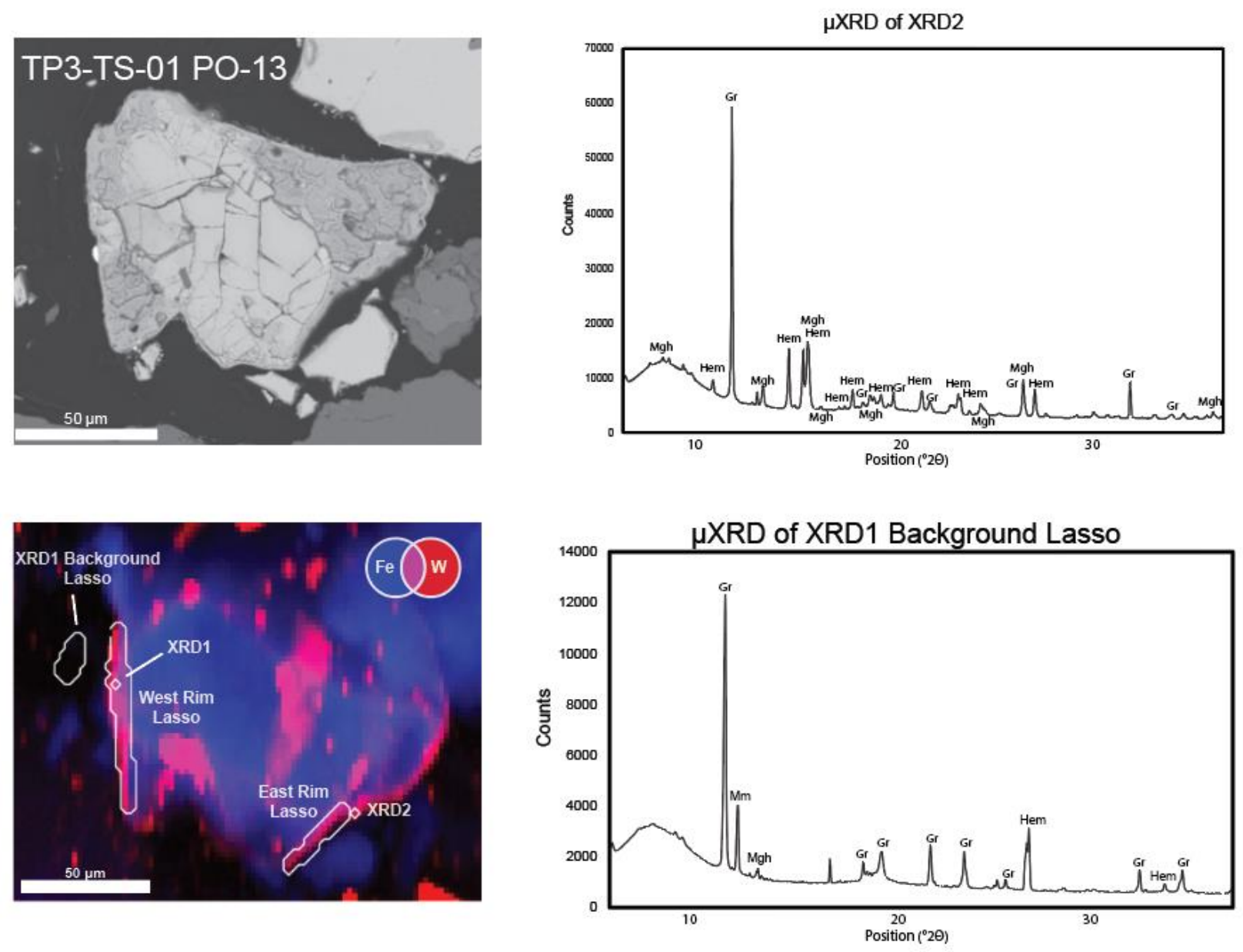

This grain is shown in figure 3.8 in section 3.3.2.4, along with the $\mu$ XRD pattern for XRD1. This was the first grain with tungsten identified on the rim of a pyrrhotite during the synchrotron analyses. The background lasso has some peaks matching with hematite and maghemite, but far less than XRD1 and XRD2. $\mathrm{Gr}=$ graphite; Hem = hematite; Mgh = maghemite. 

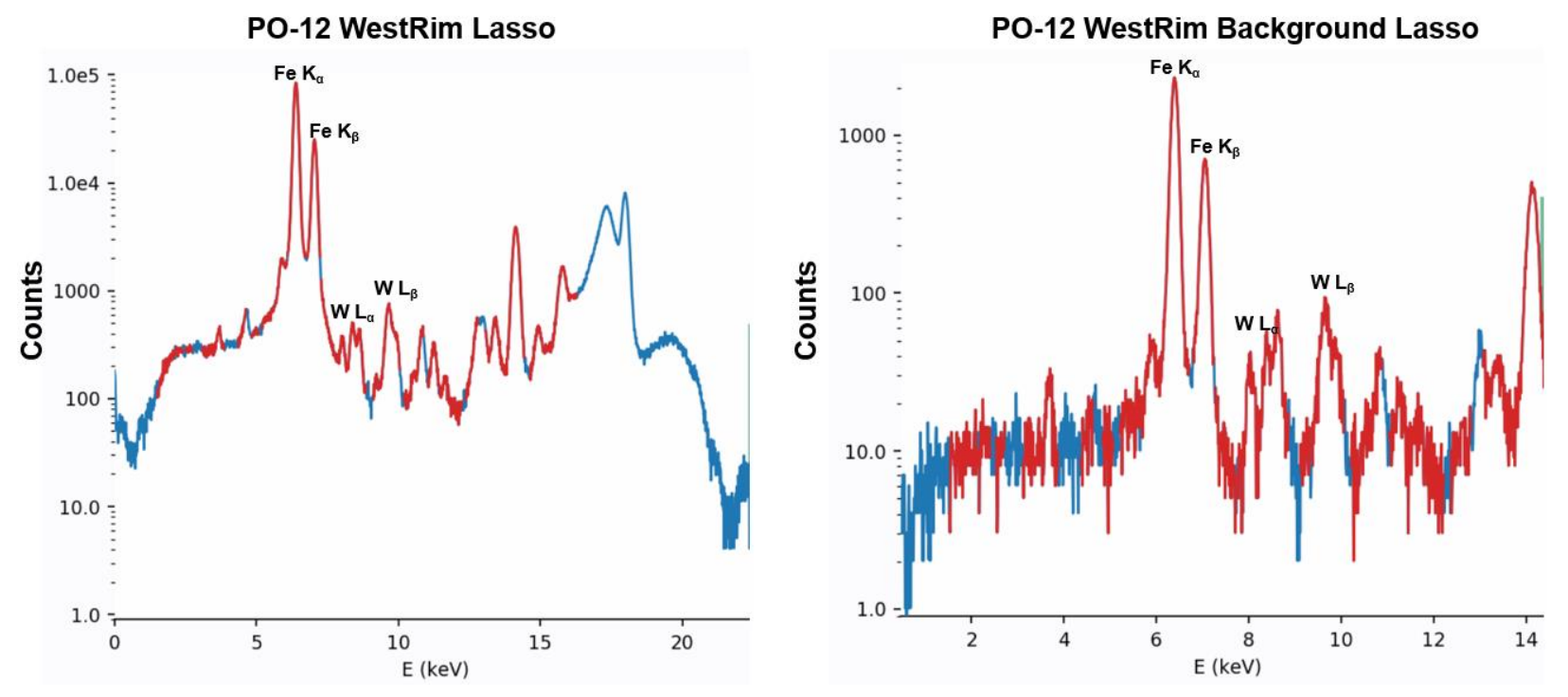

TP3-TS-01: RIM-1
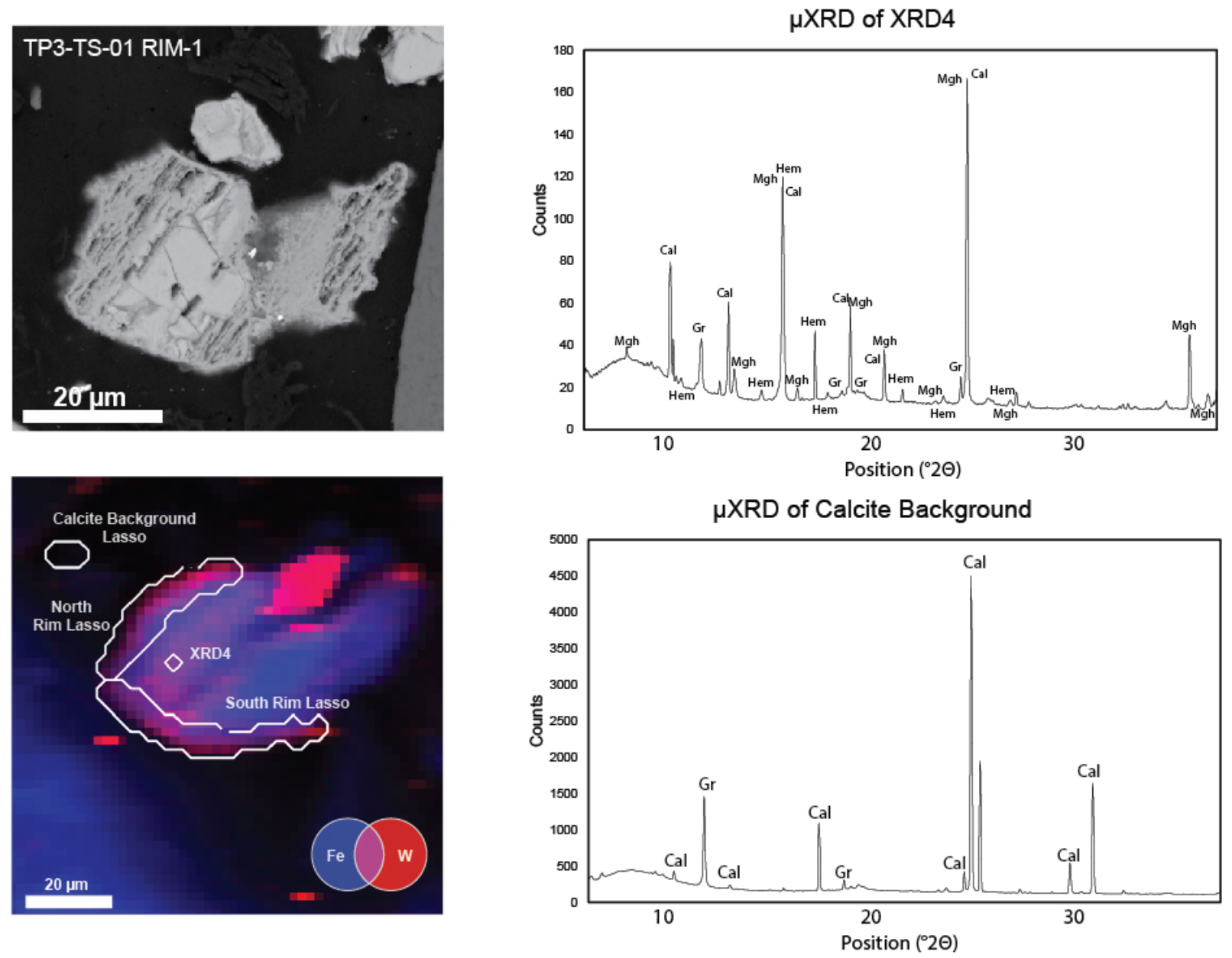
This grain was found immediately after PO-13 during the synchrotron analyses. The $\mu$ XRD pattern for XRD4 has numerous peaks that match with calcite, some of which are present in the Calcite Background pattern. The $\mu \mathrm{XRF}$ spectra have prominent strontium peaks, which are likely sourced from buried calcite in the epoxy. $\mathrm{Cal}=$ calcite $\mathrm{Gr}=$ graphite $\mathrm{Hem}=$ hematite; $\mathrm{Mgh}=$ maghemite .
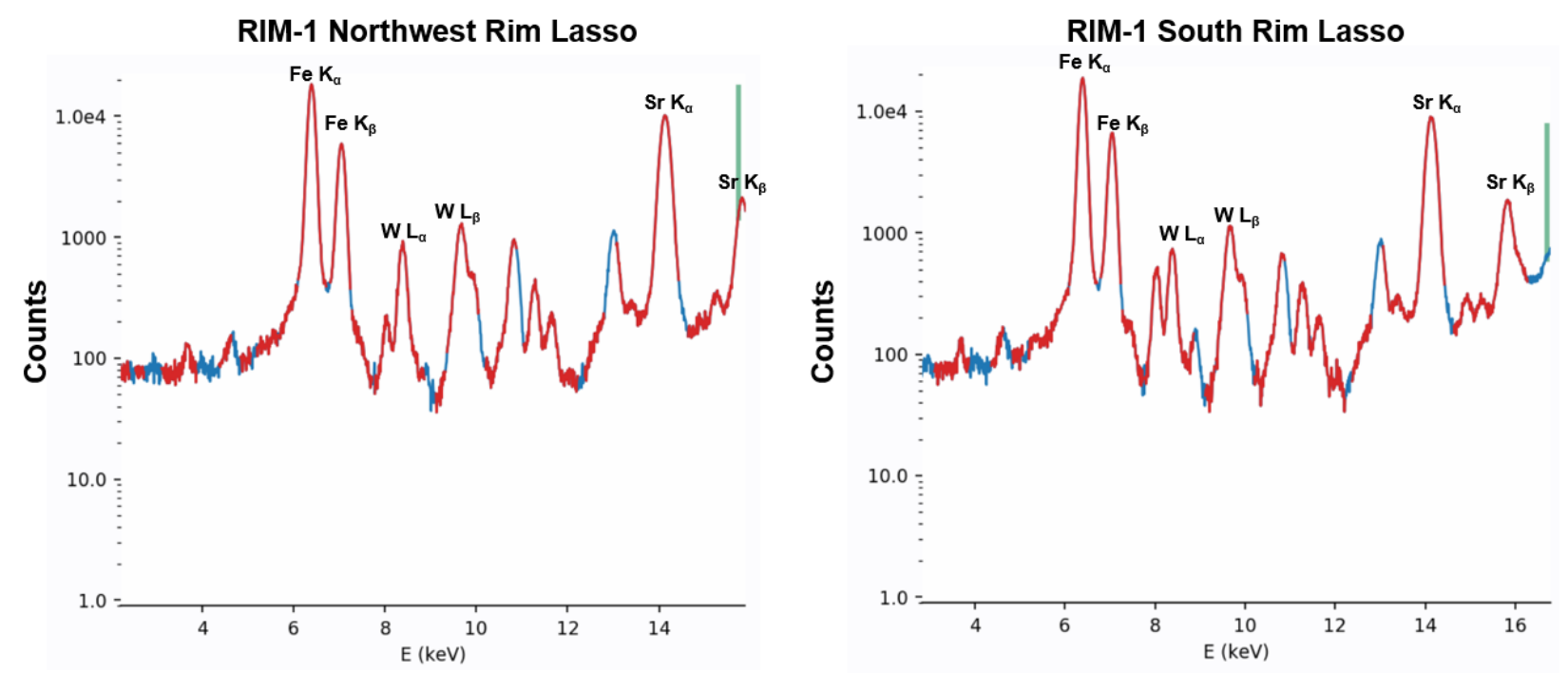
TP3-TS-01: PO-12
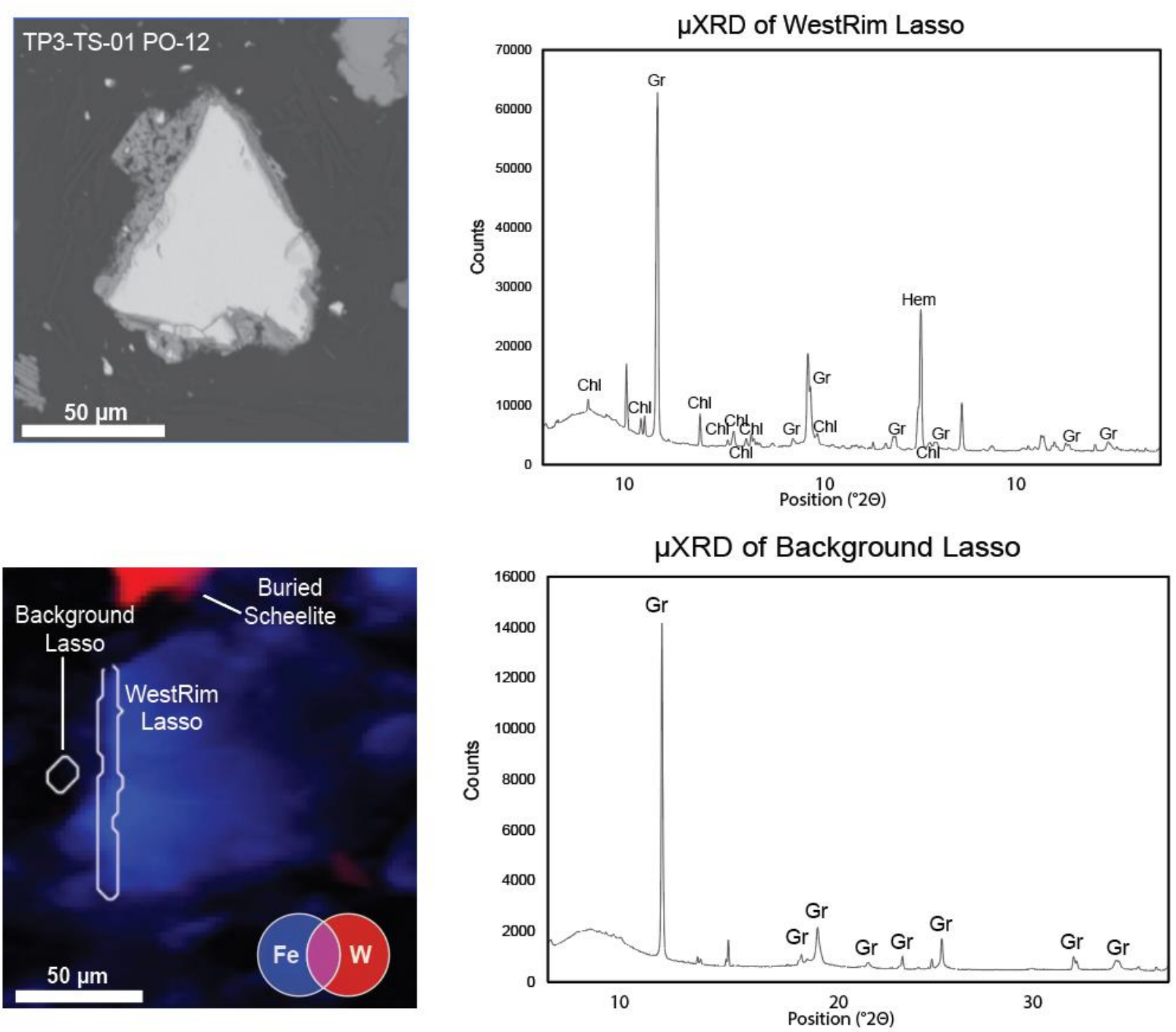

This grain is an example of a pyrrhotite rim in sample TP3-TS-01 that does not have diffraction patterns matching any Fe-oxide or Fe-oxyhydroxide minerals, and does not have tungsten on its rim. The red blotch on the $\mu$ XRF map has prominent tungsten peaks that are sourced from scheelite at depth in the epoxy. The $\mu$ XRD pattern of the west rim have some peaks that match with chlorite, graphite, and one peak that matches with hematite. The background $\mu$ XRD pattern only matches with graphite. $\mathrm{Chl}=$ chlorite; $\mathrm{Gr}=$ graphite; Hem = hematite. 

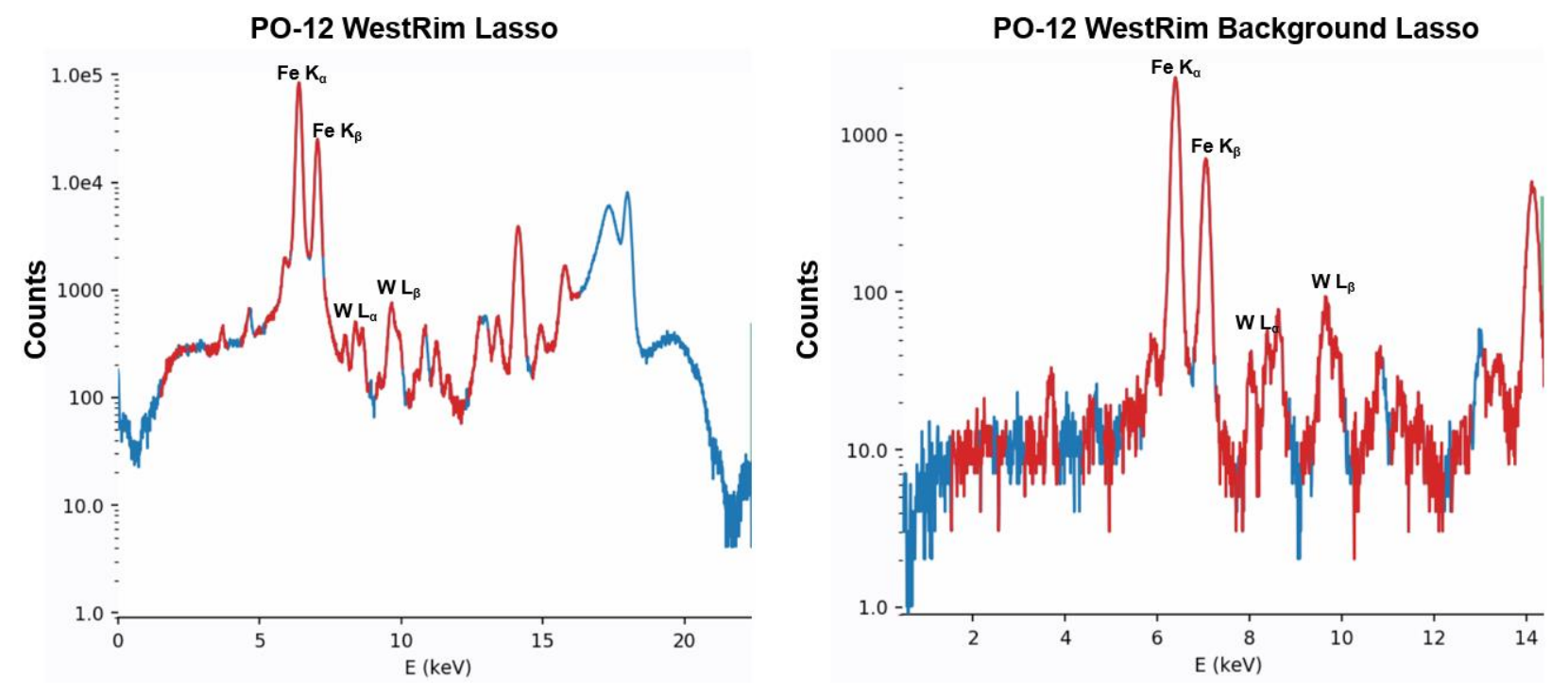

FRT-TS-03: FE-14
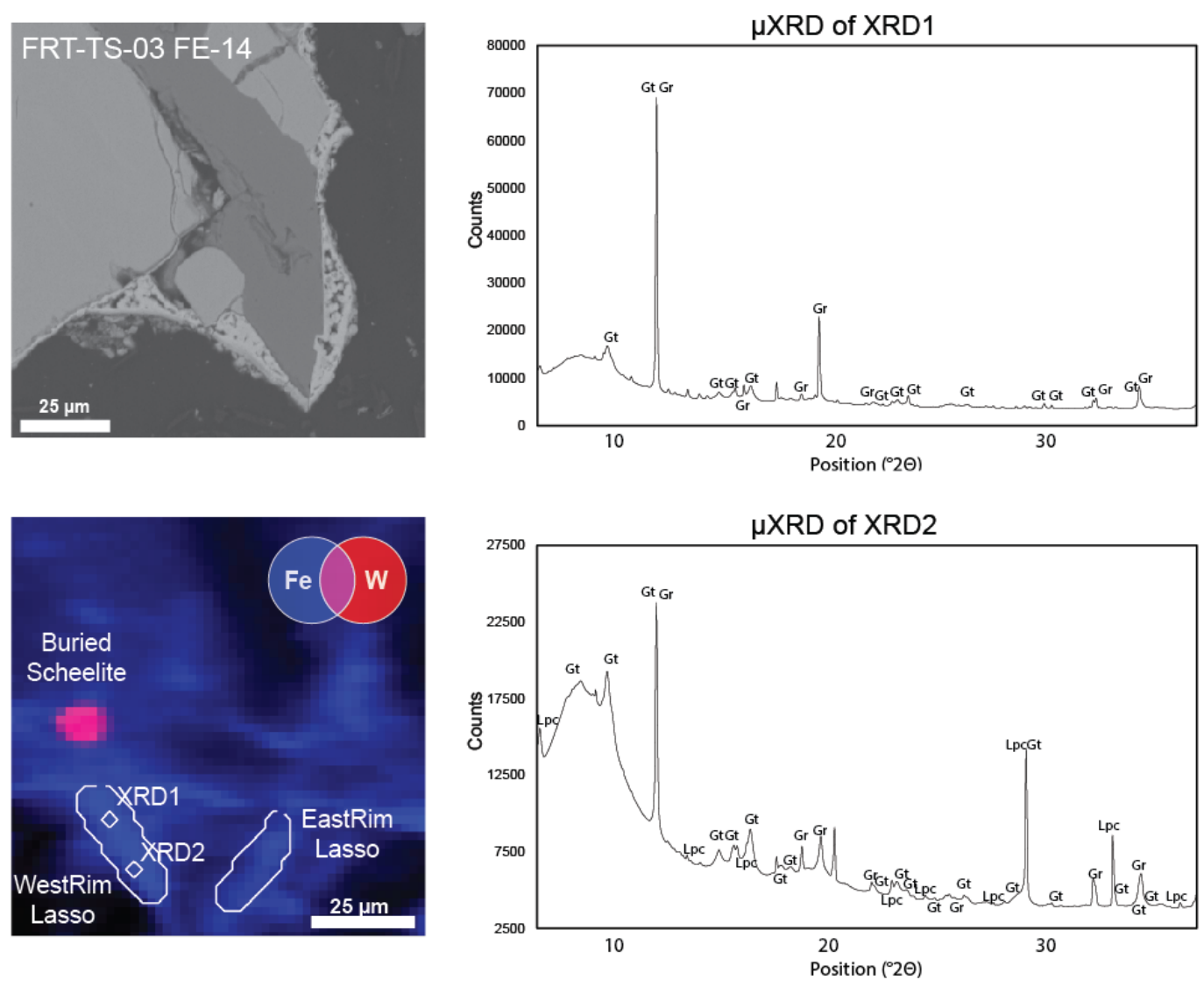
The rim on this lithic fragment (consisting of quartz and plagioclase) was chosen to determine the mineralogy of precipitated Fe-oxyhydroxide coatings on non-sulfide grains. The $\mu$ XRD patterns match well with goethite, and XRD2 has peaks matching well with lepidocrocite. Note that these patterns were not background subtracted, so peaks at $<20^{\circ} 2 \Theta$ are less prominent (particularly for XRD2). The red blotch on the $\mu$ XRF map represents scheelite buried at depth in the epoxy. Note that the $\mu$ XRF spectra significant tungsten peaks, but have copper peaks.
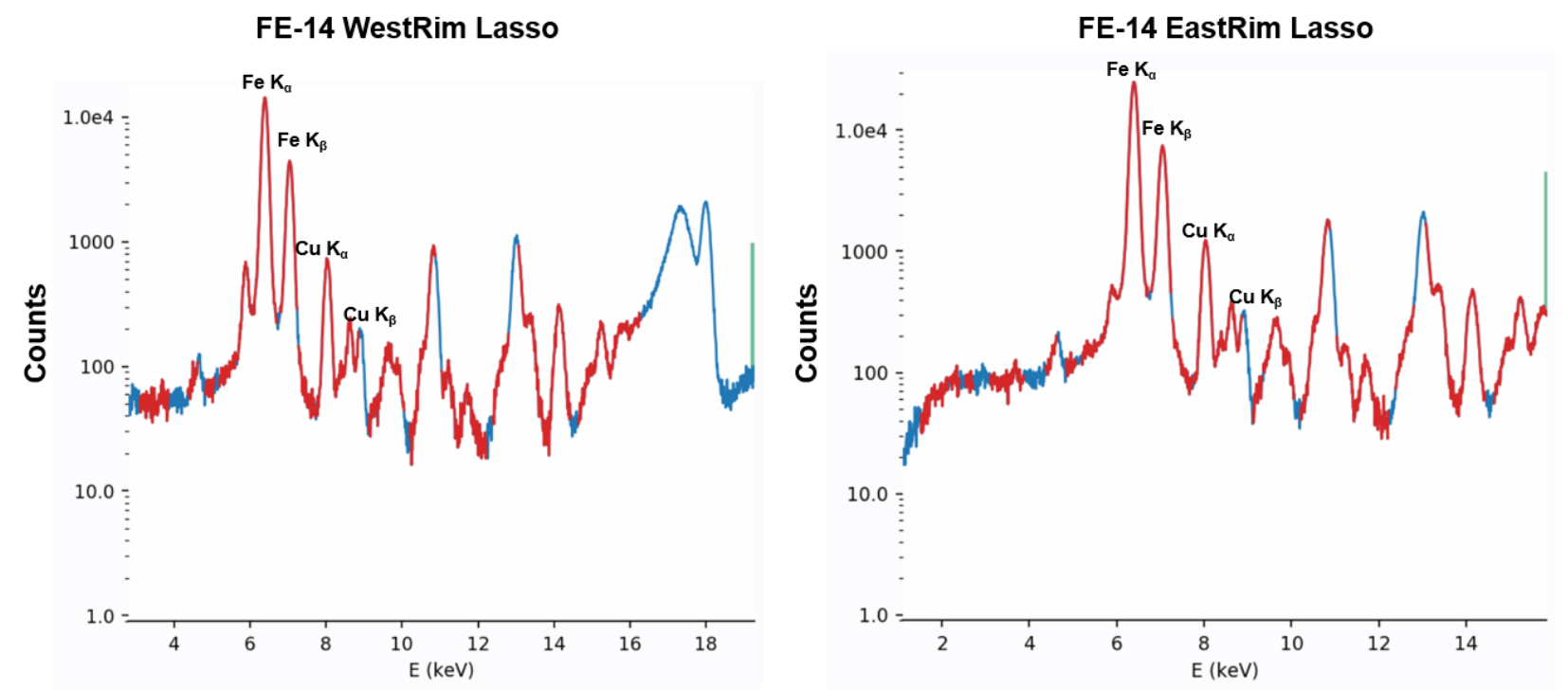


\section{Appendix K: Hydroxylamine Leach Residue Photographs}

The following are photographs of the residue in test tubes are after the hot hydroxylamine leach. Note the orange-red color in the test tubes indicative of residual Fe-oxyhydroxide minerals. Photographs of tailings samples in petri dish are before leaching.

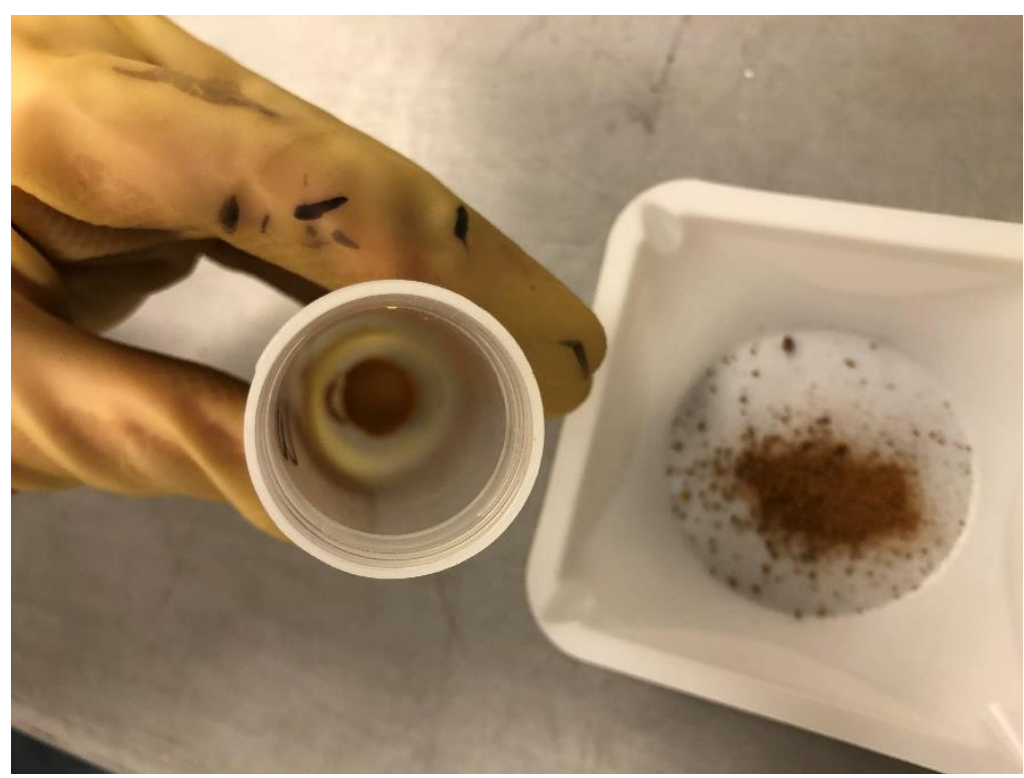

\section{FRT-TS-01}

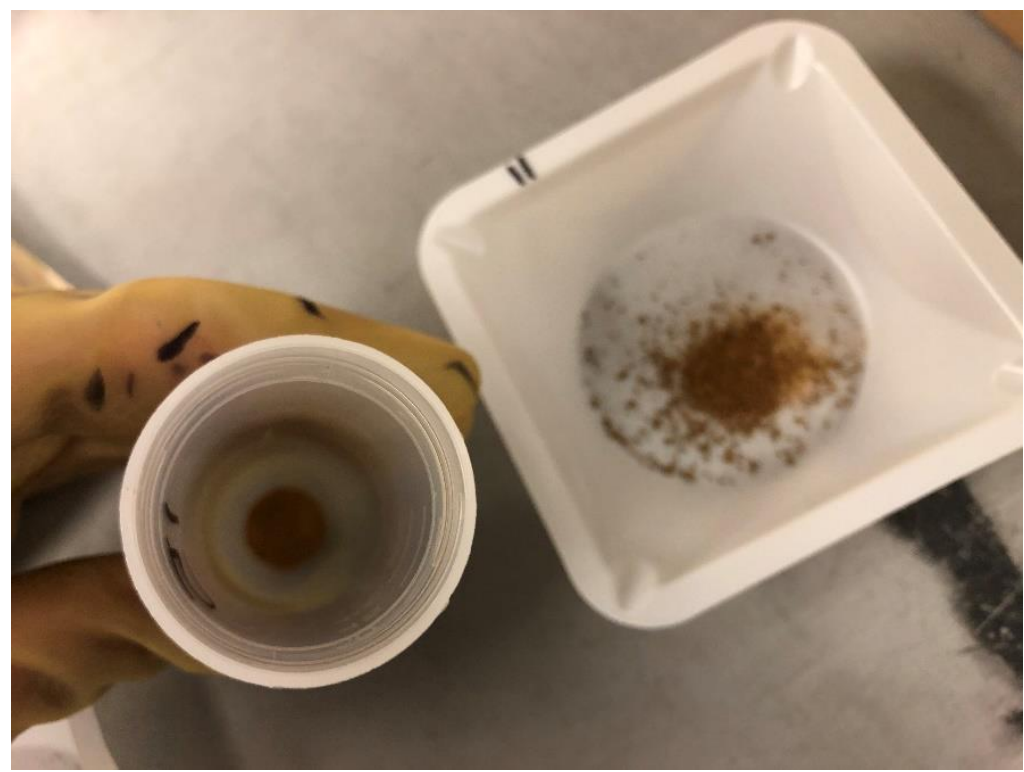

FRT-TS-02 


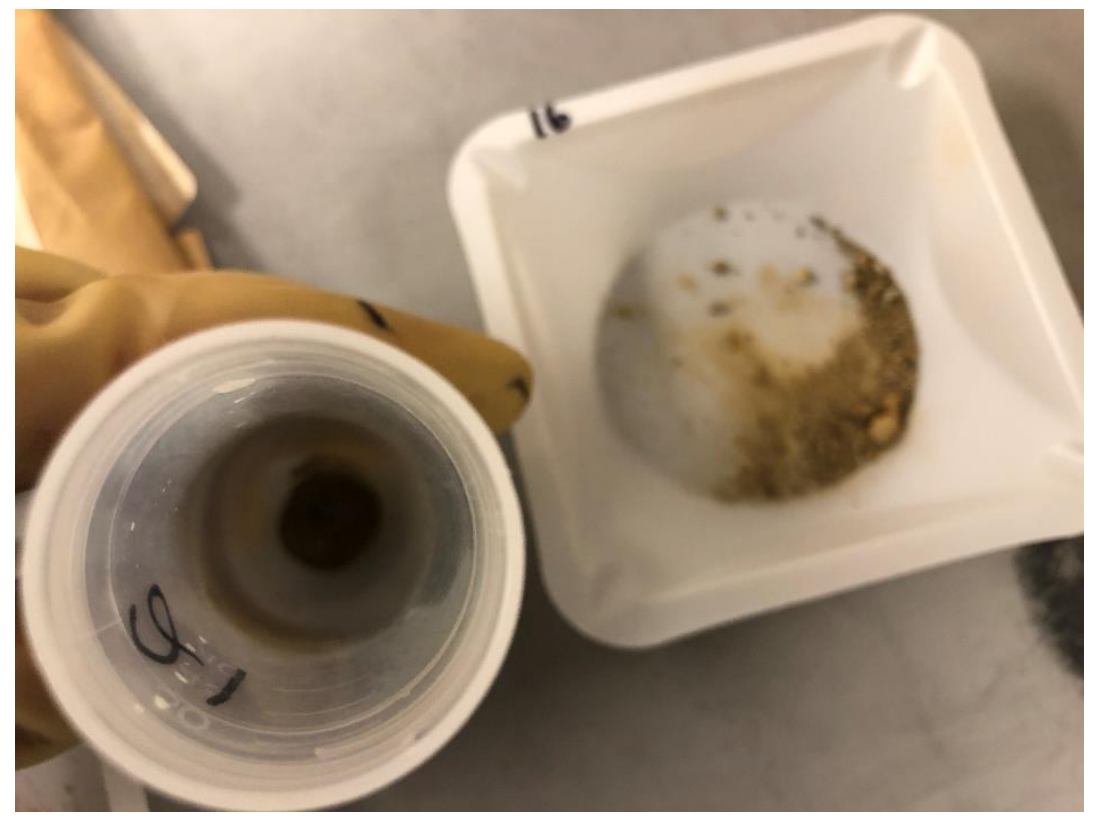

\section{FRT-TS-03}

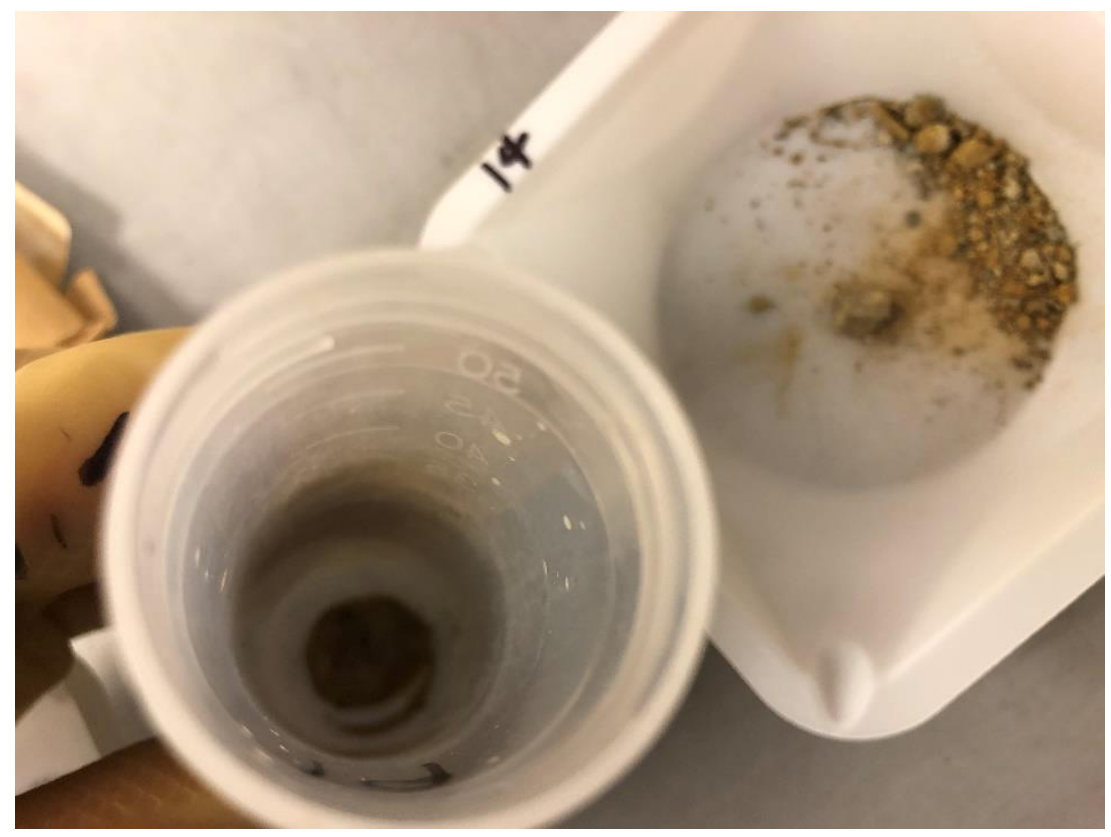

FRT-TS-03DUP 


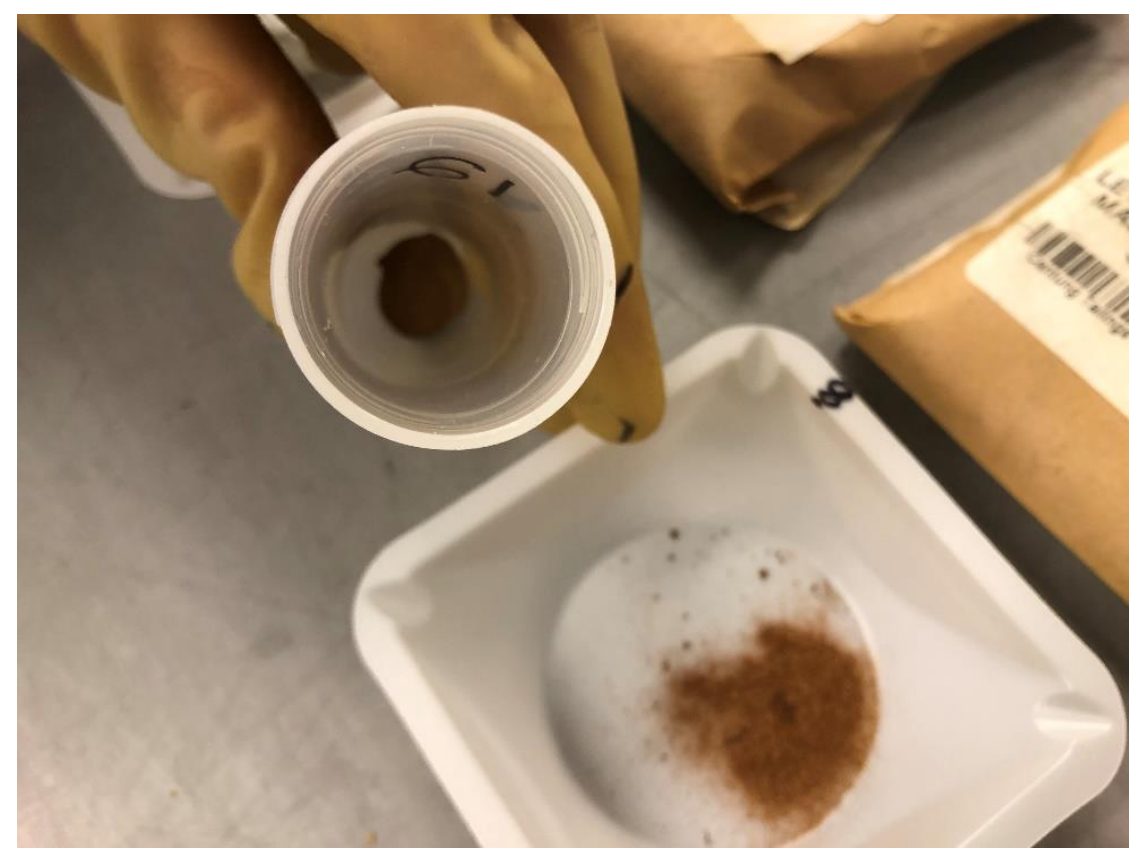

FRT-TS-04

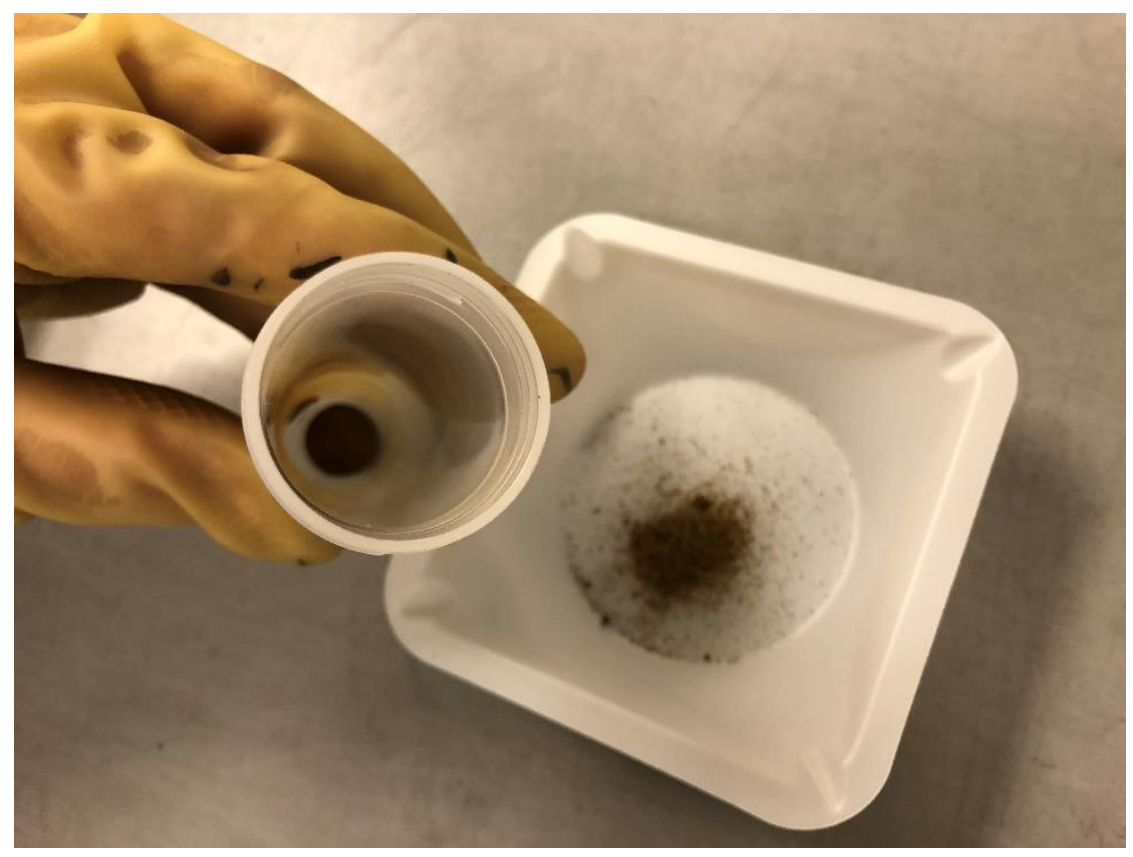

FRT-TS-05 


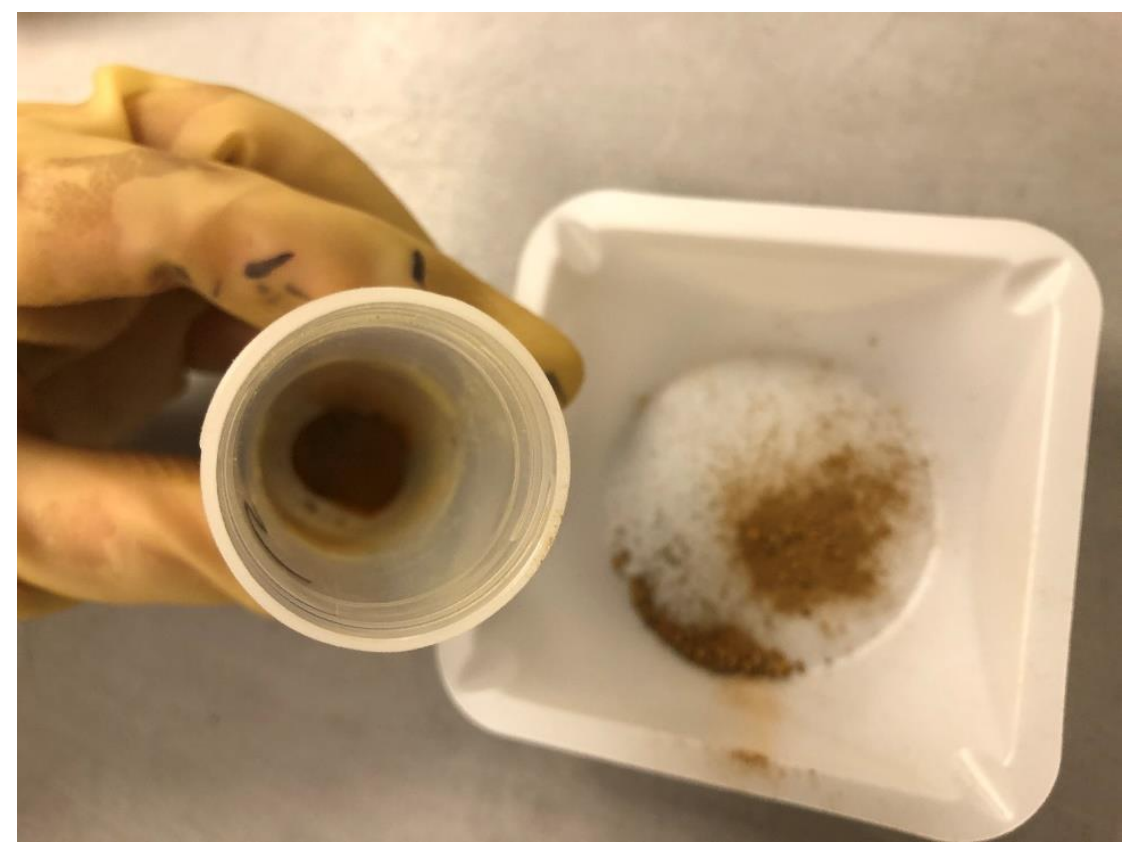

FRT-TS-06

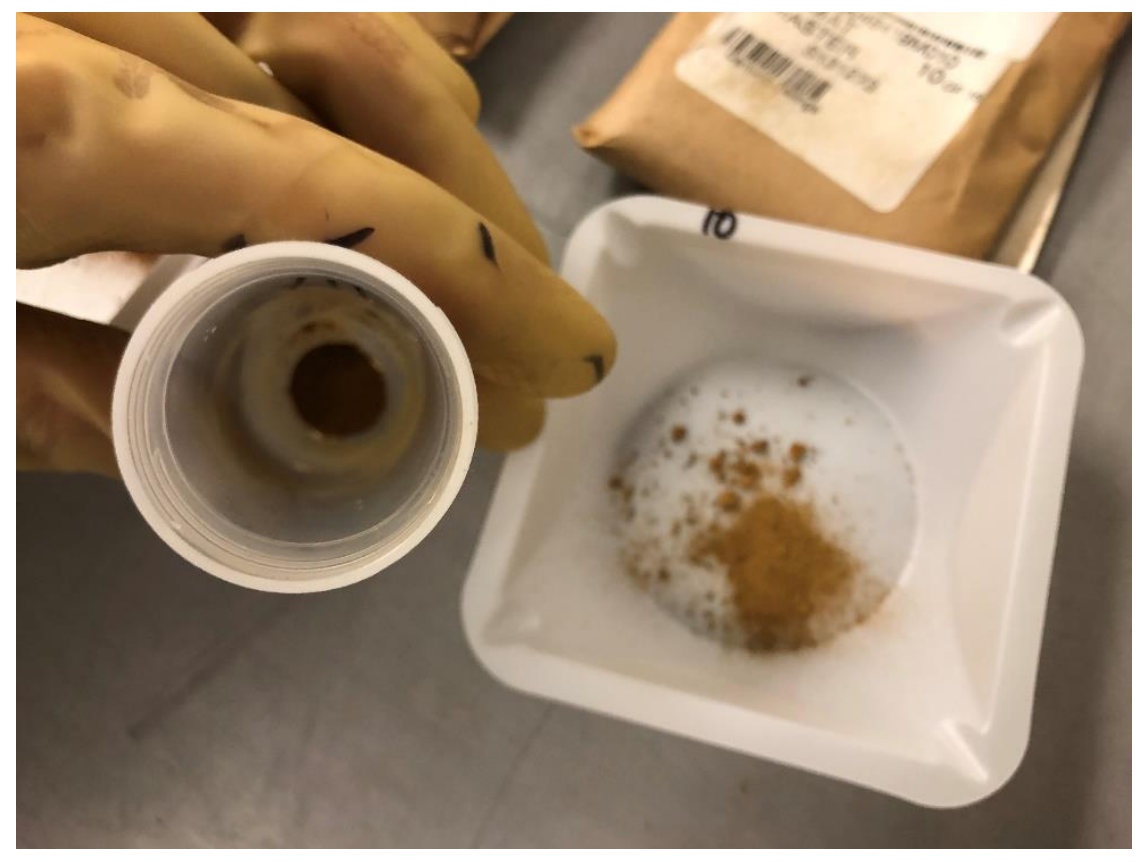

FRT-TS-06DUP 


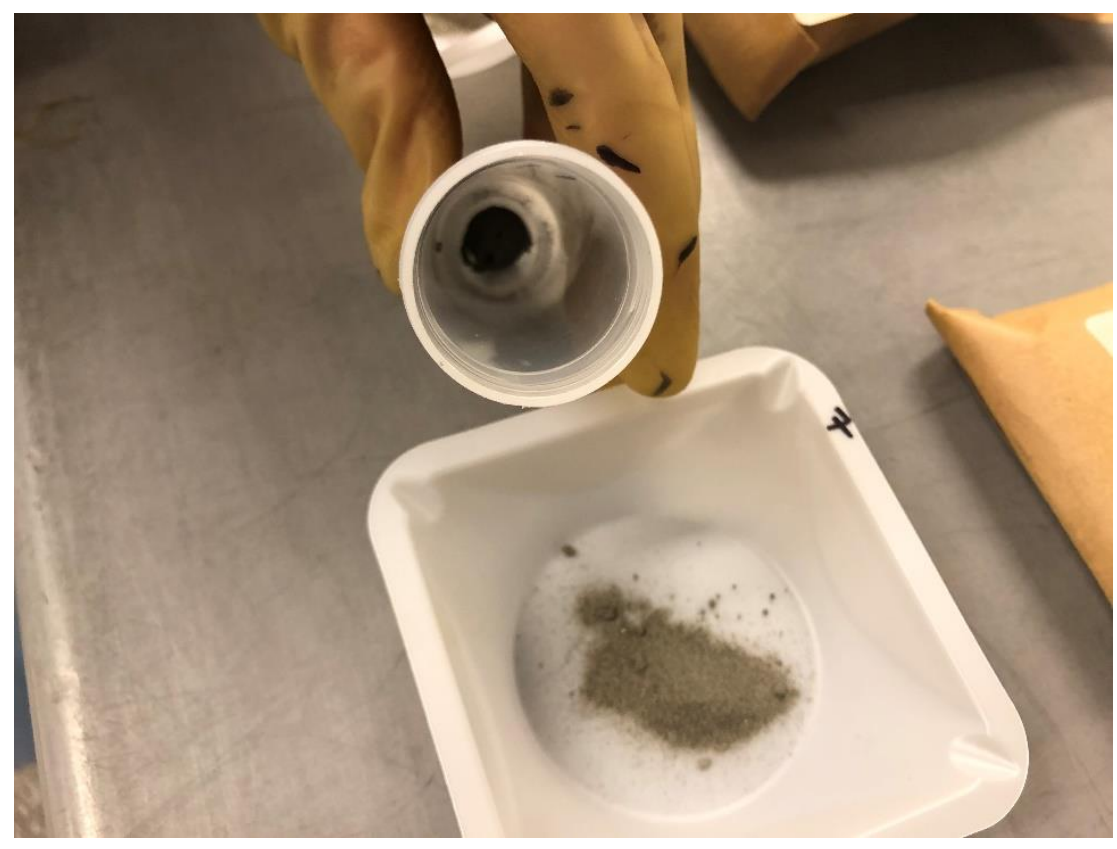

TP3-TS-01

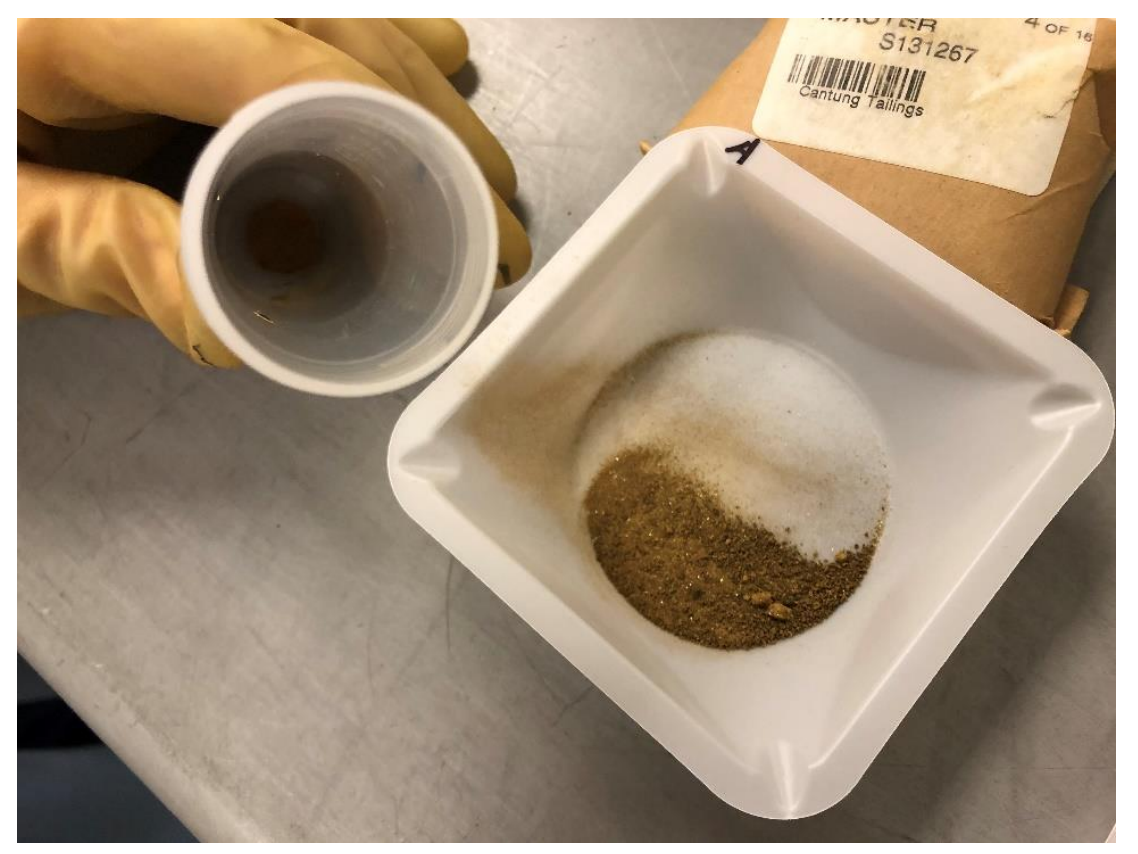

TP3-TS-02 


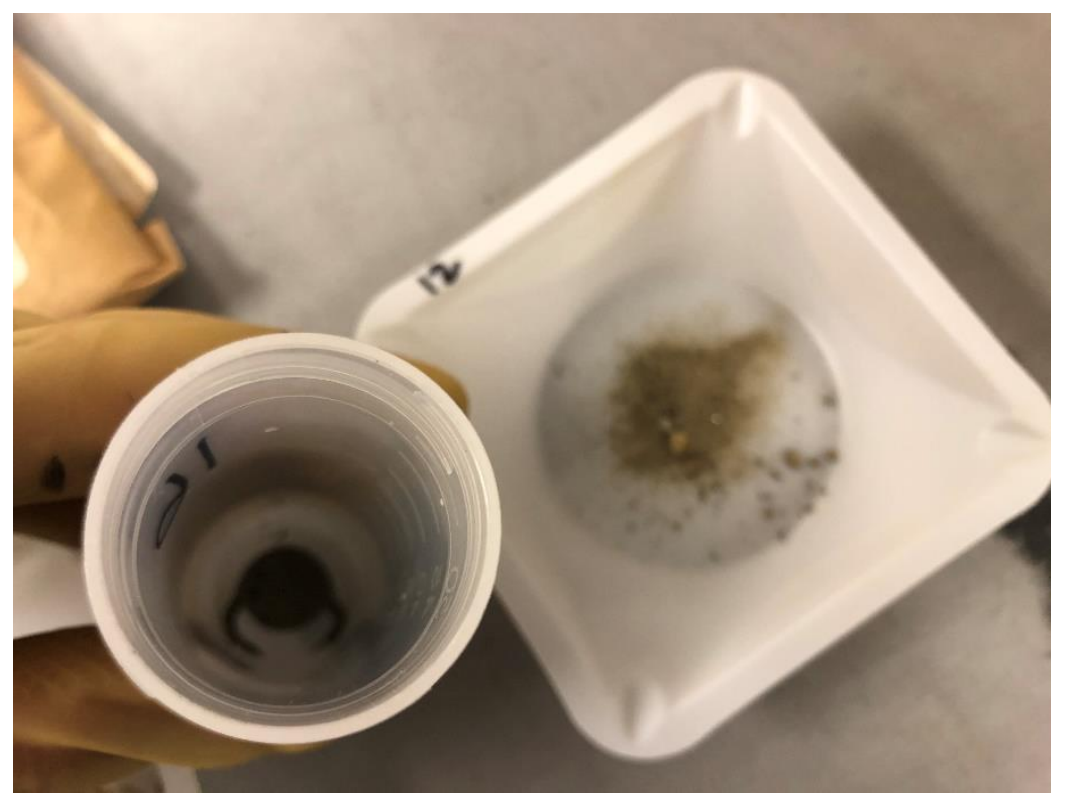

TP4-TS-01

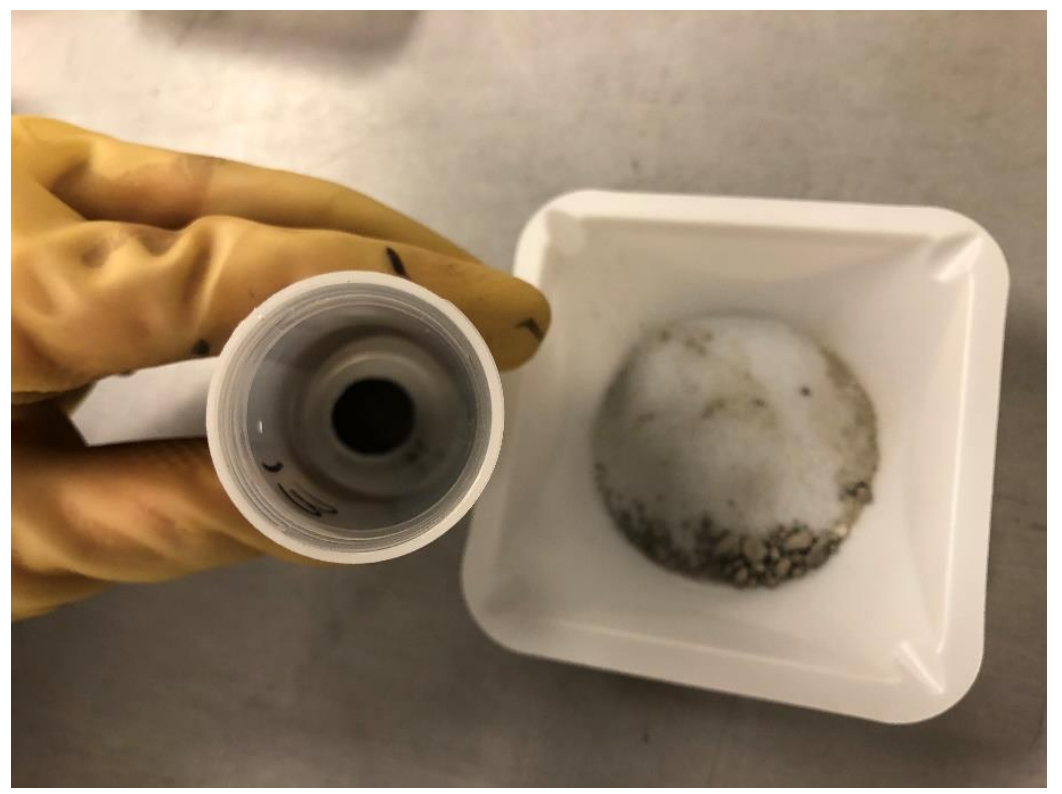

TP5-TS-01 


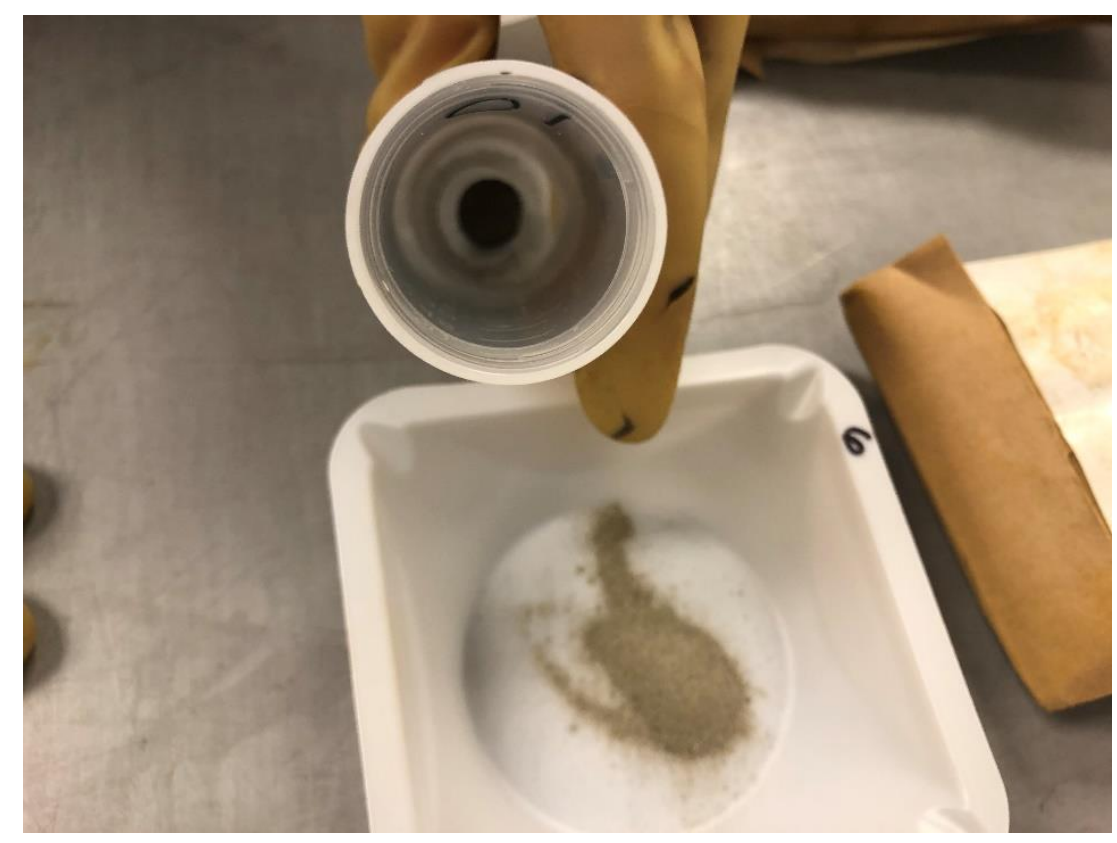

TP5-TS-02

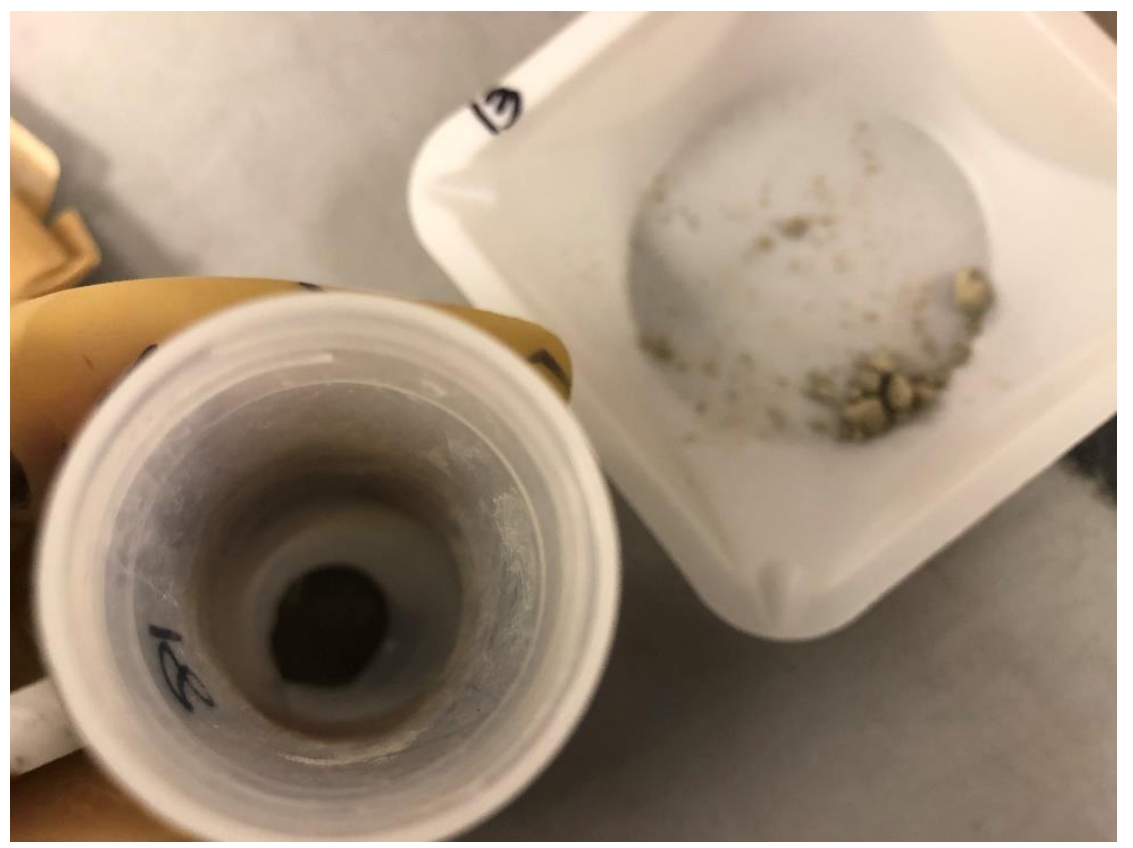

TP5-TS-03 


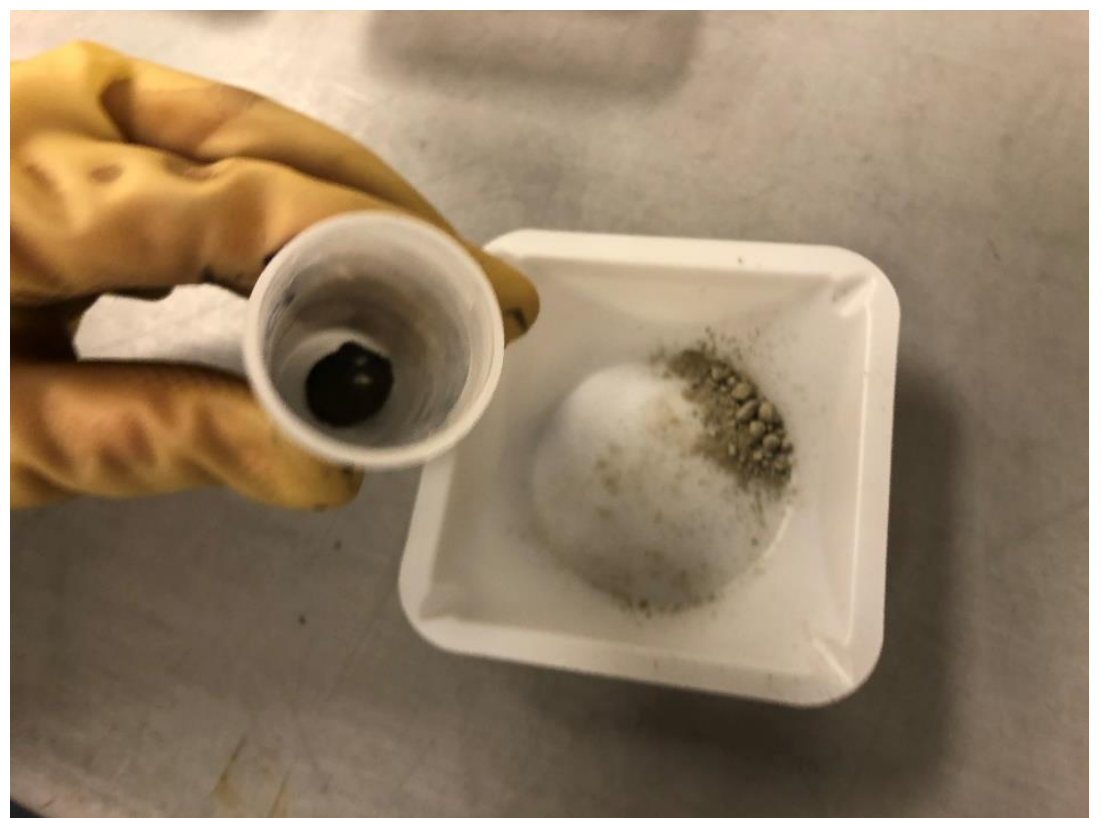

TP5-TS-03DUP

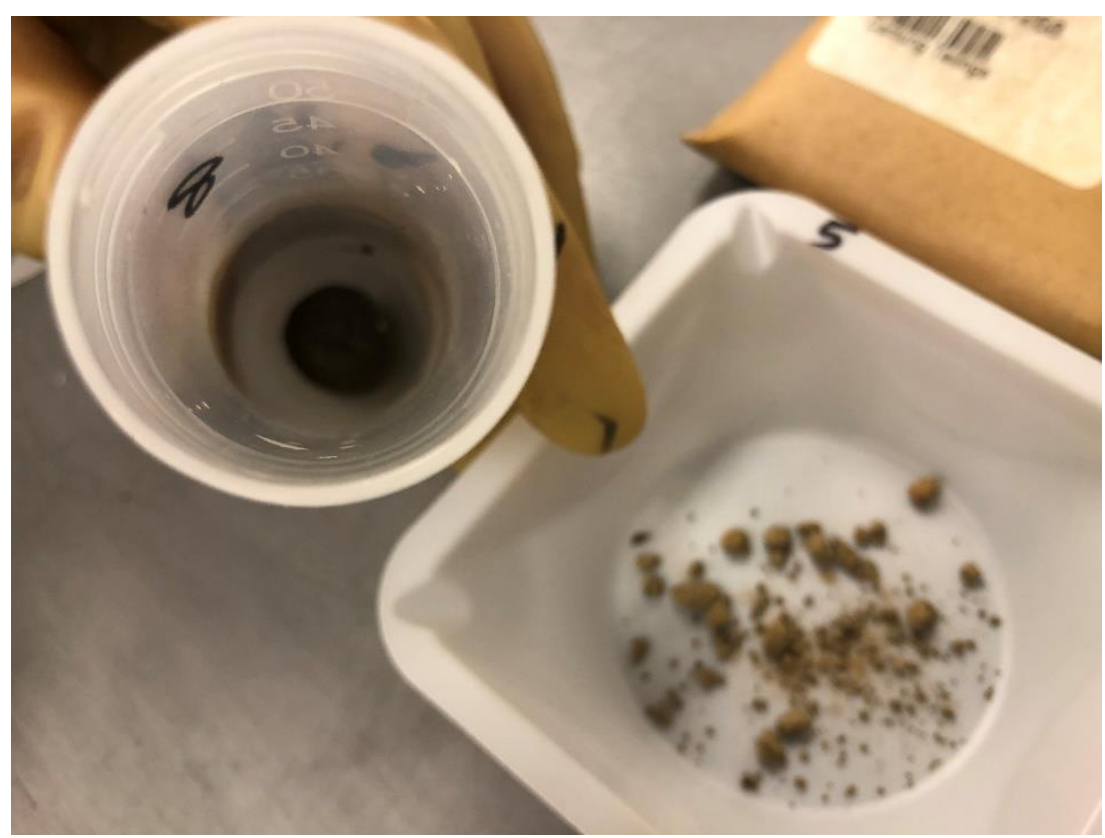

TP5-TS-04 


\section{Appendix L: SEM-MLA Modal Mineralogy Data}

The SEM-MLA modal mineralogy data can be found in the provided excel sheet titled "SEMMLA Appendix".

\section{Appendix M: Partial Leach Results}

The results and QAQC for all of the partial leach extractions conducted by ALS Geochemistry can be found in the provided excel sheet titled "Partial Leach Appendix".

\section{Appendix N: Waters Anions Results}

The results and QAQC for the anion concentration analysis for water samples conducted by the ASU at Queen's University can be found in the provided excel sheet titled "Anions Appendix".

\section{Appendix O: Waters ICP-MS Results}

The results and QAQC for the ICP-MS water sample data can be found in the provided excel sheet titled "Waters ICP-MS Appendix". 